Portland State University

PDXScholar

1998

Photoadaptation Rate of Synechococcus WH7803

Cultures at Two Iron Concentrations

Jon Daniel Moulton

Portland State University

Follow this and additional works at: https://pdxscholar.library.pdx.edu/open_access_etds

Part of the Biology Commons, and the Environmental Sciences Commons Let us know how access to this document benefits you.

Recommended Citation

Moulton, Jon Daniel, "Photoadaptation Rate of Synechococcus WH7803 Cultures at Two Iron Concentrations" (1998). Dissertations and Theses. Paper 3070.

https://doi.org/10.15760/etd.3068

This Dissertation is brought to you for free and open access. It has been accepted for inclusion in Dissertations and Theses by an authorized administrator of PDXScholar. Please contact us if we can make this document more accessible: pdxscholar@pdx.edu. 


\title{
PHOTOADAPTATION RATES OF SYNECHOCOCCUS WH7803 CULTURES AT TWO IRON CONCENTRATIONS
}

\author{
By \\ JON DANIEL MOULTON
}

A dissertation submitted in partial fulfillment of the requirements for the degree of

DOCTOR OF PHILOSOPHY

in

ENVIRONMENTAL SCIENCES AND RESOURCES: BIOLOGY

Portland State University

1998 


\section{DISSERTATION APPROVAL}

The abstract and dissertation of Jon Daniel Moulton for the Doctor of Philosophy in Environment Sciences and Resources: Biology were presented June 8, 1998, and accepted by the dissertation committee and the doctoral program.

COMMITTEE APPROVALS:

DEPARTMENTAL APPROVAL:

DOCTORAL PROGRAM APPROVAL:
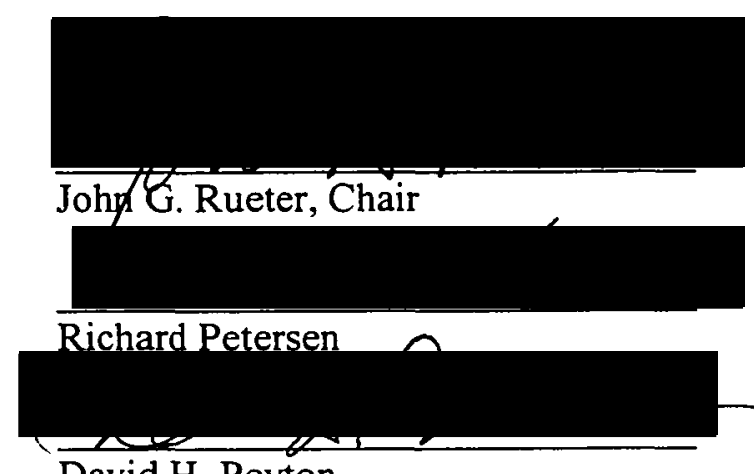

David H. Peyton

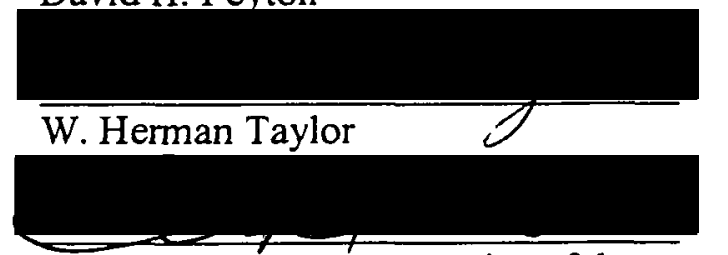

Curt Peterson, Representative of the Office of Graduate Studies

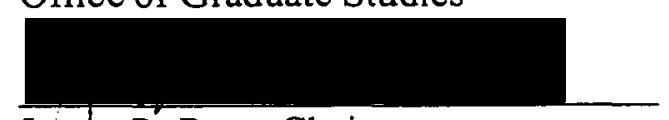

James R. Pratt, Chair

Department of Biology

James R. Pratt, Director

Environmental Sciences and

Resources Ph.D. Program 


\begin{abstract}
An abstract of the dissertation of Jon Daniel Moulton for the Doctor of Philosophy in Environmental Sciences and Resources: Biology presented June 8, 1998
\end{abstract}

Title: Photoadaptation Rates of Synechococcus WH7803 Cultures at Two Iron Concentrations.

The marine cyanobacterium Synechococcus WH7803 adapts to changes in light intensity by changing its photosynthetic physiology. This work is a study of the rate of photoadaptation of Synechococcus WH7803 in laboratory cultures.

Cultures were shifted from constant $8 \mu \mathrm{Em}^{-2} \mathrm{~s}^{-1}$ light to constant $80 \mu \mathrm{Em}^{-2} \mathrm{~s}^{-1}$ light, from constant $80 \mu \mathrm{Em}^{-2} \mathrm{~s}^{-1}$ light to constant $8 \mu \mathrm{Em}^{-2} \mathrm{~s}^{-1}$ light and from different light regimes to a single fluctuating light regime. The response of high iron cultures grown in modified aquil culture medium at $5^{*} 10^{-6} \mathrm{M}$ Fe was compared with the response of low iron cultures grown in modified aquil medium at $1^{*} 10^{-6} \mathrm{M} \mathrm{Fe}$. Cultures were assayed every 2 days for at least 10 days, assaying cell population density by fluorescence microscopy, chlorophyll $a$ by spectrophotometry of acetone extracts, total protein by the bicinchoninic acid method, and photosynthesis vs. irradiance ( $\mathrm{P}$ vs. I) response by $\mathrm{H}^{14} \mathrm{CO}_{3}{ }^{-}$uptake at 10 light intensities. 
Iron nutrition did not strongly affect the rate of photoadaptation as determined from the slopes of $\mathrm{P}$ vs. I curves as light approaches zero (the parameter called alpha). The rate of chlorophyll $a$ synthesis was the parameter most strongly affected by iron nutrition, slowing in restricted iron medium. Based on alpha per cell, the adaptation time to the shift from constant $8 \mu \mathrm{Em}^{-2} \mathrm{~s}^{-1}$ light to constant 80 $\mu \mathrm{Em}^{-2} \mathrm{~s}^{-1}$ light was less than 2 days. Based on other culture parameters the time to complete adaptation may be closer to 8 days. Based on alpha per cell, the adaptation time to the shift from constant $80 \mu \mathrm{Em}^{-2} \mathrm{~s}^{-1}$ light to constant $8 \mu \mathrm{Em}^{-2} \mathrm{~s}^{-1}$ light was on the order of 2 days. Based on other culture parameters the time to complete adaptation may exceed 10 days. 


\section{Dedication}

\section{To Hong;}

my wife, colleague and best friend. 


\section{Acknowledgments}

I wish to thank:

- M. Zoe Purtzer, reigning Queen of synthetic ocean water manufacturing, for many, many days of assistance as she filtered samples, helped me troubleshoot procedures and kept the lab running;

- Nancy Unsworth for showing me the basics of cyanobacterial labwork;

- Prof. Mary Taylor, for starting me into microbiology, introducing me to many useful ideas and techniques and always encouraging my curiosity;

- Dr. Marshall Parrott, for convincing me that if I stay very careful I can use radioisotopes safely in research;

And the members of my dissertation committee:

- Prof. Richard Petersen for advice and loans of equipment;

- Prof. David Peyton and Prof. Curt Peterson for their time serving on my dissertation committee;

- Prof. Herman Taylor for Keeping me Appraised of the Situation;

- My research advisor Prof. John Rueter, for good advice, patience and an amazing ability to find another assistantship when needed;

And very importantly,

- my wonderful wife Hong, for her encouragement and support. 
Table of Contents

Chapter 1. Introduction

Synechococcus WH7803 3

The tradeoff of light harvesting and carbon fixation 5

The photosynthesis vs. irradiance ( $\mathrm{P}$ vs. I ) curve 6

Photoadaptation and the change in initial P vs. I slope $(\alpha)$ over time 7

Iron in photosynthesis 8

Chapter 2. Materials and Methods 12

Cultures and sampling 12

P vs. I measurements 14

Protein assays 16

Chlorophyll assays 17

Cell counts 17

Data analysis 18

Chapter 3. Simple Light Shift Experiments: Increased Light and Decreased Light 20

Increased Light 20

Introduction 20

Experimental conditions: increased light 20 
Response of cultures to increased light 22

Cell count (cells/ml) 24

Chlorophyll ( $\mu \mathrm{g}$ chl $a / \mathrm{ml})$ 26

Protein $(\mu \mathrm{g}$ protein $/ \mathrm{ml})$ 29

Chlorophyll $a$ per cell ( $\mu \mathrm{g}$ chl $a /$ cell) 31

Protein per cell ( $\mu \mathrm{g}$ protein/cell) 33

Chlorophyll a per protein ( $\mu \mathrm{g} \mathrm{chl} a / \mu \mathrm{g}$ protein) 35

Alpha measurements 37

Alpha normalized per cell 37

Alpha normalized per $\mu \mathrm{g} \operatorname{chl} a$ 40

Alpha normalized per $\mu \mathrm{g}$ protein 43

Decreased Light 46

Introduction 46

Experimental conditions: decreased light 46

Response of cultures to decreased light 48

Cell count (cells/ml) 48

Chlorophyll ( $\mu \mathrm{g}$ chl $a / \mathrm{ml})$ 50

Protein $(\mu \mathrm{g}$ protein $/ \mathrm{ml})$ 53

Chlorophyll $a$ per cell ( $\mu \mathrm{g}$ chl $a /$ cell) 55

Protein per cell ( $\mu \mathrm{g}$ protein/cell) 58 
Conclusion 71

Chapter 4. Modeling the Rate of Photoadaptation using STELLA II 78

Simple model 80

Two-component model 85

Chapter 5. Comparison of Cultures from Different Light Regimes Transferred to the Same Light Regime 96

Introduction 96

Experimental conditions 97

Response of cultures 99

Cell count (cells/ml) 99

Chlorophyll ( $\mu \mathrm{g} \mathrm{chl} a / \mathrm{ml})$ 102

Protein $(\mu \mathrm{g}$ protein $/ \mathrm{ml})$ 104

Chlorophyll $a$ per cell ( $\mu \mathrm{g}$ chl $a /$ cell) 107

Protein per cell ( $\mu \mathrm{g}$ protein/cell) 109

Chlorophyll $a$ per protein ( $\mu \mathrm{g} \mathrm{chl} a / \mu \mathrm{g}$ protein)

Alpha normalized per cell 114 
Alpha normalized per $\mu \mathrm{g} \operatorname{chl} a$ 116

Alpha normalized per $\mu \mathrm{g}$ protein 118

Conclusion 120

References 124

Appendix A: Increased light $P$ vs. I curves 129

Appendix B: Decreased light P vs. I curves 151

Appendix $\mathrm{C}$ : Fluctuating light $\mathrm{P}$ vs. I curves 169

Appendix D: Touch Tone Controlled 117V AC Switching System 190 


\section{List of Tables}

Table 3.1: Cultures in each category of the fractional change tables 23

Table 3.2: Increased light -- fractional changes in cells $/ \mathrm{ml}$ for replicate cultures 24

Table 3.3: Increased light -- fractional changes in cells $/ \mathrm{ml}$ for averaged fits_24

Table 3.4: Increased light -- fractional changes in $\mu \mathrm{g} \mathrm{chl} \mathrm{a} / \mathrm{ml}$ for replicate cultures 27

Table 3.5: Increased light -- fractional changes in $\mu \mathrm{g} \mathrm{chl} a / \mathrm{ml}$ for averaged fits 27

Table 3.6: Increased light -- fractional changes in $\mu \mathrm{g}$ protein $/ \mathrm{ml}$ for replicate cultures 29

Table 3.7: Increased light -- fractional changes in $\mu \mathrm{g}$ protein $/ \mathrm{ml}$ for averaged fits 29

Table 3.8: Increased light -- fractional changes in $\mu \mathrm{g}$ chl $a /$ cell for replicate cultures

Table 3.9: Increased light - fractional changes in $\mu \mathrm{g}$ chl $a /$ cell for averaged fits

Table 3.10: Increased light -- fractional changes in $\mu \mathrm{g}$ protein/cell for replicate cultures 33

Table 3.11: Increased light -- fractional changes in $\mu \mathrm{g}$ protein/cell for averaged fits 33 
Table 3.12: Increased light -- fractional changes in $\mu \mathrm{g}$ chl $a / \mu \mathrm{g}$ protein for replicate cultures

Table 3.13: Increased light -- fractional changes in $\mu \mathrm{g} \mathrm{chl} a / \mu \mathrm{g}$ protein for averaged fits

Table 3.14: Increased light -- fractional changes in alpha/cell for replicate cultures 38

Table 3.15: Increased light -- fractional changes in alpha/cell for averaged fits 38

Table 3.16: Increased light -- fractional changes in alpha/ $\mu \mathrm{g}$ chl $a$ for replicate cultures

Table 3.17: Increased light -- fractional changes in alpha/ $\mu \mathrm{g}$ chl $a$ for averaged fits

Table 3.18: Increased light -- fractional changes in alpha/ $\mu \mathrm{g}$ protein for replicate cultures 44

Table 3.19: Increased light -- fractional changes in alpha/ $\mu \mathrm{g}$ protein for averaged fits 44

Table 3.20: Decreased light -- fractional changes in cells/ml for replicate cultures 48

Table 3.21: Decreased light -- fractional changes in cells $/ \mathrm{ml}$ for averaged fits 48 
Table 3.22: Decreased light -- fractional changes in $\mu \mathrm{g} \mathrm{chl} a / \mathrm{ml}$ for replicate cultures

Table 3.23: Decreased light -- fractional changes in $\mu \mathrm{g} \mathrm{chl} a / \mathrm{ml}$ for averaged fits 51

Table 3.24: Decreased light -- fractional changes in $\mu \mathrm{g}$ protein $/ \mathrm{ml}$ for replicate cultures 53

Table 3.25: Decreased light -- fractional changes in $\mu \mathrm{g}$ protein $/ \mathrm{ml}$ for averaged fits 53

Table 3.26: Decreased light -- fractional changes in $\mu \mathrm{g}$ chl $a /$ cell for replicate cultures 56

Table 3.27: Decreased light -- fractional changes in $\mu \mathrm{g}$ chl $a /$ cell for averaged fits 56

Table 3.28: Decreased light -- fractional changes in $\mu \mathrm{g}$ protein/cell for replicate cultures 58

Table 3.29: Decreased light -- fractional changes in $\mu \mathrm{g}$ protein/cell for averaged fits 58

Table 3.30: Decreased light -- fractional changes in $\mu \mathrm{g} \mathrm{chl} a / \mu \mathrm{g}$ protein for replicate cultures 60

Table 3.31: Decreased light -- fractional changes in $\mu \mathrm{g}$ chl $a / \mu \mathrm{g}$ protein for averaged fits 60 
Table 3.32: Decreased light -- fractional changes in alpha/cell for replicate cultures 63

Table 3.33: Decreased light -- fractional changes in alpha/cell for averaged fits 63

Table 3.34: Decreased light -- fractional changes in alpha/ug chl $a$ for replicate cultures 66

Table 3.35: Decreased light -- fractional changes in alpha/ug chl $a$ for averaged fits 66

Table 3.36: Decreased light -- fractional changes in alpha/ $\mu$ g protein for replicate cultures 69

Table 3.37: Decreased light -- fractional changes in alpha/ $\mu$ g protein for averaged fits 69

Table 3.38: Increased light alphas on day 10 from fits 76

Table 3.39: Decreased light alphas on day 10 from fits 76

Table 4.1: STELLA II equations for simple model 84

Table 4.2: STELLA II equations for two-component model 91

Table 5.1: Fractional changes in cells/ml for replicate cultures 100

Table 5.2: Fractional changes in cells $/ \mathrm{ml}$ for averaged fits 100

Table 5.3: Fractional changes in $\mu \mathrm{g}$ chl $a / \mathrm{ml}$ for replicate cultures 102

Table 5.4: Fractional changes in $\mu \mathrm{g} \mathrm{chl} a / \mathrm{ml}$ for averaged fits 102

Table 5.5: Fractional changes in $\mu$ g protein $/ \mathrm{ml}$ for replicate cultures 104 
Table 5.6: Fractional changes in $\mu \mathrm{g}$ protein $/ \mathrm{ml}$ for averaged fits 104

Table 5.7: Fractional changes in $\mu \mathrm{g}$ chl a/cell for replicate cultures 107

Table 5.8: Fractional changes in $\mu \mathrm{g}$ chl $a /$ cell for averaged fits 107

Table 5.9: Fractional changes in $\mu \mathrm{g}$ protein/cell for replicate cultures 109

Table 5.10: Fractional changes in $\mu \mathrm{g}$ protein/cell for averaged fits 109

Table 5.11: Fractional changes in $\mu \mathrm{g}$ chl $a / \mu \mathrm{g}$ protein for replicate cultures_112

Table 5.12: Fractional changes in $\mu \mathrm{g} \mathrm{chl} a / \mu \mathrm{g}$ protein for averaged fits 112

Table 5.13: Fractional changes in alpha/cell for replicate cultures 114

Table 5.14: Fractional changes in alpha/cell for averaged fits 114

Table 5.15: Fractional changes in alpha/ $\mu \mathrm{g}$ chl $a$ for replicate cultures 116

Table 5.16: Fractional changes in alpha/ $\mu$ g chl $a$ for averaged fits 116

Table 5.17: Fractional changes in alpha/ $\mu$ g protein for replicate cultures 118

Table 5.18: Fractional changes in alpha/ $\mu$ g protein for averaged fits 118 


\section{List of Figures}

Figure 3.1: Plot of cells $/ \mathrm{ml}$ for constant low light cultures 25

Figure 3.2: Plot of cells $/ \mathrm{ml}$ for increased light cultures 25

Figure 3.3: Plot of $\mu \mathrm{g} \mathrm{chl} a / \mathrm{ml}$ for constant low light cultures 28

Figure 3.4: Plot of $\mu \mathrm{g} \mathrm{chl} a / \mathrm{ml}$ for increased light cultures 28

Figure 3.5: Plot of $\mu$ g protein/ml for constant low light cultures 30

Figure 3.6: Plot of $\mu$ g protein/ml for increased light cultures 30

Figure 3.7: Plot of $\mu \mathrm{g}$ chl a/cell for constant low light cultures 32

Figure 3.8: Plot of $\mu \mathrm{g} \mathrm{chl} \mathrm{a/cell} \mathrm{for} \mathrm{increased} \mathrm{light} \mathrm{cultures}$ 32

Figure 3.9: Plot of $\mu$ g protein/cell for constant low light cultures 34

Figure 3.10: Plot of $\mu$ g protein/cell for increased light cultures 34

Figure 3.11: Plot of $\mu \mathrm{g} \mathrm{chl} a / \mu \mathrm{g}$ protein for constant low light cultures 36

Figure 3.12: Plot of $\mu \mathrm{g} \mathrm{chl} a / \mu \mathrm{g}$ protein for increased light cultures 36

Figure 3.13: Plot of alpha/cell for constant low light cultures 39

Figure 3.14: Plot of alpha/cell for increased light cultures 39

Figure 3.15: Plot of alpha/ $\mu \mathrm{g}$ chl $a$ for constant low light cultures 42

Figure 3.16: Plot of alpha/ $\mu \mathrm{g} \operatorname{chl} a$ for increased light cultures 42

Figure 3.17: Plot of alpha/ $\mu$ g protein for constant low light cultures 45

Figure 3.18: Plot of alpha/ $\mu$ g protein for increased light cultures 45

Figure 3.19: Plot of cells/ml for decreased light cultures 49 
Figure 3.20: Plot of cells/ml for constant high light cultures 49

Figure 3.21: Plot of $\mu \mathrm{g} \mathrm{chl} a / \mathrm{ml}$ for decreased light cultures 52

Figure 3.22: Plot of $\mu \mathrm{g} \mathrm{chl} \mathrm{a} / \mathrm{ml}$ for constant high light cultures 52

Figure 3.23: Plot of $\mu \mathrm{g}$ protein $/ \mathrm{ml}$ for decreased light cultures 54

Figure 3.24: Plot of $\mu \mathrm{g}$ protein $/ \mathrm{ml}$ for constant high light cultures 54

Figure 3.25: Plot of $\mu \mathrm{g} \mathrm{chl} a /$ cell for decreased light cultures 57

Figure 3.26: Plot of $\mu \mathrm{g} \mathrm{chl} a /$ cell for constant high light cultures 57

Figure 3.27: Plot of $\mu \mathrm{g}$ protein/cell for decreased light cultures 59

Figure 3.28: Plot of $\mu \mathrm{g}$ protein/cell for constant high light cultures 59

Figure 3.29: Plot of $\mu \mathrm{g} \mathrm{chl} a / \mu \mathrm{g}$ protein for decreased light cultures 61

Figure 3.30: Plot of $\mu \mathrm{g} \mathrm{chl} a / \mu \mathrm{g}$ protein for constant high light cultures 61

Figure 3.31: Plot of alpha/cell for decreased light cultures 64

Figure 3.32: Plot of alpha/cell for constant high light cultures 64

Figure 3.33: Plot of alpha/ug chl $a$ for decreased light cultures 67

Figure 3.34: Plot of alpha/ug chl $a$ for constant high light cultures 67

Figure 3.35: Plot of alpha/ $\mu \mathrm{g}$ protein for decreased light cultures 70

Figure 3.36: Plot of alpha/ $\mu$ g protein for constant high light cultures 70

Figure 4. 1: Map of simple model in STELLA II 82

Figure 4.2: Output of simple model shifting from constant light to fluctuating light 83 
Figure 4.3: Comparison of parameters in various light regimes as predicted by simple model 83

Figure 4.4: Map of two-component model in STELLA II 87

Figure 4.5: Output of two-component model shifting from constant light to fluctuating light showing the fraction of the cell that is building blocks, the fraction of the cell that is NADPH, the fraction of the cell that is storage, the fraction of the cell that is triose phosphate, and light. 90

Figure 4.6: Output of two-component model shifting from constant light to fluctuating light showing the fraction of the cell that is enzymes and biosynthetic apparatus, the fraction of the cell that is photosynthetic enzymes, the fraction of the cell that is photosynthetic membrane, the fraction of the cell that is storage, and light. 90

Figure 4.7: Output of two-component model shifting from constant light to fluctuating light showing the fraction of the cell that is burned out components of the photosynthetic membrane, the fraction of the cell that is NADPH, the fraction of the cell that is photosynthetic membrane, and light. 91

Figure 5.1: Plot of cells/ml for preadapted constant light cultures 101

Figure 5.2: Plot of cells/ml for preadapted fluctuating light cultures 101

Figure 5.3: Plot of $\mu \mathrm{g}$ chl $a / \mathrm{ml}$ for preadapted constant light cultures 103 
Figure 5.4: Plot of $\mu \mathrm{g} \mathrm{chl} a / \mathrm{ml}$ for preadapted fluctuating light cultures 103

Figure 5.5: Plot of $\mu \mathrm{g}$ protein $/ \mathrm{ml}$ for preadapted constant light cultures 105

Figure 5.6: Plot of $\mu \mathrm{g}$ protein $/ \mathrm{ml}$ for preadapted fluctuating light cultures__ 106

Figure 5.7: Plot of $\mu \mathrm{g} \mathrm{chl}$ a/cell for preadapted constant light cultures 108

Figure 5.8: Plot of $\mu \mathrm{g}$ chl $a /$ cell for preadapted fluctuating light cultures 108

Figure 5.9: Plot of $\mu \mathrm{g}$ protein/cell for preadapted constant light cultures 110

Figure 5.10: Plot of $\mu \mathrm{g}$ protein/cell for preadapted fluctuating light cultures 110

Figure 5.11: Plot of $\mu \mathrm{g}$ chl $a / \mu \mathrm{g}$ protein for preadapted constant light cultures 113

Figure 5.12: Plot of $\mu \mathrm{g} \mathrm{chl} a / \mu \mathrm{g}$ protein for preadapted fluctuating light cultures 113

Figure 5.13: Plot of alpha/cell for preadapted constant light cultures 115

Figure 5.14: Plot of alpha/cell for preadapted fluctuating light cultures 115

Figure 5.15: Plot of alpha/ $\mu$ g chl $a$ for preadapted constant light cultures 117

Figure 5.16: Plot of alpha/ $\mu \mathrm{g} \operatorname{chl} a$ for preadapted fluctuating light cultures_1 17

Figure 5.17: Plot of alpha/ $\mu$ g protein for preadapted constant light cultures_1 19

Figure 5.18: Plot of alpha/ $\mu$ g protein for preadapted fluctuating light cultures 119 


\section{Chapter 1}

\section{Introduction}

When cyanobacteria experience a change in light intensity they respond by changing their physiology, a process called photoadaptation (Tandeau de Marsac \& Houmard, 1993; Prezelin \& Matlick, 1980). Illumination by photosynthetically useful photons varies as a plankton cell is mixed vertically through the water column, mixing that is commonly driven by wind (Langmuir, 1938). The rate that an algal cell can adapt to these variations influences its immediate photosynthetic response to illumination. The time course of photoadaptation is a parameter affecting the marine component of the global carbon cycle, a cycle which is being modeled to help assess atmospheric $\mathrm{CO}_{2}$ fluctuations that affect the greenhouse effect. Because the natural light environment fluctuates, we need to know an algal cell's rate of photoadaptation in order to model accurately the photosynthesis of the cell.

The marine cyanobacterium Synechococcus WH7803 has been shown to adapt its photosynthetic response to its growth irradiance (Kana \& Glibert 1987b). The rate of photoadaptation has not been reported for Synechococcus WH7803 even through a simple shift between two constant light intensities. An alga exposed to a change in irradiance may not photosynthesize at optimal efficiency until the cell adapts to the new light conditions. Decreased photosynthetic efficiency may be caused either by photoinhibition and insufficient carbon fixation enzymes if shifted to higher light or by insufficient pigmentation if shifted to lower light. Iron participates in many processes related to photosynthesis including chlorophyll synthesis and photosynthetic electron transport. Because it is needed to synthesize 
new components of the photosynthetic apparatus, iron may limit the rate of photoadaptation if not available in sufficient concentrations. I decided to combine a study of the photoadaptation rate of Synechococcus WH7803 with an investigation of whether iron nutrition affects those rates. This research addresses these questions about Synechococcus WH7803 in laboratory culture:

- How long does it take for a culture of Synechococcus WH7803 to adapt to a shift between two fairly dim light levels?

- What is the effect of iron concentration on the rate of photoadaptation?

- Does the amount of iron available affect the final alpha (slope of the P vs. I curve as light approaches zero) after photoadaptation is complete?

- Can preadaptation to different light regimes lead to different rates of photoadaptation or to different $P$ vs. I curves after photoadaptation is complete? Specifically, do cyanobacteria respond differently if they are placed into the same illumination after preadaptation in differing light regimes that have identical spectral quality?

In the environment, light fluctuation may favor the cyanobacteria over other phytoplankton. The hypothesis underlying this work is that iron-replete cyanobacteria are able to photoadapt more rapidly than iron-limited cells. In the IronEx experiment conducted in the eastern equatorial Pacific, a ship spread iron in a $64 \mathrm{~km}^{2}$ open ocean test area south of the Galapagos islands that had an initial iron concentration of $1 * 10^{-16} \mathrm{M}$. On the ship's first return through the test area iron had increased to $5 * 10^{-14} \mathrm{M}$, phytoplankton increased their photosynthetic efficiency $60 \%$ and they were photosynthesizing at two to three times their initial rate after 
three days in the iron-fertilized test area. Chlorophyll concentrations increased by a factor of two to three in the patch (Fitzwater and Hunter 1994, Kunzig 1994). In the IronEx experiment the cyanobacteria represented a different fraction of the phytoplankton population in the shipboard incubations than their fraction of the phytoplankton population in the natural ocean patch. This led John Rueter (J. Rueter, pers. comm., NSF proposal) to hypothesize that iron nutrition was especially crucial for cyanobacteria in the rapidly fluctuating light environments of the ocean upper mixed layer.

\section{Synechococcus WH7803}

Synechococcus WH7803 (a.k.a. CCMP1334, NEPCC549, Synechococcus DC2) is a marine cyanobacterium. Like other cyanobacteria, Synechococcus are photoautotrophic gram-negative prokaryotes. Synechococcus are free-living (noncolonial) cyanobacteria that grow singly or sometimes in pairs of cells and are devoid of sheaths. This is a genus that encompasses strains that are genetically very different, with GC compositions from $39 \%$ to $71 \%$ (Rippka et al. 1979). The cells are small rods, 1 to $3 \mu \mathrm{m}$ long and 1 to $2 \mu \mathrm{m}$ wide. Light intensity for saturation of growth of Synechococcus WH7803 has been reported to be $45 \mu \mathrm{E} \mathrm{m}^{-2} \mathrm{~s}^{-1}$ (Glover 1985) or to be $200 \mu \mathrm{E} \mathrm{m}^{-2} \mathrm{~s}^{-1}$ (Kana \& Glibert 1987a), though some growth has been reported up to $2000 \mu \mathrm{E} \mathrm{m}^{-2} \mathrm{~s}^{-1}$ (Kana \& Glibert 1987a). An optimal generation time of $13 \mathrm{~h}$ was measured for cultures grown up to $70 \mu \mathrm{E} \mathrm{m} \mathrm{m}^{-2} \mathrm{~s}^{-1}$ (Glover 1985), though at irradiances over $400 \mu \mathrm{E} \mathrm{m}^{-2} \mathrm{~s}^{-1}$ a generation time of $9 \mathrm{~h}$ was measured (Kana \& Glibert 1987a). Growth of this strain was limited at $10^{-8} \mathrm{M}$ iron (Glover 1985). 
Like all cyanobacteria, cells of Synechococcus WH7803 fix $\mathrm{CO}_{2}$ into biomass by oxygenic photosynthesis, using essentially the same mechanism as higher plants: photon harvesting by pigments, ionization of chlorophyll $a$ in photosystems, transport of electrons from water to NADP with chemiosmotic coupling to ATP synthesis, and fixation of $\mathrm{CO}_{2}$ in the Calvin-Benson cycle. A feature of cyanobacterial photosynthesis that sets them apart from higher plants is their phycobilisomes. These light-harvesting systems are complexes of proteins and bilin pigments that trap photons and deliver their energy to photosystem II. Synechococcus can be separated into two groups depending on their dominant biliprotein pigment: those with green-colored cells dominated by the pigment phycocyanin are called the PC-rich group, and those with pink-colored cells dominated by the pigment phycoerythrin are called the PE-rich group. Synechococcus WH7803 is a PE-rich strain. When they are illuminated with different colors of light, Synechococcus do not adjust their pigment composition in response (some other genera of cyanobacteria do undergo this chromatic adaptation) (Glover 1985).

Marine Synechococcus live throughout world's salt water, from estuaries and the nutrient-rich coastal margins to the nutrient-poor central gyres of the major oceans. PE-rich Synechococcus are the most ubiquitous cyanobacteria in the oceans. Synechococcus are most abundant in the top 2 meters in a vertically stratified body of water, with a lesser subsurface maximum often found near the thermocline. Glover reported that deeper chlorophyll maxima are associated with larger fractional contributions of PE-rich Synechococcus to overall primary 
production at the chlorophyll maximum (Glover 1985). PE-rich Synechococcus make up the greatest fraction of the phytoplankton community in the least productive regions, such as the ocean's central gyres where they are often an order of magnitude more abundant than eukaryotic algae. Cell counts in natural populations of PE-rich Synechococcus have been measured as high as $1.5 * 10^{6}$ cells/ml in a upwelling region near the Costa Rica Dome. Synechococcus are most abundant in equatorial regions; their numbers drop by several orders of magnitude with increasing latitude (Glover 1985). Since Synechococcus are abundant in the ocean, they mediate a significant part of the planet's carbon cycle.

The tradeoff of light harvesting and carbon fixation

Cyanobacteria, like eukaryotic algae and terrestrial plants, adapt to changes in illumination by varying their composition. They can adapt to changes in light intensity by adjusting their amounts of light harvesting pigments, of electron transport capacity, and of photosynthetic enzyme activity. A large ratio of photosystems to $\mathrm{CO}_{2}$-fixing enzymes favors growth in low light but lacks the $\mathrm{CO}_{2}$ fixing capacity to grow optimally in high light; in contrast, a low ratio of photosystems to $\mathrm{CO}_{2}$-fixing enzymes favors growth in high light but lacks the lightharvesting efficiency needed to grow optimally in low light (Richardson et al. 1983).

Although much of the work on microbial photoadaptation has been done for eukaryotic algae, adaptation to varying light intensities has been reported for cyanobacteria. After photosynthetic photon flux density decreases and some time 
passes, cyanobacteria have been found to increase their light-harvesting pigments per cell, increase their photosystems per cell, and decrease their ribulose-1,5bisphosphate carbolylase/oxygenase ( $\mathrm{RuBisCO}$ ) per cell (Tandeau de Marsac et al. 1993). Measurements of pigments, photosynthesis, and growth parameters have been reported for Synechococcus WH7803 after adaptation to a range of constant light levels (Kana et al. 1987a, 1987b; Barlow and Alberte 1985).

The photosynthesis vs. irradiance (P vs. I ) curve

Since E. Steeman Neilson pioneered the use of carbon-14 to measure photosynthetic activity of seawater samples in the 1950s (Steeman Neilsen 1952), ${ }^{14} \mathrm{C}$ uptake has become a standard tool of oceanographers. The photosynthesis versus irradiance (P vs. I) curve is a graphical technique that often employs ${ }^{14} \mathrm{C}$ uptake to indicate the photoadaptation state of algal cells.

To produce a $\mathrm{P}$ vs. I curve, a group of small aliquots are taken from a source containing photosynthetic organisms, such as a culture or the environment The small aliquots are incubated for a fairly short time in different light intensities. The photosynthetic rate during incubation of each aliquot is measured, generally either by uptake of radioisotope-labeled bicarbonate $\left(\mathrm{H}^{14} \mathrm{CO}_{3}^{-}\right)$using subsequent scintillation counting or by the rate of oxygen evolution using oxygen electrodes. The incubation light intensity is plotted versus photosynthetic rate to construct a $P$ vs. I curve. 
The initial slope ( $\alpha$ ) of the $P$ vs. I curve (as illumination approaches zero) is used as an indication of photosynthetic efficiency (Barlow and Alberte 1985). For measurements based on ${ }^{14} \mathrm{C}$ uptake, $\alpha$ is the product of the specific absorption coefficient for chlorophyll $a\left(\mathrm{~m}^{2}(\mathrm{mg} \mathrm{chl} a)^{-1}\right)$ and the quantum yield for photosynthesis (mol C (mol photons) $)^{-1}$ ) (Cullen et al. 1992). The maximum photosynthesis is a function of the maximum substrate flux through $\mathrm{CO}_{2}$-fixing enzymes, which may be limited by enzymatic reactions of the Calvin cycle or by diffusion and transport processes but is generally not limited by electron transfer processes (Richardson et al. 1983, Henley 1993). The shape of a cell's P vs. I curve changes as the cell adapts (Richardson et al. 1983).

Photoadaptation and the change in initial P vs. I slope $(\alpha)$ over time

Rates of photoadaptation have been measured for some phytoplankton, including dinoflagellates (Prézelin and Matlick 1980), diatoms (Marra 1980), and Antarctic nanoflagellates (Buma et al. (1993), but similar time course studies are not available for cyanobacteria. After a shift from high to low light, pigment concentrations in the dinoflagellate Glenodinium fluctuated for at least 30 days before a new steady-state composition was reached (Prézelin and Matlick 1980). Changes in $\mathrm{O}_{2}$ evolution during adaptation of the diatom Lauderia borealis were measured using an oxygen electrode. Based on these measurements it was calculated that $L$. borealis takes $10 \pm 1$ hours to photoadapt from an illumination of $800 \mu \mathrm{E} \mathrm{m}^{-2} \mathrm{~s}^{-1}$ to $100 \mu \mathrm{E} \mathrm{m}^{-2} \mathrm{~s}^{-1}$ (Marra 1980). Antarctic nanophytoflagellates grown at $1.0^{\circ} \mathrm{C}$ took up to 700 hours for complete photoadaptation (Buma et al. 1993). 
The focus of this research was to measure the rate of photoadaptation of Synechococcus WH7803 by following changes in the photosynthetic state of cultures over time. The initial slope of a photosynthesis versus irradiance (P vs. I) curve $(\alpha)$ has been shown to be a sensitive indicator of photoadaptation in Synechococcus WH7803 at light intensities below $500 \mu \mathrm{E} \mathrm{m}^{-2} \mathrm{~s}^{-1}$ (Kana \& Glibert 1987a). $\alpha$ varies 10 -fold between cultures grown at $30 \mu \mathrm{E} \mathrm{m}^{-2} \mathrm{~s}^{-1}$ and $2000 \mu \mathrm{E} \mathrm{m}$ $s^{-1}$ constant irradiance for over 2 weeks (Kana \& Glibert 1987b). We therefore decided to use $\alpha$ as our index of the state of photoadaptation of a culture.

Iron in photosynthesis

Iron is a component of many molecules in Synechococcus, some directly involved in light adaptation. The mechanism of oxygenic photosynthesis is essentially the same in cyanobacteria and higher plants, with two major structural differences: absence of phycobilisomes in chloroplasts and lack of chloroplast grana stacks in cyanobacteria (Binder 1982). The protein complexes of the thylakoid membranes are present in cyanobacteria and higher plants: photosystem 1 (PSI), photosystem II (PSII), and the cytochrome $b_{6} / f$ complex.

Iron in Photosystem II:

- nonheme Fe associated with the PsbI protein (Green and Durnford 1996)

- $\mathrm{Q}_{\mathrm{B}}$, an Fe-plastoquinone (Andréasson and Vänngărd 1988)

- Cytochrome $b_{s 59,}$ containing a heme (Andréasson and Vänngård 1988) 


\section{Iron in Photosystem I:}

- $\mathrm{X}$, an Fe-S center [4 Fe - $4 \mathrm{~S}$ ] (Golbeck 1992)

- $\mathrm{B}$, an Fe-S center [4 Fe - 4 S] (Glazer and Melis 1987)

- A, an Fe-S center [4 Fe - 4 S] (Glazer and Melis 1987)

Iron in the cytochrome $b_{6} / f$ complex:

- cytochrome $f$ (containing heme $c$ ) (Cramer et al. 1996)

- cytochrome $b_{\delta}$ (containing heme $b$ ) (Cramer et al. 1996)

- Rieske iron-sulfur [2Fe - 2S] protein (Cramer et al. 1996)

The stoichiometry in $b_{6} / f$ complexes is heme $b$ : heme $c$ : [2Fe - 2S] at a 2:1:1 ratio (Cramer et al. 1996).

Ferredoxin, a compound containing iron, is an electron shuttle that accepts electrons from photosystem I and carries them to oxidoreductases that reduce NADP or nitrogen compounds (Pardo et al. 1990). Ferredoxin may be replaced by the iron-free electron shuttle flavodoxin when cells are iron-stressed (Sandmann \& Malkin 1983, Pardo et al. 1990, Hutber et al. 1977).

Synechococcus produce a superoxide dismutase (SOD) that contains iron (Sampson et al. 1994). Cells can be damaged by superoxide $\left(\mathrm{O}_{2}^{\circ}\right)$ produced by transfer of electrons to oxygen by intermediates in the photosynthetic electron transfer chain. This Fe-SOD may help cells resist photooxidative damage, especially during increases in irradiance when the electron transport chain is saturated with electrons. 
If photosynthetic organisms are grown in low iron concentrations, porphyrin synthesis is decreased (Guikema \& Sherman 1983). The activity of coproporphyrinogen oxidase (EC 1.3.3.3) is iron-dependent (Hsu \& Miller 1970, ExPASy database 1998). The photosynthetic bacterium Rhodopseudomonas spheroides accumulates and excretes coproporphyrin and other intermediates in the tetrapyrolle biosynthesis pathway when stressed by low iron concentrations (Spiller et al. 1982). The activity of protochlorophyllide oxido-reductase (EC 1.3.1.33) is iron dependent (GenomeNet database 1998, Unsworth 1992). The chlorophyll content of Trichodesmium NIBB1067 is iron dependent, as is the photosynthetic efficiency of Scenedesmus sp. (Rueter \& Unsworth 1991). In iron-starved Anacystis nidulans R2, measurements show that only $35 \%$ of the cellular $\mathrm{Chl} a$ content that is found in iron-replete cells (Guikema \& Sherman 1983).

Along with chlorophyll, cyanobacteria use protein complexes called phycobilisomes to harvest light. Those complexes contain phycocyanin, a biliprotein pigment. Addition of iron to iron-starved Anacystis nidulans R2 cultures resulted in the reorganization of chlorophyll and proteins in the thylakoid membranes and the synthesis and addition of new chlorophyll and phycocyanin to those pigment-protein complexes. Six to eight hours after addition of iron, new phycobilisomes appeared. Within 24 to 28 hours the chlorophyll absorption peak finished moving from its iron-starved position at $672 \mathrm{~nm}$ to its iron-replete position at $679 \mathrm{~nm}$. A similar shift from fluorescence peaks characteristic of iron-starved cells to those characteristic of iron-replete cells was seen in 14 to 24 hours (Pakrasi et al. 1985). 
Several cyanobacterial genes are known to be expressed only under lowiron conditions. In the marine Synechococcus PCC 7002, isi A codes for the photosystem II chlorophyll-binding protein $\mathrm{CP}^{4} 2^{\prime}$ and isiB codes for flavodoxin. These two genes are under tight regulation by iron concentration (Leonhardt and Straus 1992). CP42' is a component of the CPVI-4 pigment-protein complex (Burnap et al. 1993) that may replace the phycobilisome light-harvesting antenna of photosystem II under conditions of iron stress (Reithman et al. 1988). Flavodoxin is a flavin-containing electron-transfer compound that substitutes for ferredoxin in photosynthetic electron transport under iron-limited conditions (Hutber et al. 1977). Expression of flavodoxin commences under iron-limited conditions, while the mRNA transcripts of ferredoxin become much less stable in low-iron conditions (Leonhardt \& Straus 1992, Bovy et al. 1993).

I expected iron limitation to slow adaptation of Synechococcus WH7803 for the following reasons. Adaptation to decreased light requires synthesis of components of thylakoid membranes including chlorophyll, phycobilisomes (de Lorimer et al. 1992), photosystems and cytochromes. Adaptation to increased light may cause photooxidative damage which could be partially mitigated by abundant Fe-superoxide dismutase. Restricted iron nutrition affects photosynthesis and nitrogen metabolism, which leads to energetic limitation of cyanobacterial growth (Rueter \& Unsworth 1991) and therefore energetic limitation of photoadaptation. 


\section{Chapter 2}

\section{Materials and Methods}

\section{Cultures and sampling}

Cultures of Synechococcus WH7803 are descended from samples collected in 1978 by $L$. Brand from the Atlantic ocean west of Bermuda at $25 \mathrm{~m}$ depth and isolated into pure culture in 1980 by J. Waterbury. We obtained the cultures from the Provosali-Guillard Center for the Culture of Marine Phytoplankton, Bigelow Laboratory for Ocean Sciences, West Boothbay Harbor, Maine.

Cultures were maintained on modified aquil media (Morel and Rueter, 1979) with iron concentrations of either $1 * 10^{-6} \mathrm{M} \mathrm{FeCl}_{3}\left(\right.$ low Fe) or $5 * 10^{-6} \mathrm{M}$ $\mathrm{FeCl}_{3}$ (high $\mathrm{Fe}$ ). Color intensity of otherwise similar cultures grown at the two different iron concentrations were visibly very different. Aquil was formulated with nitrate as its nitrogen source, and without adding the silica component. Synthetic ocean water (SOW), nitrate solution, and phosphate solution were individually passed through a $3 \mathrm{~cm}^{3}$ column of Chelex 100 cation exchange resin (Bio-Rad). After Chelex treatment trace metal solution and $\mathrm{FeCl}_{3}$ solution were added. The concentration of phosphate was doubled and nitrate tripled compared to standard aquil, because these concentrations support more rapid growth of Synechococcus WH7803 than standard aquil (N. Unsworth, pers. comm.). SOW, nitrate, phosphate, trace metals and $\mathrm{FeCl}_{3}$ solutions were mixed in 1 liter acid-washed polycarbonate flasks. Media were sterilized using a microwave procedure (Keller et 
al., 1988). After cooling, standard aquil vitamin solution sterilized by passage through a $0.2 \mu \mathrm{m}$ filter was added to the flasks.

Summary of changes from standard aquil:

Nitrogen: as nitrate, triple concentration

Phosphate: double concentration

Silica: not included

All glass and plasticware used for culturing were acid-rinsed with $1 \% \mathrm{HCl}$ followed by at least three rinses with distilled deionized water before use. Water was purified by treating SBI piped distilled water with a Barnstead Nanopure system.

Cultures were grown in the algal culture room (room 515 SB I PSU) at $22^{\circ} \mathrm{C}$ in loosely-capped one liter polycarbonate flasks in batches of either 200 or $300 \mathrm{ml}$ per flask. Cultures were diluted every 48 hours by swirling vigorously, removing $100 \mathrm{ml}$ (including samples for analysis) from either a $200 \mathrm{ml}$ or $300 \mathrm{ml}$ culture and replacing with $100 \mathrm{ml}$ of fresh aquil at the appropriate iron concentration. Tared culture flasks were weighed before removing liquid, after removing liquid, and after diluting with fresh medium.

Light was provided by cool white fluorescent tubes, screened to the appropriate irradiance with neutral density filters (window screening of opaque black plastic). To provide a flexible source of light regimes for these experiments, a Macintosh computer-controlled light box was built, which provided software- 
selectable fluctuating light intensities (see Appendix D). Fluctuating light regimes were produced in the light box with culture room air blown through the box to maintain constant temperature.

Two days before a light shift, on the day of the light shift, and every two days for about 10 days after a light shift a set of samples was taken; this schedule was modified for the preadaptation experiment. Before the cultures were fed with fresh modified aquil, $100 \mathrm{ml}$ of culture was removed from each flask and was divided between experiments. From each $100 \mathrm{ml}$ aliquot $20 \mathrm{ml}$ were filtered onto Whatman GF/F filters for protein assays, $30 \mathrm{ml}$ were filtered onto Whatman GF/F filters for chlorophyll assays, $16 \mathrm{ml}$ were used for $\mathrm{P}$ vs. I assays, and samples for fluorescent microscopic cell counts were obtained from the remaining $34 \mathrm{ml}$.

\section{P vs. I measurements}

P vs. I measurements were done using a modified version of Lewis and Smiths' technique (Lewis and Smith 1983). From each culture, two $0.5 \mathrm{ml}$ aliquots were pipetted into two Beckman Mini Poly-Q scintillation vials labeled "no hot C" and $15 \mathrm{ml}$ was placed into its own I-liter Ehrlenmeyer flask. The flasks were put on an orbital shaker in a fume hood and the room was darkened. Each flask was spiked with $75 \mu$ l of a $100 \mu \mathrm{Ci} / \mathrm{ml}$ solution of $\mathrm{NaH}^{14} \mathrm{CO}_{3}$ to give a final activity of 2.5 $\mu \mathrm{Ci} / \mathrm{ml}$. Flasks were swirled on the shaker for 5 minutes to ensure even mixing of radioisotope throughout the culture sample. Each radioactive culture was pipetted into 24 Beckman Mini Poly-Q scintillation vials, $0.5 \mathrm{ml}$ per vial. The remaining 3 $\mathrm{ml}$ of each radioactive culture was returned to the shaker in the hood and acidified. 
Two of the 24 vials were wrapped in aluminum foil and labeled "dark". Two more were capped, labeled "alkaline", and set aside.

A photosynthesis vs. irradiance tank was built to illuminate ${ }^{14} \mathrm{C}$-spiked culture aliquots with a variety of light intensities at uniform temperature. Ten 500 $\mathrm{ml}$ beakers were held in a wooden frame in the acrylic tank. The beakers were illuminated from below with cool-white fluorescent tubes. The beakers contained short pieces of black PVC sewer pipe to shield samples from light from the sides and the PVC pipes were capped with aluminum foil to block light from above. Many of the beakers contained one or more layers of black plastic window screen on the bottom, providing a different light field in each beaker. Samples were placed onto the screens and light passed up througis the screens and into the samples. The beakers sat in about an inch of water, which was pumped from one end of the tank to the other, recirculating past the beakers to keep their temperatures the same. Light intensities were measured in each beaker using a LI-COR data logger (model LI-1000) with a LI-COR spherical quantum irradiance sensor (model LI-COR Spherical) which had been recalibrated at the factory.

The remaining 20 vials were placed in pairs into each of the 10 beakers in the $\mathbf{P}$ vs. I tank. Samples were irradiated for 1 hour in light fields ranging from 0.5 to $150 \mu \mathrm{E} \mathrm{m}^{-2} \mathrm{~s}^{-1}$, with photon flux calibrated using the LI-COR apparatus described above. Samples were removed after two hours, then all of the samples except the alkaline samples were acidified with $0.5 \mathrm{ml}$ of $1 \mathrm{~N} \mathrm{HCl}$. The acidified samples were placed on the orbital shaker in the fume hood and swirled, uncapped, overnight. After overnight shaking, $4 \mathrm{ml}$ of Beckman Ready-Safe scintillation fluid 
was added to each vial, then the vials were capped and mixed on a vortex mixer. The vials were placed in a dark box overnight, then evaluated on a Beckman LS6500 scintillation counter.

\section{Protein assays}

Protein assays were done by the enhanced bicinchoninic acid (BCA) method using kits produced by Pierce Chemical Company. In the Pierce assay, proteins quantitatively reduce $\mathrm{Cu}^{2+}$ to $\mathrm{Cu}^{1+}$ which then complexes with BCA. The concentration of the $\mathrm{BCA}-\mathrm{Cu}^{+1}$ complexes were determined by absorption spectroscopy at $562 \mathrm{~nm}$.

The $30 \mathrm{ml}$ culture aliquot for proteins were filtered through a Whatman GF/F filter and frozen. Later the filter was ground in $3 \mathrm{ml}$ of $1 \%$ sodium dodecyl sulfate (SDS) and refrigerated overnight. The sample was removed the next day and spun in a serological centrifuge to pellet the filter debris. The supernatant was collected and split into two tubes for replicate analysis. The analysis was done using a Pierce BCA protein assay reagent kit (cat \#23225, Pierce Chemical Company, Rockford, IL)A standard series was prepared from sealed one-use quantitative standards of bovine serum albumin $(2 \mathrm{mg} / \mathrm{ml}$ albumin standard ampules, cat \#23209, Pierce Chemical Company, Rockford, IL). Pierce BCA reagent was added to the standards and supernatants and they were heated to $65^{\circ} \mathrm{C}$ in a dry heat block for $1 / 2$ hour. Samples and supernatants were transferred to cuvettes and absorption of the $\mathrm{BCA}-\mathrm{Cu}^{+1}$ complexes were measured at $562 \mathrm{~nm}$ on a Pharmacia LKB Ultrospec III UV-vis spectrophotometer blanked against 1\% SDS. 


\section{Chlorophyll assays}

Chlorophyll assays were done by spectrophotometry using a Pharmacia LKB Ultrospec III UV-vis spectrophotometer. In a darkened room, each $10 \mathrm{ml}$ culture aliquot for chlorophyll was filtered through a Whatman GF/F filter with a few drops of $\mathrm{MgCO}_{3}$ suspension. Filters were placed in plastic planchettes, groups of planchettes were wrapped in aluminum foil to exclude light and were frozen at $-20^{\circ} \mathrm{C}$. The day before the assay, filters were ground in $10 \mathrm{ml}$ of cold $90 \%$ acetone with a tissue homogenizer and hand drill. The resulting slurry was refrigerated overnight in a dark cardboard box. The day of the assay the tubes were spun in a tabletop centrifuge to pellet the filter debris. An aliquot from each tube was decanted into a quartz spectrophotometer cuvette and assayed by the trichromatic spectroscopic method (Parsons et al. 1984) using the spectrophotometer with an acetone blank.

\section{Cell counts}

The graduated cylinders containing the culture samples were capped with Parafilm and then vigorously swirled and repeatedly inverted. A sample was pipetted from a freshly mixed culture and placed in a Petroff-Hauser sperm and bacteria counting chamber. Cell counts were aided by observing phycoerythrin fluorescence using a Leica fluorescence microscope with filter cubes for phycoerythrin fluorescence. Only cells fluorescing yellow were counted. Whenever possible, a minimum of 300 cells were counted from each culture. 
Data analysis

To determine $\alpha$ for our P vs. I curves, we used the equation of Platt, Gallegos and Harrison (T. Platt et al., 1980):

$$
P^{B}=P_{S}{ }^{B}\left(1-e^{-a}\right) e^{-b} \text { where } a=\alpha I / P_{S}{ }^{B} \text { and } b=\beta I / P_{S}{ }^{B}
$$

$\mathrm{I}$ is irradiance; $\alpha, \beta$, and $\mathrm{P}_{\mathrm{S}}{ }^{\mathrm{B}}$ are adjustable parameters.

This equation was entered into the program GraphPad Prism 1.0 (SoftShell International, Ltd, Grand Junction, $\mathrm{CO}$ ) along with the data from a P vs. I experiment. Prism fit a least-squares curve to the data using the Platt equation. If on inspection the curve did not appear to fit the data, the parameters of the Platt equation were hand-fit in Microsoft Excel (Microsoft Corporation, Redmond, WA) and the values from Excel were used as the initial parameters for another fit in Prism. In some cases the fit in Prism produced a negative value for $\beta$; in these cases, the curve was refit by Prism with $\beta$ assigned a constant value of zero.

In those cases where it was necessary to hand-fit the parameters, the Platt equation was entered in a MS Excel spreadsheet along with the data from a P vs. I experiment. Equation results and experimental data points were plotted at each of the experimental irradiances. The sum of the squares of the differences between the experimental points and the equation results was calculated. The parameters $\alpha, \beta$ and $P_{S}{ }^{B}$ were adjusted by hand until the curve appeared to graphically fit the data, then were fine-tuned to produce a least sum of squares fit. 
Data for alpha over time was fit with linear regressions in constant light cultures. Shifted light cultures were fit with a saturating hyperbola using the equation:

$$
\mathrm{Y}=\left(\mathrm{A}_{\text {change }} *(\mathrm{x})\right) /\left((\mathrm{x})+\mathrm{T}_{1 / 2}\right)+\mathrm{A}_{\text {initial }}
$$

where: $A_{\text {change }}$ is the change in alpha from the initial time to fully adapted $\mathrm{T}_{1 / 2}$ is the time alpha takes to become half-adapted, where

$$
\left.\alpha_{1 / 2}=\left(\left(A_{\text {change }}-A_{\text {initial }}\right) / 2+A_{\text {initial }}\right)\right)
$$

$\mathrm{A}_{\text {initial }}$ is the initial alpha at the time of the light shift

$\mathrm{x}$ is time (days)

$\mathrm{Y}$ is alpha at time $\mathrm{x}$

Note that $A_{\text {change }}$ and $A_{\text {initial }}$ have the same units as the normalized

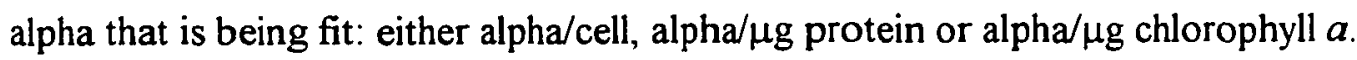

When the saturating hyperbola equation was used by the Prism software to automatically fit the shifted-light data, negative values for the half-adaptation time $\left(T_{1 / 2}\right)$ were sometimes returned. In these cases, curve fitting was done by setting $T_{1 / 2}$ constant and allowing Prism to vary the other parameters. In some cases as $T_{1 / 2}$ was decreased toward $T_{1 / 2}=0.20$ days, the goodness of fit improved (absolute sum of squares decreased). Even if the fit was improving as $T_{1 / 2}$ was decreased toward $T_{1 / 2}=0.20$ days, fits to values of $T_{1 / 2}$ below 0.2 were not performed while fitting by hand. While the curves were fit with values of $T_{1 / 2}$ down to 0.20 days, cultures were only assayed every 48 hours. Half-adaptation times shorter than 2.0 days can only be confidently reported as less than 2.0 days. 


\title{
Chapter 3
}

Simple light shift experiments: increased light and decreased light

\section{Increased Light}

\author{
Introduction
}

The purpose of this experiment was to determine the time scale of photoadaptation in Synechococcus WH7803 for a light shift from a dim constant light to a somewhat brighter constant light. Four replicate cultures were grown in low iron medium and four replicate cultures were grown in high iron medium; two cultures from each set were put through the shift in light. Cultures were maintained semi-continuously by removing $1 / 3$ of each culture and replacing the culture removed with modified aquil medium every two days. The culture removed was used for cell counts, total protein assays, chlorophyll assays, and P vs. I assays every two days over the 12-day assay.

\section{Experimental conditions: increased light}

Circadian rhythms persisting from growth in a light:dark cycle may cause Synechococcus WH7803 cultures to undergo diel periodic oscillations of cell division rates while growing in constant light (Sweeny and Borgese 1989). To avoid circadian rhythms carried over from previous light:dark cycles, cultures were kept in a constant dim light field $\left(\sim 8 \mu \mathrm{Em}^{-2} \mathrm{~s}^{-1}\right)$ for months before the experiment. 
Cultures were kept at their preadaptation illumination intensity for at least two weeks prior to the light shift.

For this experiment, eight cultures grew in constant low light intensity ( 8 $\left.\mu \mathrm{Em}^{-2} \mathrm{~s}^{-1}\right)$ for several weeks: four high iron cultures $\left(5^{*} 10^{-6} \mathrm{M} \mathrm{Fe}\right)$ and four low iron cultures $\left(1 * 10^{-6} \mathrm{M} \mathrm{Fe}\right)$. On experiment day 0 , two high iron cultures and two low iron cultures were moved into a high light intensity $\left(80 \mu \mathrm{Em}^{-2} \mathrm{~s}^{-1}\right)$ while another similar set of four cultures was kept in low light intensity $\left(8 \mu \mathrm{Em}^{-2} \mathrm{~s}^{-1}\right)$ as controls.

The control cultures kept in low light were designated:

LohvLoFe\#1 LohvLoFe\#2 LohvHiFe\#1 LohvHiFe\#2

The cultures grown in low light and shifted to high light on day 0 were designated: HihvLoFe\#1 HihvLoFe\#2 HihvHiFe\#1 HihvHiFe\#2

$300 \mathrm{ml}$ cultures were maintained semi-continuously; $100 \mathrm{ml}$ of each culture was removed and replaced with $100 \mathrm{ml}$ of modified aquil medium every two days. During the 12-day assay, the $100 \mathrm{ml}$ of culture removed every two days was used for cell counts, protein assays, chlorophyll assays, and P vs. I assays.

Samples in scintillation vials that were placed into the P vs. I tank were illuminated at $0.60,8.0,12,13,27,49,62,81,115$, and $146 \mu \mathrm{Em}^{-2} \mathrm{~s}^{-1}$.

Two chlorophyll samples were lost during grinding as cell homogenizers shattered. These were the LohvLoFe\#1 day -2 (1/24/97) sample and the 
HihvHiFe\#1 day 10 (2/5/97) sample. Contents of one of the replicate scintillation vials was lost. The $62 \mu \mathrm{Em}^{-2} \mathrm{~s}^{-1}$ point on the HihvLoFe\#1 day 2 (1/28/97) P vs. I series is based on a single unreplicated datum.

\section{Response of cultures to increased light}

Trends in cell parameters are reported as fractional changes in order to provide an index of the change over time in each of the parameters. The fractional changes are determined from data fitting. Values for day zero and day 10 are determined from the fit, then the fractional change is calculated as the day 10 value divided by the day zero value: fractional change $=($ day 10$) /($ day 0$)$. All data sets are fit with linear regressions except the data sets describing change in alpha over time; some of the alpha over time sets are fit with linear regressions and others are fit with saturating hyperbolae, as described in the "Alpha measurements" section.

In many of the following sections, data about the cultures will be presented in a table that combines several cultures into categories. This table lists which cultures are averaged into each category. Linear regressions through data from replicate cultures are calculated, then the endpoints (day zero and day 10) of these regressions are averaged with the endpoints of other culture pairs and the fractional changes are determined from those averaged endpoints. 
Table 3.1: Cultures in each category of the fractional change tables

\begin{tabular}{rl|l|} 
all cultures: & $\begin{array}{l}\text { LohvLoFe\# 1, LohvLoFe\#2, LohvHiFe\#1, LohvHiFe\#2, } \\
\text { HihLLoFe\#1, HihvLoFe\#2, HihvHiFe\#1, HihvHiFe\#2 }\end{array}$ \\
all HiFe: & LohvHiFe\#1, LohvHiFe\#2, HihvHiFe\#1, HihvHiFe\#2 \\
all LoFe: & LohvLoFe\#1, LohvLoFe\#2, HihvLoFe\#1, HihvLoFe\#2 \\
all increased light: & HihvLoFe\#1, HihvLoFe\#2, HihvHiFe\#1, HihvHiFe\#2 \\
all control: & LohvLoFe\#1, LohvLoFe\#2, LohvHiFe\#1, LohvHiFe\#2, \\
\hline
\end{tabular}




\section{Cell count (cells/ml)}

Cell counts increased in all cultures over the course of the assay. On average, cell counts at the end of the assay increased to 3.2 times the day zero cell counts. Iron did not affect cell counts. Increased light cultures increased their cell counts at double the rate of the constant low light cultures. The average cell count of constant low light cultures was 2.2 times their average day zero count. The average cell count of increased light cultures was 4.4 times their average day zero count. It appears that the increased light relieved energy limits on the cells' growth. Iron concentration had little effect on the cell counts.

Table 3.2: Increased light -- fractional changes in cells $/ \mathrm{ml}$ for replicate cultures

Control cultures Increased light Cultures: Low hv Lo Fe Lo hv Hi Fe Hi hv Lo Fe Hi hv Hi Fe Fractional change in cells $/ \mathrm{ml}$

2.2

1.9

4.1

Table 3.3: Increased light -- fractional changes in cells $/ \mathrm{ml}$ for averaged fits

\begin{tabular}{rccc|} 
& $\begin{array}{c}\text { Day zero } \\
\text { averages } \\
\text { (cells/ml) }\end{array}$ & $\begin{array}{c}\text { Day } 10 \\
\text { averages } \\
\text { (cells/ml) }\end{array}$ & $\begin{array}{c}\text { Fractional } \\
\text { change, } \\
\text { day 10/day 0 }\end{array}$ \\
\cline { 2 - 4 } all cultures: & $4.8^{*} 10^{7}$ & $1.5^{*} 10^{8}$ & 3.2 \\
all HiFe: & $6.4^{*} 10^{7}$ & $2.0^{*} 10^{8}$ & 3.2 \\
\cline { 2 - 4 } all LoFe: & $3.3 * 10^{7}$ & $1.0^{*} 10^{8}$ & 3.2 \\
\cline { 2 - 4 } all increased light: & $4.9^{*} 10^{7}$ & $2.2^{*} 10^{8}$ & 4.4 \\
\cline { 2 - 4 } all control: & $4.8^{*} 10^{7}$ & $1.1 * 10^{8}$ & 2.2 \\
\cline { 2 - 4 }
\end{tabular}




\section{Cell Counts,}

Low Light , 1/97

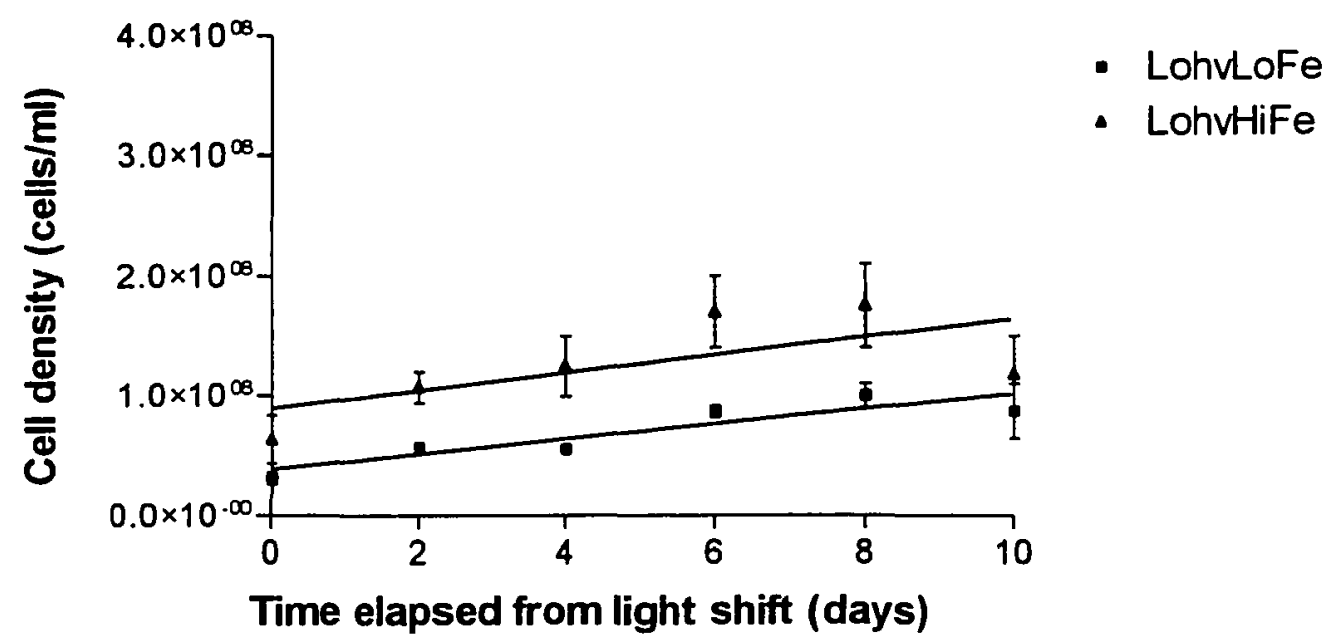

Figure 3.1: Plot of cells $/ \mathrm{ml}$ for constant low light cultures. Error bars indicate $95 \%$ confidence interval.

\section{Cell Counts,} High Light , 1/97

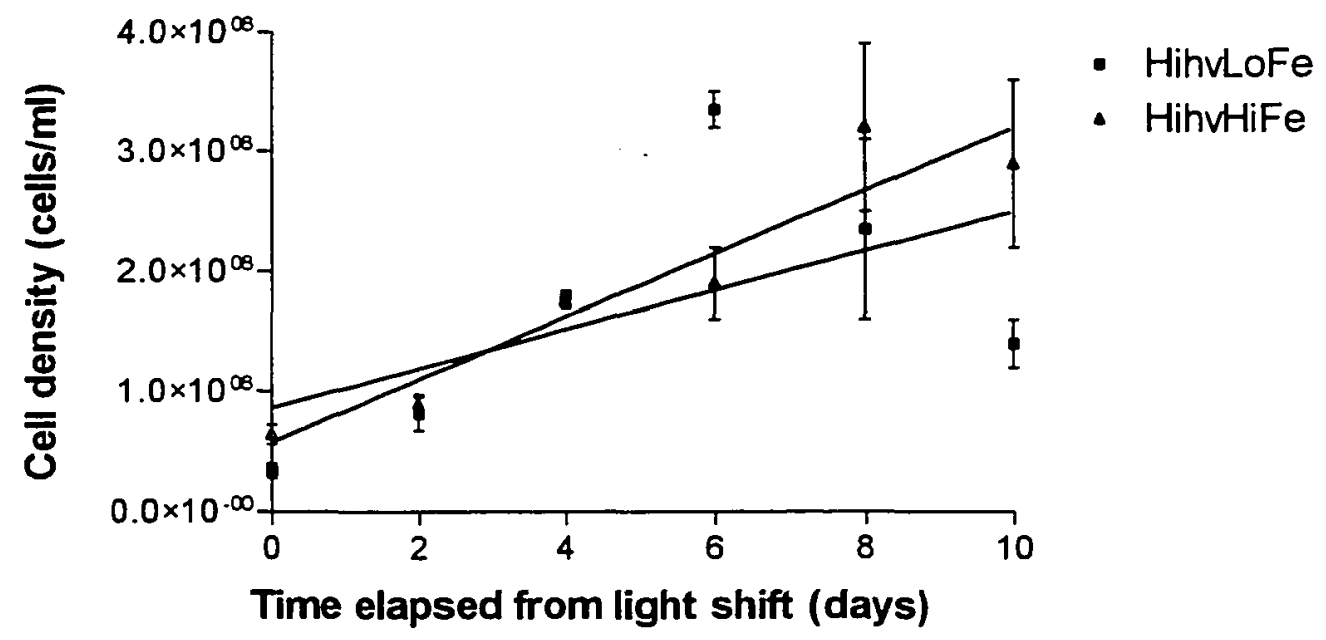

Figure 3.2: Plot of cells $/ \mathrm{ml}$ for increased light cultures. Error bars indicate $95 \%$ confidence interval. 


\section{Chlorophyll ( $\mu \mathrm{g}$ chl $a / \mathrm{ml})$}

The chlorophyll $a$ concentration in the constant low light high iron cultures increased over the course of the experiment. The chlorophyll $a$ concentration in other cultures was fairly stable throughout the experiment. The following fractional changes are based on the values at day zero and day 10 determined from linear regressions, and are calculated by dividing the regression's day 10 value by the regression's day zero value. For the increased light cultures, the average concentration of chlorophyll $a$ in the low iron cultures and high iron cultures decreased to 0.91 times and 0.87 times their initial values respectively. For the constant low light cultures, the average concentration of chlorophyll $a$ in the low iron and high iron cultures increased to 1.1 and 1.4 times their initial values respectively. None of these slopes was reported significantly non-zero by the Prism program. 
Table 3.4: Increased light -- fractional changes in $\mu \mathrm{g} \mathrm{chl} a / \mathrm{ml}$ for replicate cultures

Control cultures Increased light

\begin{tabular}{|c|c|c|c|c|}
\hline Cultures: & Low hv Lo Fe & Lo hv $\mathrm{HiFe}$ & Hi hv Lo Fe & $\mathrm{Hi} \mathrm{hv} \mathrm{Hi} \mathrm{Fe}$ \\
\hline $\begin{array}{r}\text { Fractional change } \\
\text { in } \mu \mathrm{g} \text { chl } \alpha / \mathrm{ml}:\end{array}$ & 1.1 & 1.5 & 0.91 & 0.87 \\
\hline
\end{tabular}

Table 3.5: Increased light -- fractional changes in $\mu \mathrm{g}$ chl $a / \mathrm{ml}$ for averaged fits

\begin{tabular}{rccc|} 
& $\begin{array}{c}\text { Day zero } \\
\text { averages } \\
(\mu \mathrm{g} \text { chl } a / \mathrm{ml})\end{array}$ & $\begin{array}{c}\text { Day } 10 \\
\text { averages } \\
(\mu \mathrm{g} \mathrm{chl} a / \mathrm{ml})\end{array}$ & $\begin{array}{c}\text { Fractional } \\
\text { change, } \\
\text { day 10/day } 0\end{array}$ \\
\cline { 2 - 4 } all cultures: & 0.17 & 0.19 & 1.1 \\
all HiFe: & 0.20 & 0.23 & 1.2 \\
all LoFe: & 0.14 & 0.14 & 1.0 \\
\cline { 2 - 4 } all increased light: & 0.16 & 0.14 & 0.88 \\
all control: & 0.17 & 0.23 & 1.3 \\
\cline { 2 - 4 } & & &
\end{tabular}


Low Light, 1/97

Chlorophyll a, Spectrophotometric

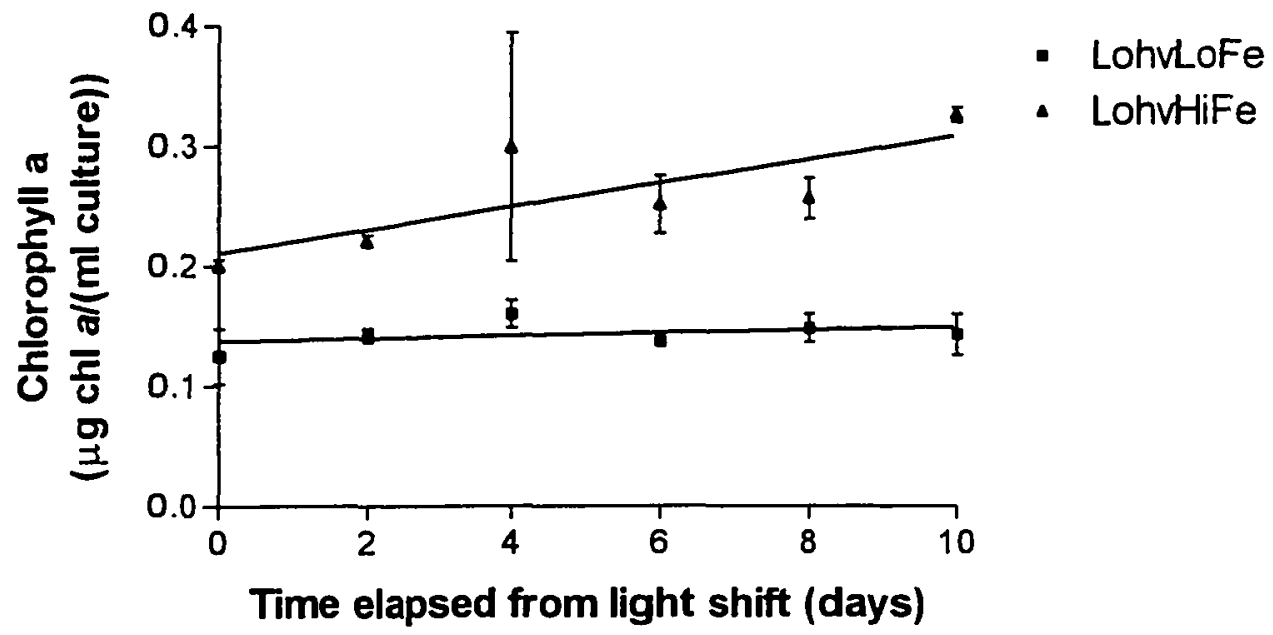

Figure 3.3: Plot of $\mu \mathrm{g} \mathrm{chl} a / \mathrm{ml}$ for constant low light cultures. Error bars span values from replicate cultures.

High Light, 1/97

Chlorophyll a, Spectrophotometric

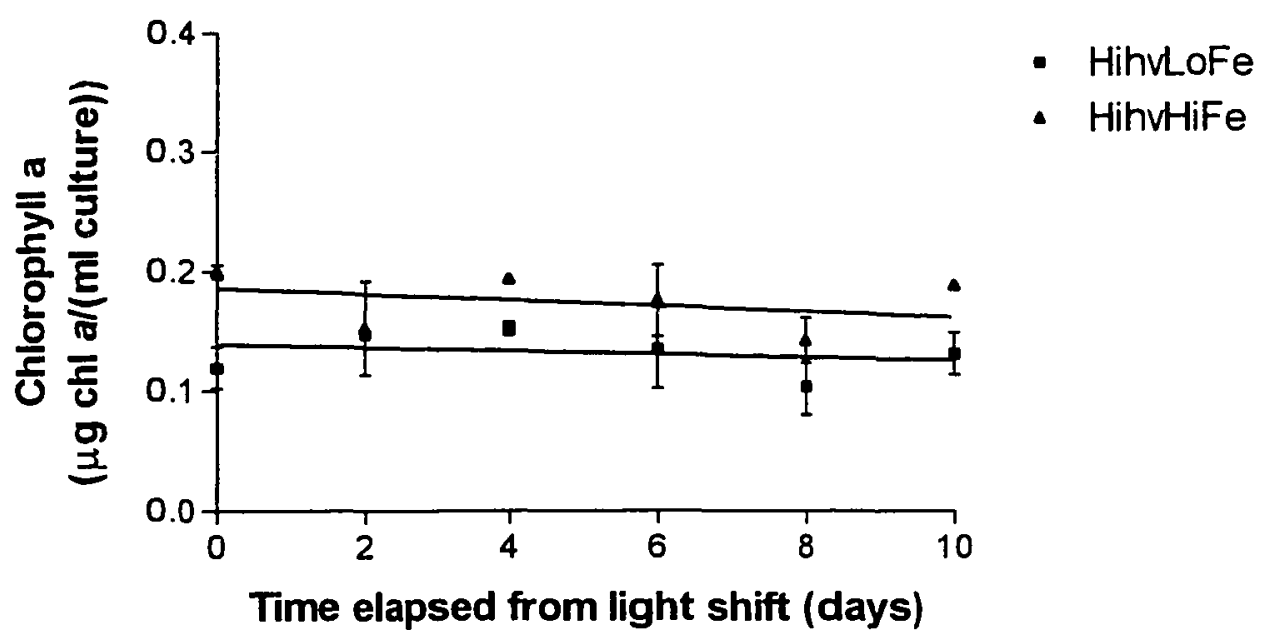

Figure 3.4: Plot of $\mu \mathrm{g}$ chl $a / \mathrm{ml}$ for increased light cultures. HihvHiFe\#1 day 10 : sample lost. Error bars span values from replicate cultures. 


\section{Protein ( $\mu \mathrm{g}$ protein $/ \mathrm{ml})$}

The total protein concentration increased in all cultures over the course of the experiment. Protein in increased light cultures increased more than in constant low light cultures. In constant low light, protein in the high iron cultures increased slightly more rapidly than low iron cultures. Proteins in the increased light cultures were essentially the same regardless of iron. The following fractional changes are based on the values at day zero and day 10 determined from linear regressions. The Prism software reported that the slope of the constant low light low iron culture was not significantly non-zero, while all the other cultures had significant slopes.

Table 3.6: Increased light -- fractional changes in $\mu \mathrm{g}$ protein $/ \mathrm{ml}$ for replicate cultures

Control cultures Increased light Cultures: Low hv Lo Fe Lo hv Hi Fe Hi hv Lo Fe Hi hv Hi Fe Fractional change in $\mu \mathrm{g}$ protein $/ \mathrm{ml}$

1.1

1.4

2.0 1.9

Table 3.7: Increased light -- fractional changes in $\mu \mathrm{g}$ protein $/ \mathrm{ml}$ for averaged fits

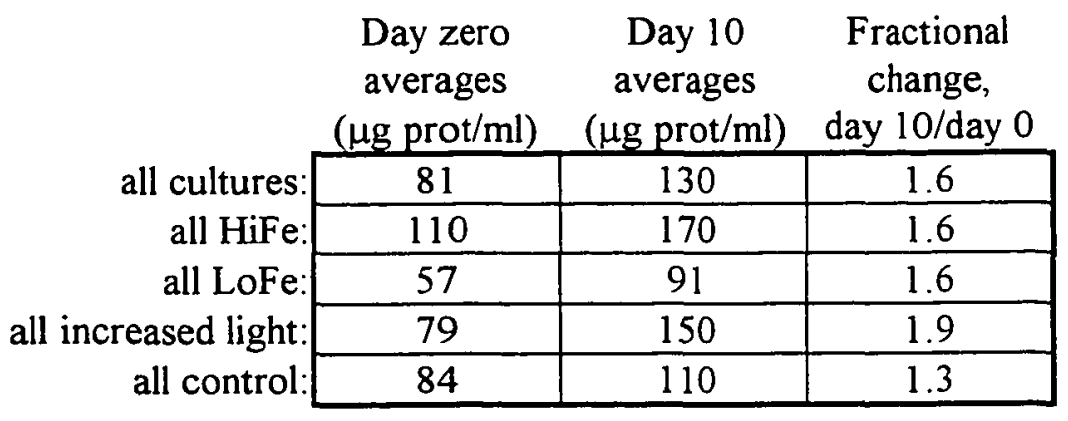




\section{Proteins $(\mu \mathrm{g} / \mathrm{ml})$ \\ Low Constant Light 1/97}

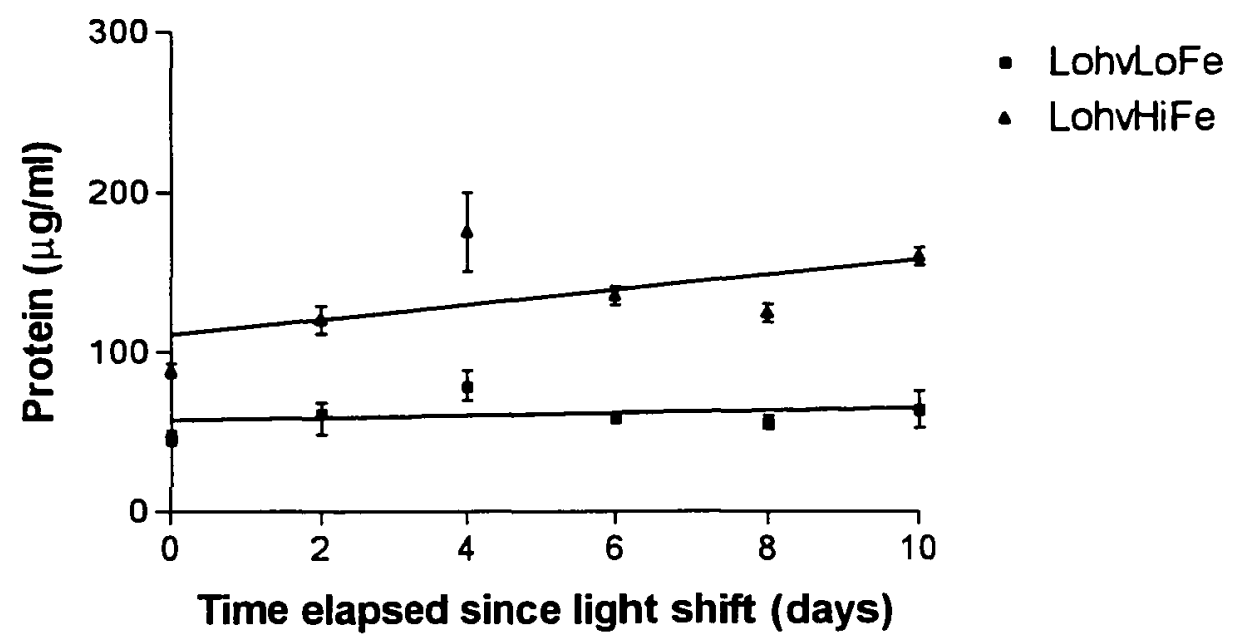

Figure 3.5: Plot of $\mu$ g protein/ml for constant low light cultures. Error bars span values from replicate cultures.

Proteins ( $\mu \mathrm{g} / \mathrm{ml})$
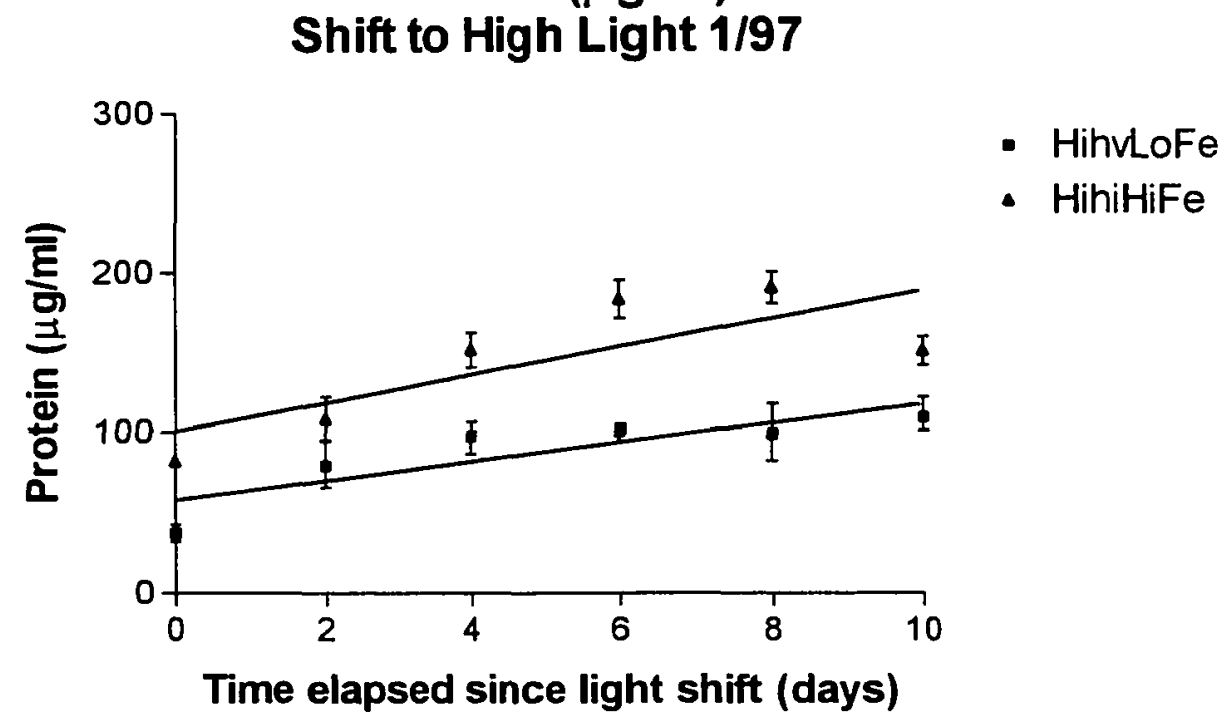

Figure 3.6: Plot of $\mu \mathrm{g}$ protein $/ \mathrm{ml}$ for increased light cultures. Error bars span values from replicate cultures. 


\section{Chlorophyll $a$ per cell ( $\mu \mathrm{g}$ chl $a /$ cell)}

Chlorophyll $a$ concentrations per cell (chl a/cell) decreased in all cultures over the course of the experiment. $\mathrm{Chl}$ a/cell in increased light cultures decreased much more than in constant low light cultures, as expected for adaptation to increased irradiance. The increased light low iron culture lost its $\mathrm{chl} \mathrm{a/cell} \mathrm{more}$ rapidly than the increased light high iron culture, finishing its decrease by about day 6 and then stabilizing. The increased light high iron culture lost chl a/cell more steadily over the 10 days. The Prism software reported that the slope of the low constant light high iron culture is not significantly non-zero; the other slopes were reported to be significant. The following fractional changes are based on the values at day zero and day 10 determined from linear regressions.

Table 3.8: Increased light -- fractional changes in $\mu \mathrm{g}$ chl $a /$ cell for replicate cultures

Control cultures Increased light Cultures: Low hv Lo Fe Lo hv Hi Fe Hi hv Lo Fe Hi hv Hi Fe

Fractional change 0.37 0.71 0.031 0.019 in $\mu \mathrm{g}$ chl $a /$ cell:

Table 3.9: Increased light -- fractional changes in $\mu \mathrm{g}$ chl $a /$ cell for averaged fits

\begin{tabular}{|c|c|c|c|}
\hline & $\begin{array}{c}\text { Day zero } \\
\text { averages } \\
(\mu \mathrm{g} \text { chl } a / \text { cell })\end{array}$ & $\begin{array}{c}\text { Day } 10 \\
\text { averages } \\
\mu \mathrm{g} \text { chl } a / \text { cell })\end{array}$ & $\begin{array}{c}\text { Fractional } \\
\text { change, } \\
\text { day } 10 / \text { day } 0\end{array}$ \\
\hline all cultures: & $2.8 * 10^{-9}$ & $8.4 * 10^{-10}$ & 0.29 \\
\hline all HiFe: & $2.6 * 10^{-9}$ & $9.9 * 10^{-10}$ & 0.37 \\
\hline all LoFe: & $3.0^{*} 10^{.9}$ & $6.8 * 10^{-10}$ & 0.22 \\
\hline all increased light: & $2.6 * 10^{\cdot 9}$ & $6.4 * 10^{-11}$ & 0.025 \\
\hline all control: & $3.1 * 10^{-9}$ & $1.6 * 10^{-9}$ & 0.52 \\
\hline
\end{tabular}




\section{Low Light \\ Chl a per Cell, 1/97}

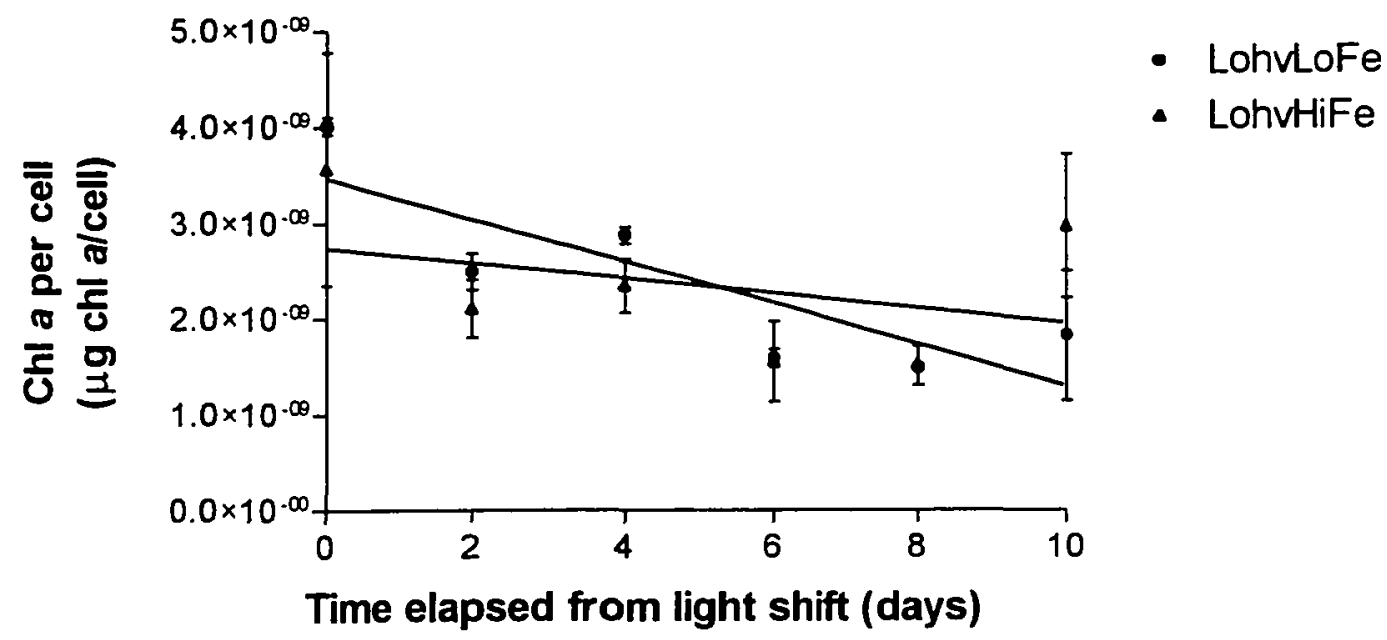

Figure 3.7: Plot of $\mu$ chl $a /$ cell for constant low light cultures. Error bars span values from replicate cultures.

High Light

Chl a per Cell, 1/97

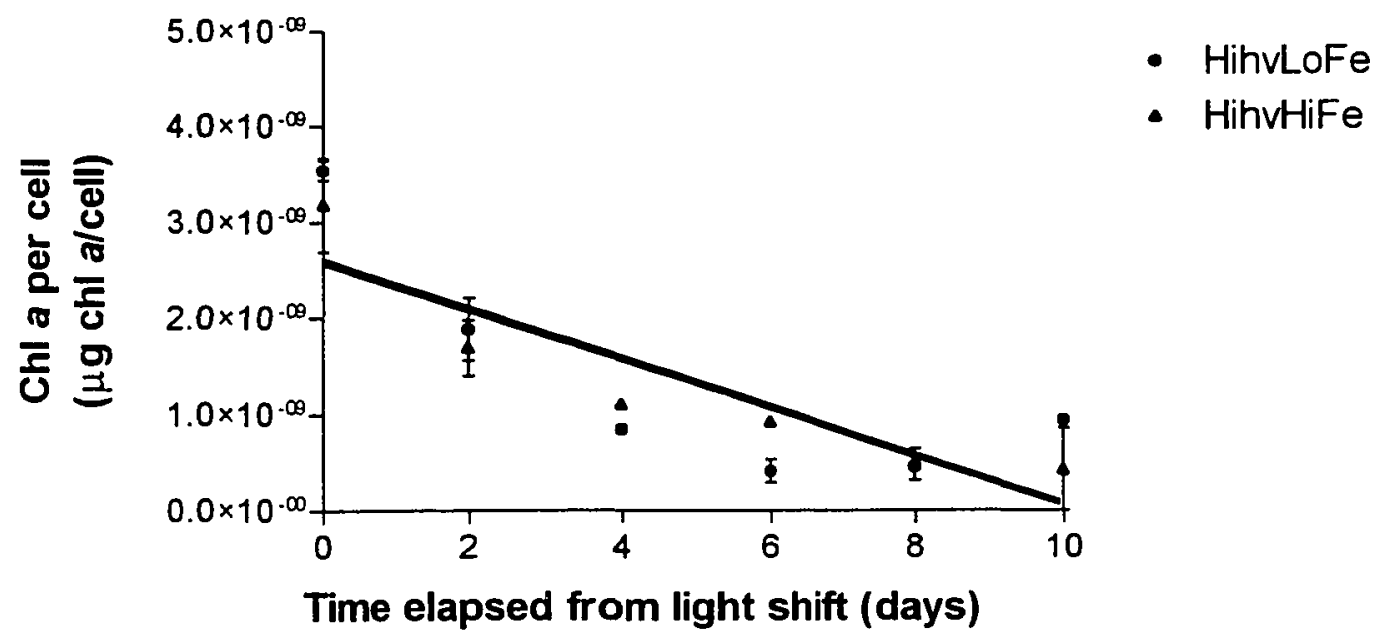

Figure 3.8: Plot of $\mu \mathrm{g}$ chl $a$ /cell for increased light cultures. HihvHiFe\#1 day 10: chl $a$ sample lost . Error bars span values from replicate cultures. 


\section{Protein per cell ( $\mu \mathrm{g}$ protein/cell)}

Total protein concentrations per cell (protein/cell) decreased in all cultures over the course of the experiment. Protein/cell in low iron cultures decreased more than in high iron cultures. Protein/cell decreased more in increased light cultures than the constant light cultures of the same iron concentrations; this may reflect the greater increase in cell number per volume in the increased light cultures. High iron cultures decreased their protein/cell less that the low iron cultures. The following fractional changes are based on the values at day zero and day 10 determined from linear regressions. The Prism software yields results that indicate that the slopes of the constant low light low iron culture and the increased light high iron culture are significantly non-zero, while the slope of the other cultures are not significant.

Table 3.10: Increased light -- fractional changes in $\mu \mathrm{g}$ protein/cell for replicate cultures

$$
\text { Control cultures Increased light }
$$

Cultures: Low hv Lo Fe Lo hv Hi Fe Hi hv Lo Fe Hi hv Hi Fe

\begin{tabular}{l|c|c|c|c|}
\hline $\begin{array}{l}\text { Fractional change } \\
\text { in } \mu \mathrm{g} \text { protein/cell: }\end{array}$ & 0.42 & 0.76 & 0.22 & 0.45 \\
\hline
\end{tabular}

Table 3.11: Increased light -- fractional changes in $\mu \mathrm{g}$ protein/cell for averaged fits

\begin{tabular}{|c|c|c|c|}
\hline & $\begin{array}{c}\text { Day zero } \\
\text { averages } \\
(\mu \mathrm{g} \text { prot/cell) }\end{array}$ & $\begin{array}{c}\text { Day } 10 \\
\text { averages } \\
(\mu \mathrm{g} \text { prot/cell) }\end{array}$ & $\begin{array}{c}\text { Fractional } \\
\text { change, } \\
\text { day } 10 / \text { day } 0\end{array}$ \\
\hline all cultures: & $1.4 * 10^{-6}$ & $6.3 * 10^{-7}$ & 0.46 \\
\hline all HiFe: & $1.3 * 10^{-6}$ & $8.0^{*} 10^{-7}$ & 0.61 \\
\hline all LoFe: & $1.4^{*} 10^{-6}$ & $4.6^{*} 10^{-7}$ & 0.32 \\
\hline 1 increased light: & $1.4^{*} 10^{-6}$ & $4.5 * 10^{-7}$ & 0.33 \\
\hline all control & $1.4^{*} 10^{-6}$ & $8.1 * 10^{-7}$ & 0.58 \\
\hline
\end{tabular}


Low Light Protein per Cell, 1/97

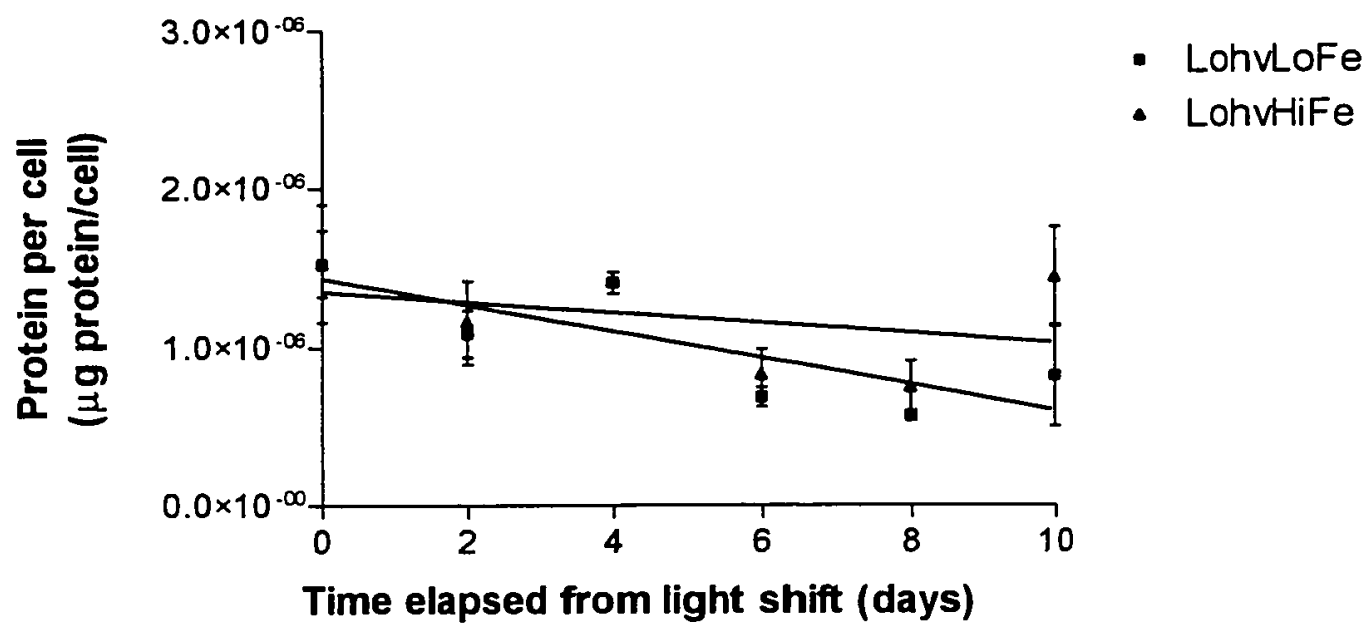

Figure 3.9: Plot of $\mu \mathrm{g}$ protein/cell for constant low light cultures. Error bars span values from replicate cultures.

High Light Protein per Cell, 1/97

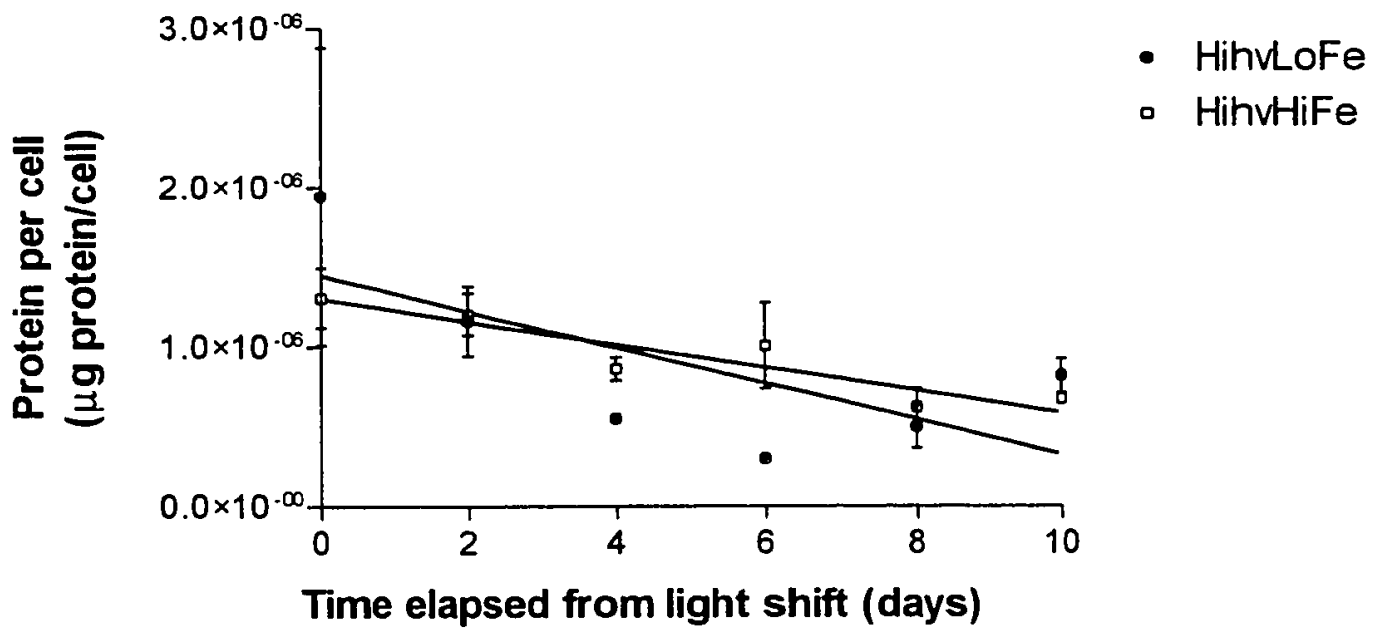

Figure 3.10: Plot of $\mu$ g protein/cell for increased light cultures. Error bars span values from replicate cultures. 


\section{Chlorophyll $a$ per protein ( $\mu \mathrm{g}$ chl $a / \mu \mathrm{g}$ protein)}

The chlorophyll a per protein decreased to less than a third of the initial values in the increased light cultures, which is the result expected during adaptation to higher light conditions. The control cultures were nearly unchanged. Iron concentration had little effect on the slopes. The Prism program yields results that indicate that the chlorophyll $a$ per protein decreased significantly in the increased light cultures but the slopes of the control cultures were not significantly different from zero.

Table 3.12: Increased light -- fractional changes in $\mu \mathrm{g}$ chl $a / \mu \mathrm{g}$ protein for replicate cultures

\section{Control cultures Increased light}

Cultures: Low hv Lo Fe Lo hv Hi Fe Hi hv Lo Fe Hi hv Hi Fe

\begin{tabular}{l|c|c|c|c|}
$\begin{array}{l}\text { Fractional change in } \\
\mu \mathrm{g} \text { chl } a / \mu \mathrm{g} \text { protein: }\end{array}$ & 0.95 & 0.97 & 0.31 & 0.30 \\
\hline
\end{tabular}

Table 3.13: Increased light -- fractional changes in $\mu \mathrm{g}$ chl $a / \mu \mathrm{g}$ protein for averaged fits

\begin{tabular}{|c|c|c|c|}
\hline & $\begin{array}{c}\text { Day zero } \\
\text { averages } \\
\text { (chl } a / \text { prot) } \\
\text { w/w }\end{array}$ & $\begin{array}{c}\text { Day } 10 \\
\text { averages } \\
\text { (chl } a / \text { prot) } \\
\text { w/w }\end{array}$ & $\begin{array}{c}\text { Fractional } \\
\text { change, } \\
\text { day } 10 / \text { day } 0\end{array}$ \\
\hline all cultures: & $2.3^{*} 10^{-3}$ & $1.4 * 10^{-3}$ & 0.63 \\
\hline all HiFe: & $2.0^{*} 10^{-3}$ & $1.3^{*} 10^{-3}$ & 0.64 \\
\hline all LoFe: & $2.5 * 10^{-3}$ & $1.6^{*} 10^{-3}$ & 0.62 \\
\hline all increased light: & $2.3^{*} 10^{-3}$ & $7.0^{*} 10^{-4}$ & 0.30 \\
\hline all control: & $2.2 * 10^{-3}$ & $2.1 * 10^{-3}$ & 0.96 \\
\hline
\end{tabular}




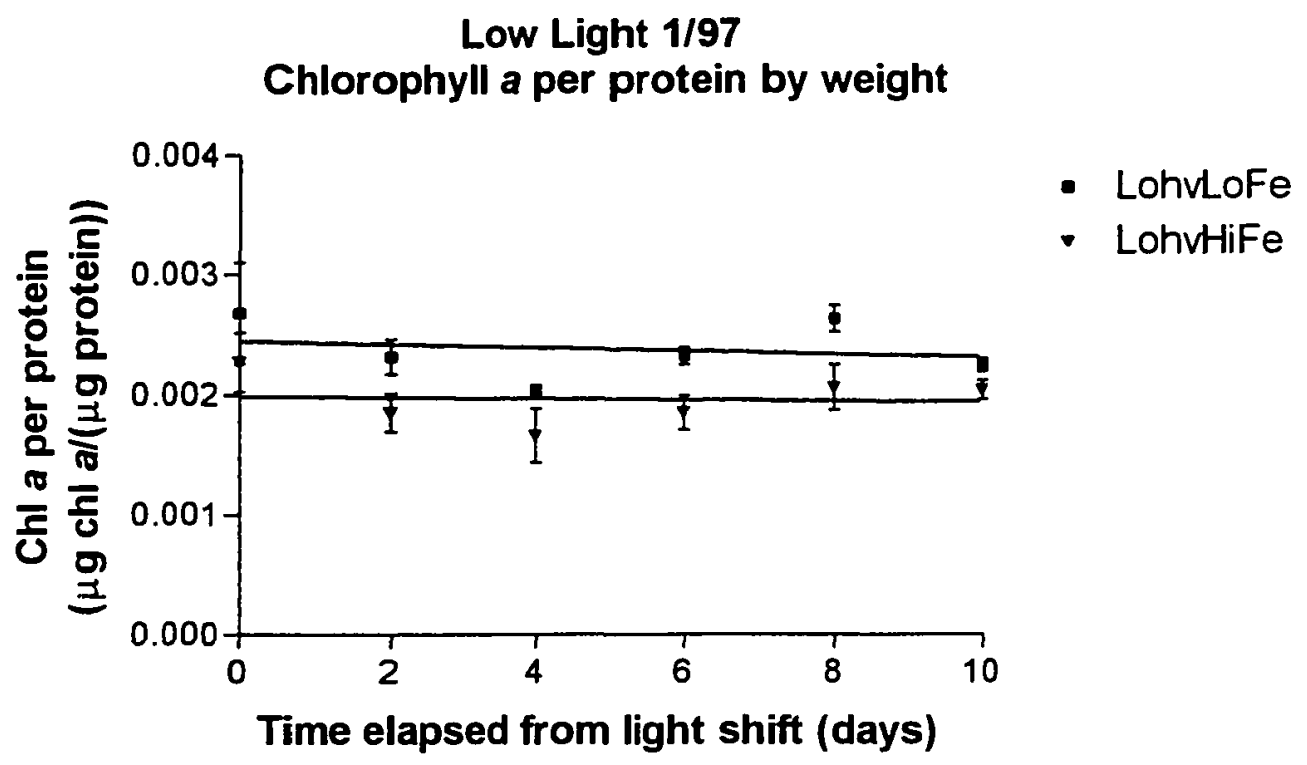

Figure 3.11: Plot of $\mu \mathrm{g}$ chl a/ $\mu \mathrm{g}$ protein for constant low light cultures. Error bars span values from replicate cultures.

High Light $1 / 97$

Chlorophyll a per protein by weight

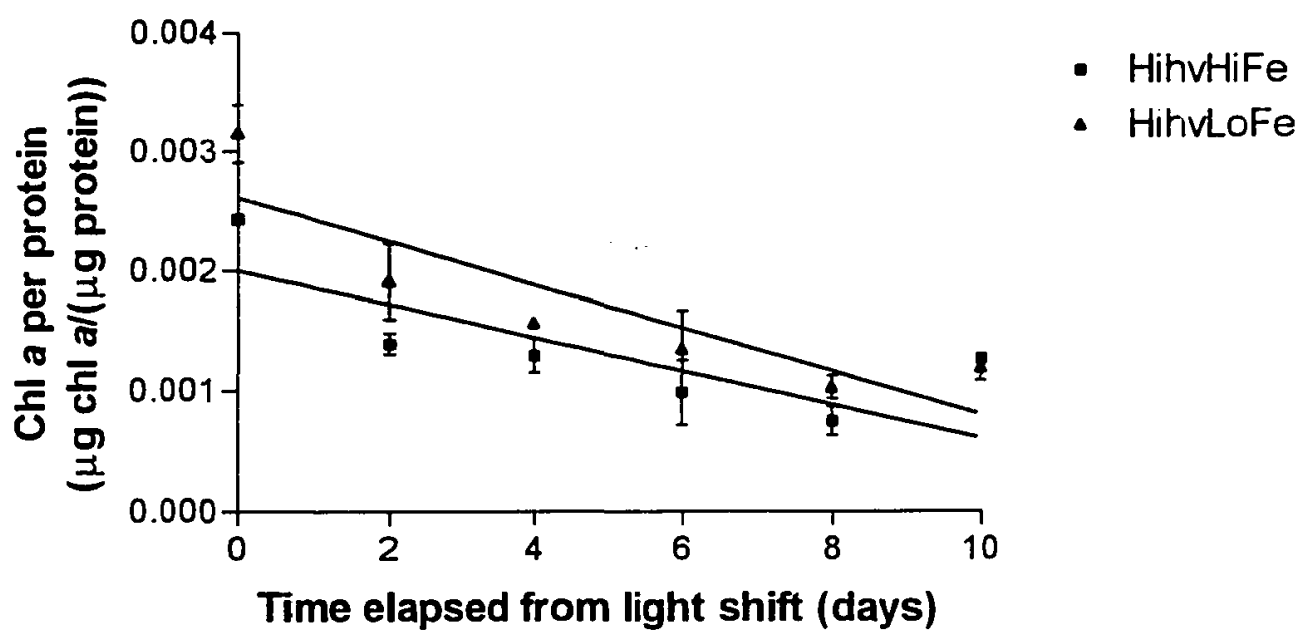

Figure 3.12: Plot of $\mu \mathrm{g}$ chl $a / \mu \mathrm{g}$ protein for increased light cultures. HihvHiFe\#l day 10: chl $a$ sample lost. Error bars span values from replicate cultures. 


\section{Alpha measurements}

Constant light cultures were fit by linear regression. Increased light cultures were fit with the saturating hyperbola equation (eq. 2) and the procedure given in Materials and Methods.

\section{Alpha normalized per cell}

Alpha per cell decreased quickly in increased light cultures. The largest decrease was in the low iron increased light cultures. Alpha per cell remained fairly stable in control cultures, decreasing only slightly. The Prism software reported that the slopes of the constant low light cultures were not significantly non-zero.

The rapid decrease in alpha per cell might be due to damage to the photosystems as the electron carriers are reduced more quickly than they can be reoxidized. Electrons from the photosynthetic electron transport chain might reduce oxygen to superoxide or cause other potentially damaging reductions (Sampson et al. 1994). A decrease in alpha is typical in photoinhibited algae (Henley 1993). A decrease in the number of functional pigments, photosystems or electron carriers per cell beyond the threshold where that component would limit photosynthesis should lead to a decrease in alpha per cell.

Increased light low iron

$$
A_{\text {change }}=-1.2^{\star} 10^{-5} \quad T_{1 / 2}=0.20 \text { days } \quad A_{\text {initial }}=1.3^{\star} 10^{-5}
$$

Increased light high iron

$$
A_{\text {change }}=-1.0^{\star 1} 10^{-5} \quad T_{1 / 2}=0.20 \text { days } \quad A_{\text {initial }}=1.1^{\star 1} 10^{-5}
$$


Table 3.14: Increased light -- fractional changes in alpha/cell for replicate cultures

$$
\text { Control cultures Increased light }
$$

Cultures: Low hv Lo Fe Lo hv Hi Fe Hi hv Lo Fe Hi hv Hi Fe

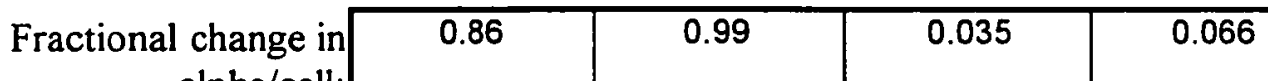
alpha/cell

Table 3.15: Increased light -- fractional changes in alpha/cell for averaged fits

\begin{tabular}{rccc|} 
& \multicolumn{1}{c}{$\begin{array}{c}\text { Day zero } \\
\text { averages } \\
\text { (alpha/cell) }\end{array}$} & $\begin{array}{c}\text { Day } 10 \\
\text { averages } \\
\text { (alpha/cell) }\end{array}$ & $\begin{array}{c}\text { Fractional } \\
\text { change, } \\
\text { day 10/day 0 }\end{array}$ \\
\cline { 2 - 4 } all cultures & $1.0^{*} 10^{-5}$ & $4.6^{*} 10^{-6}$ & 0.44 \\
all HiFe: & $1.1^{*} 10^{-5}$ & $5.4^{*} 10^{-6}$ & 0.51 \\
\cline { 2 - 4 } all LoFe: & $1.0^{*} 10^{-5}$ & $3.8^{*} 10^{-6}$ & 0.36 \\
\cline { 2 - 4 } all increased light & $1.2^{*} 10^{-5}$ & $5.8^{*} 10^{-7}$ & 0.049 \\
\cline { 2 - 4 } all control: & $9.2^{*} 10^{-6}$ & $8.6^{*} 10^{-6}$ & 0.93 \\
\cline { 2 - 4 }
\end{tabular}




\section{LoFe 1/97 Alpha \\ (14C uptake per cell)}

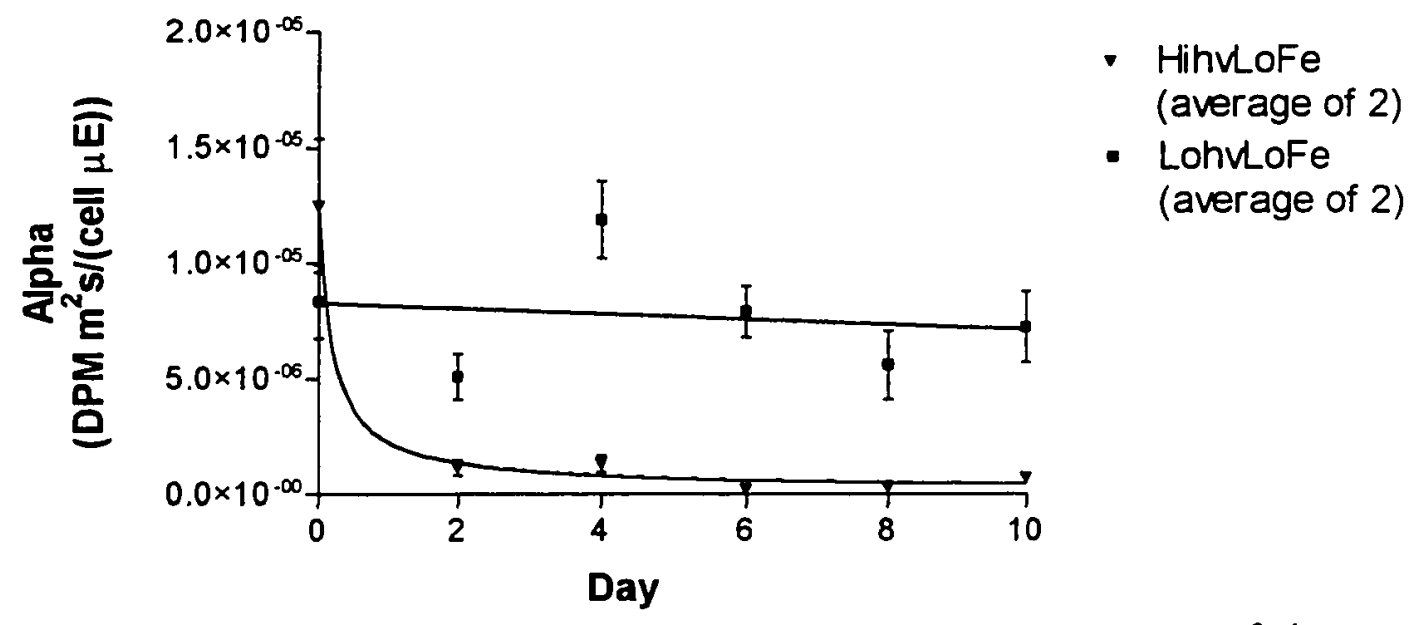

Figure 3.13: Plot of alpha/cell for constant low light cultures. The $62 \mu \mathrm{Em}^{-2} \mathrm{~s}^{-1}$ point in HihvLoFe\#1 day $2 \mathrm{P}$ vs. I is based on a single scintillation count. Error bars indicate the standard error in the initial slope of each P vs. I curve.
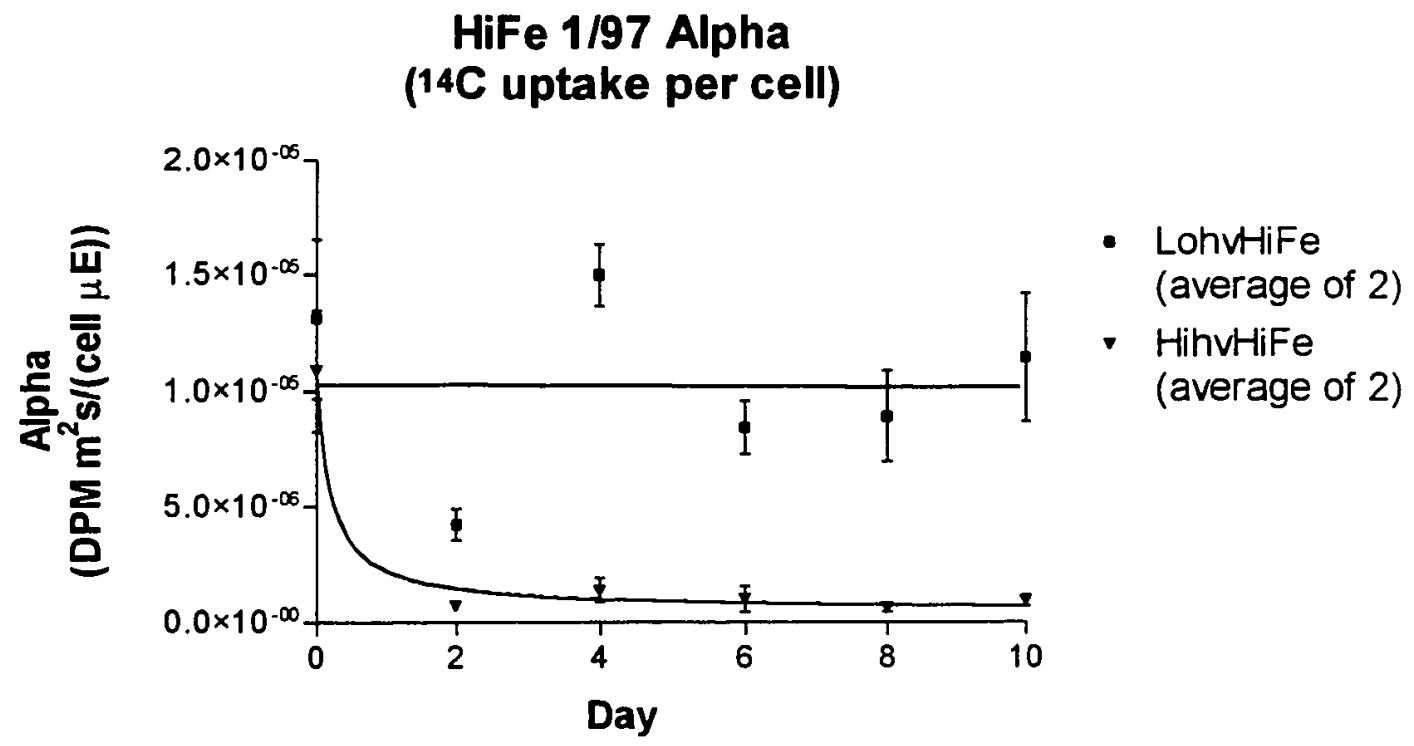

Figure 3.14: Plot of alpha/cell for increased light cultures. Error bars indicate the standard error in the initial slope of each P vs. I curve. 


\section{Alpha normalized per $\mu \mathrm{g} \operatorname{chl} a$}

Alpha per chl $a$ in the increased light cultures dropped quickly and remained low; the overall average of increased light cultures decreased to less than a third of its initial value. Alpha per chl $a$ in constant light cultures increased through the experiment, nearly doubling in the low iron cultures. Comparing overall averages of high iron and low iron cultures, iron appeared to have little effect; however, low iron cultures increased further in constant illumination and decreased further in increased illumination.

When illumination was increased, the fractional decrease in alpha per chlorophyll was not as sharp as the fractional decrease in alpha per cell. This makes sense given that when illumination was increased, chlorophyll per cell decreased 
Increased light low iron

$A_{\text {change }}=-2.7^{* 10^{3}} \quad T_{1 / 2}=0.20$ days $\quad A_{\text {initial }}=3.4^{*} 10^{3}$

Increased light high iron

$A_{\text {change }}=-2.1 * 10^{3} \quad T_{1 / 2}=0.20$ days $\quad A_{\text {initial }}=3.3^{*} 10^{3}$

Table 3.16: Increased light -- fractional changes in alpha/ $\mu \mathrm{g}$ chl $a$ for replicate cultures

Control cultures Increased light

Cultures: Low hv Lo Fe Lo hv Hi Fe Hi hv Lo Fe Hi hv $\mathrm{Hi} F$

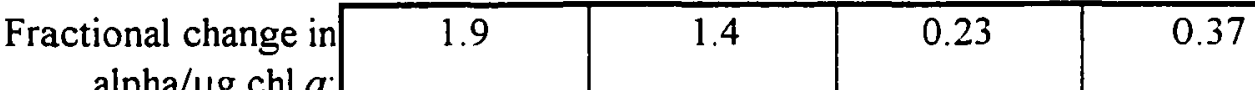

alpha/ $\mu \mathrm{g}$ chl $a$

Table 3.17: Increased light -- fractional changes in alpha/ $\mu \mathrm{g}$ chl $a$ for averaged fits

\begin{tabular}{|c|c|c|c|}
\hline & $\begin{array}{c}\text { Day zero } \\
\text { averages } \\
\text { (alpha/ } / \mathrm{g} \text { chl } a \text { ) }\end{array}$ & $\begin{array}{c}\text { Day } 10 \\
\text { averages } \\
(\text { alpha } / \mu \mathrm{g} \text { chl } a)\end{array}$ & $\begin{array}{c}\text { Fractional } \\
\text { change, } \\
\text { day } 10 / \text { day } 0\end{array}$ \\
\hline \multirow{4}{*}{$\begin{array}{r}\text { all cultures: } \\
\text { all HiFe: } \\
\text { all LoFe: }\end{array}$} & $3.2^{*} 10^{3}$ & $3.0^{*} 10^{3}$ & 0.94 \\
\hline & $3.5^{*} 10^{3}$ & $3.2 * 10^{3}$ & 0.93 \\
\hline & $2.9 * 10^{3}$ & $2.8 * 10^{3}$ & 0.94 \\
\hline & $3.4^{*} 10^{3}$ & $1.0 * 10^{3}$ & 0.30 \\
\hline all control: & $3.1 * 10^{3}$ & $5.0^{*} 10^{3}$ & 1.6 \\
\hline
\end{tabular}




\section{LoFe 1/97 Alpha (14C uptake per $\mu \mathrm{g} \mathrm{chl} \mathrm{a)}$}

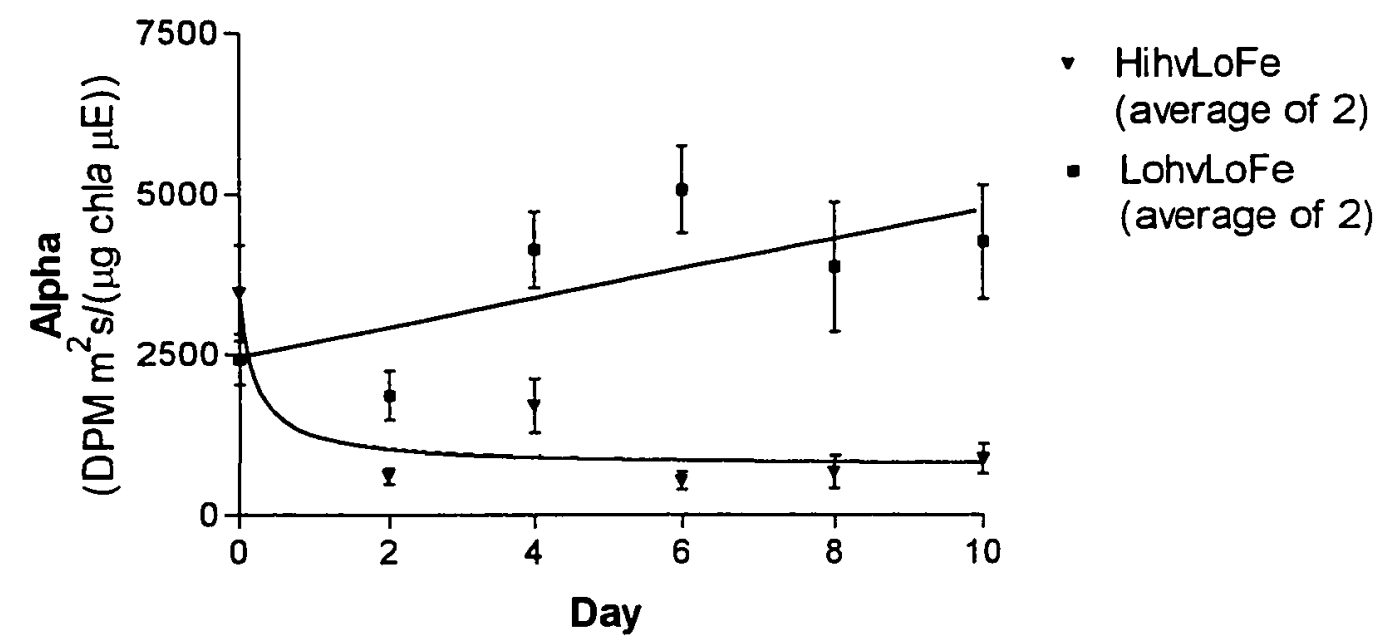

Figure 3.15: Plot of alpha/ $\mu \mathrm{g}$ chl $a$ for constant low light cultures. The $62 \mu \mathrm{Em}^{-2} \mathrm{~s}^{-}$ ${ }^{1}$ point in HihvLoFe\#1 day $2 \mathrm{P}$ vs. I is based on a single scintillation count. Error bars indicate the standard error in the initial slope of each P vs. I curve.

\section{HiFe 1/97 Alpha (14C uptake per $\mu \mathrm{g} \mathrm{chl} \mathrm{a)}$}

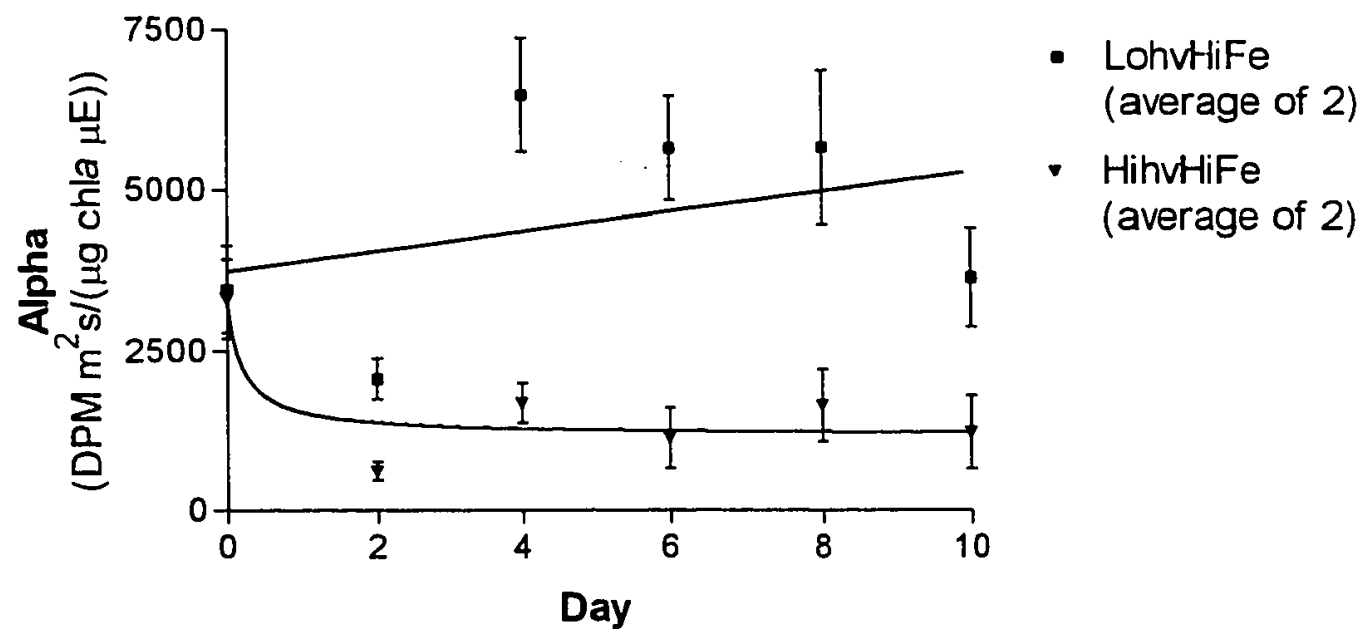

Figure 3.16: Plot of alpha/ $\mu \mathrm{g}$ chl $a$ for increased light cultures. Error bars indicate the standard error in the initial slope of each P vs. I curve. 


\section{Alpha normalized per $\mu \mathrm{g}$ protein}

Alpha per $\mu \mathrm{g}$ protein in increased light cultures decreased rapidly to about an eighth of the initial values. Alpha per $\mu \mathrm{g}$ protein in constant light cultures increased on average to 1.6 times the initial values. The Prism program yields results that indicate that the slopes of the constant irradiance low iron cultures are not significantly non-zero.

Comparing overall averages of high iron and low iron cultures, iron appeared to have little effect; however, low iron cultures increased alpha per $\mu \mathrm{g}$ protein further in constant illumination and decreased alpha per $\mu \mathrm{g}$ protein further in increased illumination. Increased illumination is expected to decrease alpha, whether by photoadaptation or as photosystems are damaged and not rapidly replaced. 
Increased light low iron

$\mathrm{A}_{\text {change }}=-9.7 \quad \mathrm{~T}_{1 / 2}=0.13$ days $\quad \mathrm{A}_{\text {initial }}=11$

Increased light high iron

$\mathrm{A}_{\text {change }}=-6.9 \quad \mathrm{~T}_{1 / 2}=0.20$ days $\quad \mathrm{A}_{\text {initial }}=8.0$

Table 3.18: Increased light -- fractional changes in alpha/ $\mu$ g protein for replicate cultures

Control cultures Increased light

Cultures: Low hv Lo Fe Lo hv Hi Fe Hi hv Lo Fe Hi hv Hi Fe

\begin{tabular}{|c|}
\hline Fractional change in \\
\hline
\end{tabular}

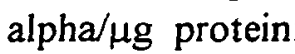

Table 3.19: Increased light -- fractional changes in alpha/ $\mathrm{gg}$ protein for averaged fits

\begin{tabular}{|c|c|c|c|}
\hline & 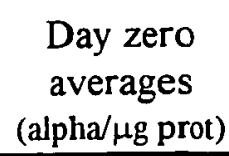 & $\begin{array}{c}\text { Day } 10 \\
\text { averages } \\
\text { (alpha/ } / \mathrm{g} \text { prot) }\end{array}$ & $\begin{array}{c}\text { Fractional } \\
\text { change, } \\
\text { day } 10 / \text { day } 0\end{array}$ \\
\hline \multirow{5}{*}{$\begin{array}{r}\text { all cultures: } \\
\text { all HiFe: } \\
\text { all LoFe: } \\
\text { creased light: } \\
\text { all control: }\end{array}$} & 7.9 & 5.9 & 0.74 \\
\hline & 7.6 & 5.6 & 0.74 \\
\hline & 8.3 & 6.1 & 0.74 \\
\hline & 9.3 & 1.2 & 0.13 \\
\hline & 6.5 & 11 & 1.6 \\
\hline
\end{tabular}




\section{LoFe 1/97 Alpha \\ (14C uptake per $\mu \mathrm{g}$ protein)}

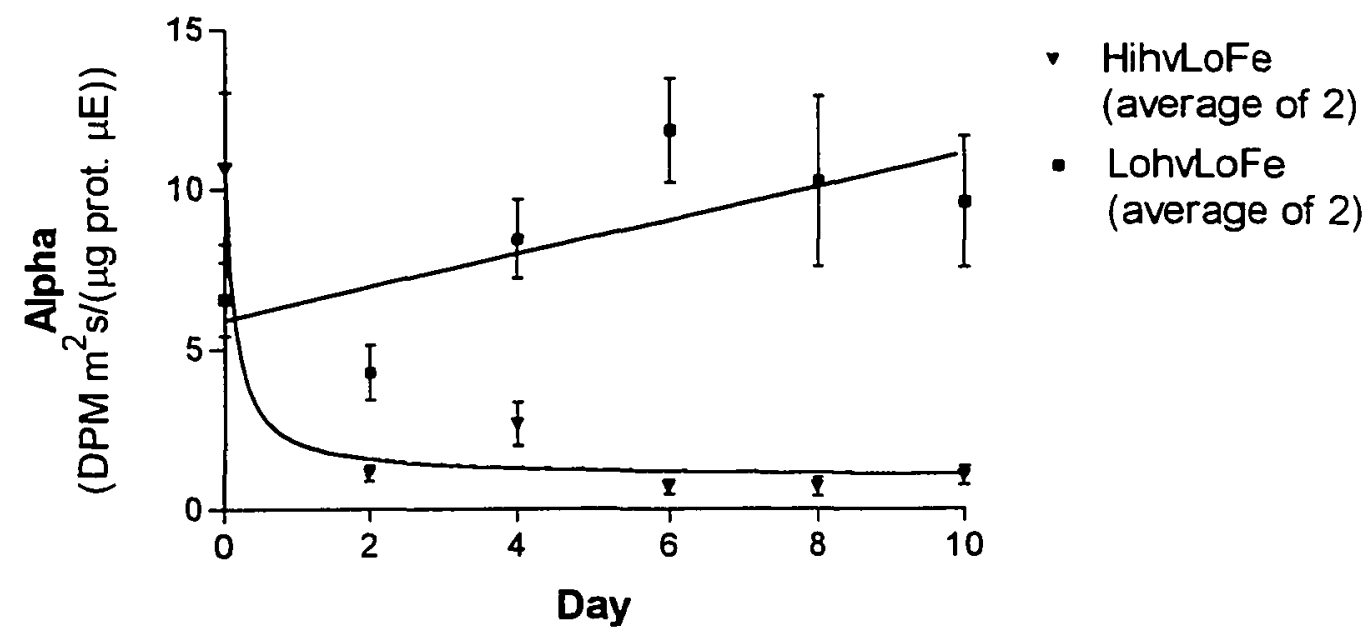

Figure 3.17: Plot of alpha/ $\mu$ g protein for constant low light cultures. The $62 \mu \mathrm{Em}^{-2} \mathrm{~s}^{-1}$ point in HihvLoFe\#1 day $2 \mathrm{P}$ vs. I is based on a single scintillation count. Error bars indicate the standard error in the initial slope of each P vs. I curve.

\section{HiFe 1/97 Alpha \\ (14C uptake per $\mu \mathrm{g}$ protein)}

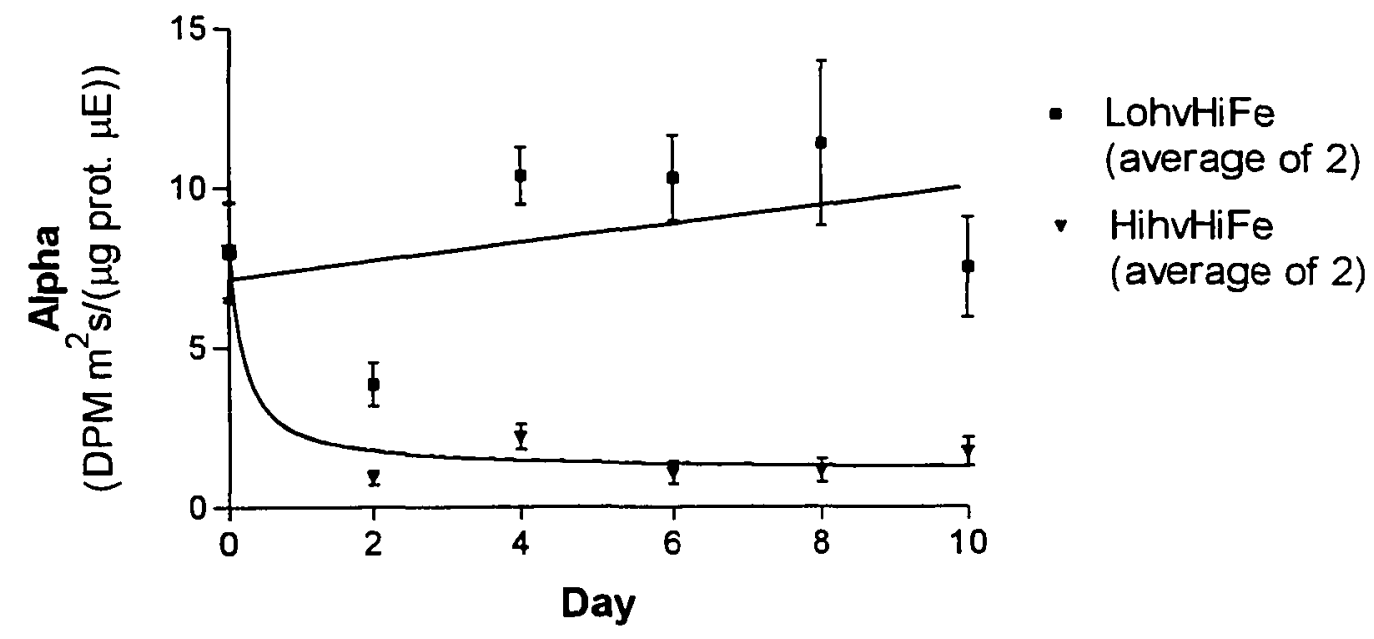

Figure 3.18: Plot of alpha/ $\mu$ g protein for increased light cultures. Error bars indicate the standard error in the initial slope of each $P$ vs. I curve. 


\section{Decreased Light}

\section{Introduction}

The purpose of this experiment was to determine the time scale of photoadaptation in Synechococcus WH7803 for a light shift from a moderate constant light to a dim constant light. Four replicate cultures were grown in low iron medium and four replicate cultures were grown in high iron medium; two cultures from each set were put through the shift in light. Cultures were maintained semi-continuously by removing $1 / 3$ of each culture and replacing the culture removed with modified aquil medium every two days. The culture removed was used for cell counts, total protein assays, chlorophyll assays, and P vs. I assays every two days over the 12-day assay.

\section{Experimental conditions: decreased light}

Cultures were kept in a constant dim light field for months before the experiment, which should have eliminated any diel periodicity due to circadian rhythms in their response to the light shift. Cultures were kept at their preadaptation illumination intensity for at least two weeks prior to the light shift.

For this experiment, eight cultures grew in constant high light intensity ( 80 $\left.\mu \mathrm{Em}^{-2} \mathrm{~s}^{-1}\right)$ for several weeks. The eight cultures were four high iron cultures $\left(5 * 10^{-6}\right.$ $\mathrm{M} \mathrm{Fe}$ ) and four low iron cultures $\left(1^{*} 10^{-6} \mathrm{M} \mathrm{Fe}\right)$. On experiment day 0 , two high iron cultures and two low iron cultures were moved into a low light intensity (8 
$\left.\mu \mathrm{Em}^{-2} \mathrm{~s}^{-1}\right)$ and another similar set of four cultures was kept in high light intensity (80 $\left.\mu \mathrm{Em}^{-2} \mathrm{~s}^{-1}\right)$ as controls.

The control cultures kept in high light were designated:

HihvLoFe\#1 HihvLoFe\#2 HihvHiFe\#1 HihvHiFe\#2

The cultures grown in high light and shifted to low light on day 0 were designated:

LohvLoFe\#1 LohvLoFe\#2 LohvHiFe\#1 LohvHiFe\#2

$300 \mathrm{ml}$ cultures were maintained semi-continuously; $100 \mathrm{ml}$ of each culture was removed and replaced with $100 \mathrm{ml}$ of modified aquil medium every two days. During the 12-day assay, the $100 \mathrm{ml}$ of culture removed every two days was used for cell counts, protein assays, chlorophyll assays, and P vs. I assays.

Samples in scintillation vials that were placed into the P vs. I tank were illuminated at $0.59,6.5,12,12,20,43,67,82,117$, and $143 \mu \mathrm{Em}^{-2} \mathrm{~s}^{-1}$.

The datum from one of the replicate dark scintillation vials was rejected. That point was very high, 274DPM; this is the largest dark value of the 4/97 run. The average of dark values for the $4 / 97$ run is 113 , the standard deviation is 69 . The dark point used for the HihvLoFe\#2 day 2 (4/28/97) P vs. I series is based on a single unreplicated datum. 


\section{Response of cultures to decreased light}

Tables of fractional changes presented in the decreased light section will use almost the same cultures as the tables of fractional changes in the increased light section. The difference is that the high light (Hihv) cultures are the controls and the low light (Lohv) cultures are the decreased irradiance cultures.

\section{Cell count (cells/ml)}

Cell counts decreased in all cultures over the course of the assay. The average cell count of constant high light cultures decreased slightly, while average cell count of decreased light cultures decreased to 0.59 times their average day zero count. Surprisingly, the average cell counts of high iron cultures decreased to 0.60 times the day zero cell counts, while average cell counts of low iron cultures only decreased to 0.88 times the day zero cell counts.

Table 3.20: Decreased light -- fractional changes in cells $/ \mathrm{ml}$ for replicate cultures

Decreased light

Cultures: Low hv Lo Fe Lo hv Hi Fe Hi hv Lo Fe Hi hv Hi Fe Fractional change
in cells $/ \mathrm{ml}$ 0.82 in cells $/ \mathrm{m}$

0.42

0.94 0.85

Table 3.21: Decreased light -- fractional changes in cells $/ \mathrm{ml}$ for averaged fits

\begin{tabular}{|c|c|c|c|}
\hline & $\begin{array}{l}\text { Day zero } \\
\text { averages } \\
\text { (cells } / \mathrm{ml} \text { ) }\end{array}$ & $\begin{array}{c}\text { Day } 10 \\
\text { averages } \\
\text { (cells } / \mathrm{ml} \text { ) }\end{array}$ & $\begin{array}{c}\text { Fractional } \\
\text { change, } \\
\text { day } 10 / \text { day } 0\end{array}$ \\
\hline all cultures & $3.0 * 10^{8}$ & $2.1 * 10^{8}$ & 0.72 \\
\hline all $\mathrm{HiFe}$ & $3.4^{*} 10^{8}$ & $2.1 * 10^{8}$ & 0.60 \\
\hline all LoFe & $2.6^{*} 10^{8}$ & $2.2 * 10^{8}$ & 0.88 \\
\hline all control & $2.7^{*} 10^{8}$ & $2.4^{*} 10^{8}$ & 0.89 \\
\hline I decreased light & $3.3 * 10^{8}$ & $1.9 * 10^{8}$ & 0.59 \\
\hline
\end{tabular}




\section{Cell Counts,}

Low Light , 4/97

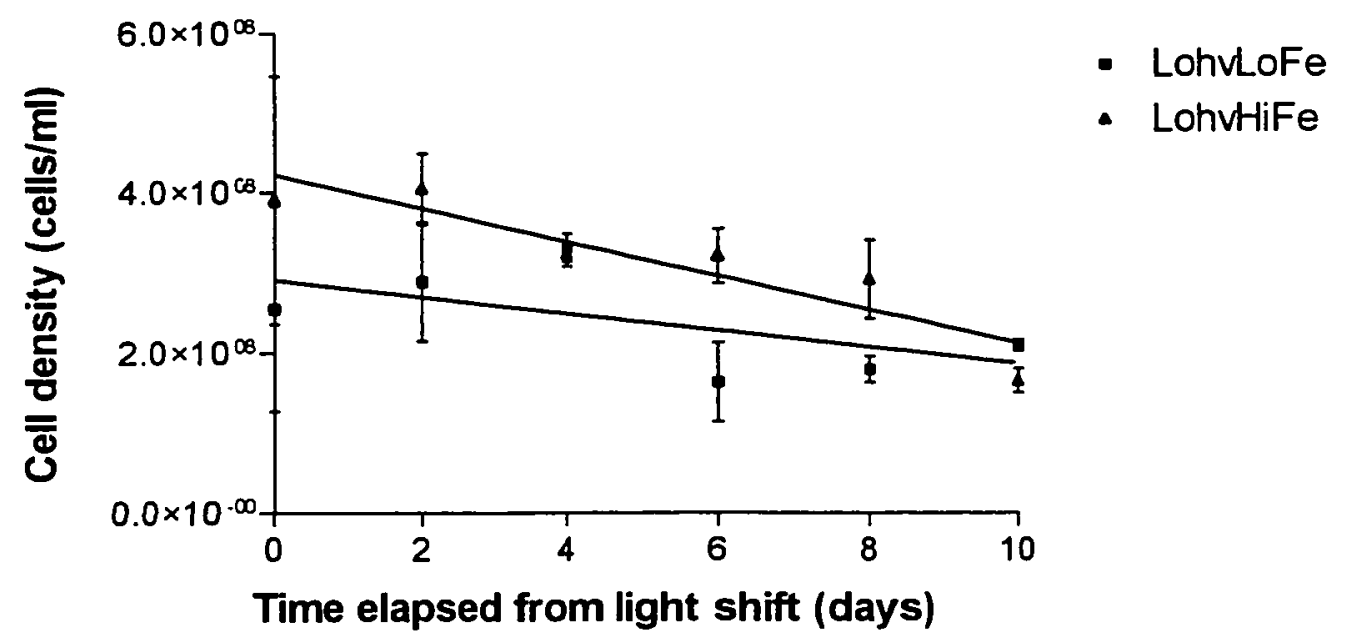

Figure 3.19: Plot of cells/ml for decreased light cultures. Error bars indicate $95 \%$ confidence intervals.

Cell Counts, High Light , 4/97

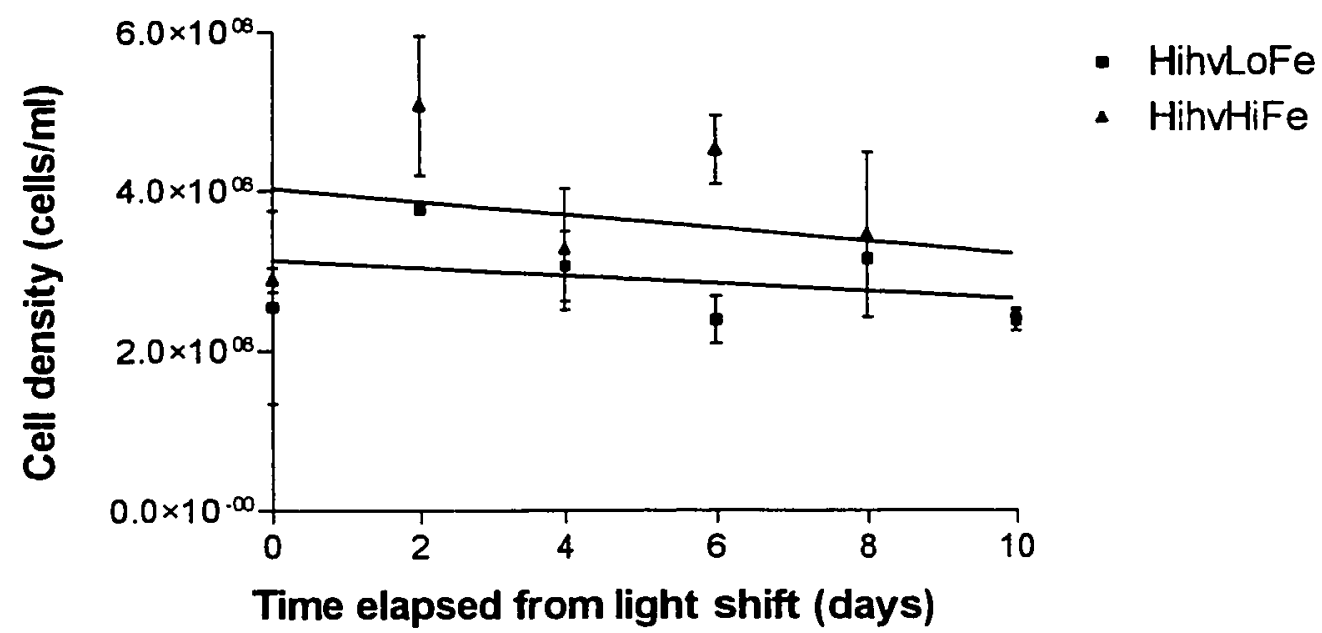

Figure 3.20: Plot of cells/ml for constant high light cultures. Error bars indicate $95 \%$ confidence intervals. 


\section{Chlorophyll ( $\mu \mathrm{g} \mathrm{chl} a / \mathrm{ml})$}

In the decreased light cultures, the chlorophyll $a$ concentrations increased over the course of the experiment. The following increases are based on the values at day zero and day 10 determined from linear regressions. For the decreased light cultures, the average concentration (w/v) of chlorophyll $a$ in the low iron cultures doubled from day zero to day 10 , while the average of the high iron cultures increased to 3.1 times its initial value. An increase in chlorophyll is expected during adaptation to lower light. The more rapid increase in chlorophyll $a$ concentration in the decreased light high iron culture may reflect the contribution of iron to the synthesis of chlorophyll $a$ and other photosystem components as well as the more efficient conversion of light energy to chemical energy if sufficient iron is available. The chlorophyll $a$ concentrations in the constant high light cultures increased more slowly throughout the experiment; the low iron culture average reached 1.7 times its initial value and the high iron culture average reached 1.4 times its initial value. All slopes were reported by the Prism software to be significantly non-zero except the slope of the constant high light high iron culture. 
Table 3.22: Decreased light -- fractional changes in $\mu \mathrm{g} \mathrm{chl} a / \mathrm{ml}$ for replicate cultures

$$
\text { Decreased light Control cultures }
$$

\begin{tabular}{|c|c|c|c|c|}
\hline Cultures: & Low hv Lo Fe & Lo hv $\mathrm{Hi} \mathrm{Fe}$ & Hi hv Lo Fe & $\mathrm{Hi} \mathrm{hv} \mathrm{Hi} \mathrm{Fe}$ \\
\hline $\begin{array}{l}\text { Fractional change } \\
\text { in } \mu \mathrm{g} \text { chl } a / \mathrm{ml} \text { : }\end{array}$ & 2.2 & 3.7 & 1.9 & 1.5 \\
\hline
\end{tabular}

Table 3.23: Decreased light -- fractional changes in $\mu \mathrm{g} \mathrm{chl} a / \mathrm{ml}$ for averaged fits

\begin{tabular}{rccc|} 
& $\begin{array}{c}\text { Day zero } \\
\text { averages } \\
(\mu \mathrm{g} \mathrm{chl} a / \mathrm{ml})\end{array}$ & $\begin{array}{c}\text { Day } 10 \\
\text { averages } \\
(\mu \mathrm{g} \mathrm{chl} a / \mathrm{ml})\end{array}$ & $\begin{array}{c}\text { Fractional } \\
\text { change, } \\
\text { day } 10 / \text { day } 0\end{array}$ \\
all cultures: & 0.067 & 0.16 & 2.4 \\
all HiFe: & 0.082 & 0.21 & 2.6 \\
all LoFe: & 0.052 & 0.11 & 2.0 \\
\cline { 2 - 4 } all control: & 0.066 & 0.11 & 1.6 \\
\cline { 2 - 4 } all decreased light: & 0.068 & 0.21 & 3.1 \\
\cline { 2 - 4 } & & &
\end{tabular}


Chlorophyll a, Spectrophotometric

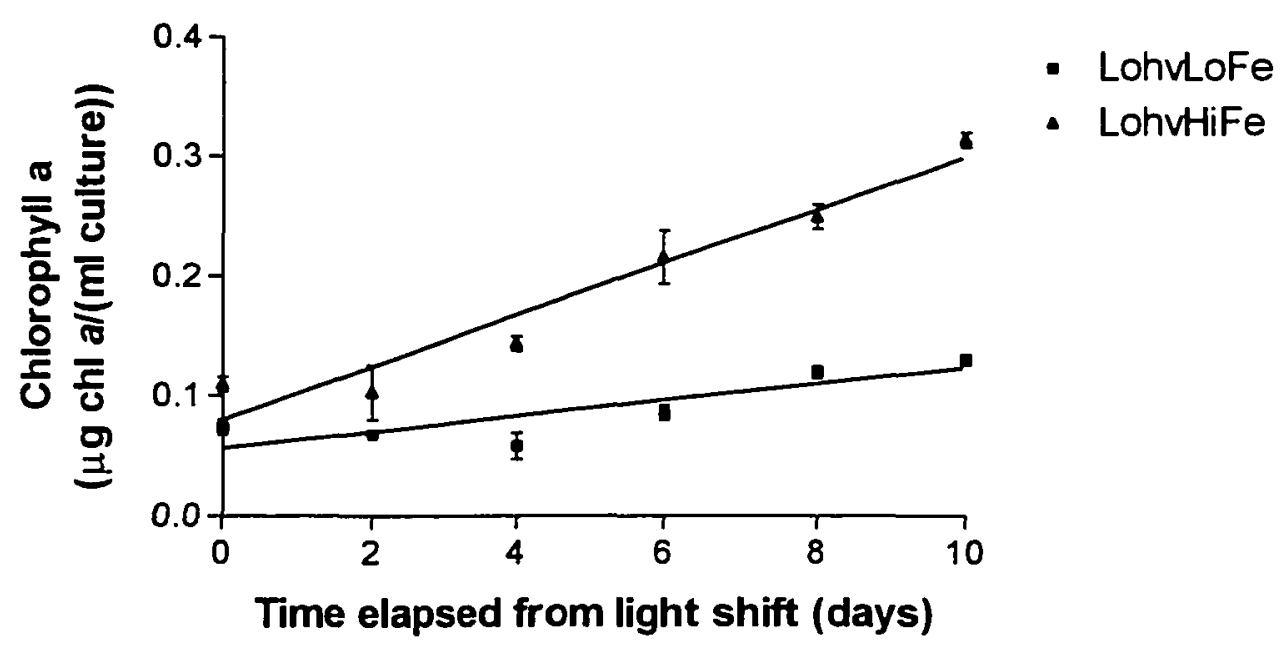

Figure 3.21: Plot of $\mu \mathrm{g}$ chl $\mathrm{a} / \mathrm{ml}$ for decreased light cultures. Error bars span values from replicate cultures.

High Light, 4/97

Chlorophyll a, Spectrophotometric

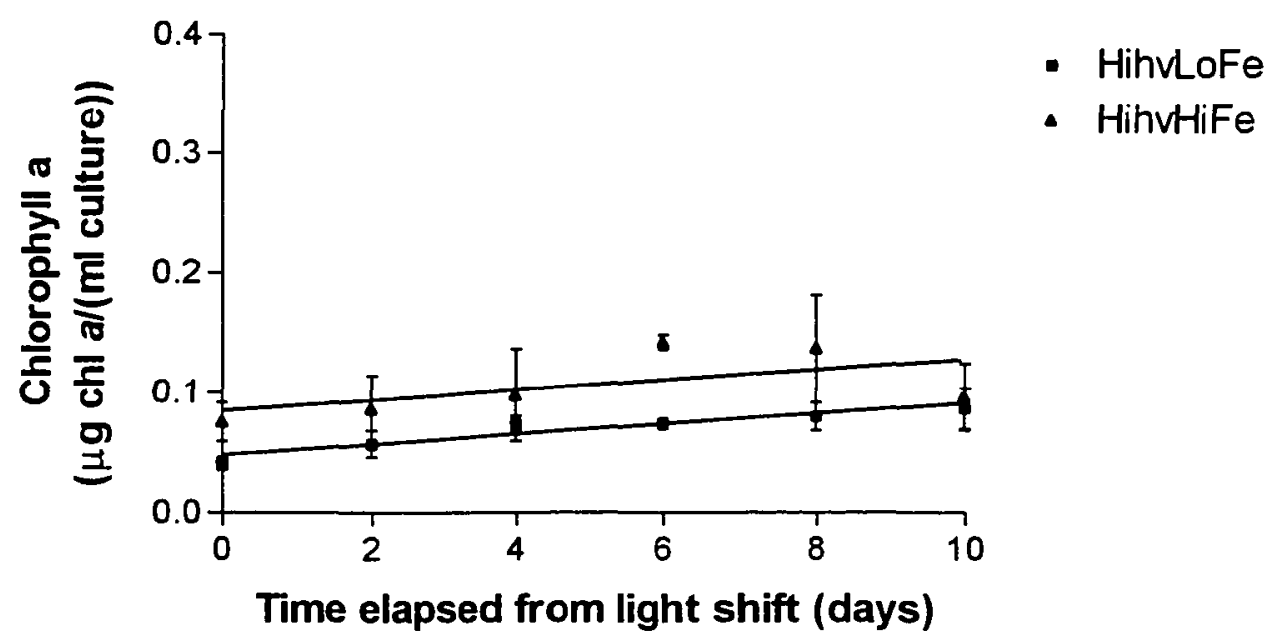

Figure 3.22: Plot of $\mu \mathrm{g} \mathrm{chl} a / \mathrm{ml}$ for constant high light cultures. Error bars span values from replicate cultures. 


\section{Protein ( $\mu \mathrm{g}$ protein $/ \mathrm{ml})$}

Total protein concentrations remained fairly constant over the course of the experiment in high iron cultures and the decreased light high iron culture, while those in the decreased light low iron culture decreased. The Prism software reported that the only significantly non-zero slope was the slope of the decreased light low iron culture. This might be caused by an energetic limitation on growth in low light that can be overcome with sufficient iron. The following fractional changes are based on the values at day zero and day 10 determined from linear regressions.

Table 3.24: Decreased light -- fractional changes in $\mu$ g protein $/ \mathrm{ml}$ for replicate cultures

Decreased light Control cultures

Cultures: Low hv Lo Fe Lo hv Hi Fe Hi hv Lo Fe $\mathrm{Hi}$ hv Hi Fe

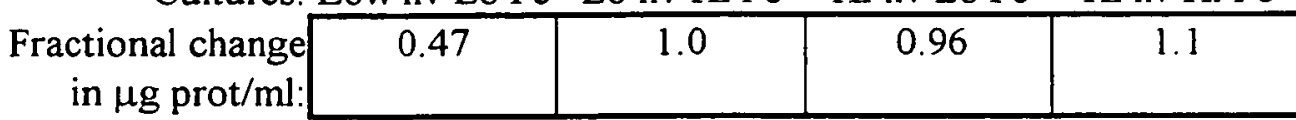

Table 3.25: Decreased light -- fractional changes in $\mu \mathrm{g}$ protein/ml for averaged fits

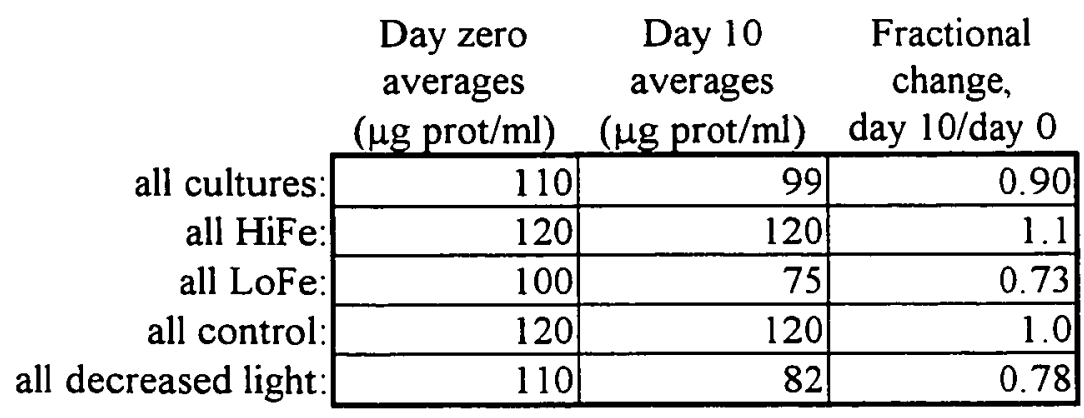




\section{Proteins $(\mu \mathrm{g} / \mathrm{ml})$ \\ Low Light 4/97}

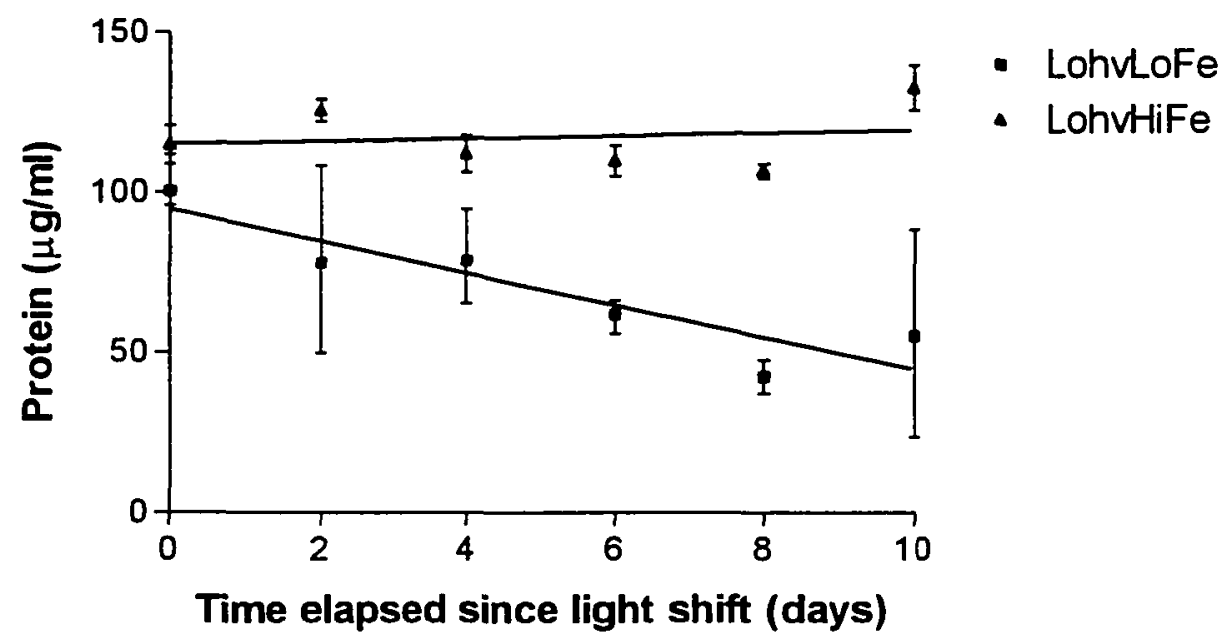

Figure 3.23: Plot of $\mu \mathrm{g}$ protein $/ \mathrm{ml}$ for decreased light cultures. Error bars span values from replicate cultures.

\section{Proteins $(\mu \mathrm{g} / \mathrm{ml})$}

\section{High Light 4/97}

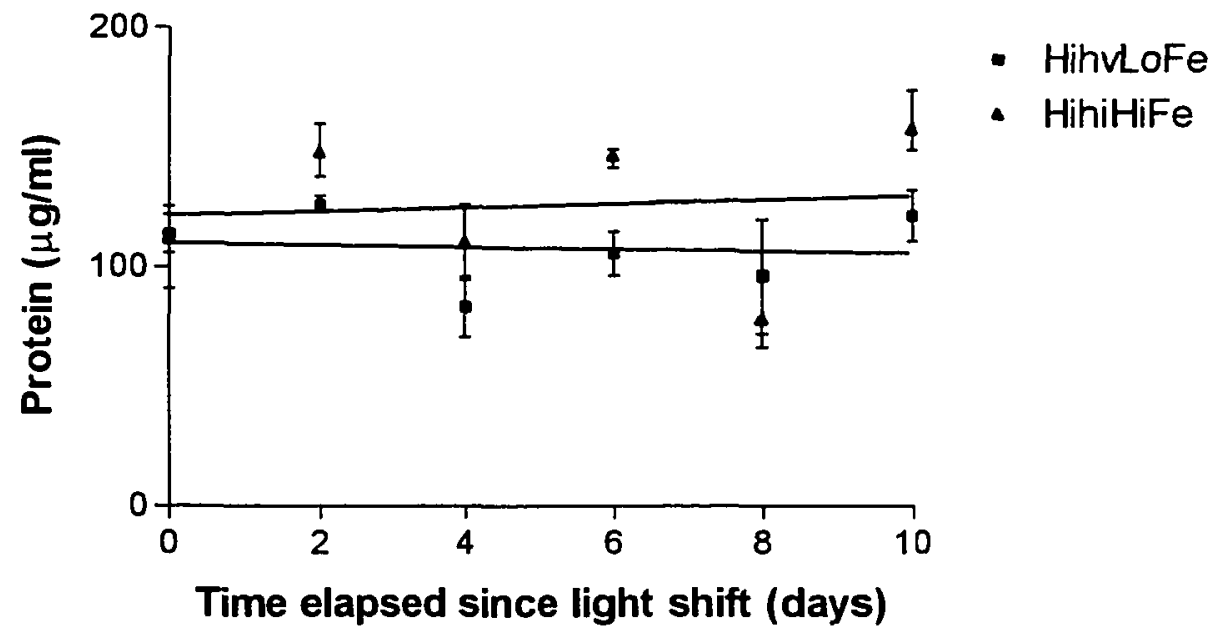

Figure 3.24: Plot of $\mu \mathrm{g}$ protein $/ \mathrm{ml}$ for constant high light cultures. Error bars span values from replicate cultures. 


\section{Chlorophyll $a$ per cell $(\mu \mathrm{g}$ chl $a /$ cell)}

Chlorophyll $a$ concentrations per cell (chl $a /$ cell) increased in all cultures over the course of the experiment. The decreased illumination high iron culture's large chl $a /$ cell increase is strongly influenced by a sudden increase from day 8 to day 10; excluding the day 10 data point gives a fractional change of 3.4 , so even ignoring that point the decreased illumination high iron culture still shows the greatest increase in chl $a /$ cell. An increase in chl $a /$ cell is expected during adaptation to decreased light. The more rapid increase in chl $a /$ cell in the decreased light high iron culture may reflect the contribution of iron to the synthesis of chlorophyll and other photosystem components as well as the more efficient conversion of light energy to chemical energy if sufficient iron is available. The Prism software yields results that indicate that the slope of the constant high light high iron culture is not significantly non-zero; all other slopes are significant. The following fractional changes are based on the values at day zero and day 10 determined from linear regressions. 
Table 3.26: Decreased light -- fractional changes in $\mu \mathrm{g}$ chl $a /$ cell for replicate cultures

Decreased light Control cultures

Cultures: Low hv Lo Fe Lo hv Hi Fe Hi hv Lo Fe Hi hv Hi Fe Fractional change in $\mu \mathrm{g} \mathrm{chl} a / \mathrm{cell}$ : 1.9

Table 3.27: Decreased light -- fractional changes in $\mu \mathrm{g}$ chl $a /$ cell for averaged fits

\begin{tabular}{|c|c|c|c|}
\hline & $\begin{array}{c}\text { Day zero } \\
\text { averages } \\
(\mu \mathrm{g} \text { chl } a / \mathrm{ml})\end{array}$ & $\begin{array}{c}\text { Day } 10 \\
\text { averages } \\
(\mu \mathrm{g} \text { chl } a / \mathrm{ml}) \text { ) }\end{array}$ & $\begin{array}{c}\text { Fractional } \\
\text { change, } \\
\text { day } 10 / \text { day } 0\end{array}$ \\
\hline all cultures & $2.2 * 10^{-10}$ & $5.9^{*} 10^{-10}$ & 2.7 \\
\hline all $\mathrm{HiFe}$ & $2.2 * 10^{-10}$ & $6.8 * 10^{-10}$ & 3.1 \\
\hline all LoFe & $2.2 * 10^{-10}$ & $4.9^{*} 10^{-10}$ & 2.3 \\
\hline all control & $2.0^{*} 10^{-10}$ & $3.7^{*} 10^{-10}$ & 1.9 \\
\hline all decreased light & $2.4^{*} 10^{-10}$ & $8.1 * 10^{-10}$ & 3.4 \\
\hline
\end{tabular}


Low Light Chl a per Cell, 4/97

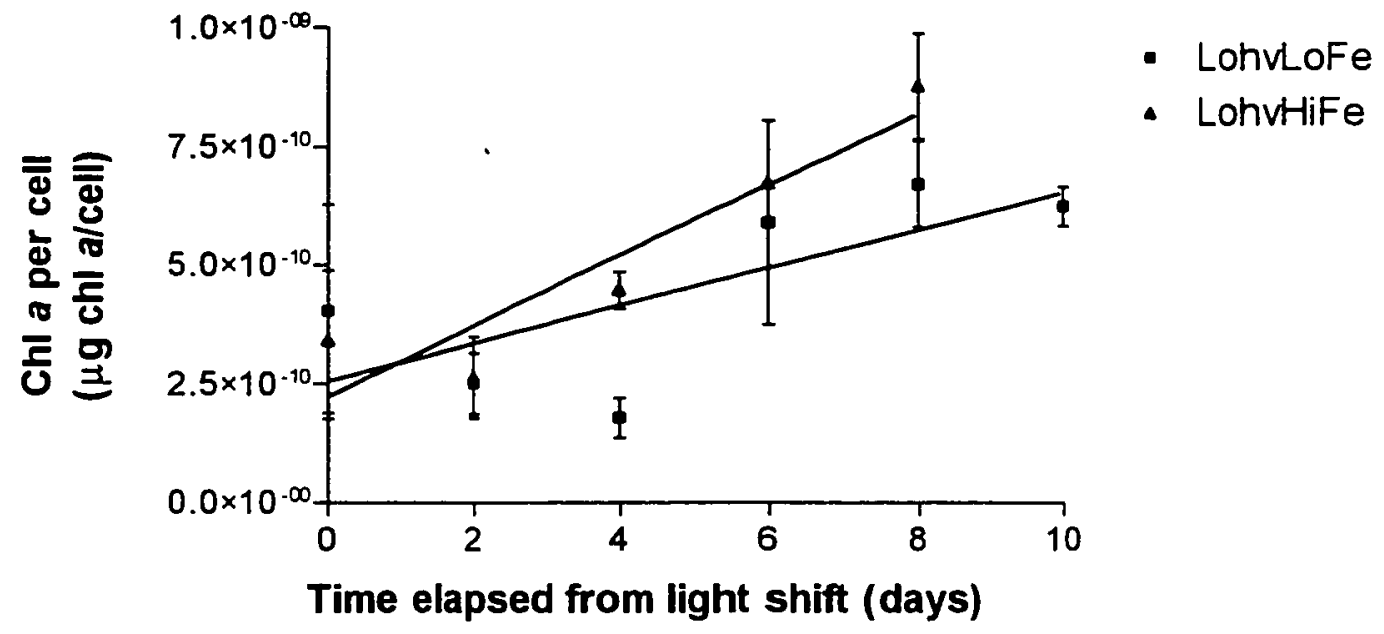

Figure 3.25: Plot of $\mu \mathrm{g} \mathrm{chl} a / \mathrm{cell}$ for decreased light cultures. LohvHiFe: Day 10 value excluded. Error bars span values from replicate cultures.

High Light Chl a per Cell, 4/97

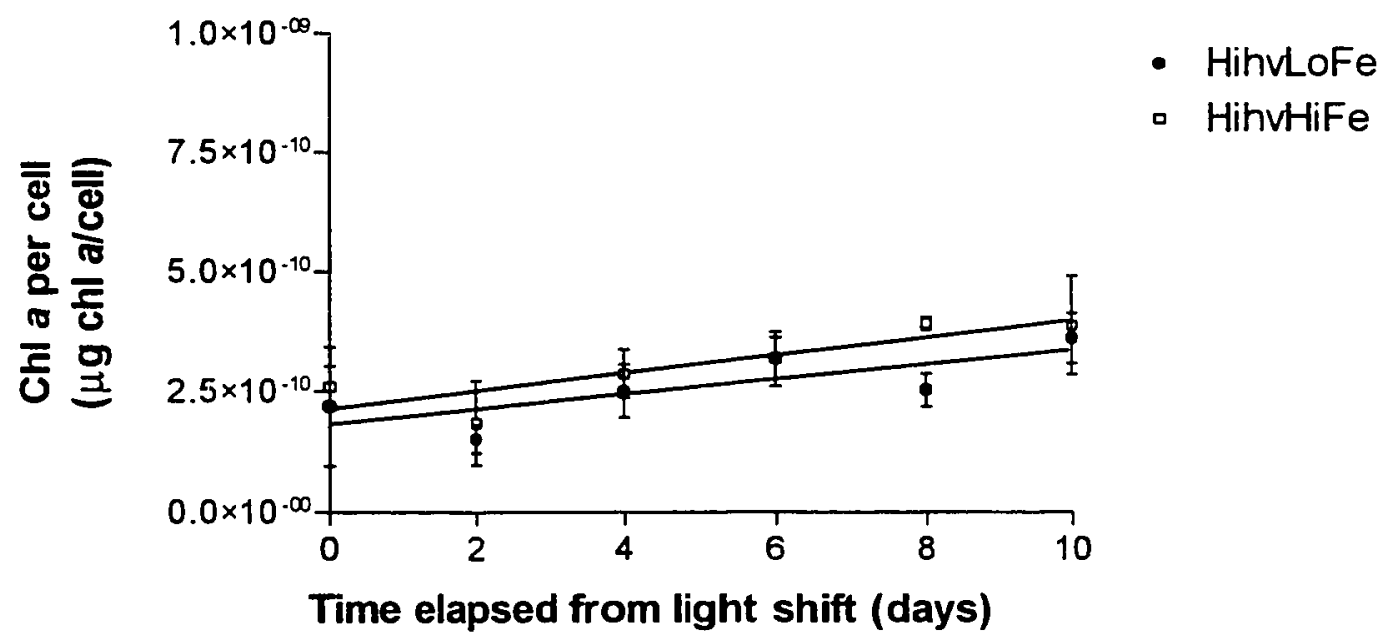

Figure 3.26: Plot of $\mu \mathrm{g}$ chl a/cell for constant high light cultures. Error bars span values from replicate cultures. 


\section{Protein per cell ( $\mu$ g protein/cell)}

Total protein concentrations per cell (protein/cell) increased in all cultures except the decreased light low iron culture, in which protein/cell decreased to almost half its initial level. The constant high light cultures had the largest increases in protein/cell. The slope of the regression of the decreased light high iron culture is strongly influenced by a high day 10 data point. Excluding the day 10 point of the decreased light high iron culture results in a fractional change of only 0.87 , but the four day 10 measurements that combined to produce that high data point are all unusually high. The following fractional changes are based on the values at day zero and day 10 determined from linear regressions. The Prism software yields results that indicate that the only significantly non-zero slope is the slope of the decreased light low iron culture.

Table 3.28: Decreased light -- fractional changes in $\mu \mathrm{g}$ protein/cell for replicate cultures

Decreased light Control cultures Cultures: Low hv Lo Fe Lo hv Hi Fe Hi hv Lo Fe Hi hv Hi Fe

\begin{tabular}{r|r|r|r|r|}
\hline $\begin{array}{l}\text { Fractional change } \\
\text { in } \mu \mathrm{g} \text { protein/cell: }\end{array}$ & 0.57 & 2.4 & 2.2 & 2.6 \\
\hline
\end{tabular}

Table 3.29: Decreased light -- fractional changes in $\mu \mathrm{g}$ protein/cell for averaged fits

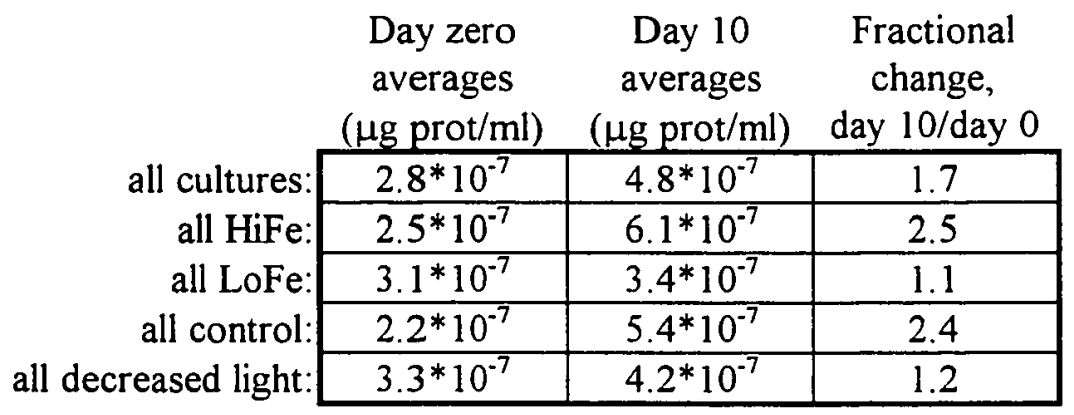




\section{Low Light 4/97 \\ Protein per Cell}

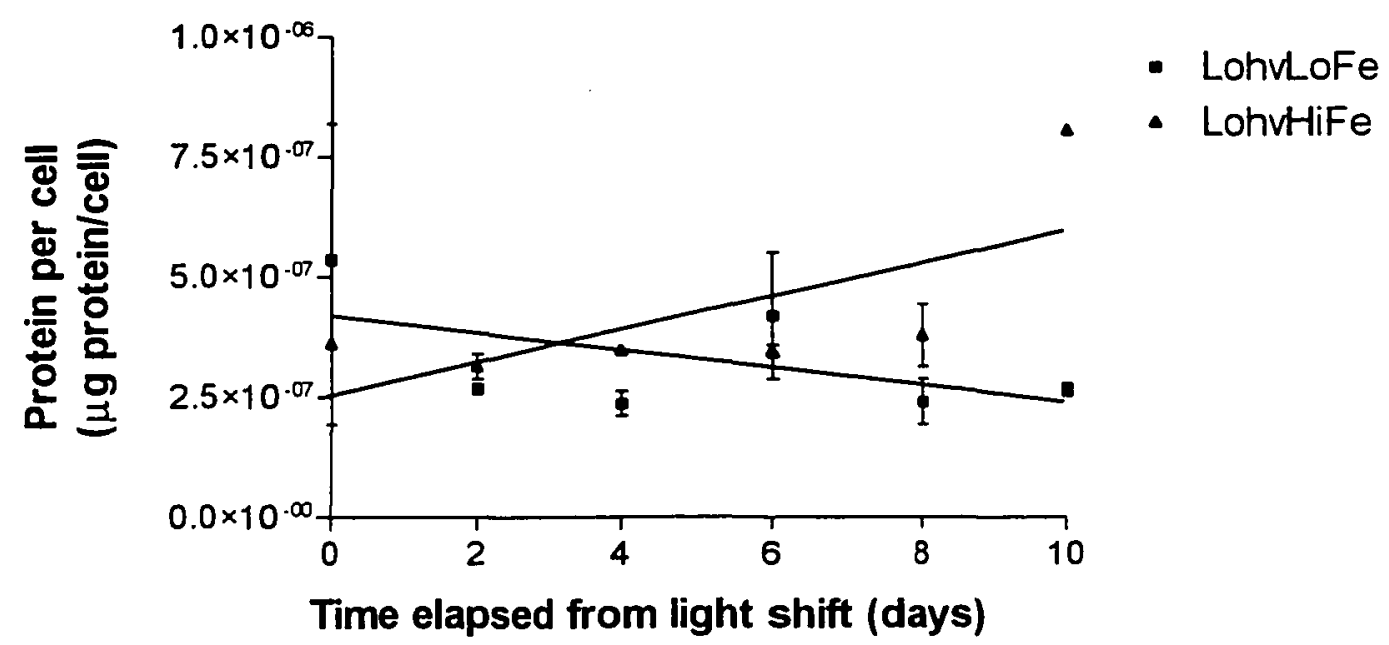

Figure 3.27: Plot of $\mu$ g protein/cell for decreased light cultures. Error bars span values from replicate cultures.

\section{High Light 4/97 \\ Protein per Cell}

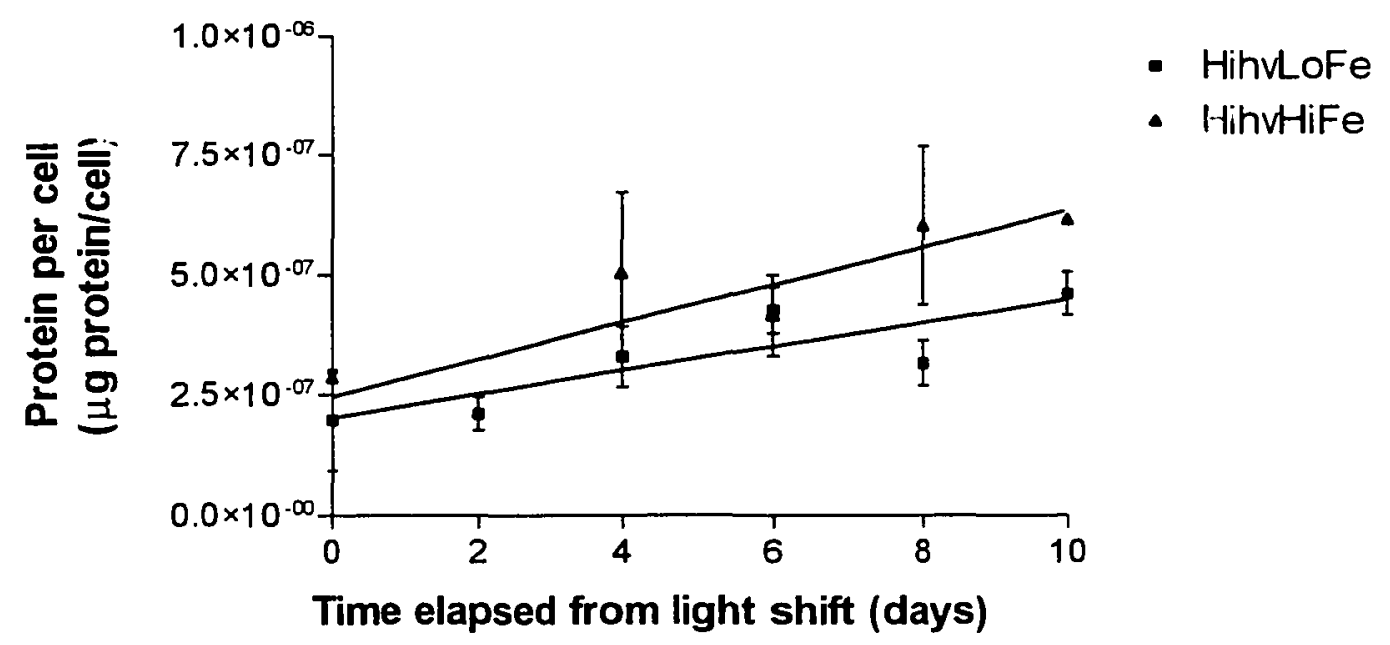

Figure 3.28: Plot of $\mu$ g protein/cell for constant high light cultures. Error bars span values from replicate cultures. 


\section{Chlorophyll $a$ per protein ( $\mu \mathrm{g}$ chl $a / \mu g$ protein)}

Chlorophyll $a$ concentration per protein concentration (chl $a /$ protein) increased in all cultures. $\mathrm{Chl} a$ /protein increased more in decreased light cultures than in constant high illumination cultures. The steepest increase in chl $a /$ protein was in the decreased light low iron cultures; the much larger fractional change is due to a slightly smaller initial value than the decreased light high iron culture (figure 3.29). An increased in chl $a /$ protein is expected when cultures are photoadapting to decreased light. Low iron cultures increased their $\mathrm{chl} a /$ protein more than high iron cultures. The Prism program reported all slopes as significantly non-zero except the slope of the decreased light low iron culture.

Table 3.30: Decreased light -- fractional changes in $\mu \mathrm{g}$ chl $a / \mu \mathrm{g}$ protein for replicate cultures

Decreased light Control cultures

Cultures: Low hv Lo Fe Lo hv Hi Fe Hi hv Lo Fe Hi hv Hi Fe

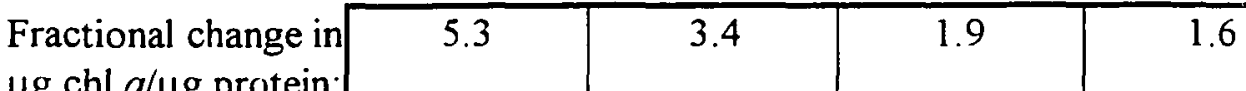

$\mu \mathrm{g} \mathrm{chl} a / \mu \mathrm{g}$ protein

Table 3.31: Decreased light -- fractional changes in $\mu \mathrm{g}$ chl $a / \mu \mathrm{g}$ protein for averaged fits

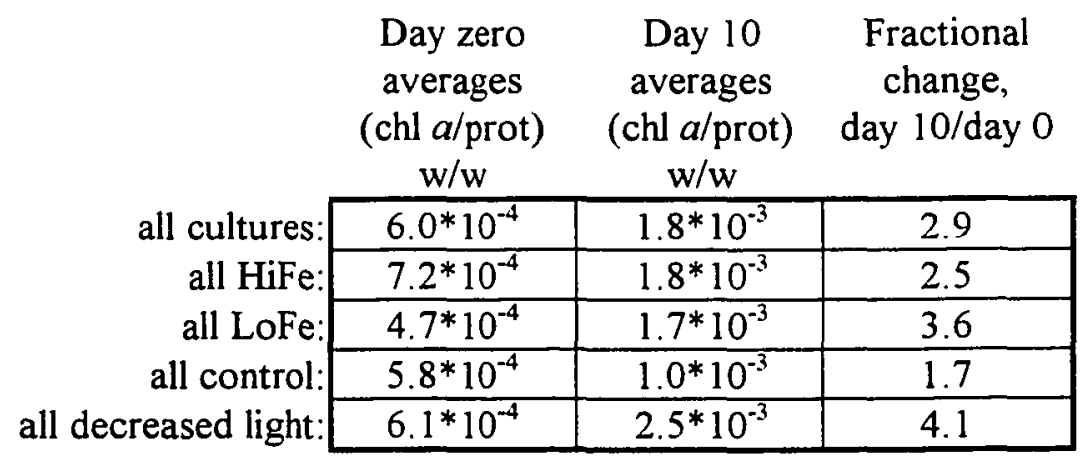




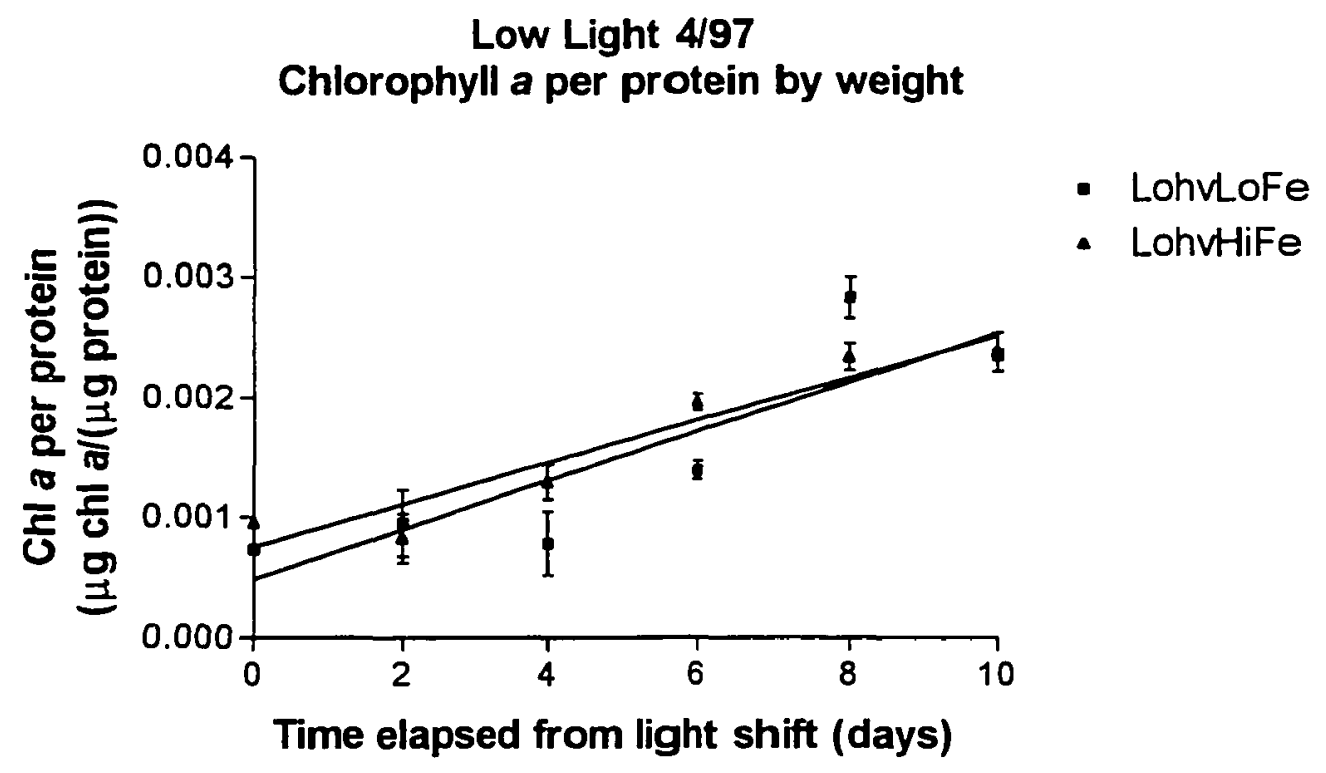

Figure 3.29: Plot of $\mu \mathrm{g}$ chl $a / \mu \mathrm{g}$ protein for decreased light cultures. Error bars span values from replicate cultures.

High Light $4 / 97$

Chlorophyll a per protein by weight

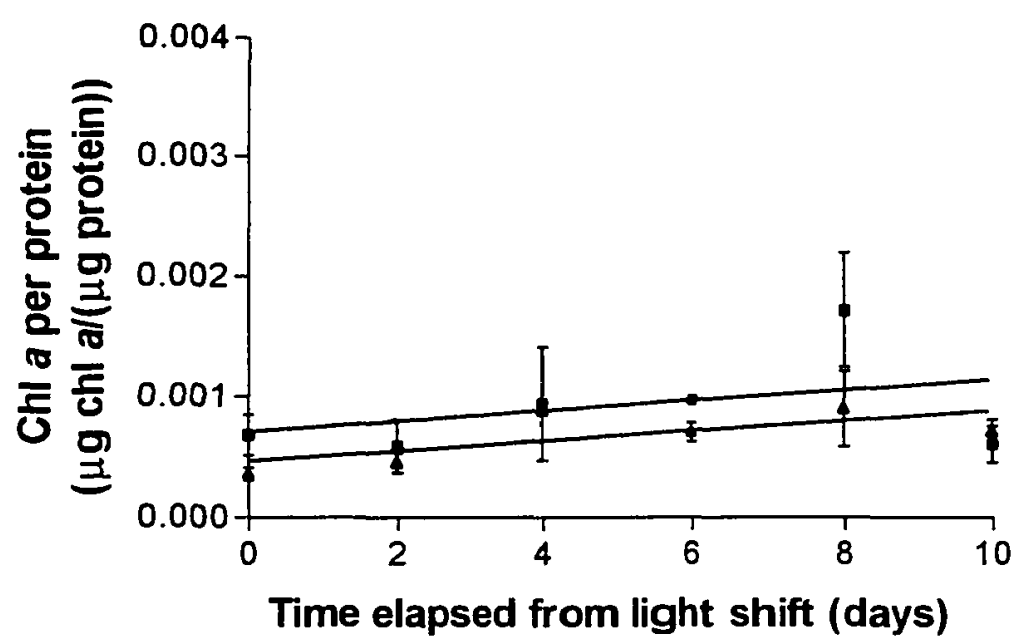

- HihvHiFe

- HihvLoFe

Figure 3.30: Plot of $\mu \mathrm{g}$ chl $\mathrm{a} / \mu \mathrm{g}$ protein for constant high light cultures. Error bars span values from replicate cultures. 


\section{Alpha measurements}

Constant light cultures were fit by linear regression. Decreased light cultures were fit with a saturating hyperbola using the saturating hyperbola equation (eq. 2) and the procedure described in Materials and Methods.

\section{Alpha normalized per cell}

Alpha per cell increased in decreased light cultures, with the largest increase in high iron cultures. Alpha per cell decreased somewhat in constant high light high iron cultures and remained fairly stable in constant high light low iron cultures. The decreased light high iron culture increased its alpha per cell in a surprisingly linear fashion (linear regression gives $r^{2}=0.95$ ) but the curve was fit with the saturating hyperbola equation to be consistent with the other plots of alpha.

The increase in alpha when illumination is decreased is the expected result. Cells build more photosystems to maintain a flow of reductant in a decreased photon flux, resulting in a steeper alpha. When subjected to decreased light the high iron cultures increased their alpha per cell much more rapidly than the low iron cultures.

The Prism software yields results that indicate that the slopes of the constant high light cultures are not significantly non-zero. Curves were fit by the Prism software without setting any of the three parameters constant. 
Increased light low iron

$\mathrm{A}_{\text {change }}=1.451 \mathrm{e}-006 \quad \mathrm{~T}_{1 / 2}=2.0$ days $\quad \mathrm{A}_{\text {initial }}=3.748 \mathrm{e}-007$

Increased light high iron

$\mathrm{A}_{\text {change }}=2.807 \mathrm{e}-006 \quad \mathrm{~T}_{1 / 2}=2.0$ days $\quad \mathrm{A}_{\text {initial }}=2.232 \mathrm{e}-007$

Table 3.32: Decreased light -- fractional changes in alpha/cell for replicate cultures

Decreased light Control cultures

Cultures: Low hv Lo Fe Lo hv Hi Fe Hi hv Lo Fe Hi hv Hi Fe

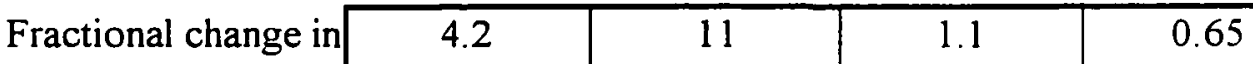

alpha/cell

Table 3.33: Decreased light -- fractional changes in alpha/cell for averaged fits

\begin{tabular}{rlrr} 
& $\begin{array}{c}\text { Day zero } \\
\text { averages } \\
\text { (alpha/cell) }\end{array}$ & $\begin{array}{c}\text { Day } 10 \\
\text { averages } \\
\text { (alpha/cell) }\end{array}$ & $\begin{array}{c}\text { Fractional } \\
\text { change, } \\
\text { day 10/day 0 }\end{array}$ \\
\cline { 2 - 4 } all cultures & $2.7^{*} 10^{-7}$ & $1.1^{*} 10^{-6}$ & 4.2 \\
\cline { 2 - 4 } all HiFe: & $2.9^{*} 10^{-7}$ & $1.4^{*} 10^{-6}$ & 4.9 \\
all LoFe: & $2.58^{*} 10^{-7}$ & $8.6^{*} 10^{-7}$ & 3.5 \\
\cline { 2 - 4 } all control: & $2.3^{*} 10^{-7}$ & $1.8^{*} 10^{-7}$ & 0.77 \\
\cline { 2 - 4 } all decreased light: & $3.0^{*} 10^{-7}$ & $2.1^{*} 10^{-6}$ & 6.9 \\
\cline { 2 - 4 } & & &
\end{tabular}




\section{LoFe 4/97 Alpha \\ (14C uptake per cell)}

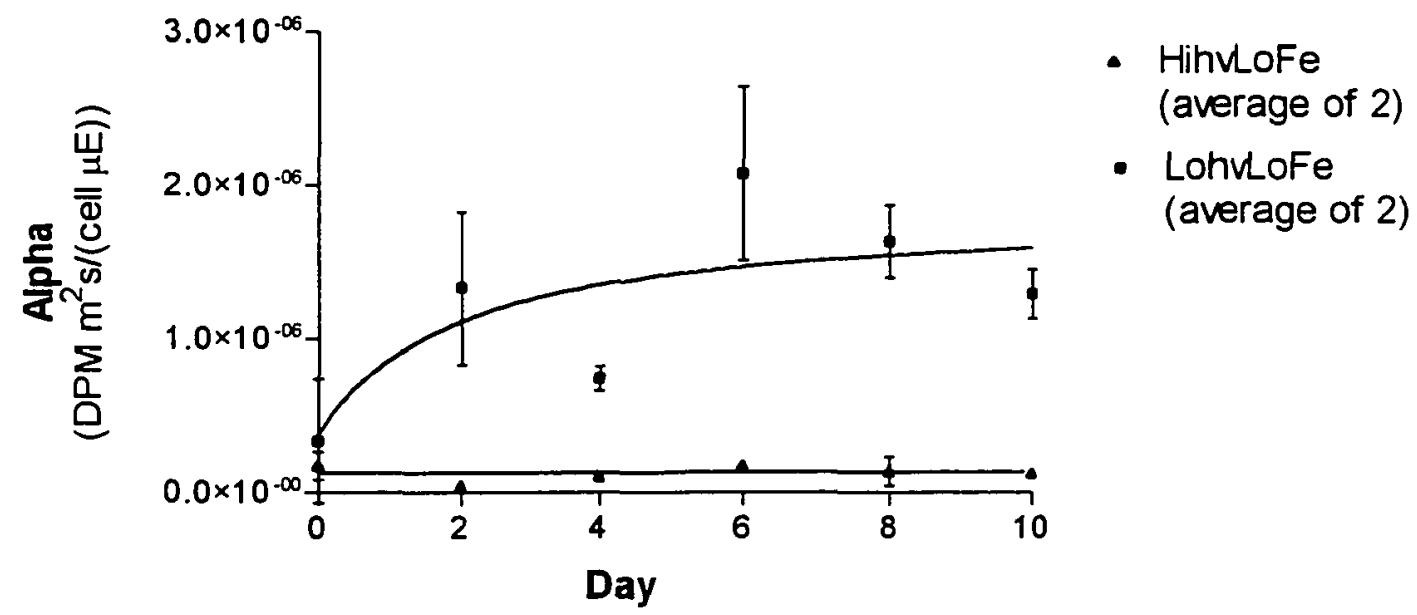

Figure 3.31: Plot of alpha/cell for decreased light cultures. Error bars indicate the standard error in the initial slope of each P vs. I curve.

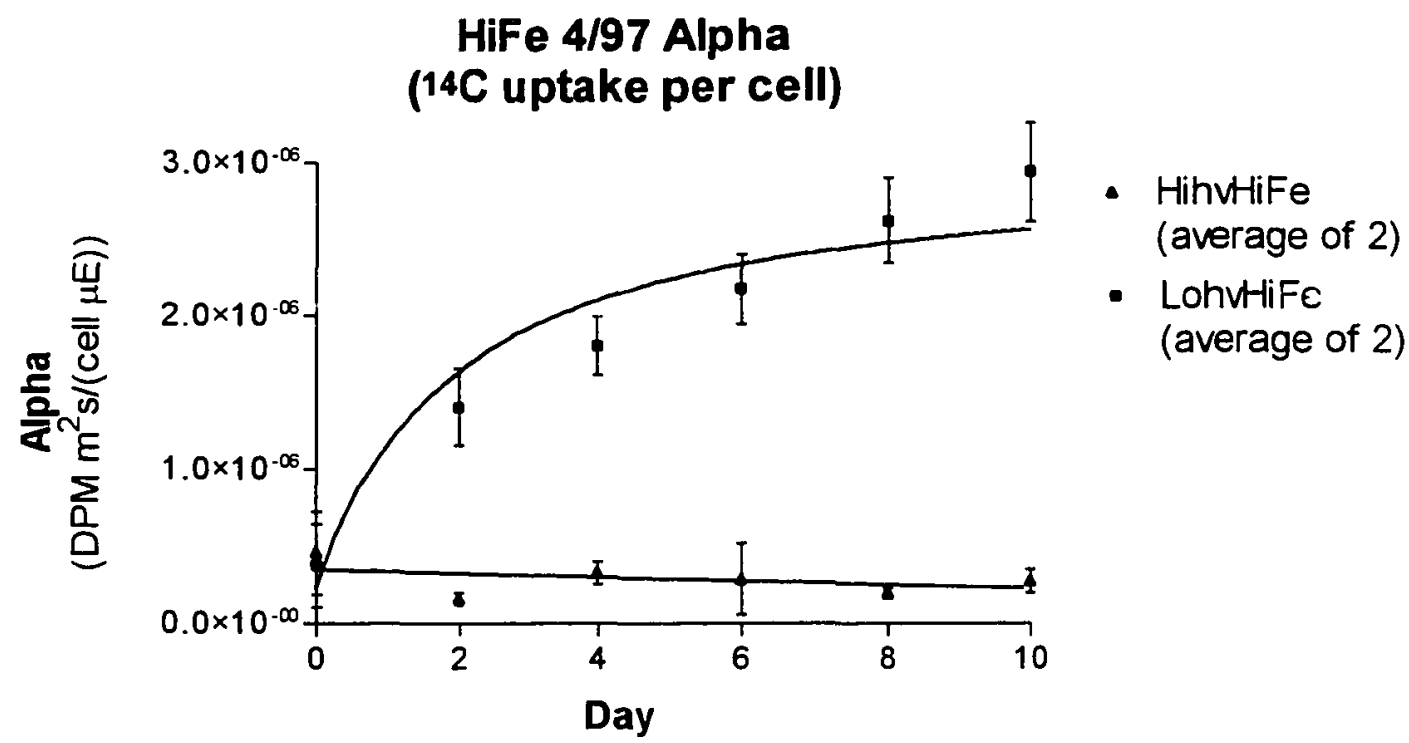

Figure 3.32: Plot of alpha/cell for constant high light cultures. Error bars indicate the standard error in the initial slope of each P vs. I curve. 


\title{
Alpha normalized per $\mu \mathrm{g} \operatorname{chl} a$
}

\author{
Alpha per $\mu \mathrm{g}$ chlorophyll $a$ of constant high light cultures dropped to about \\ half of their initial levels. Alpha per $\mu \mathrm{g}$ chlorophyll $a$ increased two to three-fold in \\ decreased light cultures. In all the decreased light cultures, alpha per $\mu$ g chlorophyll \\ $a$ increased quickly to maximum values at day 2 , then alpha per $\mu$ g chlorophyll $a$ \\ decreased in subsequent measurements. During this decrease in alpha per $\mu \mathrm{g}$ \\ chlorophyll $a$, the chlorophyll $a$ per cell was increasing.
}

An increase in alpha per cell or alpha per protein is expected to follow from the synthesis of chlorophyll, as the light trapping efficiency of the thylakoids increases. When alpha is determined on a per chlorophyll basis, an increase in chlorophyll might increase or decrease alpha per chlorophyll, depending on whether alpha or chlorophyll increases more rapidly. The rapid initial increase in alpha per $\mu \mathrm{g}$ chlorophyll $a$ is not due to rapid synthesis of new chlorophyll, as shown by the delayed increase in chlorophyll $a$ per cell seen in figure 3.25. This leaves open the question of how alpha per chlorophyll $a$ increases so rapidly; the increase might be due to reorganization of the existing components of the thylakoid membrane.

The saturating hyperbola equation did not fit the decreased light data well, as once the line increased to its highest value it could not decrease to follow the decline in alpha per $\mu$ g chlorophyll $a$, a decline caused by the increase in chlorophyll a per cell over the course of the 10-day experiment. Prism yields results that indicate that the slopes of the constant high light cultures were not significant. 
Decreased light low iron
$A_{\text {change }}=2.4 * 10^{3}$
$\mathrm{T}_{1 / 2}=0.2$ days
$\mathrm{A}_{\text {initial }}=1.2^{*} 10^{3}$

Decreased light high iron
$\mathrm{A}_{\text {change }}=2.0 * 10^{3}$
$\mathrm{T}_{1 / 2}=0.2$ days
$A_{\text {initial }}=1.7 * 10^{3}$

Tabie 3.34: Decreased light -- fractional changes in alpha/ $\mu \mathrm{g}$ chl $a$ for replicate cultures

\section{Decreased light \\ Control cultures}

Cultures: Low hv Lo Fe Lo hv Hi Fe Hi hv Lo Fe Hi hv Hi Fe

Fractional change in 3.0 2.2 0.44 0.51

Table 3.35: Decreased light -- fractional changes in alpha/ $\mu \mathrm{g} \operatorname{chl} a$ for averaged fits

\begin{tabular}{|c|c|c|c|}
\hline & 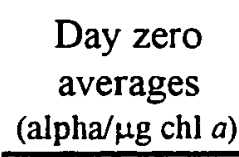 & $\begin{array}{c}\text { Day } 10 \\
\text { averages } \\
\text { (alpha/ } / \mathrm{g} \text { chl } a \text { ) } \\
\end{array}$ & $\begin{array}{c}\begin{array}{c}\text { Fractional } \\
\text { change, }\end{array} \\
\text { day } 10 / \text { day } 0 \\
\end{array}$ \\
\hline all cultures & $1.2^{*} 10^{3}$ & $2.1 * 10^{3}$ & 1.7 \\
\hline all $\mathrm{HiFe}$ & $1.5^{*} 10^{3}$ & $2.2 * 10^{3}$ & 1.5 \\
\hline all LoFe & $9.5 * 10^{2}$ & $1.9 * 10^{3}$ & 2.1 \\
\hline all control & $9.7 * 10^{2}$ & $4.7 * 10^{2}$ & 0.49 \\
\hline I decreased light & $1.4 * 10^{3}$ & $3.6 * 10^{3}$ & 2.5 \\
\hline
\end{tabular}




\section{LoFe 4/97 Alpha \\ (14C uptake per $\mu \mathrm{g} \mathrm{chl} \mathrm{a)}$}

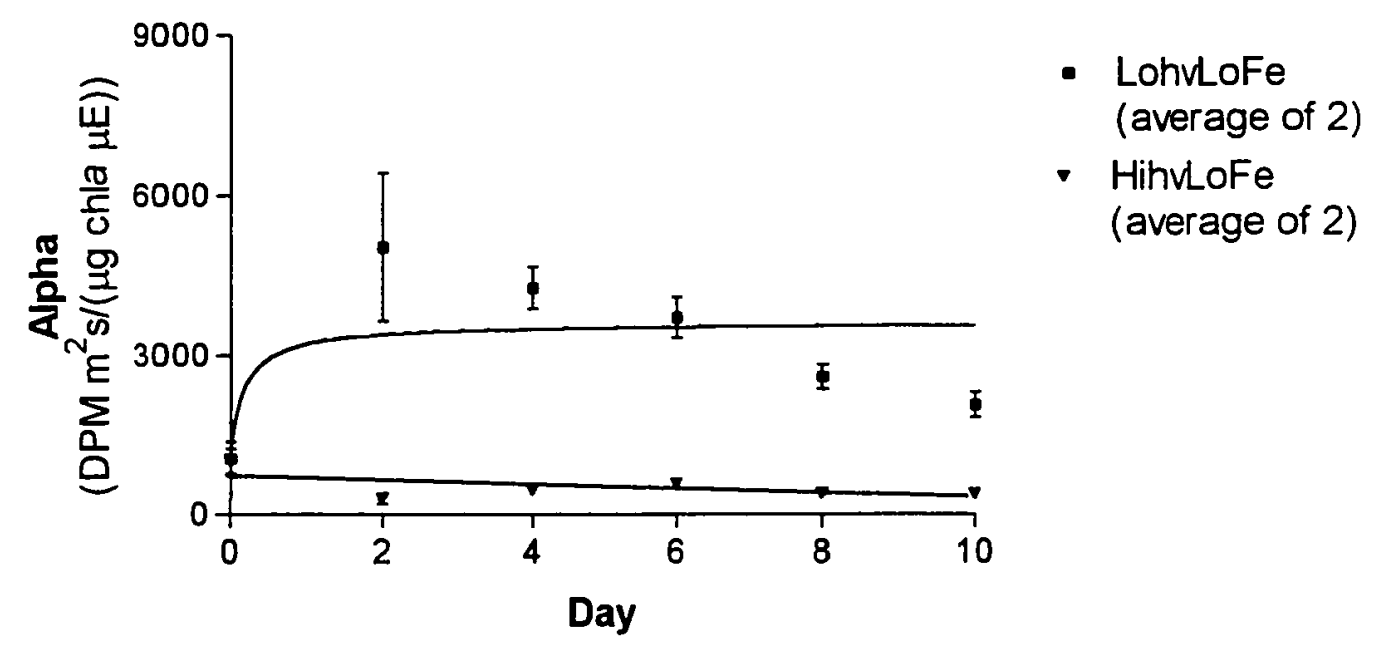

Figure 3.33: Plot of alpha/ug chl $a$ for decreased light cultures. Error bars indicate the standard error in the initial slope of each P vs. I curve.

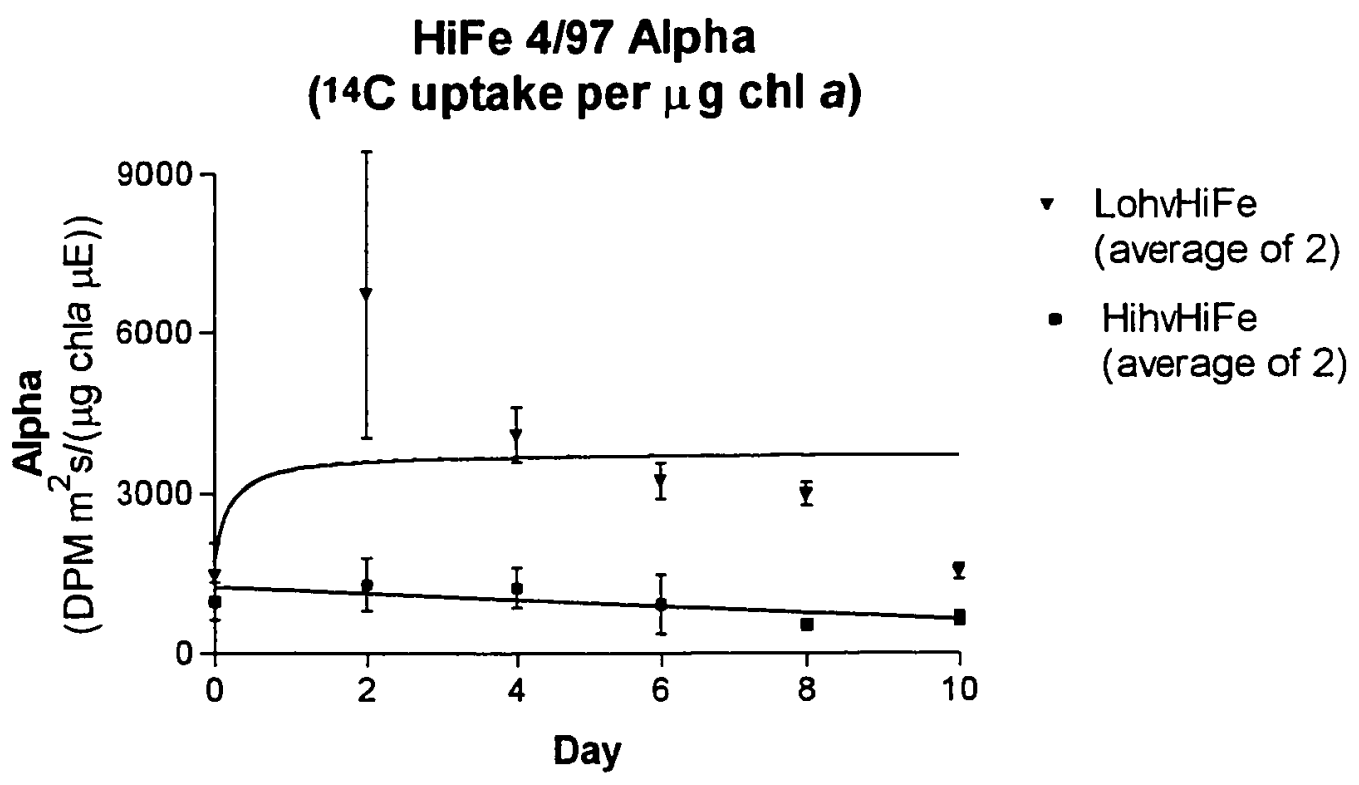

Figure 3.34: Plot of alpha/ug chl $a$ for constant high light cultures. Error bars indicate the standard error in the initial slope of each P vs. I curve. 


\section{Alpha normalized per $\mu \mathrm{g}$ protein}

Alpha per $\mu \mathrm{g}$ protein in decreased light cultures increased rapidly to about five times their initial values on average. Alpha per $\mu$ g protein in constant light cultures stayed fairly constant, decreasing about $6 \%$ on average. While the fractional increase of the decreased light low iron culture is much greater than the fractional increase of the decreased light high iron culture, this is due to a small absolute difference in their initial values; their final adapted values of alpha per $\mu \mathrm{g}$ protein are very similar. The Prism software yields results that indicate that the slopes of the constant high light cultures are not significantly non-zero. Curves were fit by the Prism software without setting any of the three parameters constant. 
Decreased light low iron

$\mathrm{A}_{\text {change }}=5.1 \quad \mathrm{~T}_{1 / 2}=0.75$ days $\quad \mathrm{A}_{\text {initial }}=0.80$

Decreased light high iron

$\mathrm{A}_{\text {change }}=4.2 \quad \mathrm{~T}_{1 / 2}=0.17$ days $\quad \mathrm{A}_{\text {initial }}=1.4$

Table 3.36: Decreased light -- fractional changes in alpha/ $\mu \mathrm{g}$ protein for replicate cultures

Decreased light Control cultures

Cultures: Low hv Lo Fe Lo hv Hi Fe Hi hv Lo Fe Hi hv Hi Fe

Fractional change in

$\alpha / \mu \mathrm{g}$ protein:

\begin{tabular}{l|l}
6.9 & 3.9
\end{tabular}

0.96

0.92

Table 3.37: Decreased light -- fractional changes in alpha/ $\mu \mathrm{g}$ protein for averaged fits

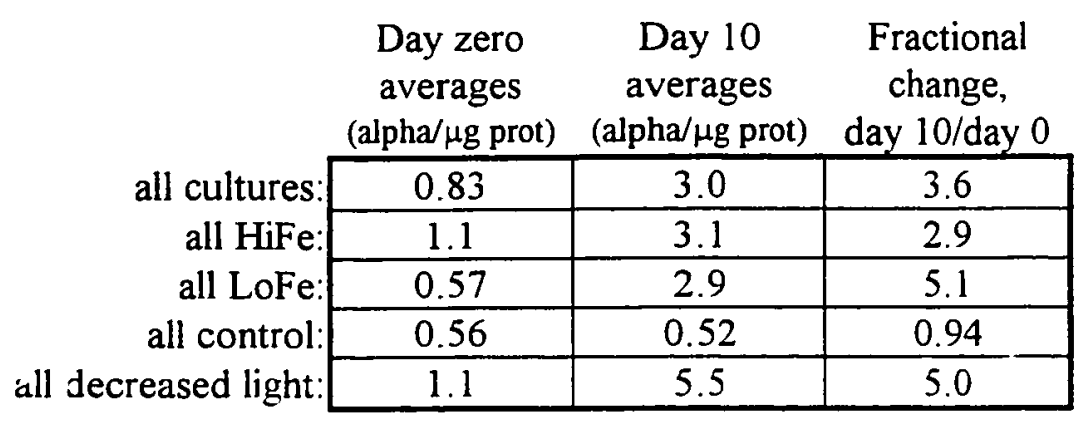




\section{LoFe 4/97 Alpha \\ (14C uptake per $\mu \mathrm{g}$ protein)}

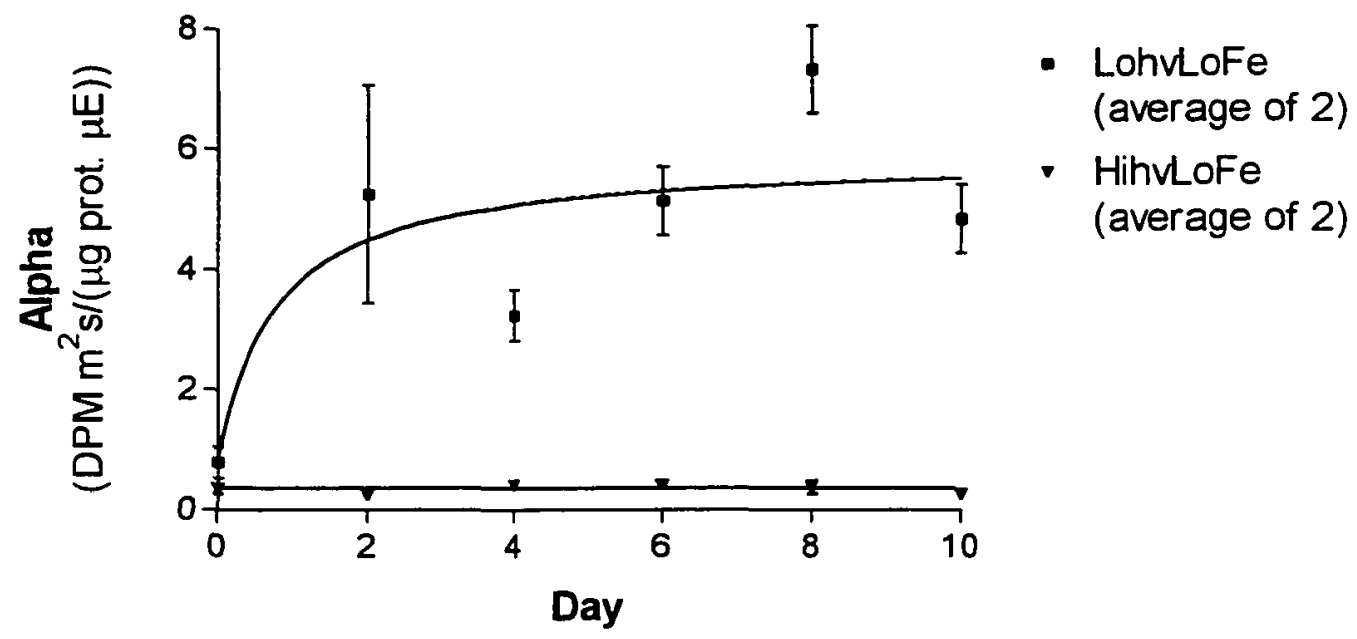

Figure 3.35: Plot of alpha/ $\mu \mathrm{g}$ protein for decreased light cultures. Error bars indicate the standard error in the initial slope of each P vs. I curve.

\section{HiFe 4/97 Alpha \\ (14C uptake per $\mu \mathrm{g}$ protein)}

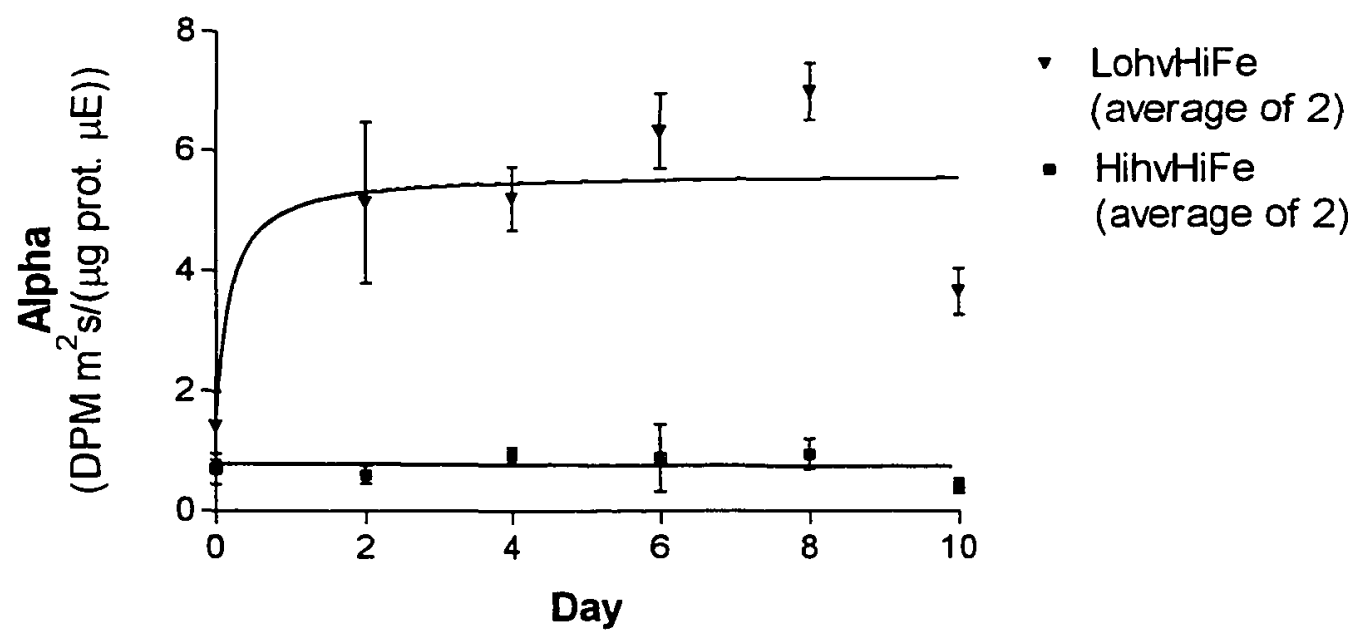

Figure 3.36: Plot of alpha/ $\mu \mathrm{g}$ protein for constant high light cultures. Error bars indicate the standard error in the initial slope of each P vs. I curve. 


\section{Conclusion}

- How long does it take for a culture of Synechococcus WH7803 to adapt to a shift between two fairly dim light levels?

When shifted from $8 \mu \mathrm{Em}^{-2} \mathrm{~s}^{-1}$ to $80 \mu \mathrm{Em}^{-2} \mathrm{~s}^{-1}$, alpha per cell decreased rapidly. The time required for alpha to decrease from its initial value halfway to its final value was less than 2 days, based on fitting the saturating hyperbola equation to the alpha per cell data. However, this decrease in alpha may be due to damage to photosystem components rather than true adaptation: there is no evidence that the carbon fixation enzymes had increased in this short time to a new optimum level. Similarly alpha per $\mu \mathrm{g}$ chlorophyll $\boldsymbol{a}$ and alpha per $\mu \mathrm{g}$ protein decreased rapidly, reaching half-adaptation within 2 days.

Some other culture parameters suggest that the time needed for the cells in increased irradiance cultures to optimize for their new light environment may be close to 8 days. Cell counts were still increasing through day 4 , reaching their maximum at 6 to 8 days into the experiment. Chlorophyll $a$ stayed fairly constant. Proteins increased at first, then stabilized around day 6 to 8 . Chlorophyll $a$ per cell decreased at first, stabilizing around day 6 to 8 . Protein per cell decreased at first, reaching a minimum near day 6 for the low iron cultures and around day 8 for the high iron cultures. Chlorophyll $a$ per protein decreased to a minimum on day 8 The time required for these other culture parameters to stabilize suggests that the change in alpha values does not tell the entire adaptation story for increases in light. 
Based on the cellular parameters analyzed here, the cells were adapted to the new light level by day 8 .

When shifted from $80 \mu \mathrm{Em}^{-2} \mathrm{~s}^{-1}$ to $8 \mu \mathrm{Em}^{-2} \mathrm{~s}^{-1}, 2.0$ days were required for alpha to increase from its initial value halfway to its final value, based on fitting the saturating hyperbola equation to the alpha per cell data. Fitting the alpha per $\mu \mathrm{g}$ protein data gave intermediate values, with half-adaptation times of less than 2 days for low iron cultures and less than 2 days for high iron cultures. Fitting the alpha per $\mu \mathrm{g}$ chlorophyll $a$ data again gives an adaptation time of less than 2 days. An increase in alpha per cell indicates that new pigments and photosynthetic components are being synthesized and becoming operational. This is true adaptation; the increase in alpha does not reflect damage to a component but instead indicates that new systems are becoming functional in order to increase the effective cross-section of the photosynthetic apparatus. The rapid change in alpha per $\mu$ g chlorophyll $a$ may be due to an unexpected initial decrease in $\mu \mathrm{g}$ chlorophyll $a$ per cell when light was decreased (figure 3.25). A similar decrease in $\mu \mathrm{g}$ protein per cell (figure 3.27) when light was decreased may cause the more rapid change in alpha per protein compared to alpha per cell.

Some other culture parameters may suggest the time needed for the cells in decreased irradiance cultures to entirely optimize to their new light environment may exceed 10 days. Up to the tenth day cell counts were still decreasing, with the last point below the regression line. Chlorophyll $a$ was still increasing to the tenth day. Proteins in the high iron culture remain stable, but proteins in the low iron culture decreased to a minimum around day 8 . Chlorophyil $a$ per cell increased in 
the low iron culture to a maximum on day 8 and increased to day 8 in the high iron culture, the last day for which good high iron culture data was available; a very high value was excluded for day 10 of the high iron culture. Protein per cell stayed fairly stable except for an isolated high value on day 10 for the high iron culture.

Chlorophyll $a$ per protein increased to a maximum on day 8 . The time required for these other culture parameters to stabilize suggests that the adaptation of all cellular systems to optimize to a new light level may take longer than the change in alpha values alone would indicate. Based on the culture parameters analyzed here, the cells were mostly adapted to the new light level by day 8 though chlorophyll may have continued increasing after the end of the assay.

Curve fitting to determine the half-adaptation times based on changes in alpha over time returned values as low as 0.17 days, as reported in the "Response of Cultures to Increased Light" and "Response of Cultures to Decreased Light" sections. However, since the first data after the shift in light were collected two days after the shift the half adaptation times are not discussed here at a finer resolution than "less than two days".

- What is the effect of iron concentration on the rate of photoadaptation?

When shifted from $8 \mu \mathrm{Em}^{-2} \mathrm{~s}^{-1}$ to $80 \mu \mathrm{Em}^{-2} \mathrm{~s}^{-1}$, iron did not affect photoadaptation rate based on alpha per cell, alpha per $\mu \mathrm{g}$ chlorophyll $a$ or alpha per $\mu \mathrm{g}$ protein. Rates of change of other culture parameters in increased light cultures showed little response to differences in iron. An exception was protein in 
the high iron cultures, which increased more rapidly than in the low iron cultures (figure 3.6).

When shifted from $80 \mu \mathrm{Em}^{-2} \mathrm{~s}^{-1}$ to $8 \mu \mathrm{Em}^{-2} \mathrm{~s}^{-1}$, iron did not affect photoadaptation rate based on alpha per cell or alpha per $\mu \mathrm{g}$ chlorophyll $a$. Based on the fit of the saturating hyperbola equation, alpha per $\mu \mathrm{g}$ protein adapted more rapidly in the high iron culture than the low iron culture; this difference was caused largely by a single data point from the low iron culture on day four that was well below the curve (figure 3.35).

Rates of change of other culture parameters in decreased light cultures showed some response to differences in iron. The cell counts of high iron cultures decreased more rapidly than the cell counts of low iron cultures (figure 3.19). The initial cell counts of the high iron cultures were higher than the low iron cultures and the final counts were similar; neither set of cultures could keep up with dilution after the shift to low light. Chlorophyll $a$ increased much more rapidly in high iron cultures than in low iron cultures (figure 3.21). Proteins in low iron cultures decreased while those in high iron cultures stayed fairly constant (figure 3.23). Chlorophyll $a$ per cell increased more rapidly in high iron cultures than in low iron cultures (figure 3.25). Protein per cell of high iron cultures increased more than low iron cultures, though much of the difference is due to an isolated high data point on day 10 from the high iron culture (figure 3.27). The more rapid increase in chlorophyll $a$ of the high iron cultures may be the cause of the other differences in protein parameters, as the increased energy available from photosynthesis could support more protein synthesis. 
- Does the amount of iron available affect the final alpha after photoadaptation is complete?

The following tables report the day 10 values of the data fits (saturating hyperbola or linear regression) for cultures that went through a shift in light. Alpha values of high iron cultures are greater than or equal to the alpha values for low iron cultures. Note that the day 10 alpha per chlorophyll $a$ values for the decreased irradiance are not fit well by the saturating hyperbola (figure $3.33,3.34$ ); nevertheless, the curves are fit using the same equation and so the values may serve as a comparison between high and low iron. 
Increased irradiance Day 10 average

Ratio

cultures and parameters

(high $\mathrm{Fe} /$ low $\mathrm{Fe}$ )

\begin{tabular}{|c|c|c|}
\hline High iron, alpha/cell & $7.2 * 10^{-7}$ & \\
\hline Low iron, alpha/cell & $4.4^{*} 10^{-7}$ & alpha/cell: 1.6 \\
\hline High iron, alpha/ $\mu \mathrm{g} \operatorname{chl} a$ & 1200 & \\
\hline Low iron, alpha $/ \mu \mathrm{g} \operatorname{chl} a$ & 810 & alpha/ $\mathrm{gg}$ chl $a: \quad 1.5$ \\
\hline High iron, alpha/ $\mu \mathrm{g}$ prot. & 1.3 & \\
\hline Low iron, alpha/ $\mu \mathrm{g}$ prot. & 1.1 & alpha/ $\mu$ g prot.: \\
\hline
\end{tabular}

Table 3.38: Increased light alphas on day 10 from fits

Note: ratios were calculated before day 10 values were rounded to 2 sig. figures

Decreased irradiance

Day 10 average

Ratio

cultures and parameters

\begin{tabular}{|c|c|c|}
\hline High iron, alpha/cell & $2.6^{*} 10^{-6}$ & \\
\hline Low iron, alpha/cell & $1.6^{*} 10^{-6}$ & alpha/cell: 1.6 \\
\hline High iron, alpha/ $\mu \mathrm{g} \operatorname{chl} a$ & 3700 & \\
\hline Low iron, alpha/ $\mu \mathrm{g} \operatorname{chl} a$ & 3600 & alpha/ $\mathrm{gg}$ chl $a: \quad 1.0$ \\
\hline High iron, alpha/ $\mu \mathrm{g}$ prot. & 5.5 & \\
\hline Low iron, alpha/ $\mu \mathrm{g}$ prot. & 5.5 & 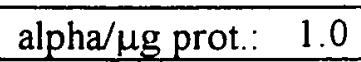 \\
\hline
\end{tabular}

Table 3.39: Decreased light alphas on day 10 from fits

Note: ratios were calculated before day 10 values were rounded to 2 sig. figures

The periodic nutrient increases resulting from the semi-continuous culture procedure might be causing periodic variations in control culture parameters.

During the planning stages of this project, I assumed that because the light was constant in control cultures, there would be no periodicity evident in their growth.

To ensure that circadian rhythms would not carry over to the experiment, the organisms were grown at constant light for months before each experimental run was commenced. Since the cultures were always sampled 48 hours after 
fertilization with fresh media, it seemed reasonable that they would always be in the same stage of growth when sampled and so their measured parameters should be constant over time. However, variations in culture parameters were observed in most control cultures, sometimes appearing periodic. A possible explanation for this seemingly periodic behavior might be the periodicity of dilutions. The cyanobacteria experienced a sudden increase in nutrients every 48 hours. These nutrient pulses might interact with periodic oscillations in the metabolism of the cell, leading to the observed variations in measured parameters of control cultures. Metabolic oscillations are not well understood phenomena, and I will not attempt to correlate the variation of culture parameters with a specific oscillation; I have introduced this discussion to offer a possible explanation for an unexpected set of observations and to suggest a path for future studies. 


\section{Chapter 4}

\section{Modeling the Rate of Photoadaptation using STELLA II}

Marine Synechococcus live in a variable environment, experiencing changes in light, temperature, nutrients, currents and predation. Understanding the physiology of Synechococcus and being able to predict their response to changing conditions will help us build more valid and reliable models of their growth, which may contribute to models of the marine food web and of ocean-atmosphere interactions.

A plankton dynamics model was developed by Fasham et al. (1990) to describe a planktonic marine community in the Caribbean Ocean near Bermuda. The model tracks the populations of phytoplankton, zooplankton and bacteria based on their response to and contributions to nitrate nitrogen, ammonium nitrogen, labile dissolved organic nitrogen and detritus. Ecosystem scale models like this may benefit from photoadaptation rate measurements. The model contains simple algal representations that do not adapt to nutrient or light shifts. For example, a value was chosen for the phytoplankton maximum growth rate based on a single photosynthesis vs. light (P vs. I) curve as the light approaches infinite; no explicit account is taken of the photoadaptation or nutrient acclimation of the organism. The light attenuation due to phytoplankton in the water column is set 
constant, taking no account of variations in pigment per cell due to photoadaptation (Fasham et al. 1990).

A previous example of physiological modeling of algae is the model of photoadaptation written by Brian Shuter (Shuter 1979). His model assumes that if an algal culture is grown for many generations under stable conditions, material will be apportioned into various cellular compartments in a ratio characteristic of the environmental conditions. Shuter's model describes four compartments: photosynthetic, enzymatic/biosynthetic, structural and reserve. Given values for a set of parameters (Shuter 1979 p.525-526) that describe the cell and its environment, Shuter's model will predict the relative proportion of biomass that will be in each of these four compartments after the cells have completely acclimated to their culture conditions. This model describes only steady environments with stable light regimes. Real environments undergo diel light cycles with superimposed mixing and weather variations. To extend Shuter's model to describe algae in the environment, measurements are needed of the rates of adaptation to various shifts in light under a range of nutrient conditions; realizing this provided the motive for the laboratory work described in this dissertation.

The approach of Shuter was not suited for modeling changes over time in a dynamic environment. Instead a dynamic system model was needed, a model that 
could track changes in quantities in a cell over time. The continuous dynamic systems modeling software STELLA II (High Performance Systems, Lyme, NH) provides a graphical interface used to construct dynamic models and then to run the models and plot the state of variables in the models over time. STELLA is useful both as a modeling tool and as a communication tool, since the graphic depictions of how the parts of a model interact can be used to help explain these interactions to another person (Costanza 1987).

Two models are presented here: 1 . a simple model that predicts changes in the concentration of active photosystems which was used to help design the fluctuating light regime used in the preadaptation experiments; 2. a two component model that includes gene regulation and physiological changes in a cyanobacterial cell. These models helped me to clarify my ideas of cyanobacterial physiology. They are not validated models. They are instead working hypotheses describing the interactions of photosynthetic systems within a cyanobacterial cell.

\section{Simple model}

The first model tracks changes in a single quantity, representing the concentration of photosystems in a cell. The model is not quantitatively accurate. 
Its purpose was to aid in selecting a light regime that would emphasize differences between cultures that had been preadapted to different light regimes.

After trying several light regimes, $I$ realized that the longer the duration of each period of light or dark, the more time the cells would have to change their measurable parameters. If cultures preadapted to different light regimes or grown in different iron concentrations were changing their measurable parameters at different rates, longer light or dark periods would allow greater differences in those parameters to accumulate. Since I was sampling every 48 hours, I chose the 48 hour light : 48 hour dark light cycle for my final fluctuating light regime. This way, the entire duration between samples would either be in constant light or in the dark; my trials with the simple model indicated that this would produce the greatest difference in measurable culture parameters (see Figure 4.3). 


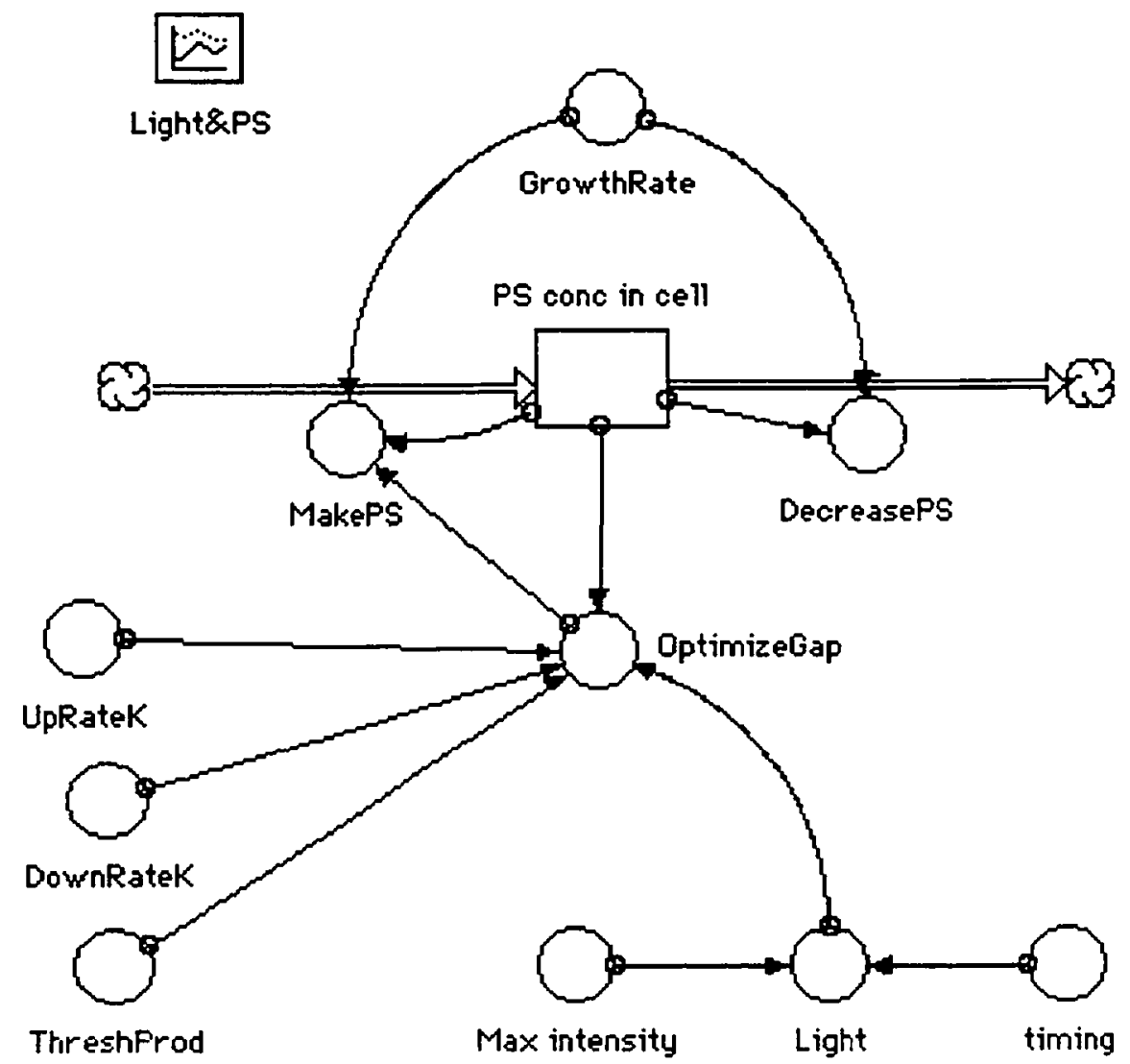

Figure 4.1: Map of simple model in STELLA II 


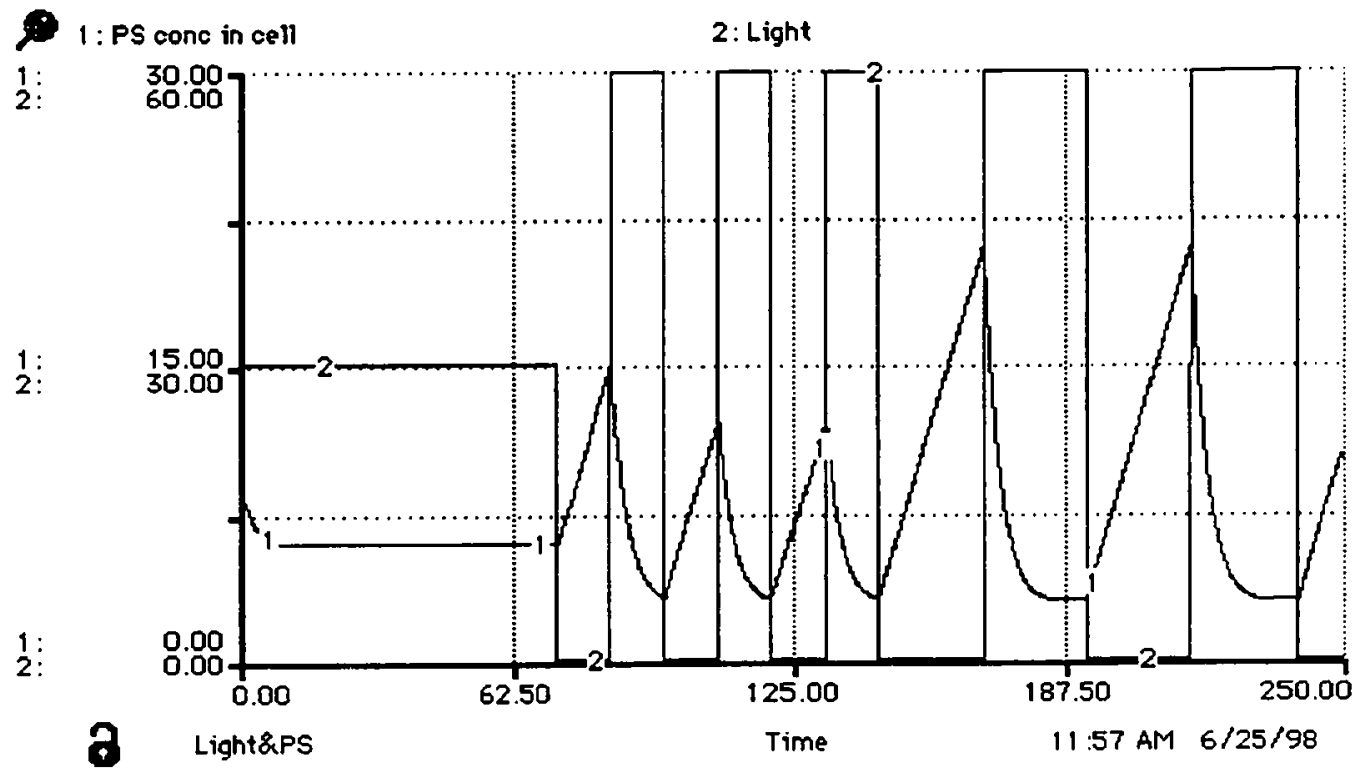

Figure 4.2: Output of simple model shifting from constant light to fluctuating light

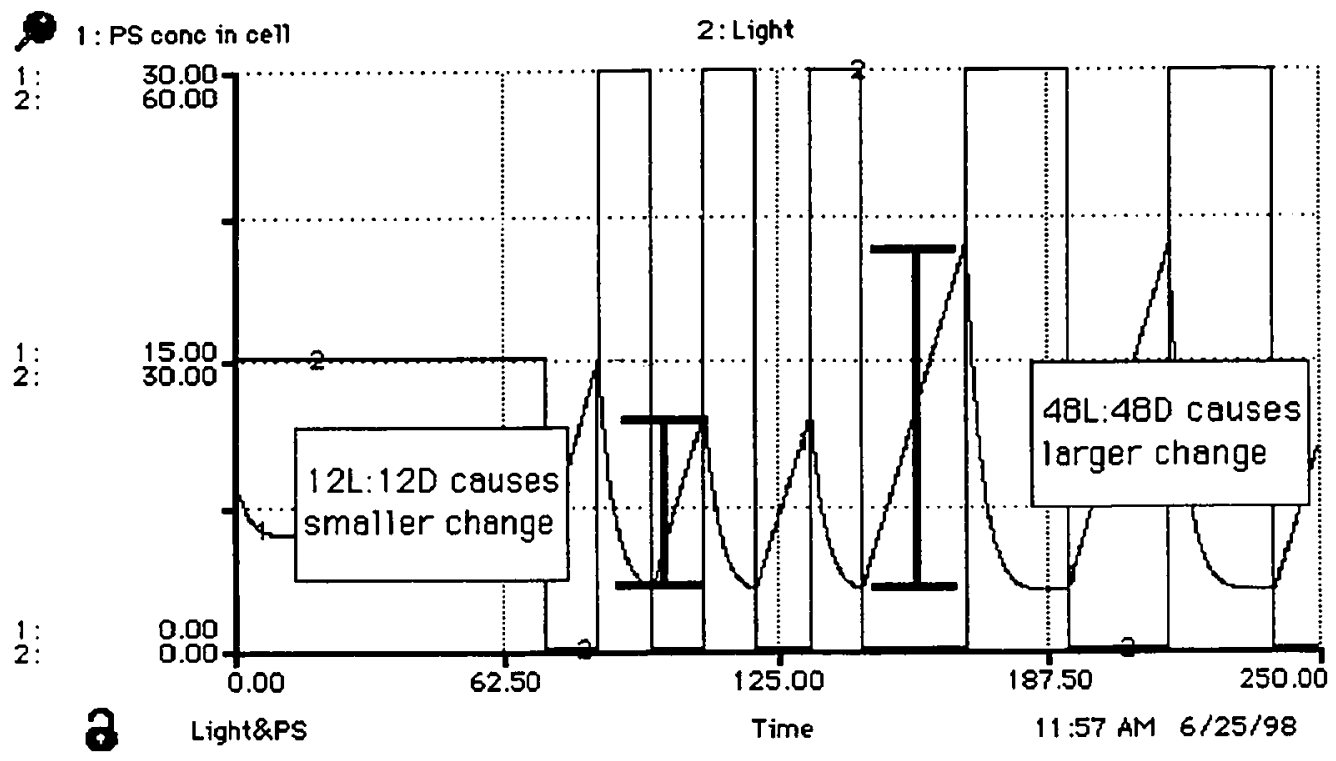

Figure 4.3: Comparison of parameters in various light regimes as predicted by simple model 


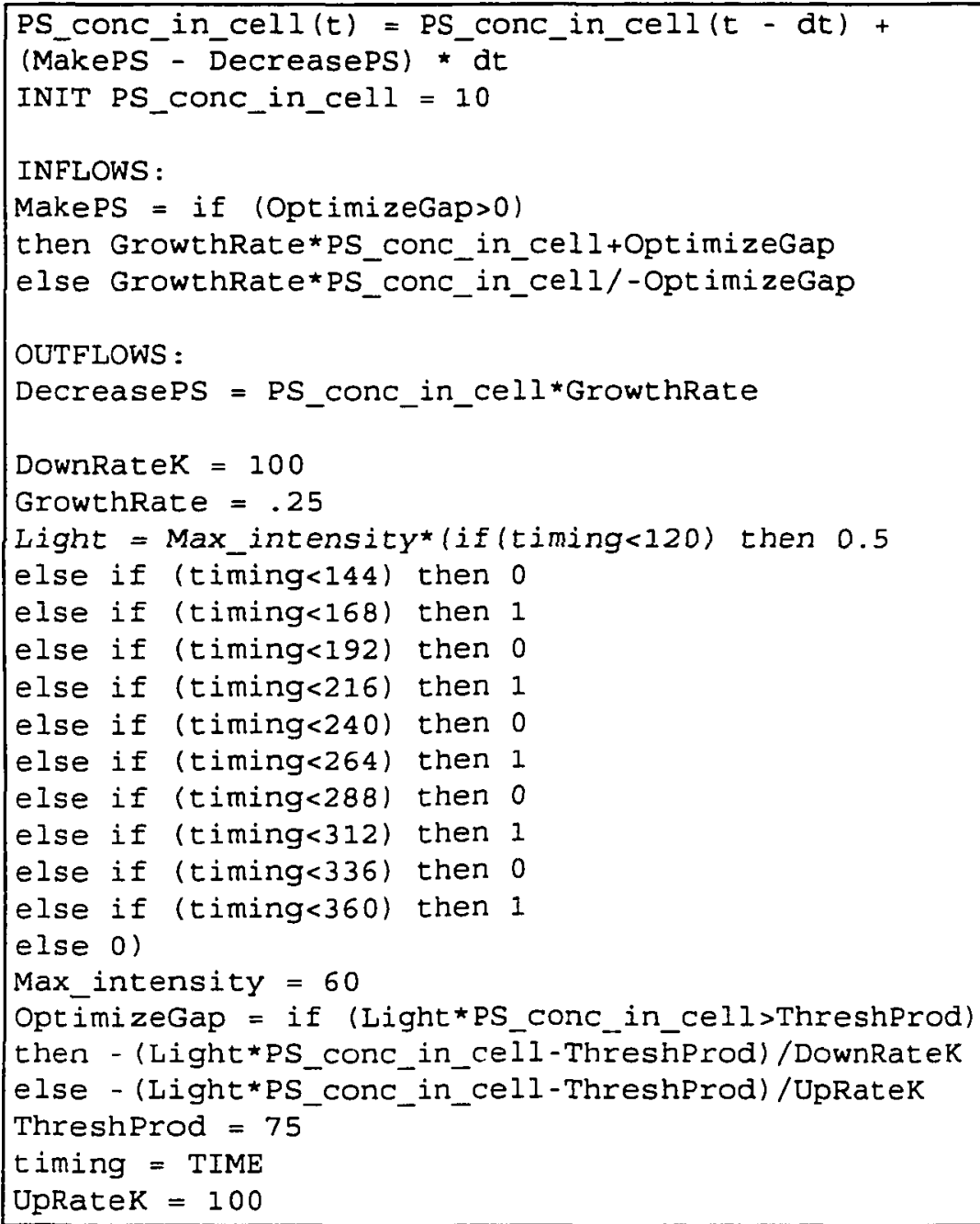

Table 4.1: STELLA II equations for simple model 


\section{Two-component Model}

This model is an attempt to represent regulation at two levels, both the level of protein synthesis and the level of enzyme activation and deactivation. This model addresses some of the major the interactions within a cell that are involved in photoadaptation. The model is not quantitatively accurate; this was constructed as a tool to examine scenarios and stimulate discussion.

The model apportions newly-fixed carbon into five major cell components. The first four are discussed by Shuter: photosynthetic membrane (Pmemb), photosynthetic enzymes (Penzy), biosynthetic components (Enzy\&Biosynt), and structure. These components affect the rate that new carbon can be fixed. An additional major cell component is the photosynthetic membrane components that have been damaged by light (BurnedPmemb). I hypothesize that damage to the photosystems by excessive light should be an important factor in controlling photosynthetic rate. This damage is modeled as an irreversible step; if the cell is exposed to light at higher intensities than it is adapted to, photosystems are moved from the functional pool (Pmemb) to the inactive pool (BurnedPmem) and their activity cannot be restored. Cells can immediately synthesize new photosystems if energy is available, but they cannot get rid of the damaged photosystems. The overall concentration of damaged photosystems in a population can only increase. The concentration of damaged photosystems per cell can be decreased as the cells 
grow and divide, diluting the concentration of damaged photosystems per individual cell. In an environmental model, as cells are removed from the population through sinking or being eaten their damaged photosystems would be removed from the population's damaged photosystem pool. These losses are not tracked in this physiological model.

Energy from light is converted to NADPH which is then converted to triose phosphate. This is not intended as a literal flow of material, but rather as a flow of energy which becomes fixed carbon at triose phosphate. The triose phosphate can be converted to storage polymers or can be made into building blocks, a quantity representing the pool of raw materials such as amino acids, nucleic acids, lipids and pigments.

The quantities described increase as the model runs, representing the total amount of material in all the cells of a growing culture. To describe the amounts in a single cell, absolute quantities are converted into cellular fractions by the structure in the lower left quadrant of the map. The lower right quadrant of the model represents the decision-making logic that selects how much of the building block pool to apportion to the cellular components. 


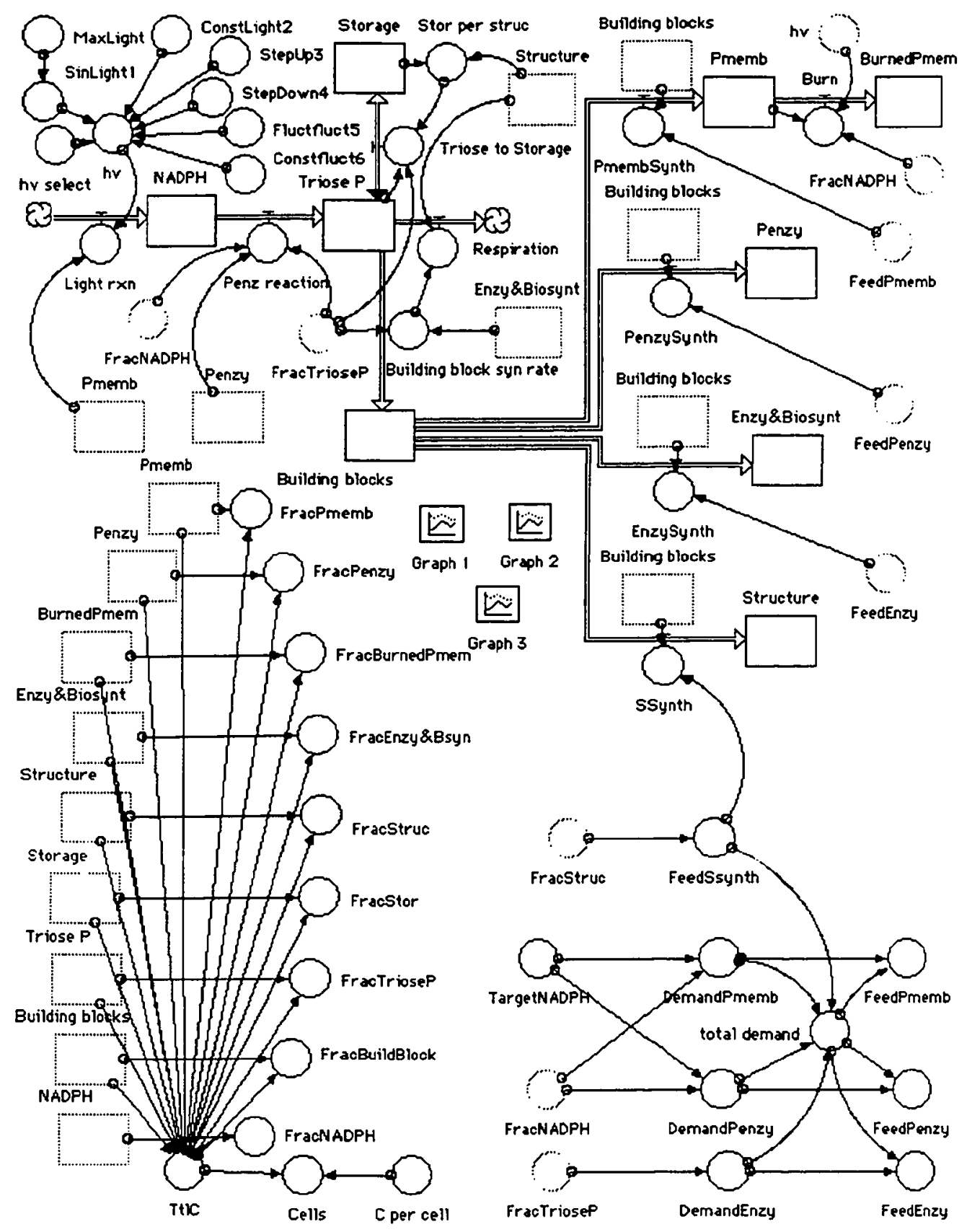

Figure 4.4: Map of two-component model in STELLA II 
In the first 240 hours of the run represented in the following output graphs (figures $4.5-4.7$ ), the light variable is set constant and the cells converge to stable ratios of metabolic concentrations and components. When a living cell reaches such a steady composition, Shuter would call it optimized for growth at the constant light intensity. The model was not tuned to produce maximum carbon assimilation at that steady state, but like the cells of Shuter's model the cells of the two-component model respond to steady light by attaining a steady composition. An important difference between the behavior of Shuter's model and the behavior of the two-component model is that Shuter's model only predicts the final adapted composition of the model cells, while the two component model predicts the path the cells take to reach that final adapted state.

As in real phytoplankton cells, in constant light the ratios of components in the model cells are a function of their light environment. During runs of the model where light is shifted from one constant illumination to another (not shown here), ratios of photosynthetic membranes to photosynthetic enzymes shift from one stable composition through an adaptation period that begins with the light shift and eventually arrives at another stable composition. During the initial constant light period of the model run shown in figures $4.5-4.7$, the fraction of carbon in photosynthetic membranes is larger than the fraction in photosynthetic enzymes, as expected for cyanobacteria in dim light. Later when the light varies between double 
the initial intensity and dark, the photosynthetic enzymes become more abundant than photosystems; during these fluctuations the model cell can build photosynthetic enzymes in response to the increased demand during the light periods, but cannot build much photosynthetic membrane in the dark as light energy for carbon fixation is not available. Some photosynthetic membrane is built at the start of each dark period using pools of fixed carbon left from the previous light period and some stored carbon, but the fraction of photosynthetic membrane decreases rapidly with the onset of the light period as some photosystems are burned and then the model cells grow without synthesizing more photosynthetic membrane, diluting the concentration of existing photosynthetic membrane.

During the period that the light variable fluctuates, the model cells attain stable composition during dark periods when they have no energy available for growth. During periods of light, the model cells make new components but cannot attain stable compositions during the 48 hour light periods. For example, the FracEnzy\&Bsyn and the FracPEnzy shown in Figure 4.6 have non-zero slopes at the onset of darkness, indicating that they are still adapting and that the adaptation is truncated by the onset of darkness. 


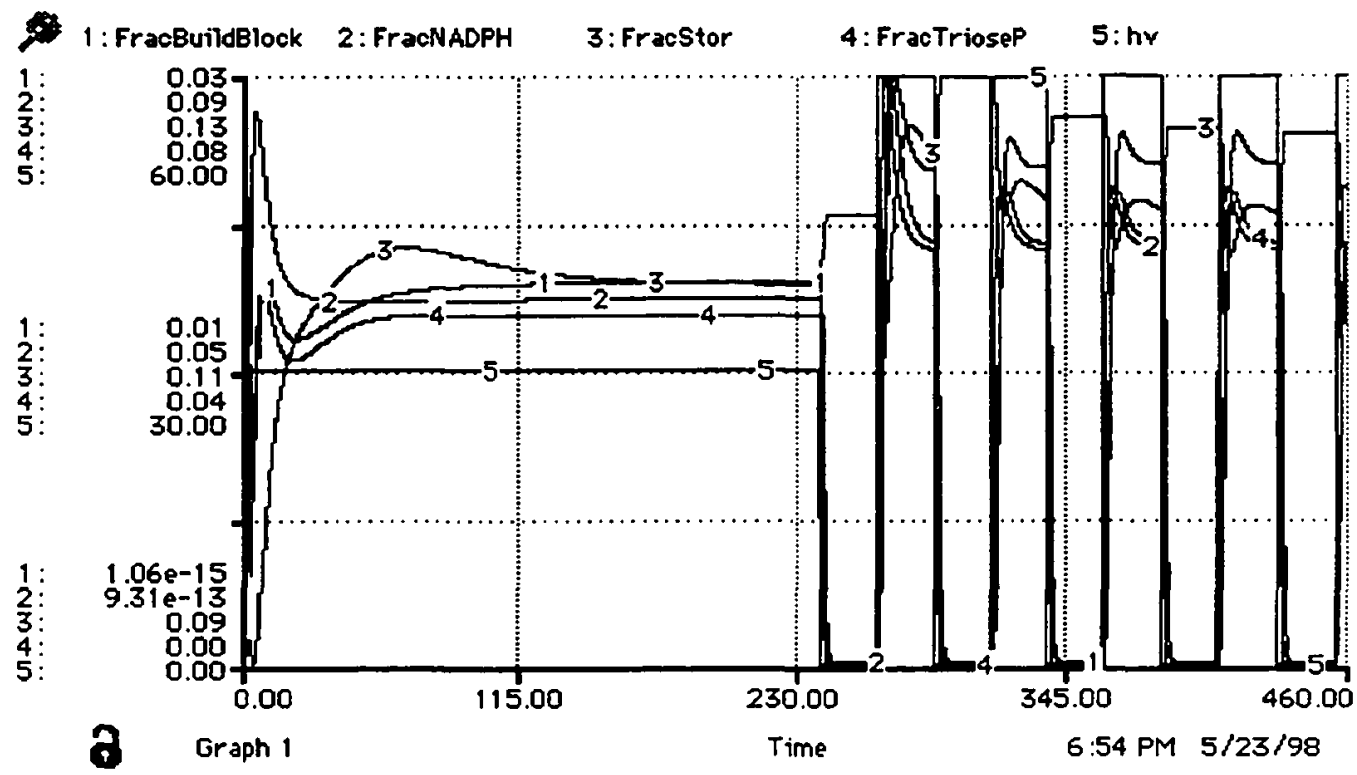

Figure 4.5: Output of two-component model shifting from $30 \mu \mathrm{Em}^{-2} \mathrm{~s}^{-1}$ constant light to fluctuating light showing the fraction of the cell that is building blocks, the fraction of the cell that is NADPH, the fraction of the cell that is storage, the fraction of the cell that is triose phosphate, and light.

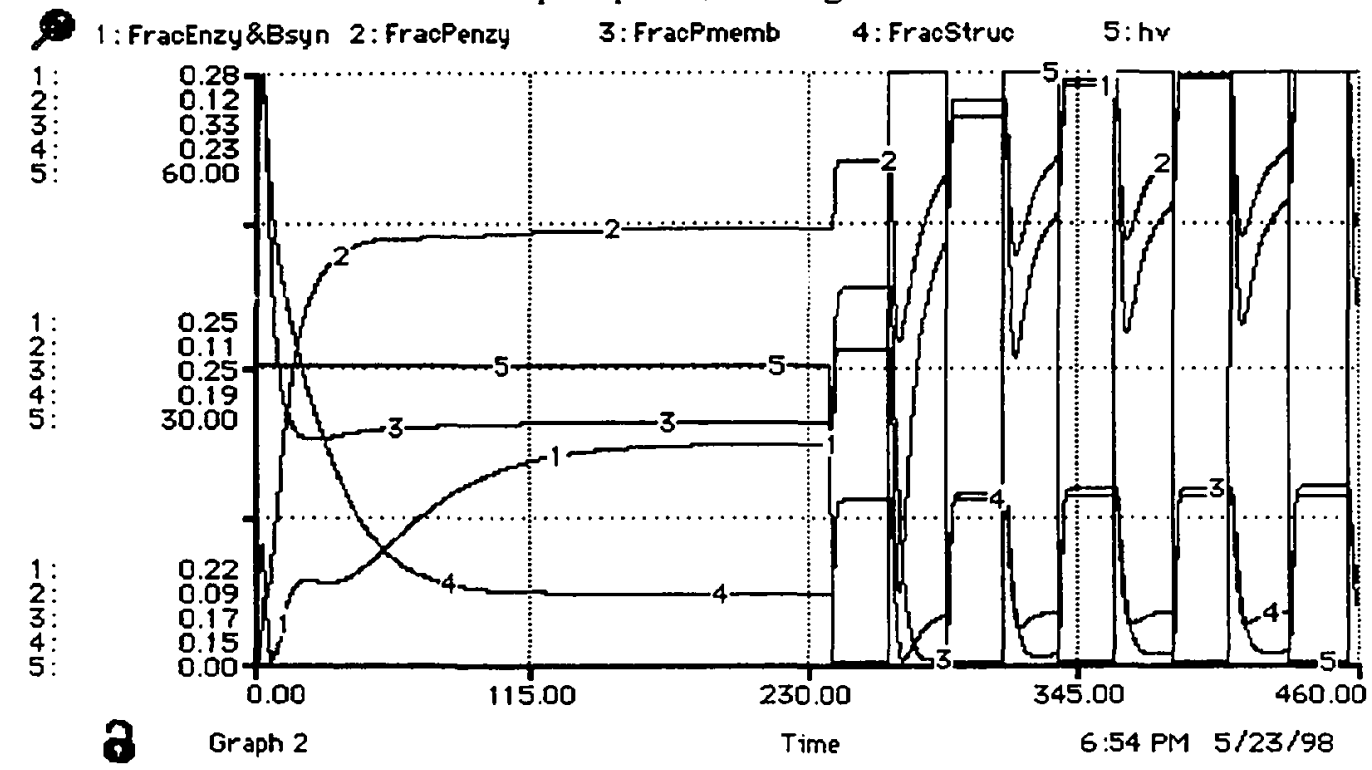

Figure 4.6: Output of two-component model shifting from $30 \mu \mathrm{Em}^{-2} \mathrm{~s}^{-1}$ constant light to fluctuating light showing the fraction of the cell that is enzymes and biosynthetic apparatus, the fraction of the cell that is photosynthetic enzymes, the fraction of the cell that is photosynthetic membrane, the fraction of the cell that is storage, and light. 


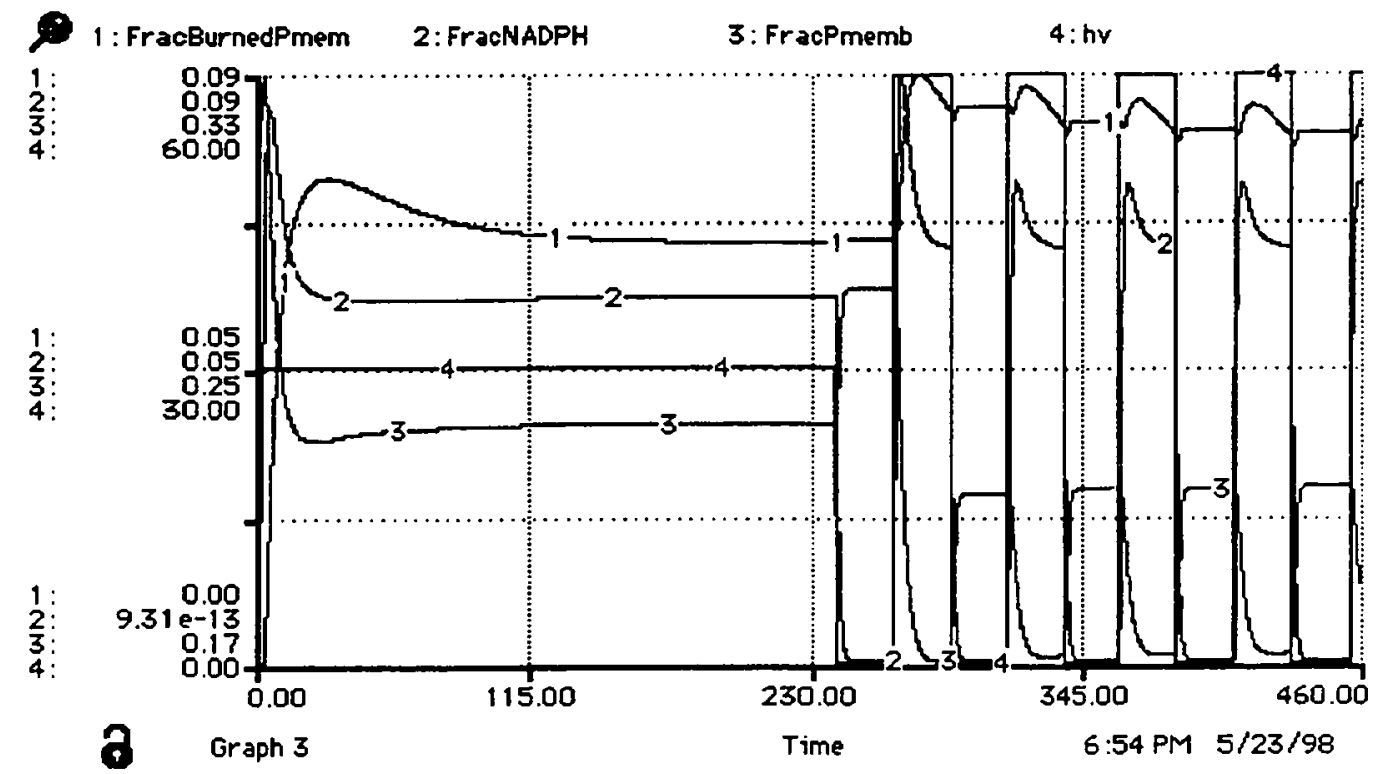

Figure 4.7: Output of two-component model shifting from $30 \mu \mathrm{Em}^{-2} \mathrm{~s}^{-1}$ constant light to fluctuating light showing the fraction of the cell that is burned out components of the photosynthetic membrane, the fraction of the cell that is $\mathrm{NADPH}$, the fraction of the cell that is photosynthetic membrane, and light.

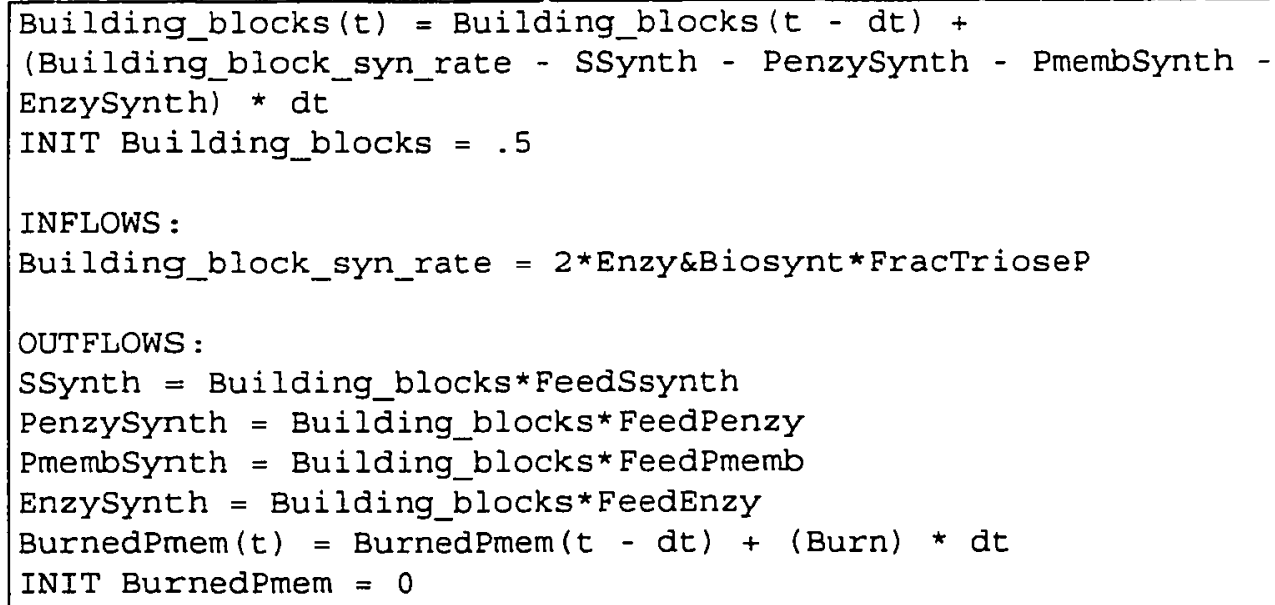

Table 4.2 continues on next page 
Table 4.2 continued from previous page

INFLOWS :

Burn $=$ if $(\mathrm{hv}>1)$

then if (FracNADPH>.05)

then (FracNADPH -.05)*Pmemb

else 0

else 0

Enzy\&Biosynt $(t)=$ Enzy\&Biosynt $(t-d t)+($ EnzySynth $) \star d t$

INIT Enzy\&Biosynt $=5$

INFLOWS :

EnzySynth = Building_blocks* FeedEnzy

$\mathrm{NADPH}(t)=\mathrm{NADPH}(t-d t)+($ Light_rxn - Penz_reaction $) \star d t$

INIT NADPH $=.5$

INFLOWS :

Light_rxn $=$ Pmemb*hv/(100+hv)

OUTFLOWS :

Penz_reaction $=$ if Fractriosep $>.2$

then $((-1 *($ FracTrioseP -0.2$)+1) *($ PenzY* $(8 *$ FracNADPH $)))$

else Penzy* $(8 *$ FracNADPH)

Penzy $(t)=$ Penzy $(t-d t)+($ PenzySynth $) * d t$

INIT Penzy $=2$

INFLOWS :

PenzySynth = Building_blocks*FeedPenzy

Pmemb $(t)=$ Pmemb $(t-\bar{d} t)+($ PmembSynth - Burn $) * d t$

INIT Pmemb $=7$

INFLOWS :

PmembSynth = Building_blocks*FeedPmemb

OUTFLOWS :

Burn = if $($ hv $>1)$

then if (FracNADPH>.05)

then (FracNADPH -.05)*Pmemb

else 0

else 0

Storage $(t)=$ Storage $(t-d t)+($ Triose_to_Storage $)$ * $d t$

INIT Storage $=2$

INFLOWS :

Triose_to_Storage $=$ Triose_P*FracTriose $P \star 1 /$ Stor_per_struc

Structure $(t)=$ Structure $(t-d t)+($ SSynth $) * d t$

INIT Structure $=5$

Table 4.2 continues on next page 


\section{Table 4.2 continued from previous page}

\section{INFLOWS:}

SSynth $=$ Building_blocks*Feedssynth

Triose_ $P(t)=$ Triose_ $P(t-d t)+($ Penz_reaction -

Building_block_syn_rate - Respiration - Triose_to_storage) *dt

INIT Triose_P $=.5$

INFLOWS :

Penz_reaction $=$ if FractrioseP $>.2$

then $((-1 *($ FracTrioseP -0.2$)+1) *($ Penzy* $(8 *$ FracNADPH $)))$

else Penzy* $(8 *$ FracNADPH $)$

OUTFLOWS :

Building_block_syn_rate $=2 \star E n z y \& B i o s y n t *$ FracTrioseP

Respiration $=$ MAX $(.03 * 5 *$ Structure, $.66 *$ Building_block_syn_rate $)$

Triose_to_Storage $=$ Triose_P*FracTrioseP*I/Stor_per_struc

Celis = TtIC/C_per_cell

Constfluct $6=$ if $($ TIME $<240)$

then 30

else if $(((($ TIME-24)/48)-ROUND $(($ TIME-24)/48))>0)

then 60

else 0

ConstLight2 $=60$

C_per_cell $=17$

Demandenzy $=5 *($ FracTrioseP $/ .05)$

DemandPenzy $=2 \star$ (FracNADPH $/$ TargetNADPH)

DemandPmemb $=7 \star($ TargetNADPH/FracNADPH $)$

FeedEnzy $=$ DemandEnzy/total_demand

FeedPenzy $=$ DemandPenzy/total demand

FeedPmemb $=$ DemandPmemb/total_demand

FeedSsynth $=.2 *(.2 /$ FracStruc $)$

Fluctfluct $5=$ if $($ TIME $<240)$

then if $(((($ TIME -12$) / 24)-\operatorname{ROUND}(($ TIME -12$) / 24))>0)$

then 60

else 0

else if $(((($ TIME-24)/48)-ROUND $(($ TIME-24)/48))>0)

then 60

else 0

FracBuildBlock = Building_blocks $/$ TtlC

FracBurnedPmem = BurnedPmem $/ \mathrm{Tt} l \mathrm{C}$

FracEnzy\&Bsyn $=$ Enzy\&Biosynt $/ \mathrm{Tt} I \mathrm{C}$

FracNADPH $=\mathrm{NADPH} / \mathrm{TL} I \mathrm{C}$

FracPenzy $=$ Penzy $/$ Tt lC

FracPmemb $=$ Pmemb $/ \mathrm{Tt} 1 \mathrm{C}$

Fracstor = Storage $/ \mathrm{Tt} I \mathrm{C}$

Table 4.2 continues on next page 
Table 4.2 continued from previous page

Fracstruc $=$ Structure $/ \mathrm{Tt} I \mathrm{C}$

FractrioseP $=$ Triose_P $/$ Tt IC

hv $=$ if (hv_select $=1)$

then SinLight 1

else if (hv_select=2)

then Constight2

else if (hv_select $=3$ )

then Stepup $\overline{3}$

else if ( $h v_{\text {_select }}=4$ )

then StepDown4

else if (hv_select $=5)$

then Fluctflucts

else if (hv_select=6)

then Constfiuct 6

else SinLight 1

hv_select $=6$

MaxLight $=500$

SinLight $1=$ if $\sin (2 * P i * t i m e / 24)<0$

then 0

else (MaxLight* $\sin \left(2{ }^{*} \mathrm{P}^{\star} t_{\mathrm{t}} \mathrm{ime} / 24\right)$ )

StepDown 4 if $(t$ ime $<24)$

then 100

else 10

StepUp3 = if $($ TIME<24)

then 10

else 100

Stor_per_struc = Storage/Structure

Target NADPH $=.05$

total_demand $=$ DemandEnzy+DemandPenzy+DemandPmemb+FeedSsynth

TtIC =

Enzy\&Biosynt+Penzy+Pmemb+Storage+Structure+Triose_P+Building_block

s+BurnedPmem

Table 4.2: STELLA II equations for two-component model 
The two models presented here served different purposes. The simple model aided in designing the light regime for the experiments described in Chapter 5. Different light regimes were simulated; the regime causing the largest difference in photosystem concentration (PS conc in cell) between each sampling period was chosen for the fluctuating light experiment.

The two component model is a dynamic model that like Shuter's model predicts cell composition in response to light, but also extends its predictions through the process of adaptation. Shuter's model predicts only optimized states of phytoplankton cells. The experiments of Chapter 3 measured changes cultures go through to reach optimized states. In simulated shifts between constant light intensities, the two component model also goes through changes over time to reach stable states. In simulations of fluctuating light, the model cells undergo truncated adaptive responses that cannot be predicted with Shuter's approach.

In addition to metabolic pools in rapid flux, the two component model introduces a new persistent structural element, damaged photosystems, to Shuter's scheme. While this model did not account for iron concentration, iron should have a protective effect on photosystems both in its role as an electron carrier and as a component of Fe-superoxide dismutase. Future models that account for iron concentration might use the effect of iron on the rate of photosystem damage. 


\section{Chapter 5}

\section{Comparison of Cultures from Different Light Regimes Transferred to the Same Light Regime}

\section{Introduction}

The purpose of this experiment was to determine the effect of preadaptation to different light regimes on photoadaptation of Synechococcus WH7803. Specifically, this experiment was to test if preadaptation to a fluctuating light regime gave an advantage to a cell transferred to a second, different fluctuating light regime compared to a cell preadapted to constant light and transferred to the same second light regime. Another question was whether populations in culture would physiologically adjust to a light regime while remaining genetically similar to their initial state (phenotypic adaptation), or if instead the process of photoadaptation is driven by selection (genotypic adaptation).

Two cultures were grown in media containing $1 * 10^{-6} \mathrm{M} \mathrm{Fe}$, one preadapted to fluctuating light and the other preadapted to constant light. Two cultures were grown in media containing $5 * 10^{-6} \mathrm{M} \mathrm{Fe}$, one preadapted to fluctuating light and the other preadapted to constant light. One preadaptation regime was constant dim illumination and the other was a 12 hour light : 12 hour dark cycle at twice the illumination intensity during light periods. These preadaptation regimes were 
maintained for 14 days. On experiment day zero all cultures were moved into the light fluctuator on a 48 hour light : 48 hour dark cycle at the same light intensity as the fluctuating preadaptation regime. $200 \mathrm{ml}$ cultures were maintained semicontinuously; $100 \mathrm{ml}$ of each culture was removed and replaced with $100 \mathrm{ml}$ of modified aquil medium every two days. The culture removed was used for cell counts, protein samples, chlorophyll samples and P vs. I assays every two days over the 10-day assay then once again 20 days after the cultures went into the 48 hour light : 48 hour dark cycle. The cultures were maintained in the 48 hour light : 48 hour dark cycle through the entire 20 days even though no data was collected between day 10 and day 20 .

\section{Experimental conditions}

For this experiment, one high iron culture and one low iron culture grew in constant high light intensity $\left(80 \mu \mathrm{Em}^{-2} \mathrm{~s}^{-1}\right)$ for several weeks, then the cultures were split into pairs. One high iron culture and one low iron culture were placed into constant illumination at $30 \mu \mathrm{Em}^{-2} \mathrm{~s}^{-1}$. Another high iron culture and one low iron culture were placed into a 12 hour light : 12 hour dark cycle at $60 \mu \mathrm{Em}^{-2} \mathrm{~s}^{-1}$ during light periods. Preadaptation continued for 14 days, from 8/31/97 to 9/14/97. Next, on experiment day 0 (9/14/97), all cultures were moved into a 48 hour light : 48 hour dark cycle at $60 \mu \mathrm{Em}^{-2} \mathrm{~s}^{-1}$ during light periods. The shift started with a 48 hour light period. 
The cultures preadapted to constant light were designated:

\section{Const LoFe Const HiFe}

The cultures preadapted to fluctuating light were designated:

Fluct LoFe Fluct HiFe

$200 \mathrm{ml}$ cultures were maintained semi-continuously; $100 \mathrm{ml}$ of each culture was removed and replaced with $100 \mathrm{ml}$ of modified Aquil medium every two days. During the 10-day assay, the $100 \mathrm{ml}$ of culture removed every two days was used for cell counts, protein samples, chlorophyll samples and P vs. I assays; an additional sample was taken and assayed on day 20 .

Samples in scintillation vials that were placed into the $P$ vs. I tank were illuminated at $0.44,5.61,9.9,11.3,21.6,42.0,59.8,79.0,115$ and $145 \mu \mathrm{Em}^{-2} \mathrm{~s}^{-1}$.

Two culture samples were accidentally discarded. These were the preadapted constant, low iron day $2(9 / 16 / 97)$ sample and the preadapted fluctuating, low iron day $2(9 / 16 / 97)$ sample. No data was gathered on either of those cultures on those days. 


\section{Response of cultures}

\section{Cell count (cells/ml)}

The population density of the cultures preadapted to constant light decreased after moving to the 48 hour light: 48 hour dark cycle, while the population density of cultures preadapted to fluctuating light remained fairly constant. In the low iron cultures and the preadapted constant high iron culture, the cell counts increased after 48-hour light periods and decreased after 48-hour dark periods. The preadapted fluctuating high iron culture remained fairly constant through light and dark periods. The preadapted fluctuating low iron culture varied less than the preadapted constant high iron culture. In general, cell counts of each of the preadapted constant cultures varied more over each 48 -hour light or dark period than its iron-matched preadapted fluctuating culture.

Cell counts of the cultures preadapted to constant light decreased after moving to the 48 hour light: 48 hour dark cycle. This could be due to photosystem damage due to the doubled peak light on transfer from $30 \mu \mathrm{Em}^{-2} \mathrm{~s}^{-1}$ constant light to $60 \mu \mathrm{Em}^{-2} \mathrm{~s}^{-1}$ during the light periods of the fluctuating cycle. The highest initial counts were from the preadapted constant low iron cultures, and these were the cultures that underwent the greatest decrease over a dark period; in general the 
oscillations in cell counts were widest in the preadapted constant low iron cultures.

When 48-hour increases in cell counts occurred, they were during light periods.

Table 5.1: Fractional changes in cells/ml for replicate cultures

$$
\text { Preadapted constant Preadapted fluctuating }
$$

Cultures: Const Lo Fe Const Hi Fe Fluct Lo Fe Fluct $\mathrm{Hi} \mathrm{Fe}$

\begin{tabular}{|c|c|c|c|c|}
\hline $\begin{array}{r}\text { Fractional } 10 \text { day change } \\
\text { of cells } / \mathrm{ml} \text { : }\end{array}$ & 0.29 & 0.43 & 0.99 & 0.90 \\
\hline
\end{tabular}

Table 5.2: Fractional changes in cells $/ \mathrm{ml}$ for averaged fits

\begin{tabular}{|c|c|c|c|}
\hline & $\begin{array}{l}\text { Day zero } \\
\text { averages } \\
\text { (cells } / \mathrm{ml} \text { ) }\end{array}$ & $\begin{array}{c}\text { Day } 20 \\
\text { averages } \\
\text { (cells } / \mathrm{ml} \text { ) }\end{array}$ & $\begin{array}{l}\text { Fractional } \\
\text { change, } \\
\text { day } 20 / \text { day } 0\end{array}$ \\
\hline all cultures: & $2.10 * 10^{8}$ & $1.28 * 10^{8}$ & 0.61 \\
\hline all HiFe: & $2.10^{*} 10^{8}$ & $1.38 * 10^{8}$ & 0.66 \\
\hline all LoFe: & $2.11^{*} 10^{8}$ & $1.18 * 10^{8}$ & 0.56 \\
\hline preadapted constant: & $2.38 * 10^{8}$ & $8.42 * 10^{7}$ & 0.35 \\
\hline 1 preadapted fluctuating: & $1.83 * 10^{8}$ & $1.72 * 10^{8}$ & 0.94 \\
\hline
\end{tabular}




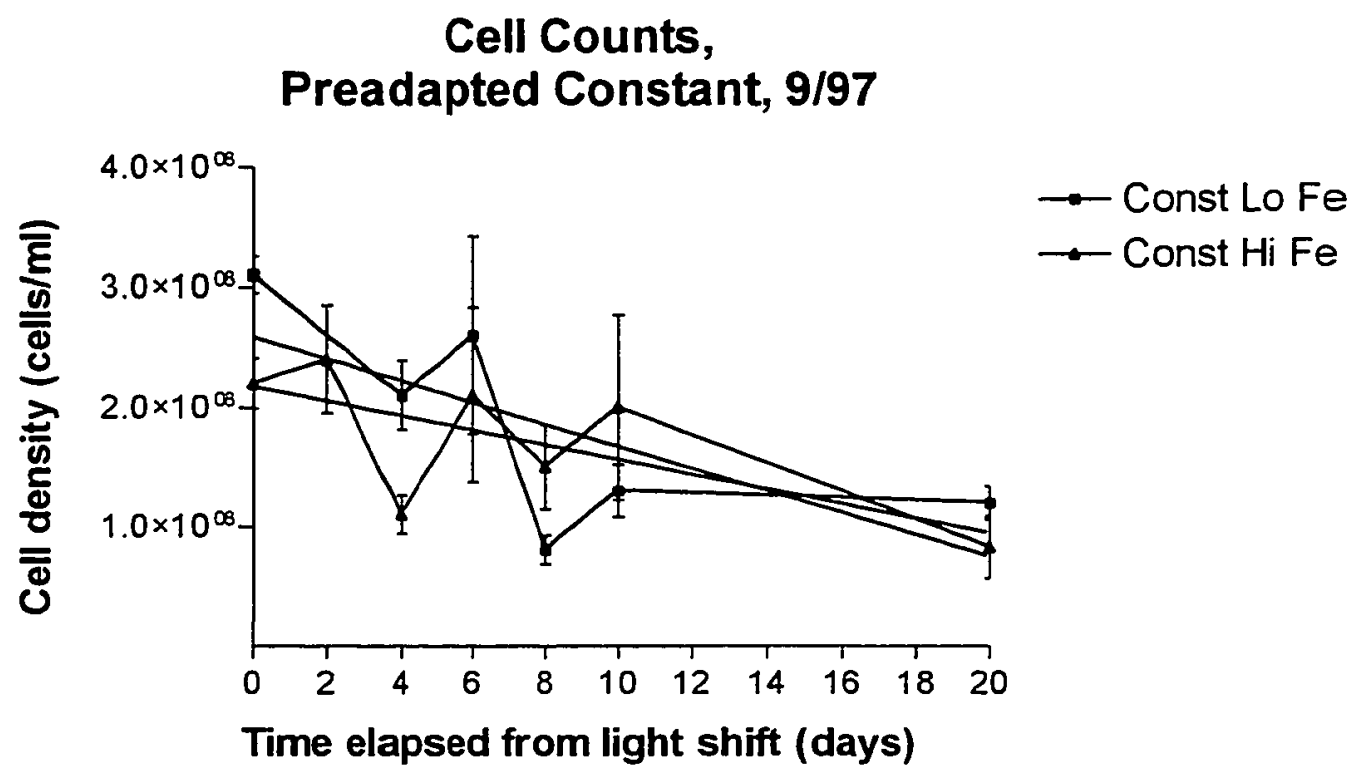

Figure 5.1: Plot of cells/ml for preadapted constant light cultures. Error bars indicate $95 \%$ confidence interval.

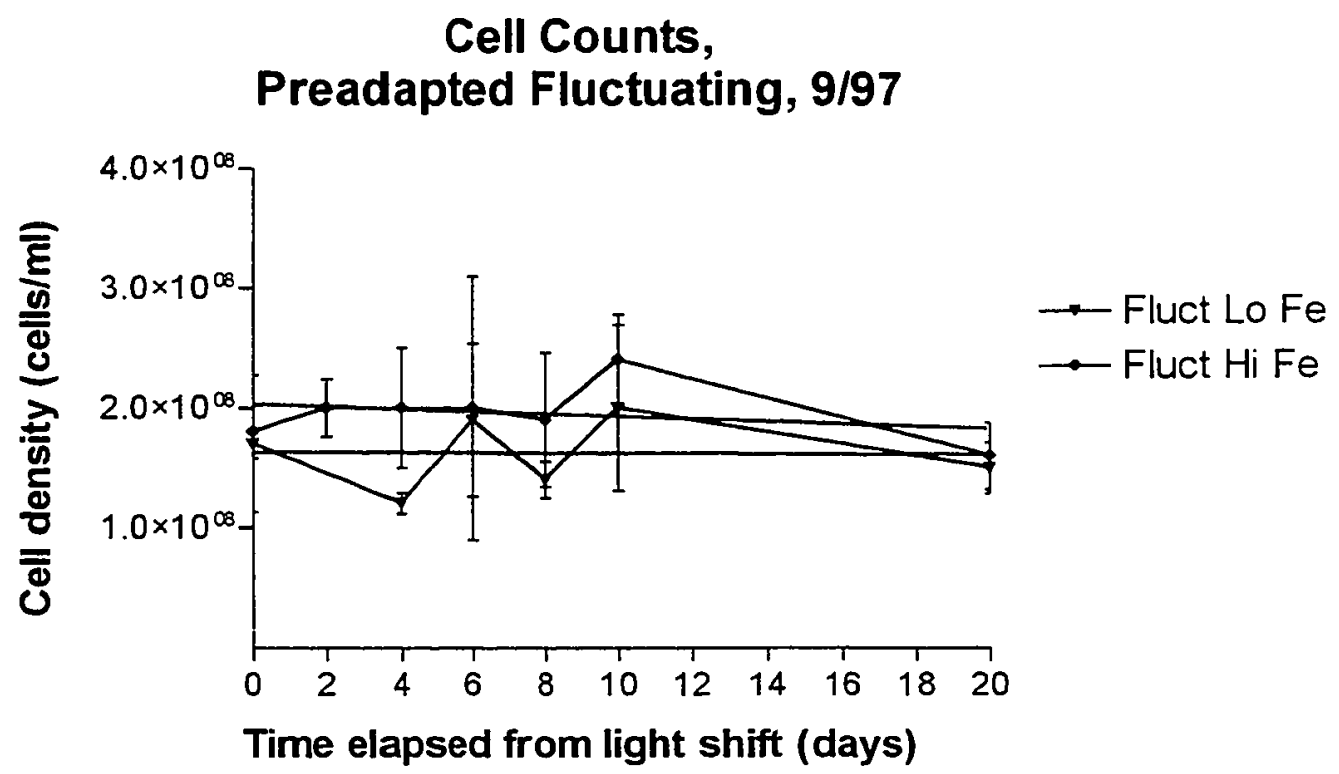

Figure 5.2: Plot of cells $/ \mathrm{ml}$ for preadapted fluctuating light cultures. Error bars indicate $95 \%$ confidence interval. 


\section{Chlorophyll ( $\mu \mathrm{g}$ chl $a / \mathrm{ml})$}

Chlorophyll $a$ concentrations decreased in preadapted constant light high iron cultures and increased in preadapted fluctuating light low iron cultures. When 48-hour increases in chlorophyll $a$ occurred, they were during light periods.

Table 5.3: Fractional changes in $\mu \mathrm{g}$ chl $a / \mathrm{ml}$ for replicate cultures

\section{Preadapted constant Preadapted fluctuating}

Cultures: Const Lo Fe Const $\mathrm{Hi} \mathrm{Fe}$ Fluct Lo Fe Fluct $\mathrm{Hi} \mathrm{Fe}$

Fractional 10 day change of $\mu \mathrm{g} \mathrm{chl} a / \mathrm{ml}$

Table 5.4: Fractional changes in $\mu \mathrm{g} \mathrm{chl} a / \mathrm{ml}$ for averaged fits

\begin{tabular}{|c|c|c|c|}
\hline & $\begin{array}{c}\text { Day zero } \\
\text { averages } \\
(\mu \mathrm{g} \text { chl } a / \mathrm{ml})\end{array}$ & $\begin{array}{c}\text { Day } 20 \\
\text { averages } \\
(\mu \mathrm{g} \text { chl } a / \mathrm{ml})\end{array}$ & $\begin{array}{c}\text { Fractional } \\
\text { change, } \\
\text { day } 20 / \text { day } 0\end{array}$ \\
\hline \multirow{5}{*}{$\begin{array}{l}\text { all cultures: } \\
\text { all HiFe: } \\
\text { all LoFe: } \\
\text { preadapted constant: } \\
\text { adapted fluctuating: }\end{array}$} & 0.13 & 0.10 & 0.77 \\
\hline & 0.19 & 0.091 & 0.48 \\
\hline & 0.071 & 0.11 & 1.5 \\
\hline & 0.14 & 0.078 & 0.55 \\
\hline & 0.12 & 0.12 & 1.0 \\
\hline
\end{tabular}




\section{Preadapt Constant Light 9/97}

Chlorophyll a, Spectrophotometric

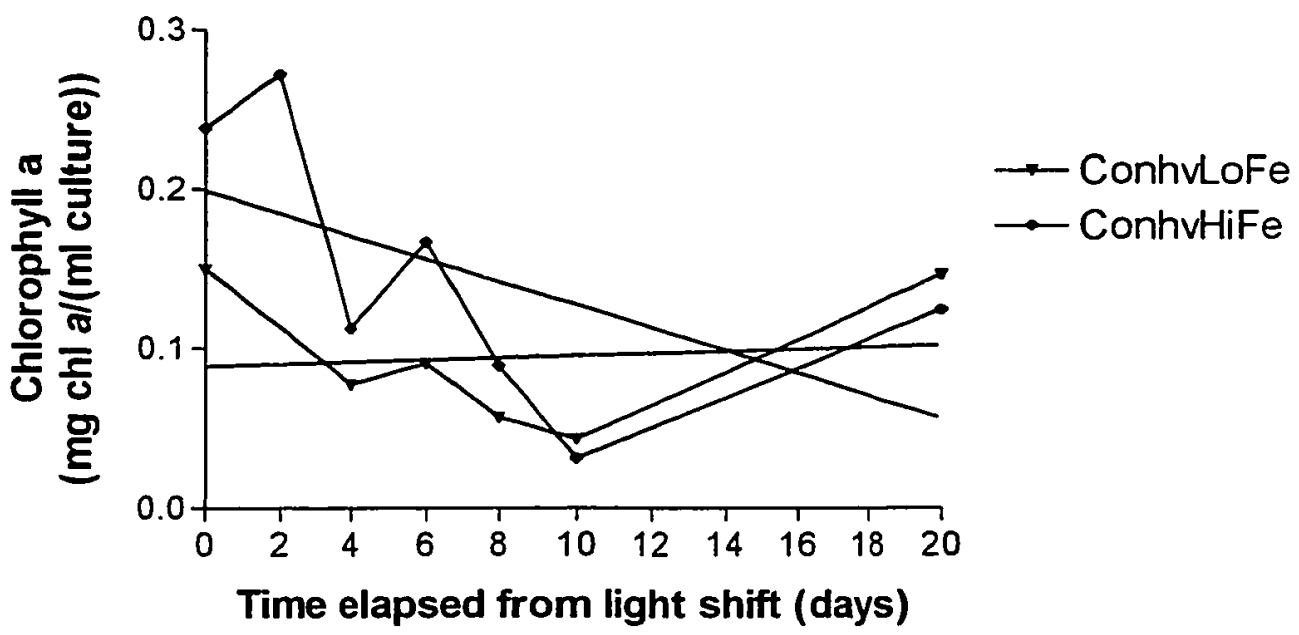

Figure 5.3: Plot of $\mu \mathrm{g} \mathrm{chl} a / \mathrm{ml}$ for preadapted constant light cultures. ConhvLoFe day 2 sample lost. Each point is the result of a single spectrophotometric assay using the trichromatic method for determination of chlorophyll $a$.

\section{Preadapt Fluctuating Light 9/97 \\ Chlorophyll a, Spectrophotometric}

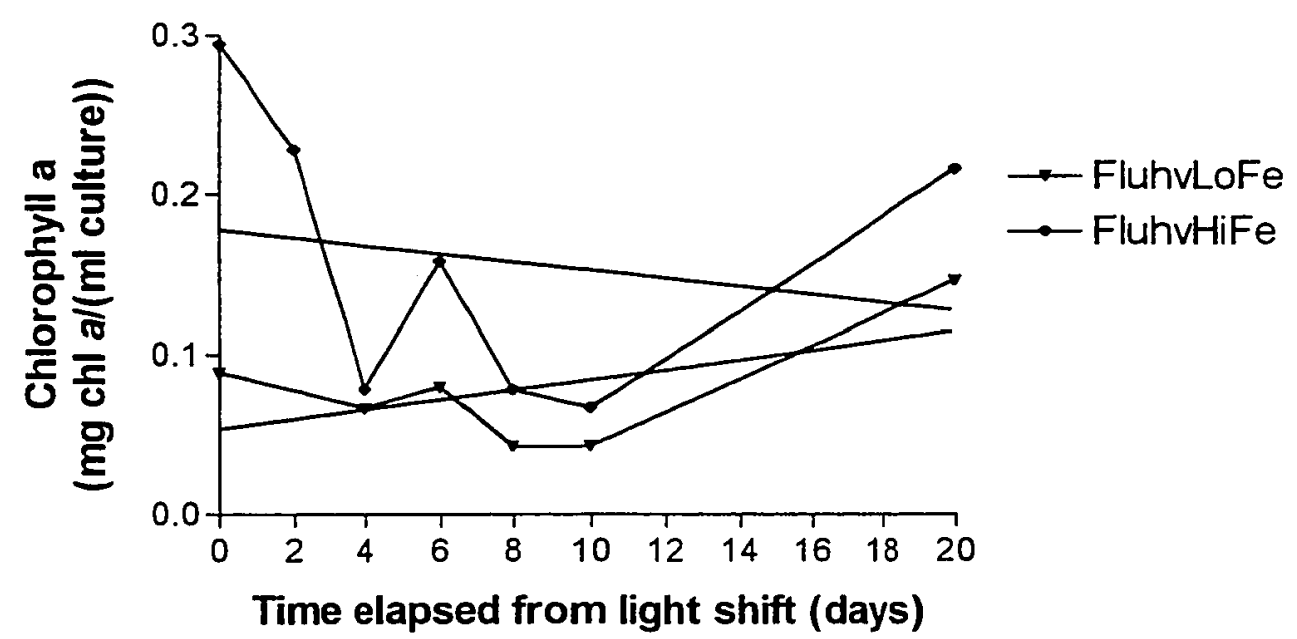

Figure 5.4: Plot of $\mu \mathrm{g} \mathrm{chl} a / \mathrm{ml}$ for preadapted fluctuating light cultures.

FlucthvLoFe day 2 sample lost. Each point is the result of a single spectrophotometric assay using the trichromatic method for determination of chlorophyll $a$. 


\section{Protein ( $\mu \mathrm{g}$ protein $/ \mathrm{ml})$}

Total protein concentrations decreased in all cultures. The greatest decreases were in the cultures preadapted to constant light. When 48 -hour increases in protein concentration occurred, they were during light periods.

Table 5.5: Fractional changes in $\mu \mathrm{g}$ protein/ml for replicate cultures

$$
\text { Preadapted constant Preadapted fluctuating }
$$

Cultures: Const Lo Fe Const Hi Fe Fluct Lo Fe Fluct Hi Fe

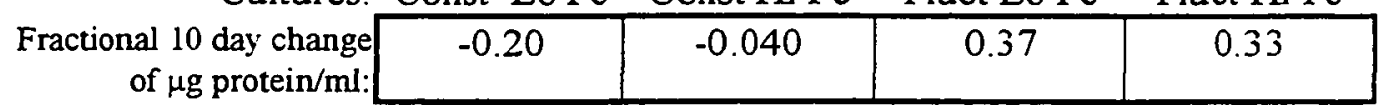

Regression lines crossed below the $x$ axis in the last few days of the experiment for both preadapted constant low iron and preadapted constant high iron cultures. This caused the negative fractional change for those cultures.

Table 5.6: Fractional changes in $\mu \mathrm{g}$ protein $/ \mathrm{ml}$ for averaged fits

\begin{tabular}{rlc|c|} 
& $\begin{array}{c}\text { Day zero } \\
\text { averages } \\
(\mu \mathrm{g} \text { protein/m) }\end{array}$ & $\begin{array}{c}\text { Day } 20 \\
\text { averages } \\
(\mu \mathrm{g} \text { protein/m) }\end{array}$ & $\begin{array}{c}\text { Fractional } \\
\text { change, } \\
\text { day 20/day 0 }\end{array}$ \\
\cline { 2 - 4 } all cultures & 130 & 13 & 0.10 \\
all HiFe: & 170 & 23 & 0.14 \\
all LoFe: & 90 & 3.6 & 0.040 \\
\cline { 2 - 4 } all preadapted constant: & 140 & -14 & -0.10 \\
\cline { 2 - 4 } all preadapted fluctuating: & 120 & 11 & 0.089 \\
\cline { 2 - 4 } & & &
\end{tabular}

Regression lines crossed below the $x$ axis in the last few days of the experiment for both preadapted constant low iron and preadapted constant high iron cultures. This caused the negative fractional change for preadapted constant cultures. 


\section{Preadapt Constant Light 9/97 \\ Proteins $(\mu \mathrm{g}$ protein $/ \mathrm{ml})$}

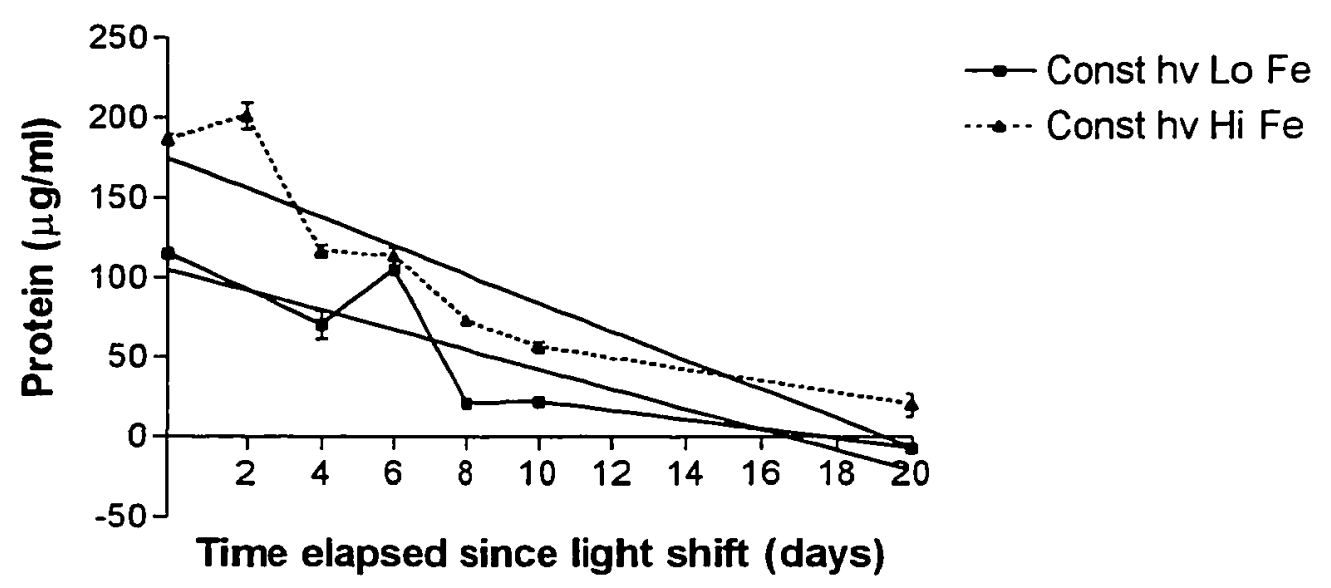

Figure 5.5: Plot of $\mu \mathrm{g}$ protein $/ \mathrm{ml}$ for preadapted constant light cultures.

ConhvLoFe day 2 sample lost. Data points are averages of two bicinchoninic acid assays from single filters. Error bars span the minimum and maximum values of those assays. 


\section{Preadapt Fluctuating Light 9/97 Proteins ( $\mu \mathrm{g}$ protein/ml)}

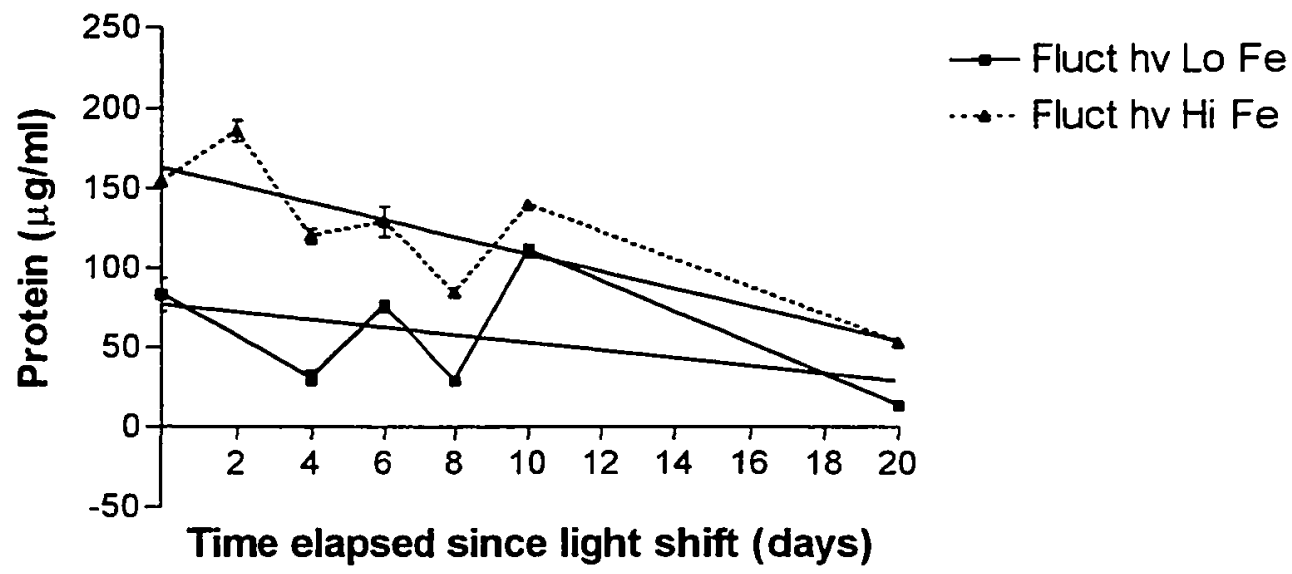

Figure 5.6: Plot of $\mu \mathrm{g}$ protein $/ \mathrm{ml}$ for preadapted fluctuating light cultures.

FlucthvLoFe day 2 sample lost. Data points are averages of two bicinchoninic acid assays from single filters. Error bars span the minimum and maximum values of those assays. 


\section{Chlorophyll $a$ per cell ( $\mu \mathrm{g}$ chl $a /$ cell)}

Chlorophyll $a$ concentrations per cell (chl $a /$ cell) in high iron cultures stayed fairly constant, while chl $a /$ cell in low iron cultures increased. The greatest increase in chl $a /$ cell was in preadapted constant low iron cultures.

Table 5.7: Fractional changes in $\mu \mathrm{g}$ chl a/cell for replicate cultures

$$
\text { Preadapted constant Preadapted fluctuating }
$$

\begin{tabular}{|c|c|c|c|c|}
\hline Cultures: & Const Lo Fe & Const $\mathrm{Hi} \mathrm{Fe}$ & Fluct Lo Fe & Fluct $\mathrm{Hi} \mathrm{Fe}$ \\
\hline $\begin{array}{r}\text { Fractional } 10 \text { day change } \\
\text { of } \mu \mathrm{g} \text { chl } a / \text { cell: }\end{array}$ & 4.2 & 1.2 & 2.3 & 0.90 \\
\hline
\end{tabular}

Table 5.8: Fractional changes in $\mu \mathrm{g} \mathrm{chl} a /$ cell for averaged fits

\begin{tabular}{rlcc|} 
& $\begin{array}{c}\text { Day zero } \\
\text { averages } \\
(\mu \mathrm{g} \mathrm{chl} \text { a/cell })\end{array}$ & $\begin{array}{c}\text { Day } 20 \\
\text { averages } \\
(\mu \mathrm{g} \mathrm{chl} \text { a/cell })\end{array}$ & $\begin{array}{c}\text { Fractional } \\
\text { change, } \\
\text { day 20/day 0 }\end{array}$ \\
all cultures & $5.7^{*} 10^{-10}$ & $9.0^{*} 10^{-10}$ & 1.6 \\
all HiFe: & $8.6^{*} 10^{-10}$ & $9.1 * 10^{-10}$ & 1.1 \\
\cline { 2 - 4 } all LoFe & $2.9^{*} 10^{-10}$ & $9.0^{*} 10^{-10}$ & 3.1 \\
\cline { 2 - 4 } all preadapted constant & $5.4^{*} 10^{-10}$ & $1.0^{*} 10^{-09}$ & 1.9 \\
\cline { 2 - 4 } all preadapted fluctuating: & $6.1^{*} 10^{-10}$ & $7.7^{*} 10^{-10}$ & 1.3 \\
\cline { 2 - 4 } & & &
\end{tabular}




\section{Preadapted Constant 9/97 $\mu \mathrm{g} \mathrm{Chl} \mathrm{a} \mathrm{per} \mathrm{Cell}$}

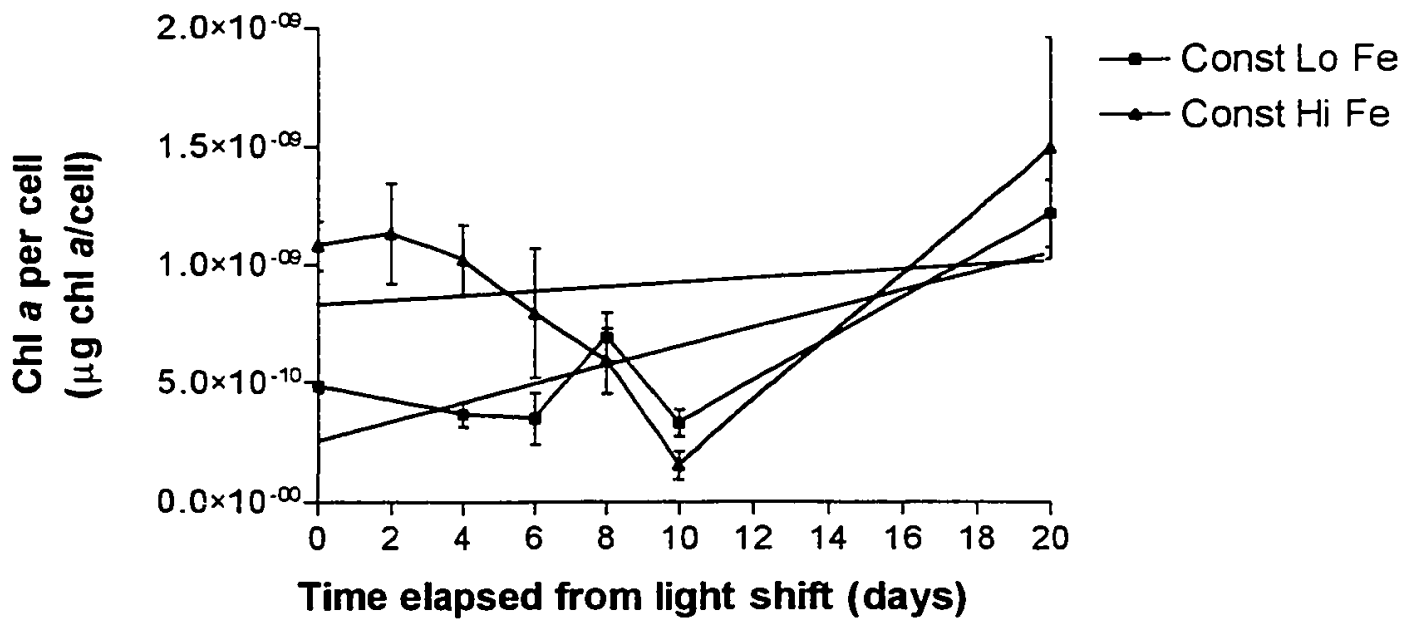

Figure 5.7: Plot of $\mu \mathrm{g} \mathrm{chl} \mathrm{a/cell} \mathrm{for} \mathrm{preadapted} \mathrm{constant} \mathrm{light} \mathrm{cultures.} \mathrm{ConhvLoFe}$ day 2 sample lost. Each point is a single spectrophotometric measurement of $\mathrm{Chl}$ a. Error bars show fractional errors derived from the cell count $95 \%$ confidence interval.

\section{Preadapted Fluctuating 9/97 $\mu \mathrm{g} \mathrm{Chl} \mathrm{a} \mathrm{per} \mathrm{Cell}$}

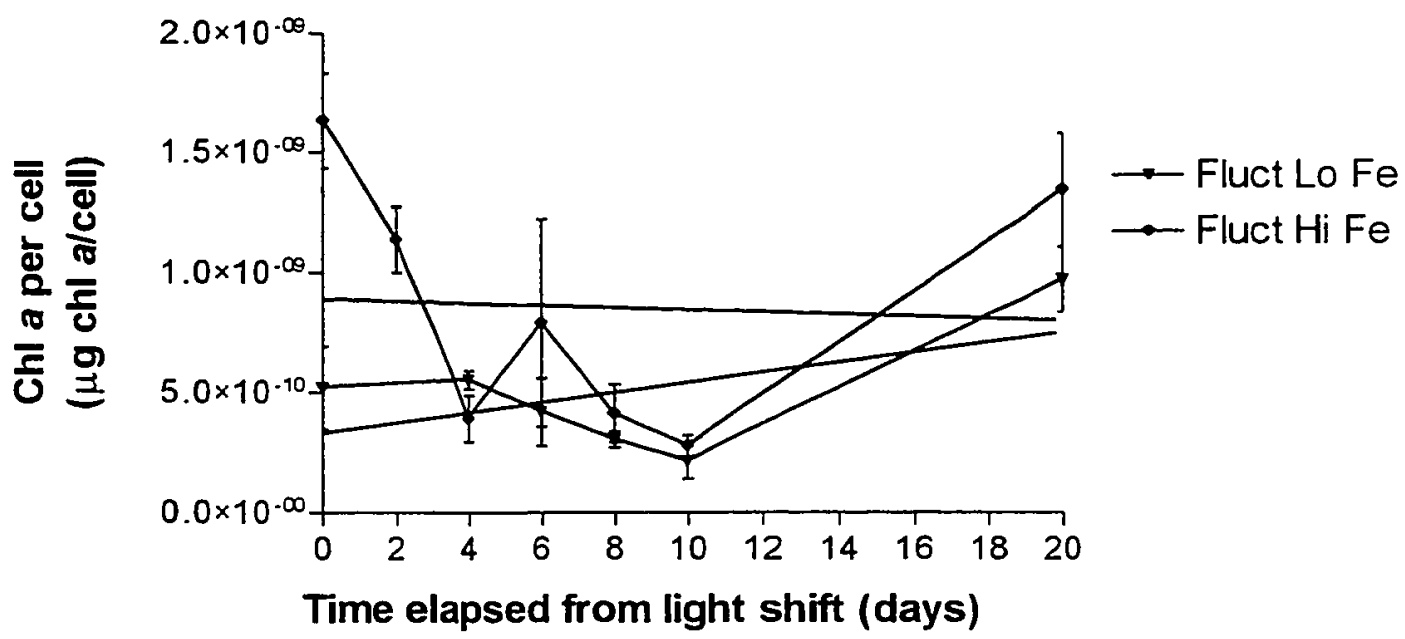

Figure 5.8: Plot of $\mu \mathrm{g}$ chl a/cell for preadapted fluctuating light cultures. FlucthvLoFe day 2 sample lost. Each point is a single spectrophotometric measurement of $\mathrm{Chl}$ a. Error bars show fractional errors derived from the cell count $95 \%$ confidence interval. 


\section{Protein per cell ( $\mu \mathrm{g}$ protein/cell)}

Protein concentrations per cell decreased in all cultures.

Table 5.9: Fractional changes in $\mu \mathrm{g}$ protein/cell for replicate cultures

$$
\text { Preadapted constant Preadapted fluctuating }
$$

Cultures: Const Lo Fe Const $\mathrm{Hi} \mathrm{Fe}$ Fluct Lo Fe Fluct $\mathrm{Hi} \mathrm{Fe}$

\begin{tabular}{r|c|c|c|c} 
Fractional 10 day change & -0.091 & 0.14 & 0.32 & 0.33 \\
\hline
\end{tabular}

The regression line for the constant low light cultures passed below the $\mathrm{x}$

axis at day 18 , leading to the negative value for the fractional change in these

cultures.

Table 5.10: Fractional changes in $\mu \mathrm{g}$ protein/cell for averaged fits

\begin{tabular}{|c|c|c|c|}
\hline & $\begin{array}{c}\text { Day zero } \\
\text { averages } \\
(\mu \mathrm{g} \text { protein/cell) }\end{array}$ & $\begin{array}{c}\text { Day } 20 \\
\text { averages } \\
(\mu \mathrm{g} \text { protein/cell })\end{array}$ & $\begin{array}{l}\text { Fractional } \\
\text { change, } \\
\text { day } 20 / \text { day } 0\end{array}$ \\
\hline \multirow{5}{*}{$\begin{array}{r}\text { all cultures: } \\
\text { all HiFe: } \\
\text { all LoFe: } \\
\text { readapted constant: } \\
\text { dapted fluctuating: }\end{array}$} & $6.5^{*} 10^{-7}$ & $1.3 * 10^{-7}$ & $\overline{0.19}$ \\
\hline & $8.5^{*} 10^{-7}$ & $2.0^{*} 10^{-7}$ & 0.23 \\
\hline & $4.5^{*} 10^{-7}$ & $5.4 * 10^{-8}$ & 0.12 \\
\hline & $6.6 * 10^{-7}$ & $4.2 * 10^{-8}$ & 0.063 \\
\hline & $6.4 * 10^{-7}$ & $2.1 * 10^{-7}$ & 0.33 \\
\hline
\end{tabular}


Preadapted Constant 9/97

$\mu \mathrm{g}$ Protein per Cell

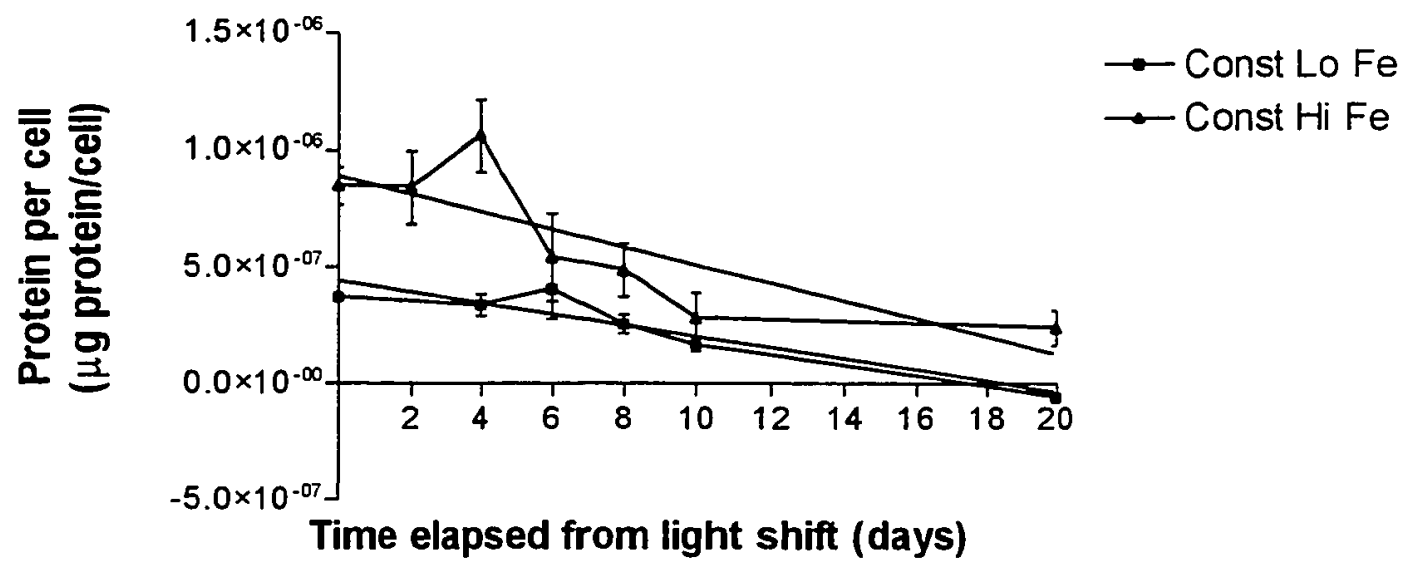

Figure 5.9: Plot of $\mu \mathrm{g}$ protein/cell for preadapted constant light cultures. ConsthvLoFe day 2 sample lost. Each data point is the averages of two bicinchoninic acid assays from single filters divided by the cell count. Error bars show fractional errors derived from the cell count $95 \%$ confidence interval.

\section{Preadapted Fluctuating 9/97 $\mu \mathrm{g}$ Protein per Cell}

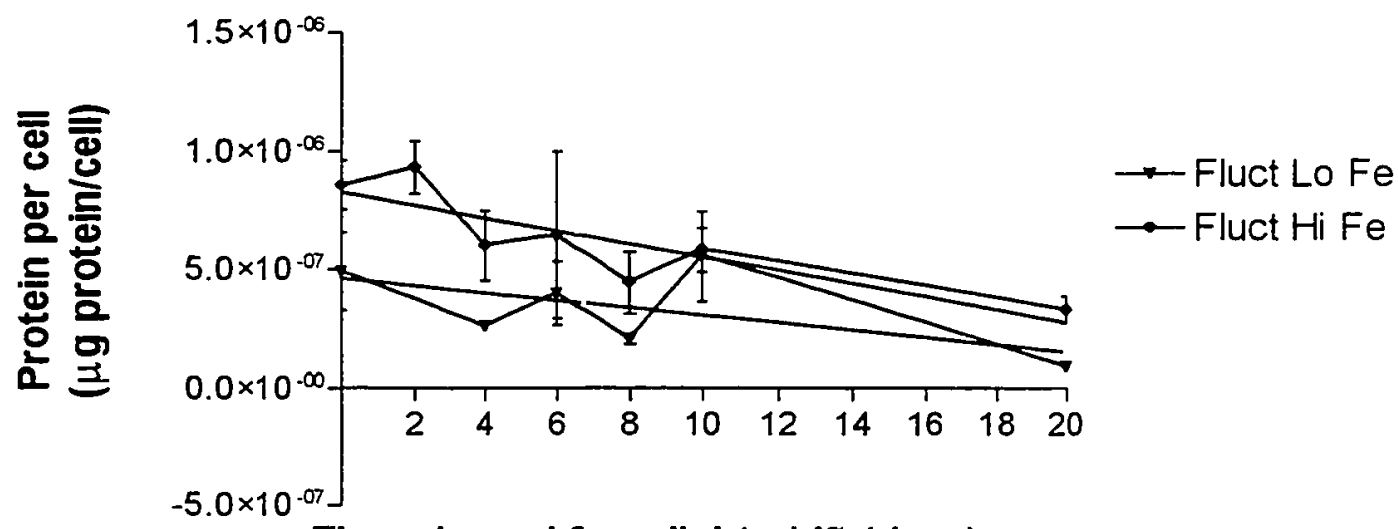

Time elapsed from light shift (days)

Figure 5.10: Plot of $\mu \mathrm{g}$ protein/cell for preadapted fluctuating light cultures.

FlucthvLoFe day 2 sample lost. Each data point is the averages of two bicinchoninic acid assays from single filters divided by the cell count. Error bars show fractional errors derived from the cell count $95 \%$ confidence interval. 


\section{Chlorophyll $a$ per protein ( $\mu \mathrm{g}$ chl $a / \mu g$ protein)}

Small initial values of chlorophyll $a$ concentration per protein concentration (Chl $a /$ protein), especially for the preadapted constant light high iron culture, lead to large fractional changes in chl $a$ /protein. Decreases in chlorophyll $a$ concentrations by day 20 lead to large final values.

The preadapted constant light low iron cultures had a negative value for protein on day 20. Combined with a unusually large chlorophyll $a$ value this produced an outlying chl $a /$ protein value of -0.020 for the day 20 point. This point was excluded to produce these fractional change tables and plots. After excluding the outlying day 20 point, the slope of the preadapted constant light low iron cultures falls within 1 standard deviation of the average slope of all four culture groups; before excluding the outlier, the slope of the preadapted constant light low iron cultures was nearly 2 standard deviations from the average. 
Table 5.11: Fractional changes in $\mu \mathrm{g} \mathrm{chl} a / \mu \mathrm{g}$ protein for replicate cultures Preadapted constant Preadapted fluctuating Cultures: Const Lo Fe Const Hi Fe Fluct Lo Fe Fluct Hi Fe Fractional 10 day change 3.3 of $\mu \mathrm{g} \mathrm{chl} \mathrm{a} / \mu \mathrm{g}$ protein: 28 $-8.2$ 4.7

The negative values of the preadapted fluctuating low iron culture is caused by the early part of the regression line, which is less than zero until day 2 .

Table 5.12: Fractional changes in $\mu \mathrm{g} \mathrm{chl} a / \mu \mathrm{g}$ protein for averaged fits

\begin{tabular}{r|ccc|} 
& $\begin{array}{c}\text { Day zero } \\
\text { averages } \\
\text { (chl a/protein) } \\
\mathbf{w} / \mathbf{w}\end{array}$ & $\begin{array}{c}\text { Day } 20 \\
\text { averages } \\
(\mathrm{chl} \text { a/protein) } \\
\mathbf{w} / \mathbf{w}\end{array}$ & $\begin{array}{c}\text { Fractional } \\
\text { change, } \\
\text { day } 20 / \text { day } 0\end{array}$ \\
\cline { 2 - 4 } $\begin{array}{r}\text { all cultures } \\
\text { all HiFe }\end{array}$ & $1.8^{*} 10^{-4}$ & $5.0^{*} 10^{-3}$ & 27 \\
\cline { 2 - 4 } all LoFe & $4.1^{*} 10^{-4}$ & $4.0^{*} 10^{-3}$ & 9.6 \\
\cline { 2 - 4 } & $-5.1^{*} 10^{-5}$ & $6.0^{*} 10^{-3}$ & -118 \\
\hline all preadapted constant & $5.7^{*} 10^{-4}$ & $4.1^{*} 10^{-3}$ & 7.1 \\
\cline { 2 - 4 } all preadapted fluctuating & $-2.1^{*} 10^{-4}$ & $5.9^{*} 10^{-3}$ & -28 \\
\cline { 2 - 4 }
\end{tabular}

The negative values are caused by the early part of the regression line of the preadapted fluctuating low iron culture, which is less than zero until day 2 . 


\section{Preadapt Constant Light 9/97 \\ Chlorophyll a per protein by weight}

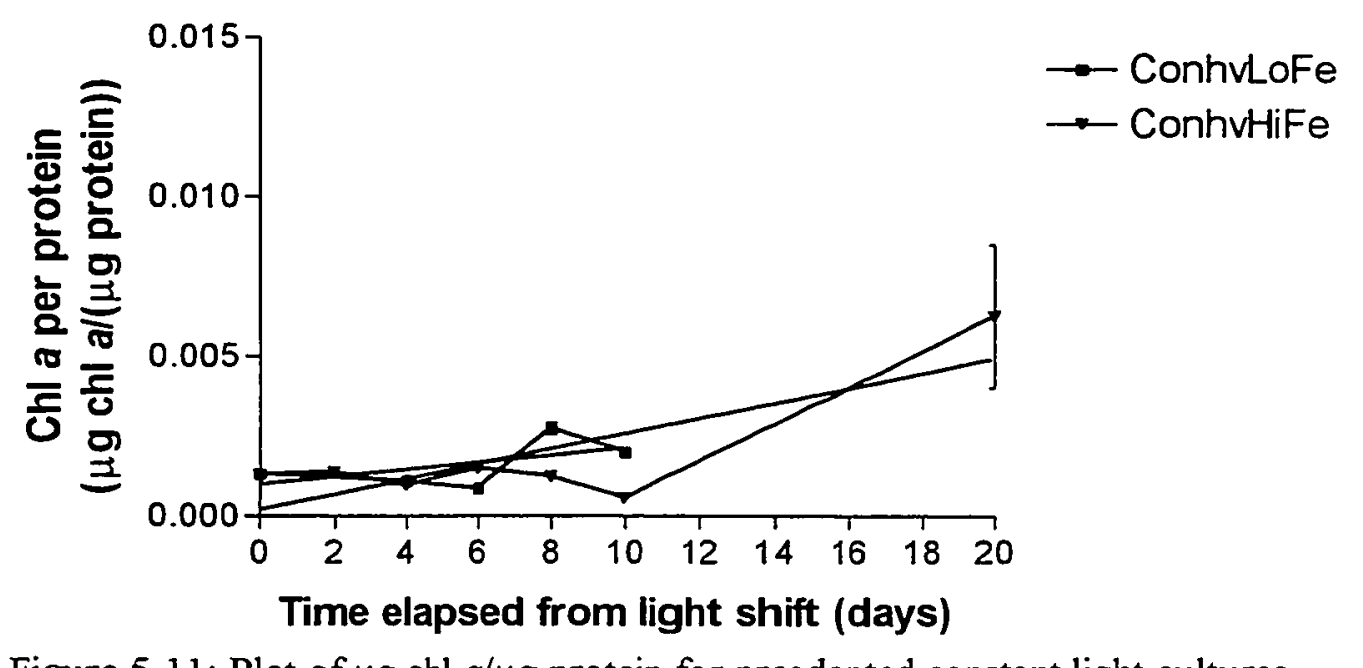

Figure 5.11: Plot of $\mu \mathrm{g} \mathrm{chl} a / \mu \mathrm{g}$ protein for preadapted constant light cultures. ConsthvLoFe day 2 sample lost. Each data point is a chlorophyll measurement divided by the average of replicate protein assays from a single protein filter. Error bars span the fractional ranges of the protein assays.

\section{Preadapt Fluctuating Light 9/97 Chlorophyll a per protein by weight}

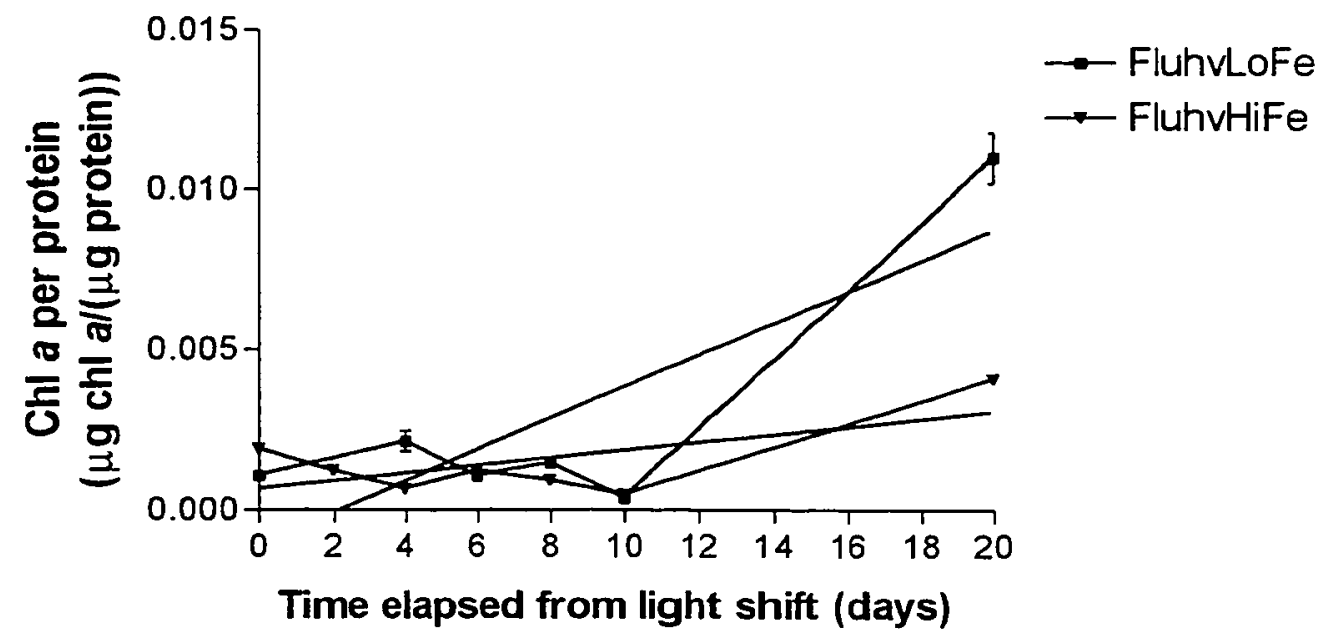

Figure 5.12: Plot of $\mu \mathrm{g}$ chl $a / \mu \mathrm{g}$ protein for preadapted fluctuating light cultures. FlucthvLoFe day 2 sample lost. Each data point is a chlorophyll measurement divided by the average of replicate protein assays from a single protein filter. Error bars span the fractional ranges of the protein assays. 


\section{Alpha normalized per cell}

Table 5.13: Fractional changes in alpha/cell for replicate cultures Preadapted constant Preadapted fluctuating Cultures: Const Lo Fe Const Hi Fe Fluct Lo Fe Fluct $\mathrm{Hi} \mathrm{Fe}$

Fractional 10 day change 0.89 of alpha/cell:

0.085

1.55

0.21

Table 5.14: Fractional changes in alpha/cell for averaged fits

\begin{tabular}{r|rrr|} 
& $\begin{array}{c}\text { Day zero } \\
\text { averages } \\
\text { (alpha/cell) }\end{array}$ & $\begin{array}{c}\text { Day } 20 \\
\text { averages } \\
\text { (alpha/cell) }\end{array}$ & $\begin{array}{c}\text { Fractional } \\
\text { change, } \\
\text { day 20/day 0 }\end{array}$ \\
\cline { 2 - 4 } all cultures & $3.6 * 10^{-7}$ & $1.3 * 10^{-7}$ & 0.37 \\
all HiFe: & $5.6 * 10^{-7}$ & $8.2 * 10^{-8}$ & 0.15 \\
\cline { 2 - 4 } all LoFe: & $1.6 * 10^{-7}$ & $1.9 * 10^{-7}$ & 1.20 \\
\cline { 2 - 4 } all preadapted constant: & $3.7 * 10^{-7}$ & $9.9 * 10^{-8}$ & 0.27 \\
\cline { 2 - 4 } all preadapted fluctuating: & $3.6^{*} 10^{-7}$ & $1.7 * 10^{-7}$ & 0.48 \\
\cline { 2 - 4 } & & &
\end{tabular}




\section{Low Fe 9/97 Alpha \\ (14C uptake per cell)}

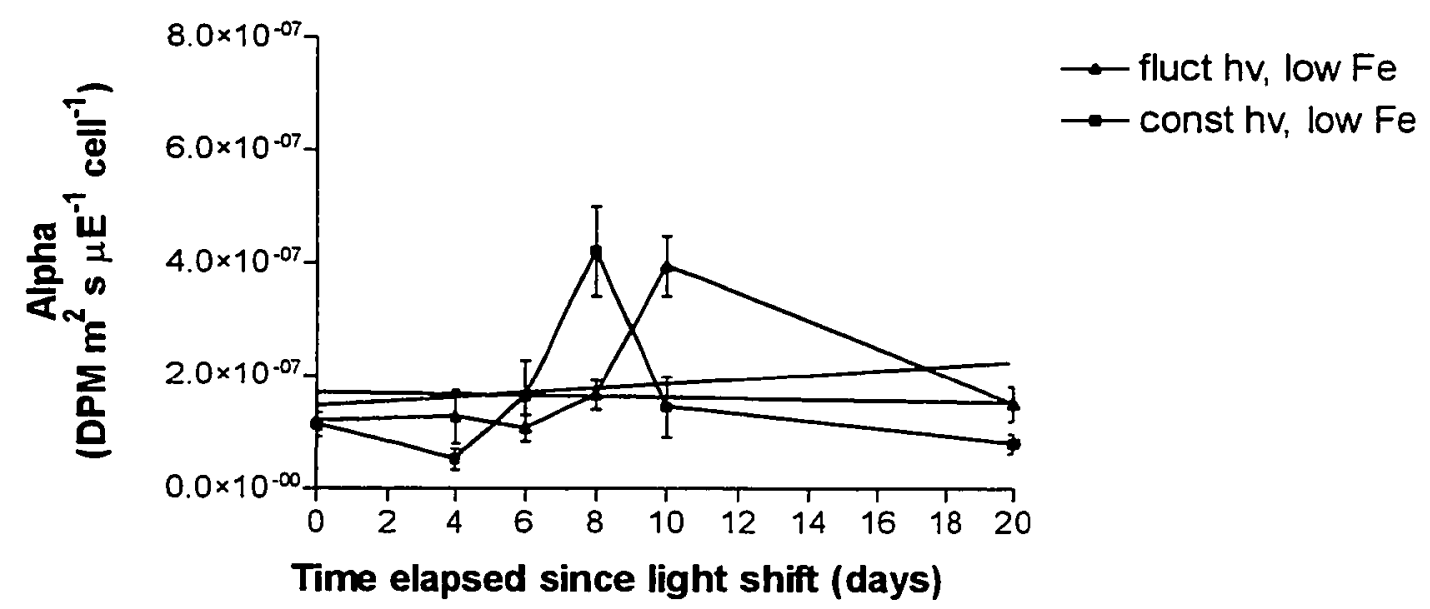

Figure 5.13: Plot of alpha/cell for preadapted constant light cultures. FlucthvLoFe and ConstloFe day 2 samples lost. Error bars indicate the standard error in the initial slope of each $\mathbf{P}$ vs. I curve.

High Fe 9/97 Alpha

(14C uptake per cell)

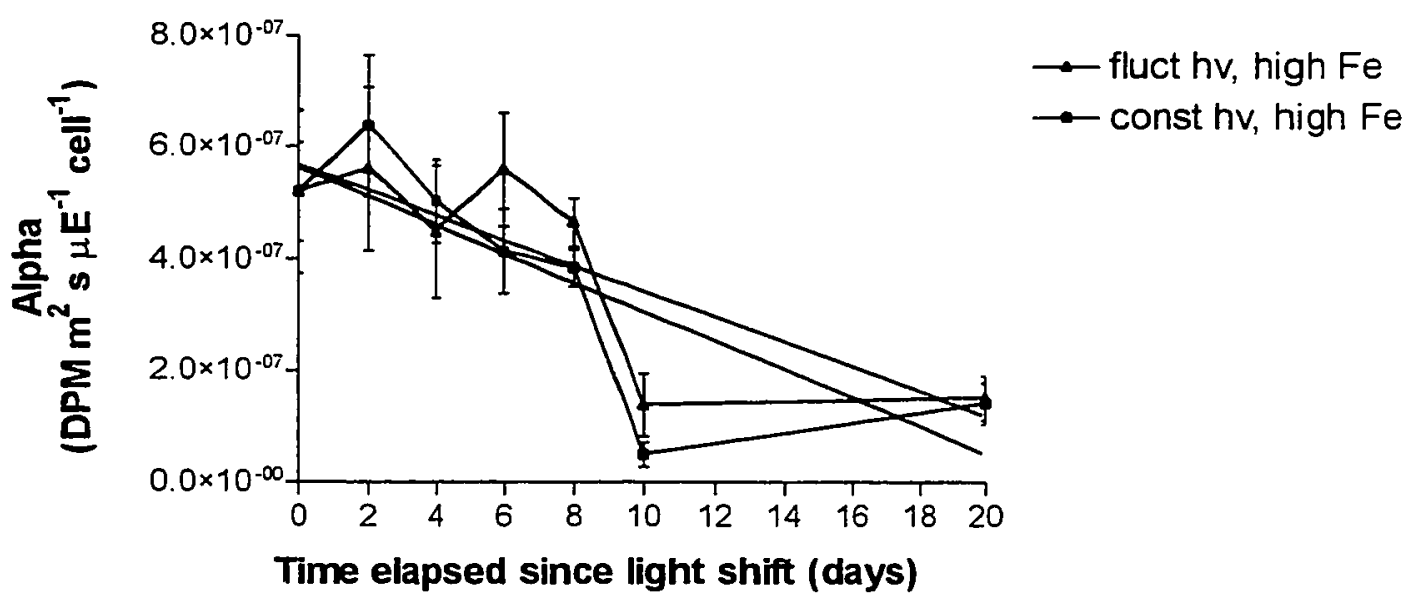

Figure 5.14: Plot of alpha/cell for preadapted fluctuating light cultures. Error bars indicate the standard error in the initial slope of each $\mathrm{P}$ vs. I curve. 


\section{Low Fe 9/97 Alpha \\ (14C uptake per $\mu \mathrm{g} \mathrm{Chl} \mathrm{a)}$}

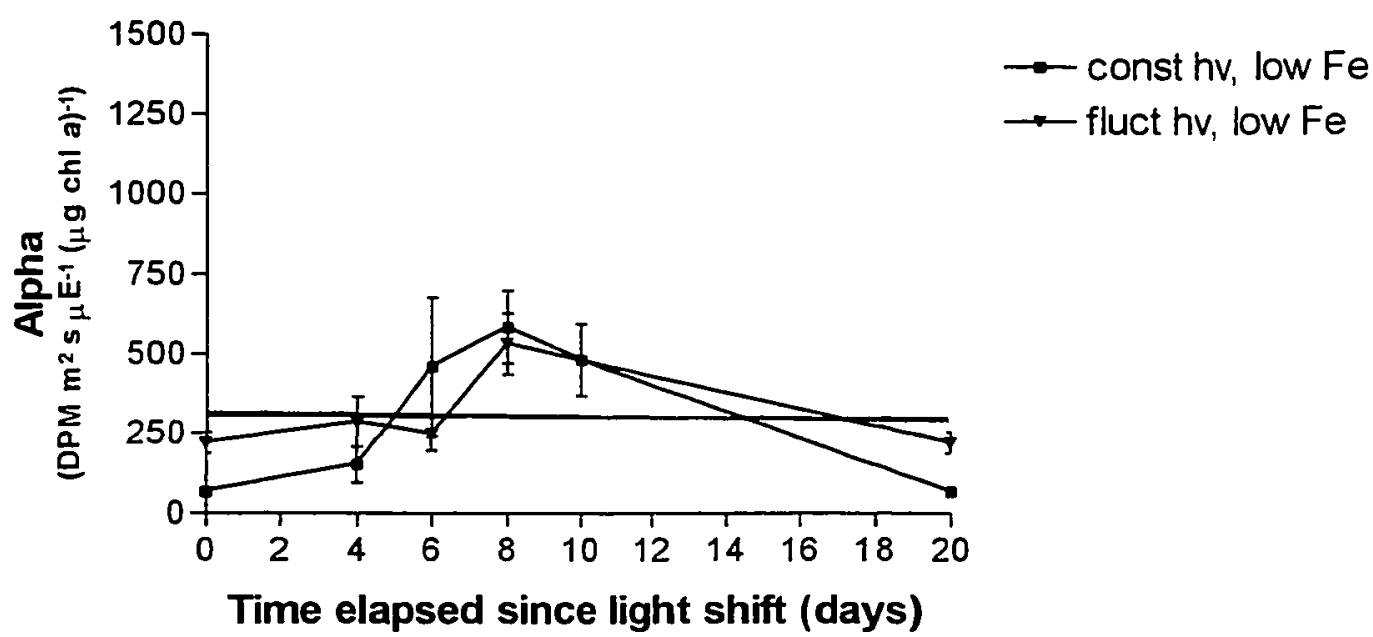

Figure 5.15: Plot of alpha/ $\mu$ g chl $a$ for preadapted constant light cultures.

FlucthvLoFe and ConstloFe day 2 samples lost. Day 10: value of 2235 excluded from fluctuating light low iron data set. Error bars indicate the standard error in the initial slope of each P vs. I curve.

High Fe 9/97 Alpha (14C uptake per $\mu \mathrm{g} \mathrm{chl} \mathrm{a)}$

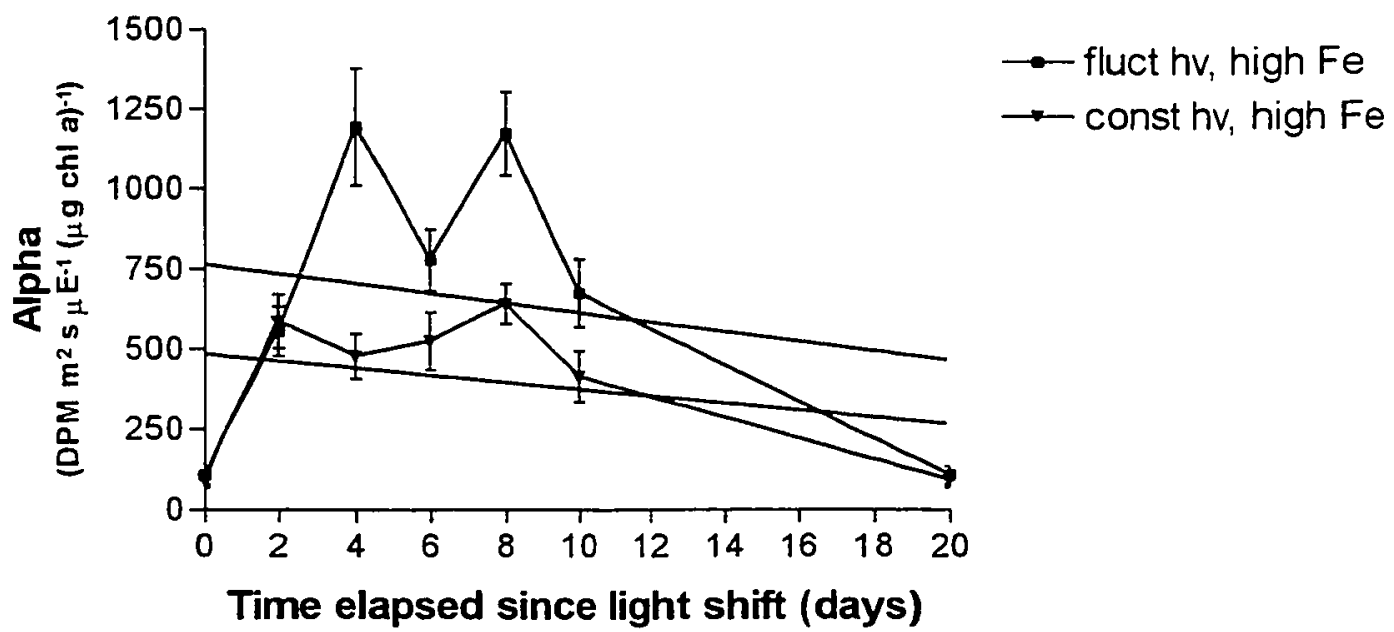

Figure 5.16: Plot of alpha/ $\mu \mathrm{g}$ chl $a$ for preadapted fluctuating light cultures. Error bars indicate the standard error in the initial slope of each P vs. I curve. 


\section{Alpha normalized per $\mu \mathrm{g}$ protein}

Table 5.17: Fractional changes in alpha/ $\mu \mathrm{g}$ protein for replicate cultures Preadapted constant Preadapted fluctuating Cultures: Const Lo Fe Const Hi Fe Fluct Lo Fe Fluct Hi Fe

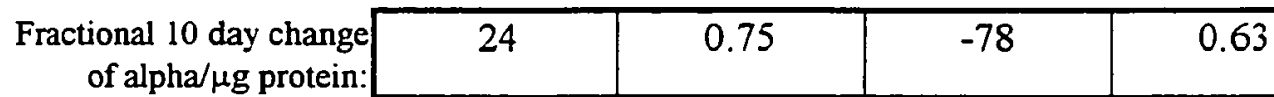

The regression for the preadapted fluctuating low iron culture starts just below zero on day zero, causing the negative sign of the fractional change. The difference between the very small magnitude initial value and the large day 20 value causes the many-fold increase.

Table 5.18: Fractional changes in alpha/ $\mu \mathrm{g}$ protein for averaged fits

\begin{tabular}{|c|c|c|c|}
\hline & 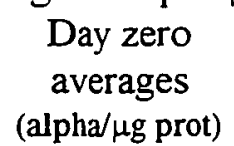 & $\begin{array}{c}\text { Day } 20 \\
\text { averages } \\
\text { (alpha/ } \mu \text { g prot) }\end{array}$ & $\begin{array}{c}\text { Fractional } \\
\text { change, } \\
\text { day } 20 / \text { day } 0\end{array}$ \\
\hline \multirow{5}{*}{$\begin{array}{r}\text { all cultures: } \\
\text { all HiFe: } \\
\text { all LoFe: } \\
\text { pted constant: }\end{array}$} & 0.38 & 1.3 & 3.5 \\
\hline & 0.73 & 0.50 & 0.68 \\
\hline & 0.031 & 2.2 & 70 \\
\hline & 0.38 & 1.3 & 3.6 \\
\hline & 0.39 & 1.4 & 3.5 \\
\hline
\end{tabular}

The very low day zero value for the low iron cultures led to the large magnitude of the fractional change for those cultures. 


\section{Low Fe 9/97 Alpha \\ (14C uptake per $\mu \mathrm{g}$ protein)}

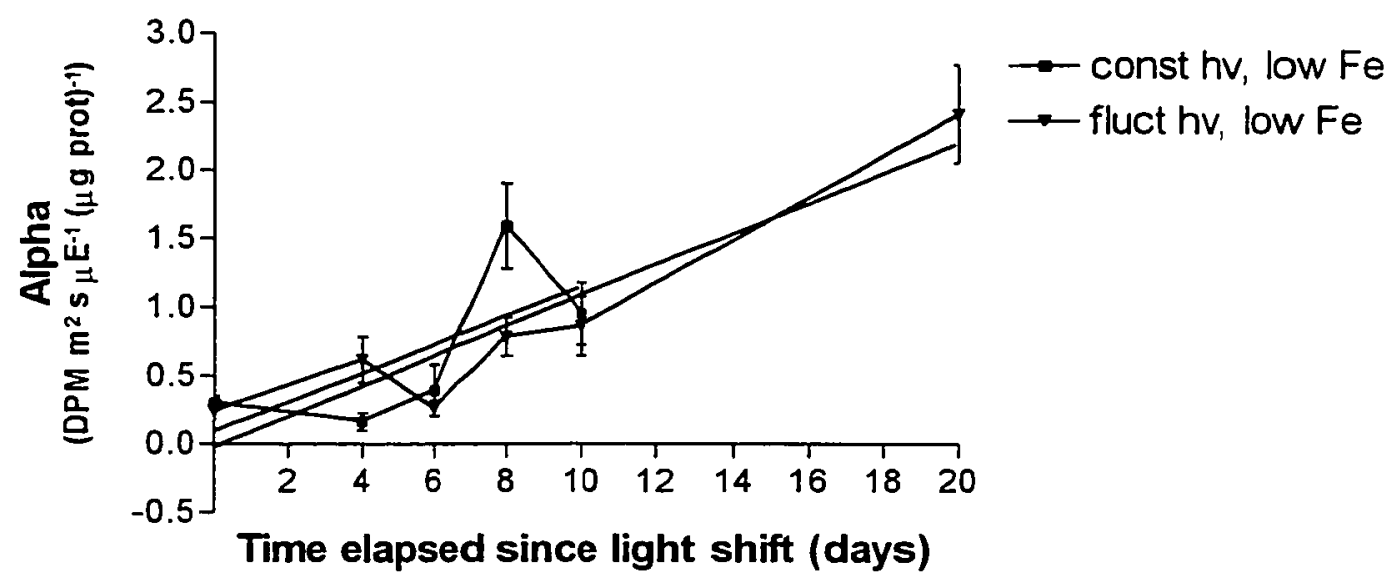

Figure 5.17: Plot of alpha/ $\mu$ g protein for preadapted constant light cultures.

FlucthvLoFe and ConstLoFe day 2 samples lost. The protein assay for the day 20, preadapted constant illumination low iron culture yielded a negative protein concentration; this erroneous data point was rejected. Error bars indicate the standard error in the initial slope of each $P$ vs. I curve.

\section{High Fe 9/97 Alpha \\ (14C uptake per $\mu \mathrm{g}$ protein)}

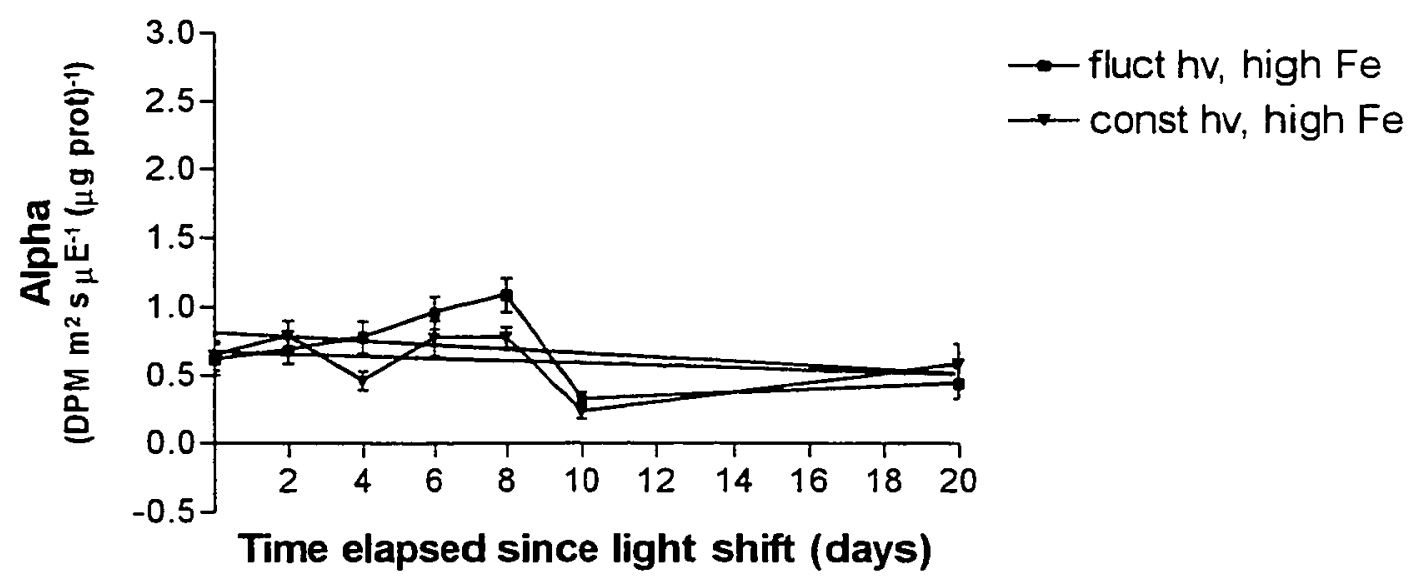

Figure 5.18: Plot of alpha/ $\mu \mathrm{g}$ protein for preadapted fluctuating light cultures. Error bars indicate the standard error in the initial slope of each $P$ vs. I curve. 


\section{Conclusion}

This experiment was designed to explore whether preadaptation to a fluctuating light regime gave an advantage to a cell transferred to a different fluctuating light regime compared to a cell adapted to constant light and transferred to the same second light regime. One of the challenges of algal physiology is that when representing processes normalized to some cell parameter, the selection of the normalizing parameter can obscure or illuminate useful information from the experiments. In a dynamic system given time for adaptation, almost all algal species will change their cell size and relative cell composition. This makes the choice of the normalizing parameter crucial. The two most common parameters used are cell number per $\mathrm{ml}$ and chlorophyll concentration. Cell number is a difficult parameter to measure accurately and reproducibly. The most direct method, microscopic cell counting, is a very tedious and lengthy process. Chlorophyll is also a problematic choice. It is easy to measure but chlorophyll concentrations change rapidly with all major parameters of the culture or environment such as light intensity, nitrogen sources and iron concentration. Growth rate can affect the chlorophyll concentration. These data show the value of including protein measurements. Protein is very conserved in these studies. For example, alpha on a per cell (Figure 5.13) and per chlorophyll (figure 5.15) basis both show a shift after day 10 whereas alpha per protein (figure 5.17) shows a continuous increase. Normalization of measurements against all three of these 
parameters provide different pictures of the specific change in alpha that help us understand the overall cell response.

Cell counts of cultures preadapted to constant light decreased to about a third of their initial levels while cell counts of fluctuating cultures remained fairly constant. Preadapted constant light low iron cultures lost more chlorophyll $a$ and more protein than preadapted fluctuating light cultures. Plots of alpha do not consistently show higher alphas for either preadapted constant light or preadapted fluctuating light cultures, regardless of whether alpha is calculated per cell, per $\mu \mathrm{g}$ protein or per $\mu \mathrm{g}$ chlorophyll $a$.

Based on the decreased cell counts, protein and chlorophyll $a$ in preadapted constant light cultures compared with preadapted fluctuating light cultures, preadaptation to a fluctuating light regime appears to confer some advantage over cells preadapted to a constant light regime when the cells are transferred to a different fluctuating light regime. However, the peak irradiance of the fluctuating preadaptation regime matched the peak irradiance of the final fluctuating regime, while the peak irradiance of the constant light regime was half of the peak irradiance of the final fluctuating regime. It may be the physiological demand of adapting to a new peak light intensity that decreased the cell counts, protein and chlorophyll $a$ in preadapted constant light cultures 
Another question this experiment addressed was whether populations in culture would undergo phenotypic adaptation to a light regime while remaining genetically similar to their initial state, or if instead photoadaptation in Synechococcus is a process of genotypic adaptation, driven by selection rather than physiological adjustment. While this experiment could not answer this question definitely, had the final state of the cultures after 20 days been considerably different that would support the hypothesis that adaptation was occurring by selection (genotypic adaptation) rather than physiological adjustments (phenotypic adaptation). Since the final alphas of all cultures were similar, the physiological adjustment model (phenotypic adaptation) remains a reasonable hypothesis.

The work described in this dissertation includes measurements of Synechococcus WH7803 cultures shifted from constant dim to constant brighter light, constant brighter to constant dim light, constant light to $48 \mathrm{~h}$ light: $48 \mathrm{~h}$ dark, and $12 \mathrm{~h}$ light: $12 \mathrm{~h}$ dark to $48 \mathrm{~h}$ light: $48 \mathrm{~h}$ dark. All of these experiments were performed in parallel on higher iron and lower iron cultures. Photoadaptation rates were compared between higher and lower iron cultures for various culture parameters, including: alpha per cell, alpha per $\mu \mathrm{g}$ chlorophyll $a$, alpha per $\mu \mathrm{g}$ protein, $\mu \mathrm{g}$ chlorophyll $a$ per cell, $\mu \mathrm{g}$ protein per cell, and $\mu \mathrm{g}$ chlorophyll $a$ per $\mu \mathrm{g}$ protein. Continuous dynamic models were constructed to help choose light 
regimes for the fluctuating light experiments and to extend the cellular composition models of Brian Shuter (Shuter 1979) to predict the time course of photoadaptation.

Marine Synechococcus fix inorganic carbon into biomolecules and are important participants in the global carbon cycle, especially in the central oceans. Understanding their response to iron concentrations and light variation will help us to build more accurate models of the marine component of the global carbon cycle. Comparison of the response of iron-replete and iron-limited Synechococcus to environmental fluctuations will help us understand the contribution of iron to the biochemical efficiency of the cells and to their biogeochemical activity. 


\section{References}

Andréasson, L. -E. \& Vänngård, T. (1988). Electron Transport in Photosystems I and II. Ann. Rev. Plant Physiol. Plant Mol. Biol., 39, 379-411.

Barlow, R. G. and R. S. Alberte (1985). Photosynthetic Characteristics of

Phycoerythrin-Containing Marine Synechococcus spp. Marine Biology, 86, 63-74.

Binder, Andres. (1982). Respiration and Photosynthesis in Energy-Transducing Membranes of Cyanobacteria. Journal of Bioenergetics and Biomembranes, 14(4/5), 271-286.

Bovy, A., Vrieze, G. D., Lugones, L., Horssen, P. V., Berg, C. V. D., Borrias, M., \& Weisbeek, P. (1993). Iron-Dependent Stability of the Ferredoxin 1 Transcripts from the Cyanobacterial Strains Synechococcus Species PCC 7942 and Anabaena Species PCC 7937. Molecular Microbiology, 7(3), 429-439.

Buma, A. G. J., Noordeloos, A. A. M., \& Larsen, J. (1993). Strategies and Kinetics of Photoacclimation in Three Antarctic Nanophytoflagellates. Journal of Phycology, 29, 407-417.

Burnap, R. L., Troyan, T., \& Sherman, L. A. (1993). The Highly Abundant Chlorophyll-Protein Complex of Iron-Deficiant Synechococcus sp. PCC7942 (CP43') is Encoded by the isiA Gene. Plant Physiology, 103, 893-902.

Custanza, Robert. (1987). Simulation Modeling on the Macintosh using STELLA. BioScience, 37(2), 129-132.

Cramer, W. A., Soriano, G. M., Ponomarev, M., Huang, D., Zhang, H., Martinez, S. E., \& Smith, J. L. (1996). Some New Structural Aspects and Old Controversies Concerning the Cytochrome $b_{6} f$ Complex of Oxygenic Photosynthesis. Annu. Rev. Plant Physiol. Plant Mol. Biol. 47, 477-508

Cullen, J. J., Yang, X., \& Macintyre, H. L. (1992). Nutrient Limitation of Marine Photosynthesis. In P. G. Falkowski (Ed.), Primary Productivity and Biogeochemical Cycles in the Sea (pp. 69-88). New York: Plenum Press.

de Lorimer, R. M., Smith, R. L., \& S. Edward Stevens, J. (1992). Regulation of Phycobilisome Structure and Gene Expression by Light Intensity. Plant Physiology, 98, 1003-1010. 
ExPASy for coproporphyrinogen oxidase: "http://expasy.hcuge.ch/htbin/getenzyme-entry?1.3.3.3". (1998). ExPASy World Wide Web (WWW) molecular biology server of the Swiss Institute of Bioinformatics.

Fasham, M. J. R., Ducklow, H. W., \& McKelvie, S. M. (1990). A Nitrogen-Based Model of Plankton Dynamics in the Oceanic Mixed Layer. Journal of Marine Research, 48, 591-639.

GenomeNet WWW server. Protochlorophyllide reductase (EC 1.3.1.33) iron-sulfur ATP-binding protein chlL - red alga (Porphyra purpurea) chloroplast. (1998). http://www.genome.ad.jp/dbget-bin/www_bget?pir+S73108. GenomeNet WWW server at Kanehisa laboratory in the Institute for Chemical Research, Kyoto University.

Glazer, Alexander N. and Melis, Anastasios. (1987). Photochemical Reaction Centers: Structure, Organization, and Function. Ann. Rev. Plant Physiol., 38, 11 45

Glover, Hilary E. (1985). The Physiology and Ecology of the Marine Cyanobacterial Genus Synechococcus. In Holger W. Jannasch and Peter LeB. Williams (Eds.), Advances in Aquatic Microbiology (pp. 49-107). Academic Press Inc., London.

Golbeck, John H. (1992). Structure and Function of Photosystem I. Annu. Rev. Plant Physiol. Plant Mol. Biol., 43, 293-324

Green, B. R. \& Durnford, D. G. (1996). The Chlorophyll-Carotenoid Proteins of Oxygenic Photosynthesis. Annu Rev. Plant Physiol. Mol. Biol., 47, 685-714

Guikema, J. A., \& Sherman, L. A. (1983). Organization and Function of Chlorophyll in Membranes of Cyanobacteria during Iron Starvation. Plant Physiol, $73,250-256$

Henley, W. J. (1993). Measurement and Interpretation of Photosynthetic LightResponse Curves in Algae in the Context of Photoinhibition and Diel Changes. J. Phycol., 29, 729-739.

Hsu, W. P., \& Miller, G. W. (1970). Coproporphyrinogenase in Tobacco. Biochem. J., $117,215-220$. 
Hutber, G. N., Hutson, K. G., \& Rodgers, L. J. (1977). Effect of Iron Deficiency on Levels of Two Ferredoxins and Flavodoxin in a Cyanobacterium. FEMS Microbiology Letters, 1, 193-196.

Kana, T. M., \& Glibert, P. M. (1987a). Effect of Irradiances up to $2000 \mu \mathrm{E} \mathrm{m}^{-2} \mathrm{~s}^{-2}$ on marine Synechococcus WH7803 -- I. Growth, Pigmentation, and Cell Composition. Deep-Sea Research, 34(4), 479-495.

Kana, T. M., \& Glibert, P. M. (1987b). Effect of Irradiances up to $2000 \mu \mathrm{E} \mathrm{m}^{-2} \mathrm{~s}^{-}$ 2 on marine Synechococcus WH7803 -- II. Photosynthetic Responses and Mechanisms. Deep-Sea Research, 34(4), 497-516.

Keller, M. D., Bellows, W. K., \& Guillard, R. R. L. (1988). Microwave Treatment for Sterilization of Phytoplankton Culture Media. J. Exp. Mar. Biol. Ecol., 117, 279-283.

Langmuir, Irving. (1938). Surface Motion of Water Induced by Wind. Science, 87(2250), 119-123

Leonhardt, K., \& Straus, N. A. (1992). An Iron Stress Operon Involved in Photosynthetic Electron Transport in the Marine Cyanobacterium Synechococcus sp. PCC 7002. Journal of General Microbiology, 138, 1613-1621.

Lewis, Marlon R. \& Smith, John C. (1983). A Small Volume, Short-incubationtime Method for Measurement of Photosynthesis as a Function of Incident Irradiance. Mar. Ecol. Prog. Ser., 13, 99-102.

Marra, J. (1980). Time Course of Light Intensity Adaptation in a Marine Diatom. Marine Biology Letters, 1, 175-183.

Morel, F. M. M., \& J.G.Rueter (1979). Aquil: a Chemically Defined Phytoplankton Culture Medium for Trace Metal Studies. J. Phycol., 15, 135-141.

Pakrasi, H. B., Goldenberg, A., \& Sherman, L. A. (1985). Membrane Development in the Cyanobacterium, Anacystis nidulans, During Recovery from Iron Starvation. Plant Physiol., 79, 290-295.

Pardo, M. B., Gómez-Moreno, C., Peleato, M. L. (1990). Effect of Iron Deficiency on Ferredoxin Levels in Anabaena variabilis PCC 6309. Arch. Microbiol. 153, 528-530 
Parsons, T. R., Maita, Y., \& Lalli, C. M. (1984). A Manual of Chemical and Biological Methods for Seawater Analysis (1st ed.). Oxford: Pergamon Press.

Platt, T., Gallegos, C. L., \& Harrison, W. G. (1980). Photoinhibition of Photosynthesis in Natural Assemblages of Marine Phytoplankton. Journal of Marine Research, 38(4), 687-701.

Prezelin, B. B., \& Matlick, H. A. (1980). Time-Course of Photoadaptation in the Photosynthesis-Irradiance Relationship of a Dinoflagellate Exhibiting Photosynthetic Periodicity. Marine Biology, 58, 85-96.

Reithman, H., Bullerjahn, G., Reddy, K. J., \& Sherman, L. A. (1988). Regulation of Cyanobacterial Pigment-Protein Composition and Organization by Environmental Factors. Photosynthesis Research, 18, 133-161.

Richardson, K.,Beardall, J., \& Raven, J. A. (1983). Adaptation of Unicellular Algae to Irradiance: an Analysis of Strategies. New Phytologist, 93, 157-191.

Rippka, Rosmarie, Deruelles, Josette, Waterbury, John B., Herdman, Michael, \& Stanier, Roger Y. (1979). Generic Assignments, Strain Histories and Properties of Pure Cultures of Cyanobacteria. Journal of General Microbiology, 11 1, 1-61

Rueter, J. G., \& Unsworth, N. L. (1991). Response of Marine Synechococcus (Cyanophyceae) Cultures to Iron Nutrition. J. Phycol., 27, 173-178.

Sampson, Guy, Herbert, Stephen K., Fork, David C., Laudenbach, David E (1994). Acclimation of the Photosynthetic Apparatus to Growth Irradiance in a Mutant Strain of Synechococcus Lacking Iron Superoxide Dismutase. Plant Physiol., 105, 287-294.

Sandmann, Gerhard, \& Malkin, Richard. (1983). Iron-Sulfur Centers and Activities of the Photosynthetic Electron Transport Chain in Iron-Deficient Cultures of the Blue-Green Alga Aphanocapsa. Plant Physiol., 73, 724-728.

Shuter, B. (1979). A Model of Physiological Adaptation in Unicellular Algae. J. Theor. Biol., 78, 519-552.

Spiller, S. C.,Castelfranco, A. M., \& Castelfranco, P. A. (1982). Effects of Iron and Oxygen on Chlorophyll Biosynthesis 1. in vivo Observations on Iron and OxygenDeficiant Plants. Plant Physiology, 69, 107-111. 
Steeman Neilson, E. (1952). The Use of Radioactive Carbon $\left({ }^{14} \mathrm{C}\right)$ for Measuring Organic Production in the Sea. J. Cons. Perm. Int. Explor. Mer, 18, 117-140.

Sweney, Beatrice M. and Borgese, M. Beatriz. (1989). A Circadian Rhythm in Cell Division in a Prokaryote, the Cyanobacterium Synechococcus WH7803.

Tandeau de Marsac, N. , \& Houmard, J. (1993). Adaptation of Cyanobacteria to Environmental Stimuli: New Steps Towards Molecular Mechanisms. FEMS Microbiology Reviews, 104, 119-190.

Unsworth, Nancy W. (1992). The Physiology and Molecular Biology of Iron Nutrition for Cyanobacteria. Master's Thesis, Portland State University. 


\section{Appendix A}

Increased light $\mathrm{P}$ vs. I curves, fit by Platt's equation as described in materials and methods. P vs. I curves for the increased light experiment have been normalized per cell, per $\mu \mathrm{g}$ chlorophyll $a$ and per $\mu \mathrm{g}$ protein and will follow in that order.

- radioactivity per cell (DPM/cell)

- radioactivity per chlorophyll (DPM/ $/ \mathrm{g} \operatorname{chl} a)$

- radioactivity/protein (DPM/ $\mu \mathrm{g}$ protein)

Error bars show standard deviations of four data points: two scintillations each from two replicate cultures. 
P vs. I, LohvLoFe d-2 1/24/97

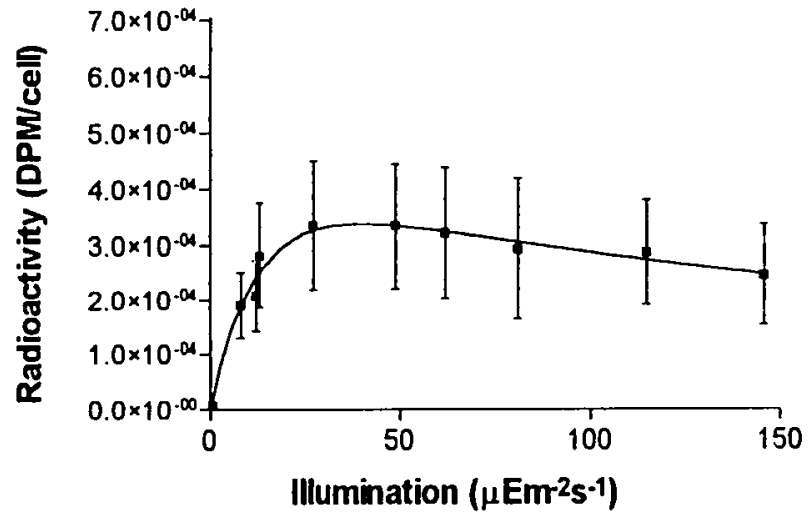

P vs. I, LohvHiFe d-2 1/24/97

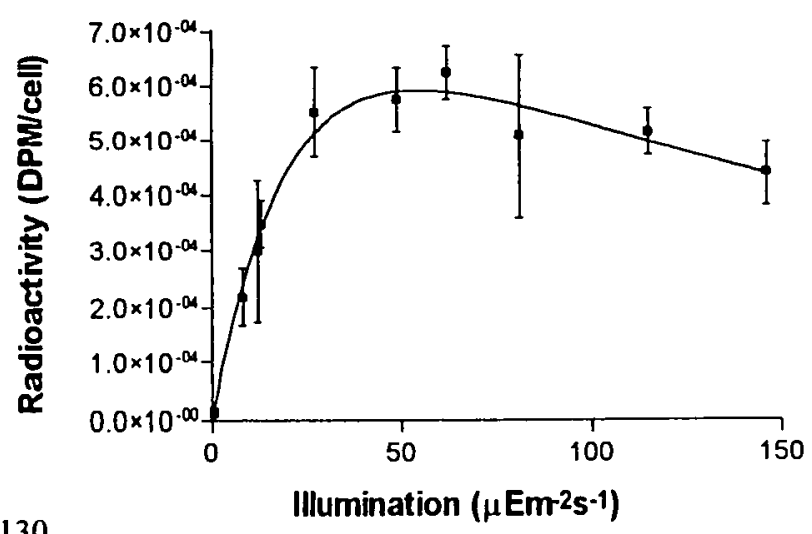

P vs. I, HihvLoFe d-2 1/24/97

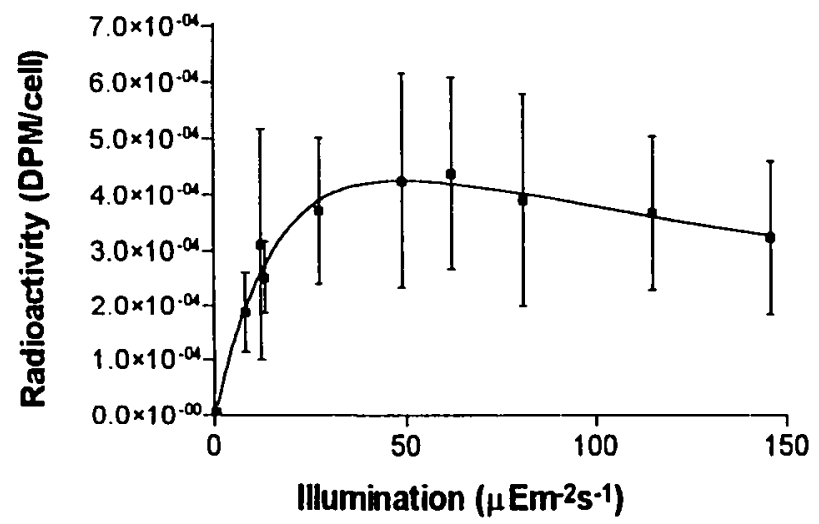

P vs. I, HihvHiFe d-2 1/24/97

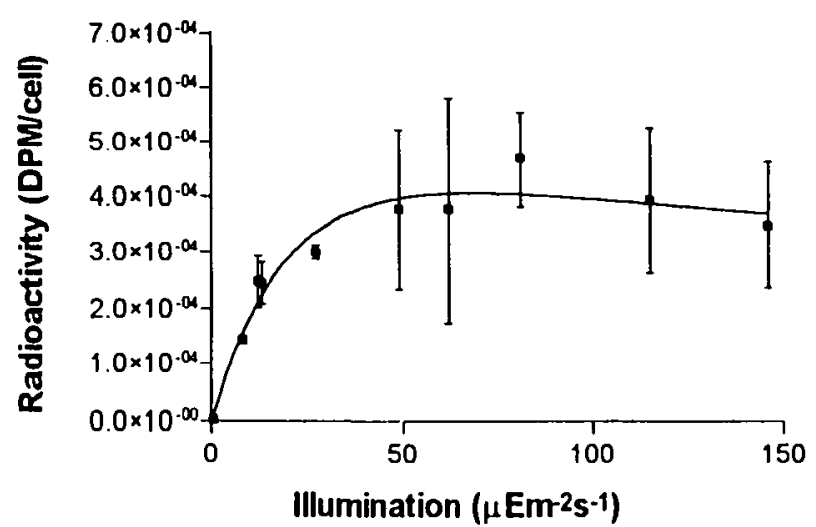

Averages of four scintillations plotted, two from each replicate culture. Error bars are standard deviation. 

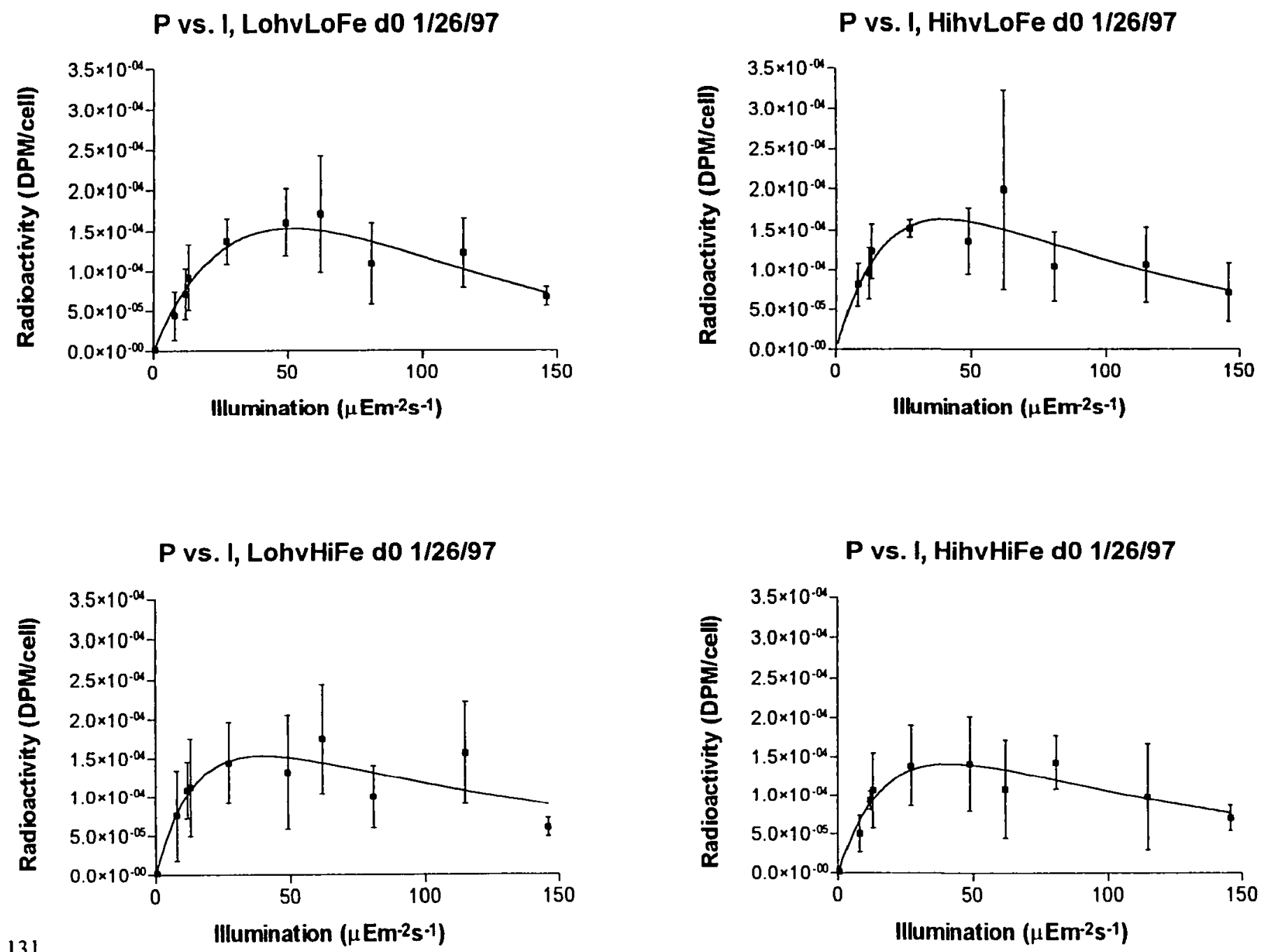

Averages of four scintillations plotted, two from each replicate culture. Error bars are standard deviation. 
P vs. I, LohvLoFe d2 1/28/97

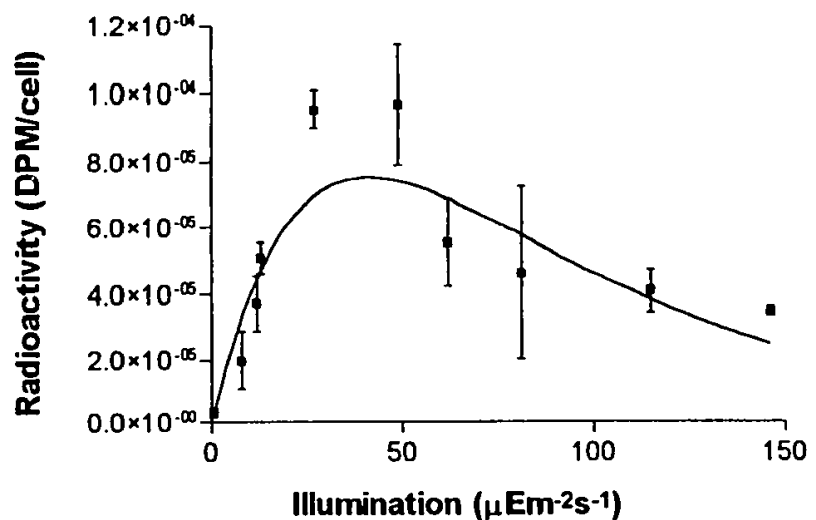

P vs. I, LohvHiFe d2 1/28/97

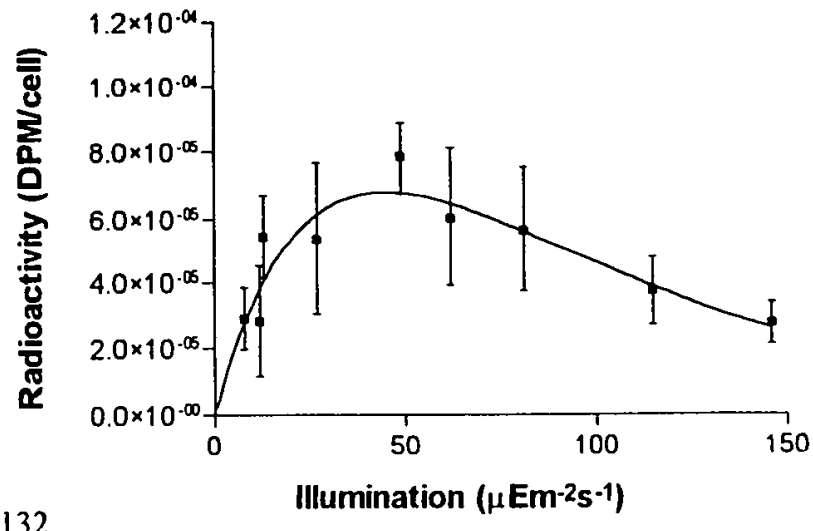

P vs. I, HihvLoFe d2 1/28/97

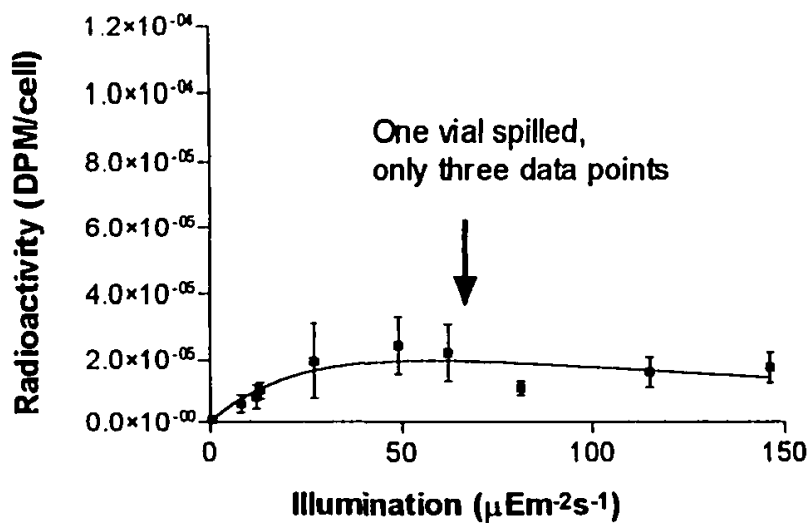

P vs. I, HihvHiFe d2 1/28/97

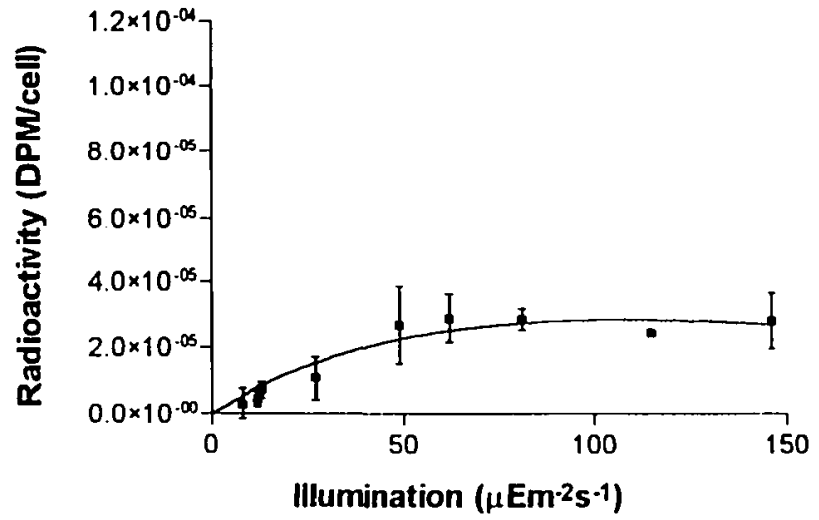

Averages of four scintillations plotted, two from each replicate culture. Error bars are standard deviation. 
P vs. I, LohvLoFe d4 1/30/97

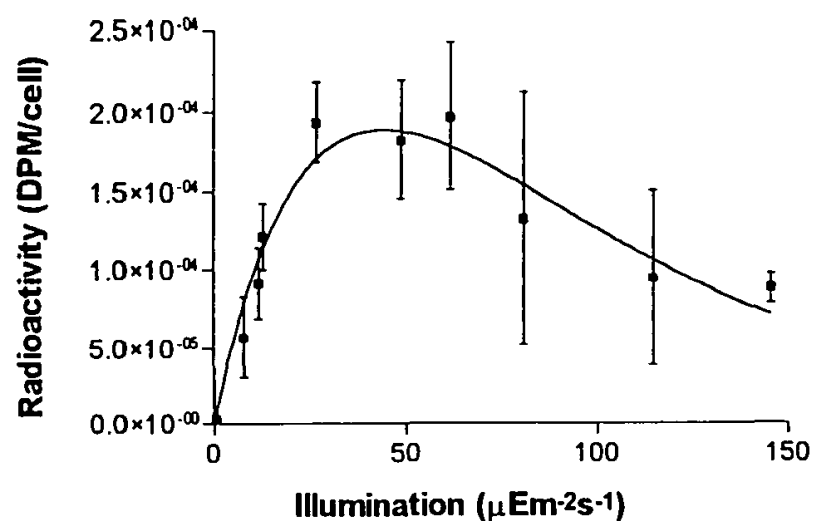

P vs. I, LohvHiFe d4 1/30/97

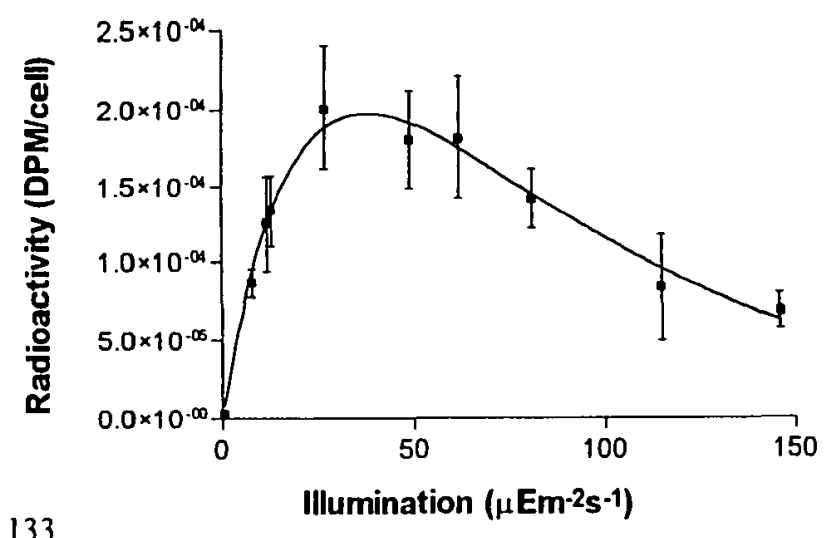

P vs. I, HihvLoFe d4 1/30/97

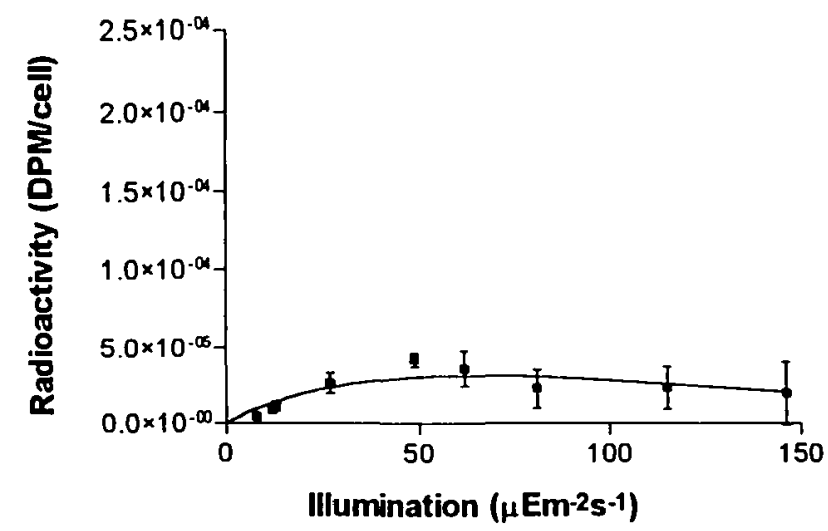

P vs. I, HihvHiFe d4 1/30/97

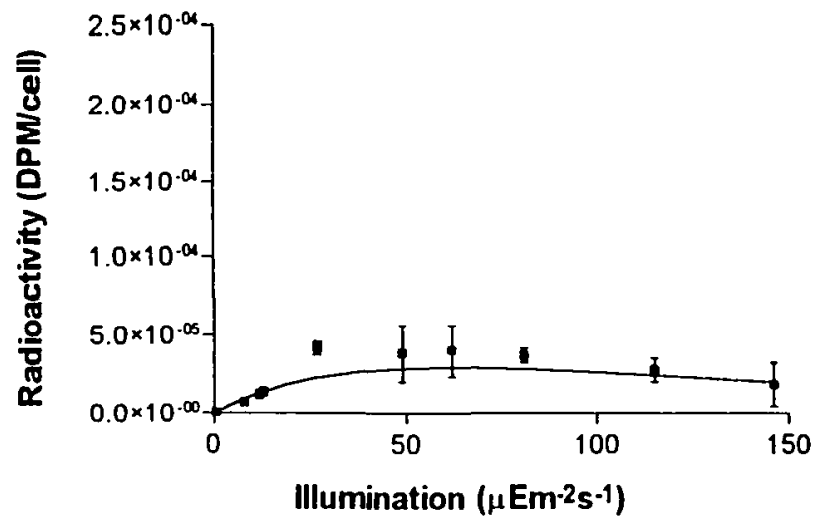

Averages of four scintillations plotted, two from each replicate culture. Error bars are standard deviation. 
P vs. I, LohvLoFe d6 2/1/97

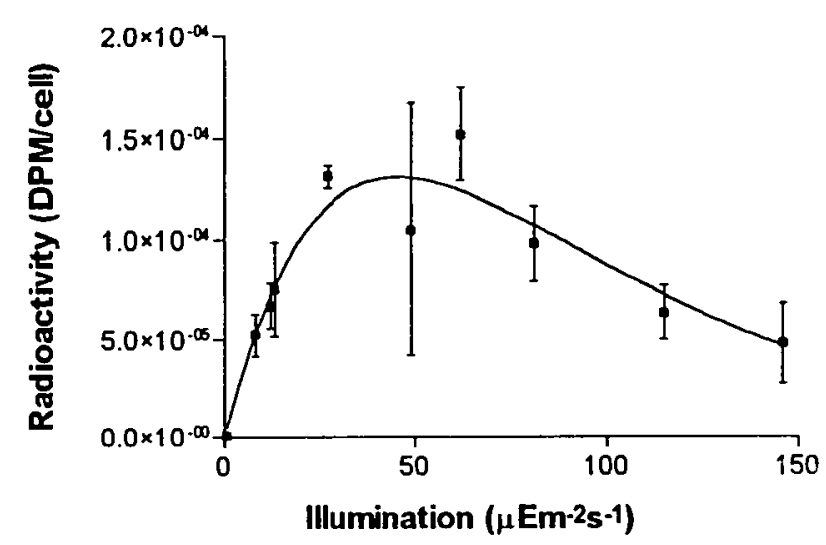

P vs. I, LohvHiFe d6 2/1/97

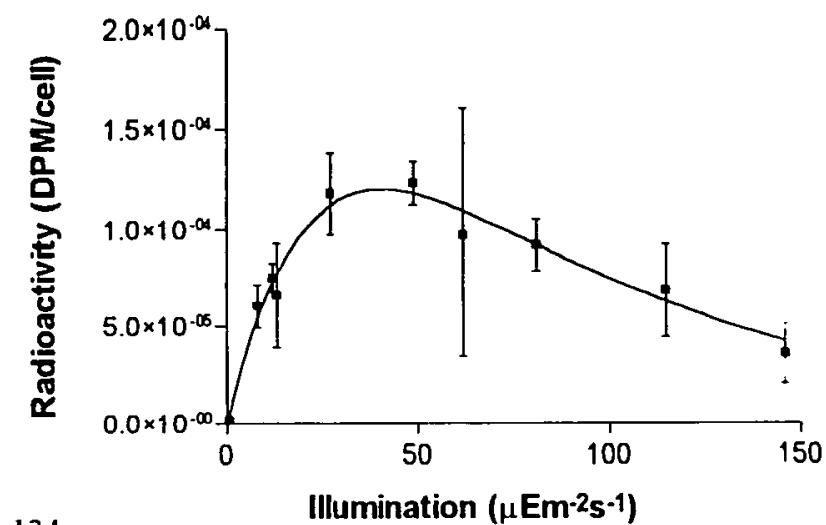

P vs. I, HihvLoFe d6 2/1/97

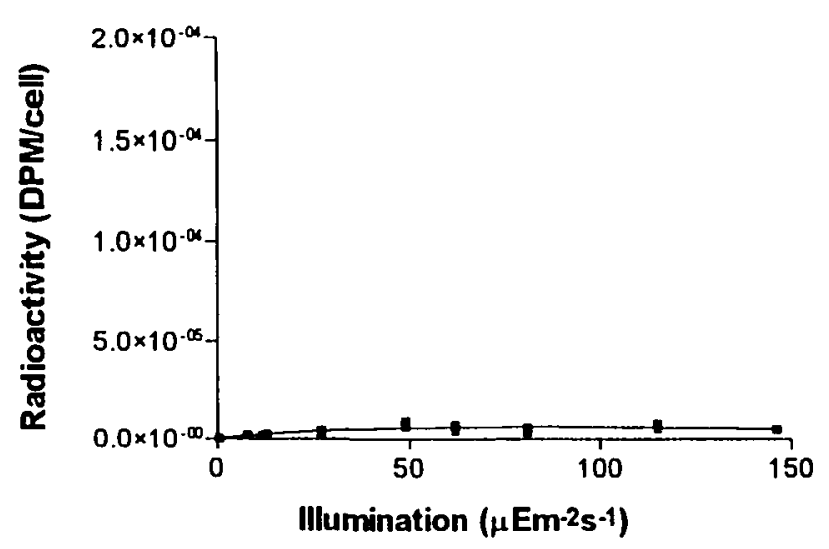

P vs. I, HihvHiFe d6 2/1/97

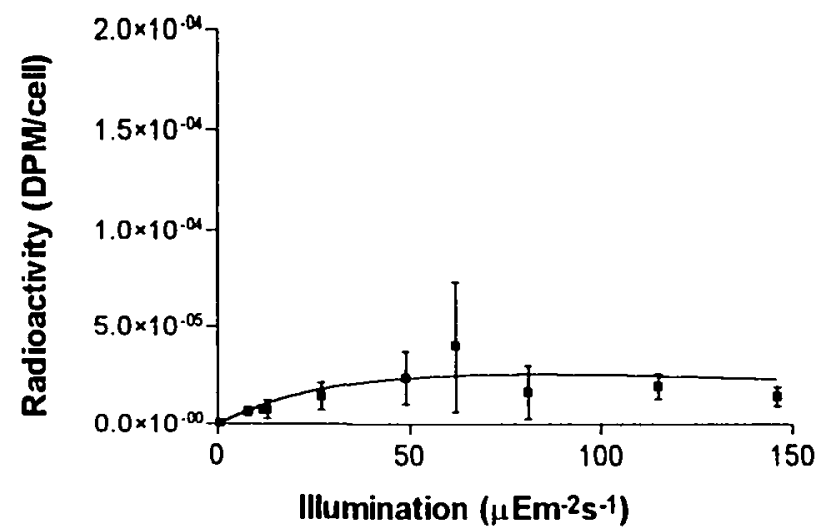

Averages of four scintillations plotted, two from each replicate culture. Error bars are standard deviation. 

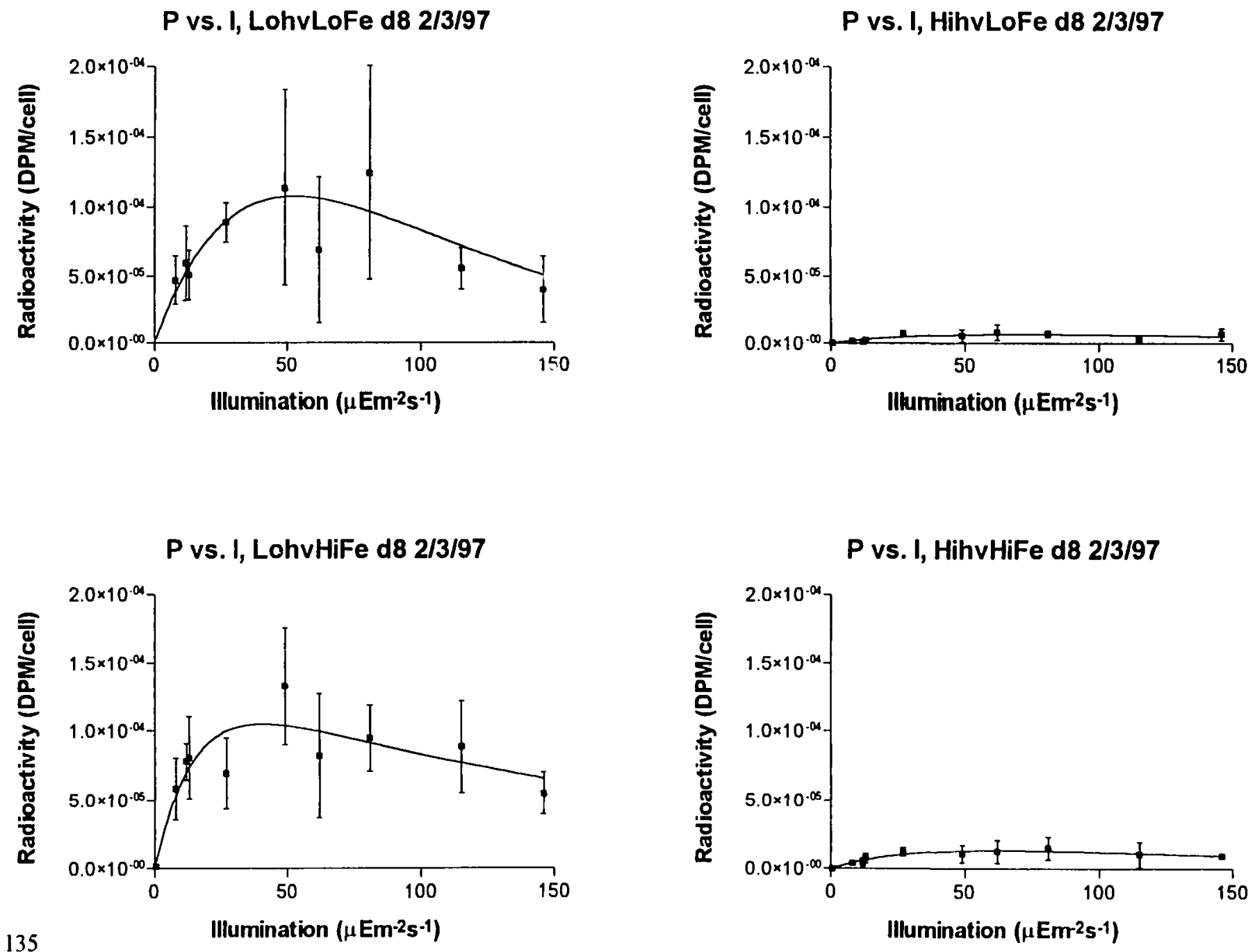

Averages of four scintillations plotted, two from each replicate culture. Error bars are standard deviation. 
P vs. I, LohvLoFe d10 2/5/97

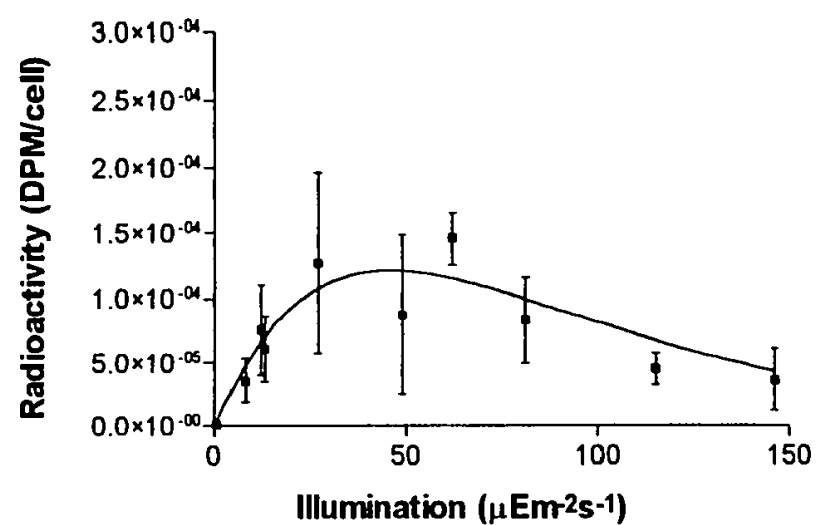

P vs. I, LohvHiFe d10 2/5/97

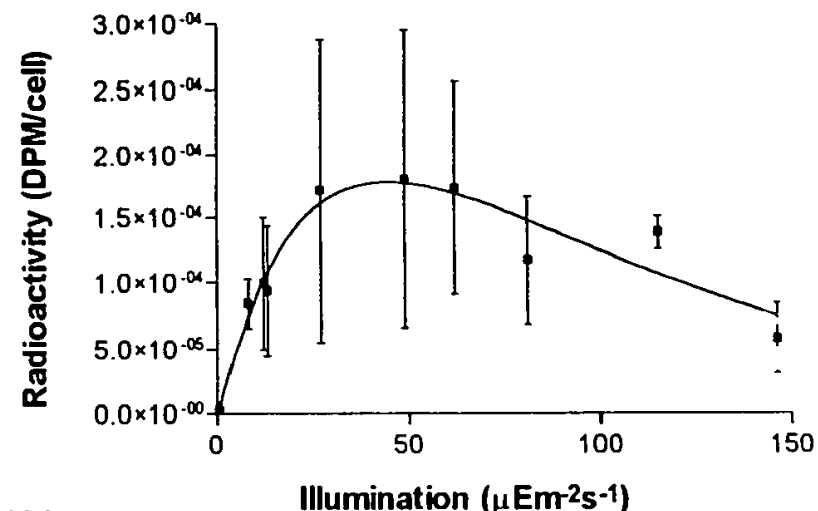

P vs. I, HihvLoFe d10 2/5/97

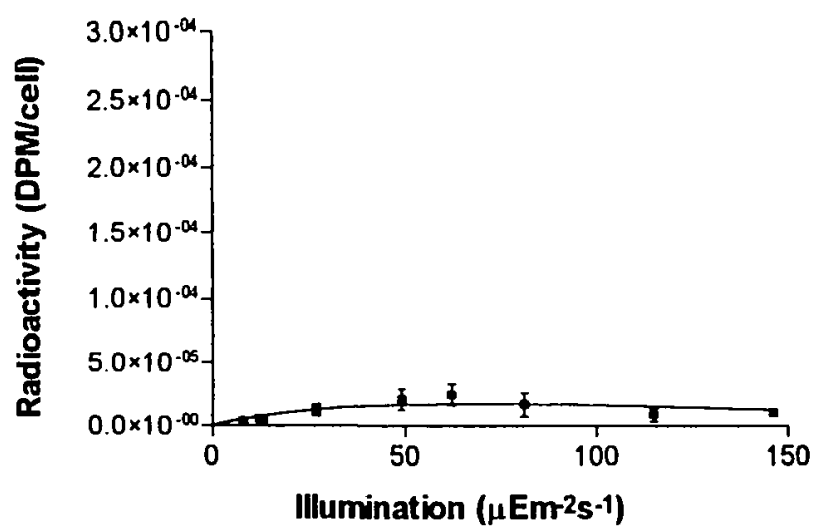

P vs. I, HihvHiFe d10 2/5/97

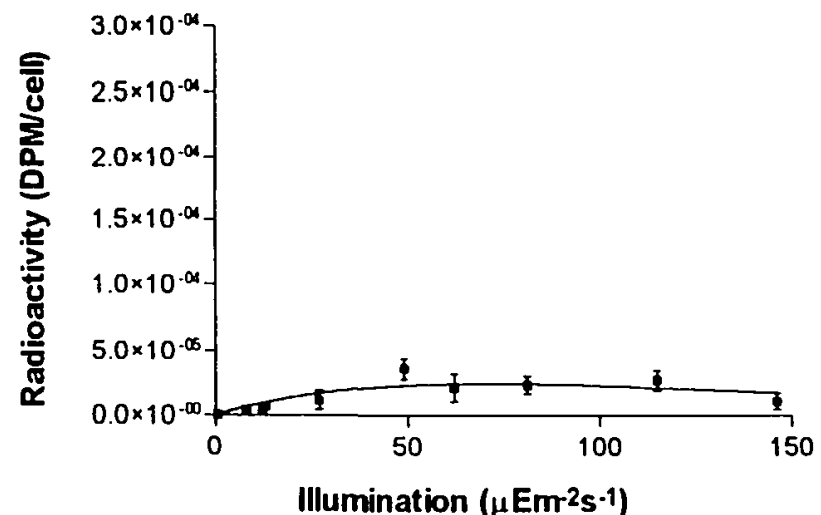

Averages of four scintillations plotted, two from each replicate culture. Error bars are standard deviation. 
P vs. I, LohvLoFe d-2 1/24/97

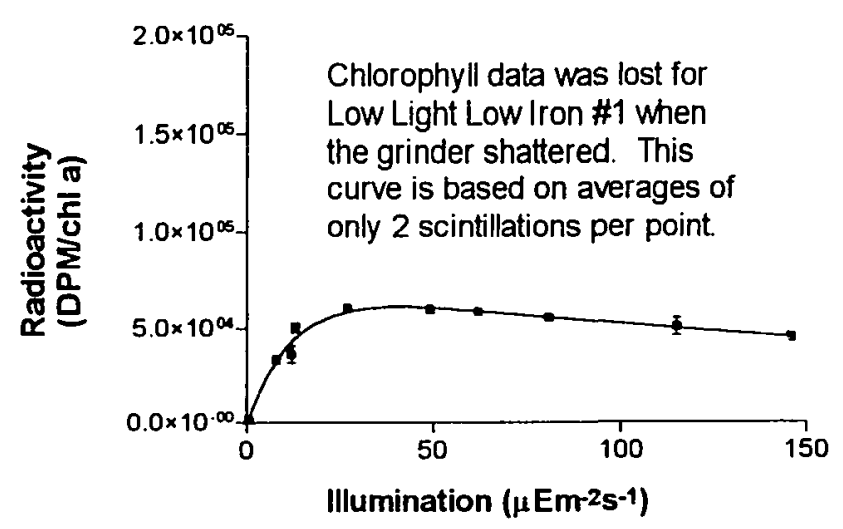

P vs. I, LohvHiFe d-2 1/24/97

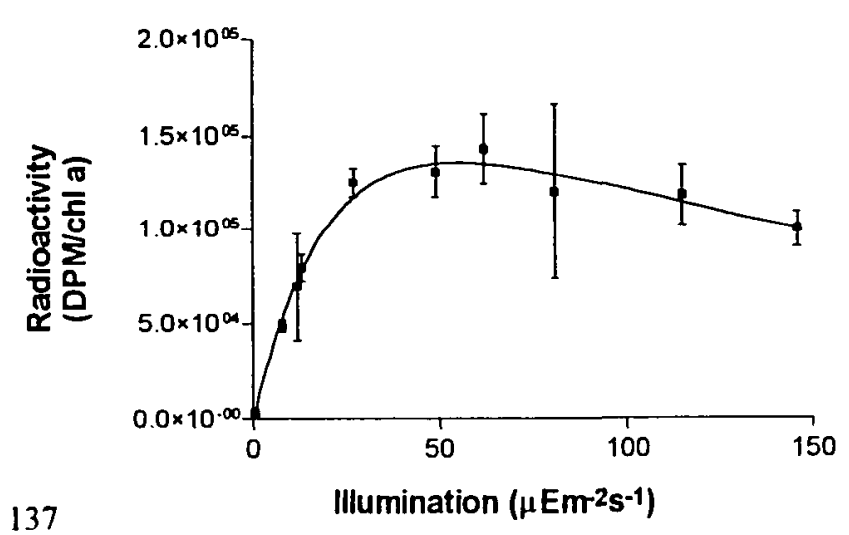

P vs. I, HihvLoFe d-2 1/24/97

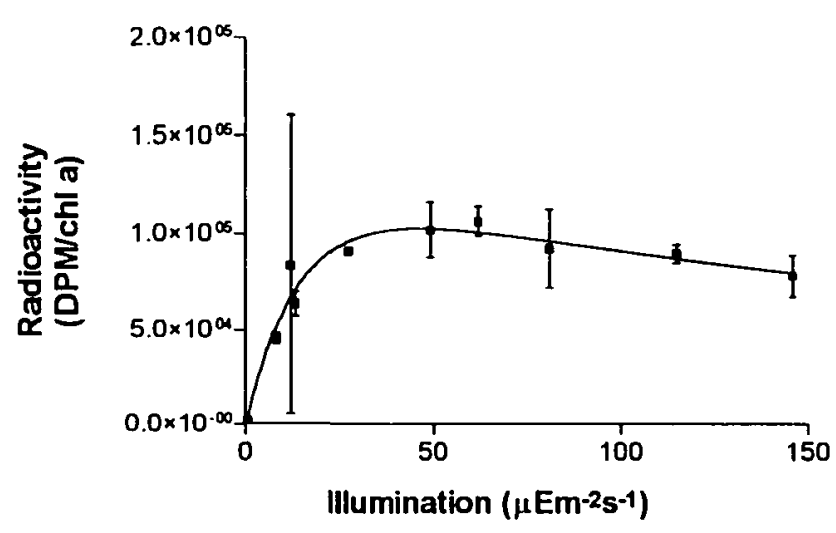

P vs. I, HihvHiFe d-2 1/24/97

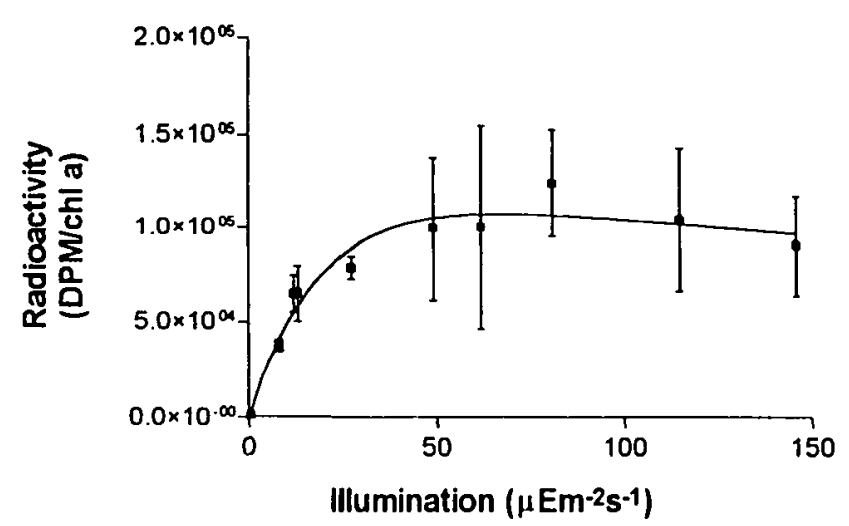

Averages of four scintillations plotted, two from each replicate culture. Error bars are standard deviation. 
P vs. I, LohvLoFe do 1/26/97

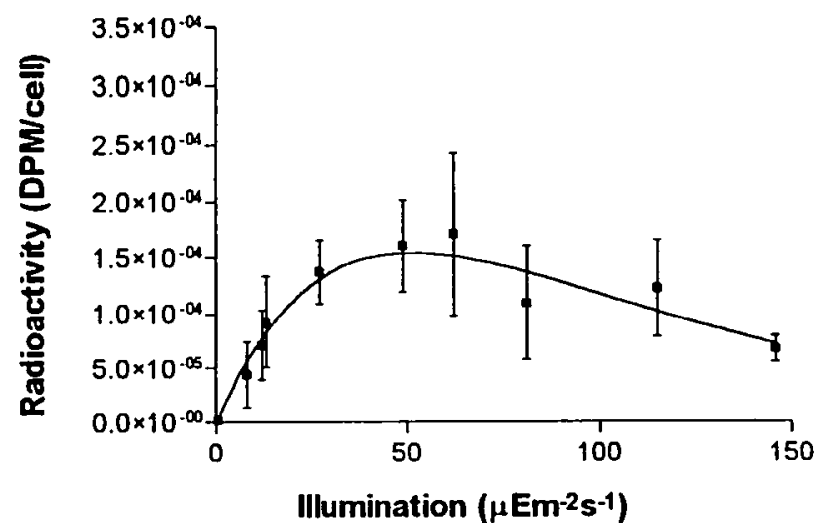

P vs. I, LohvHiFe d0 1/26/97

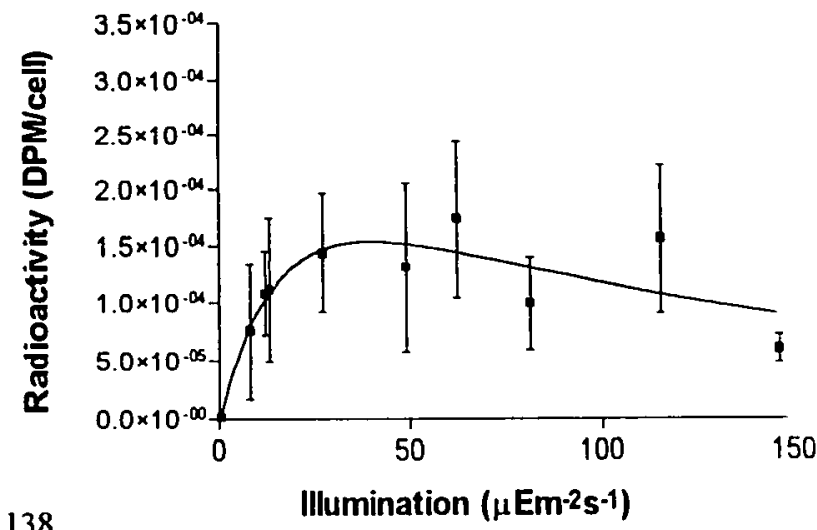

P vs. I, HihvLoFe do 1/26/97

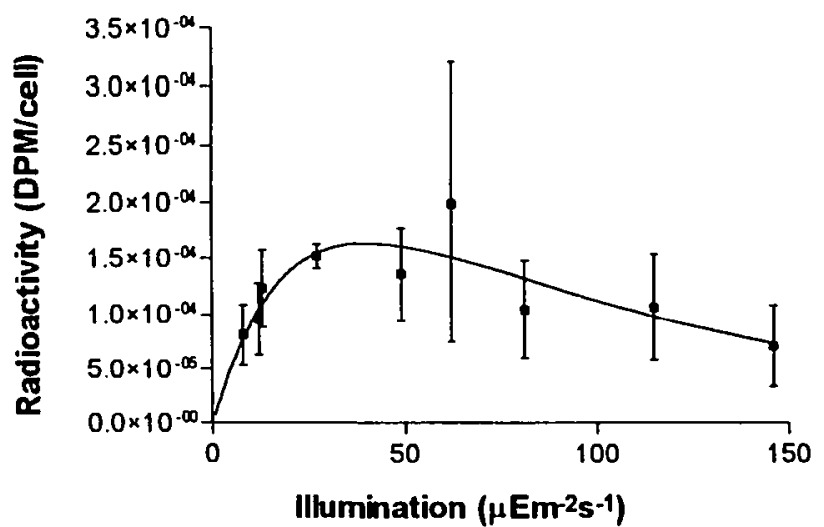

P vs. I, HihvHiFe d0 1/26/97

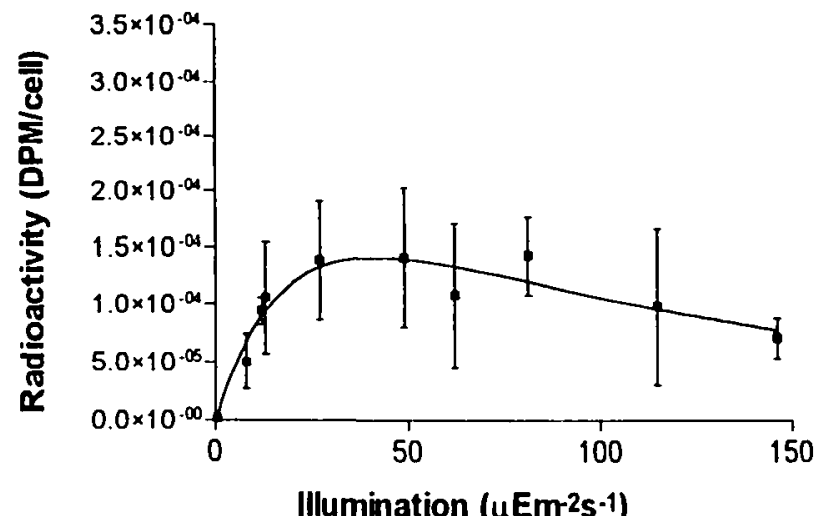

Averages of four scintillations plotted, two from each replicate culture. Error bars are standard deviation. 
P vs. I, LohvLoFe d2 1/28/97

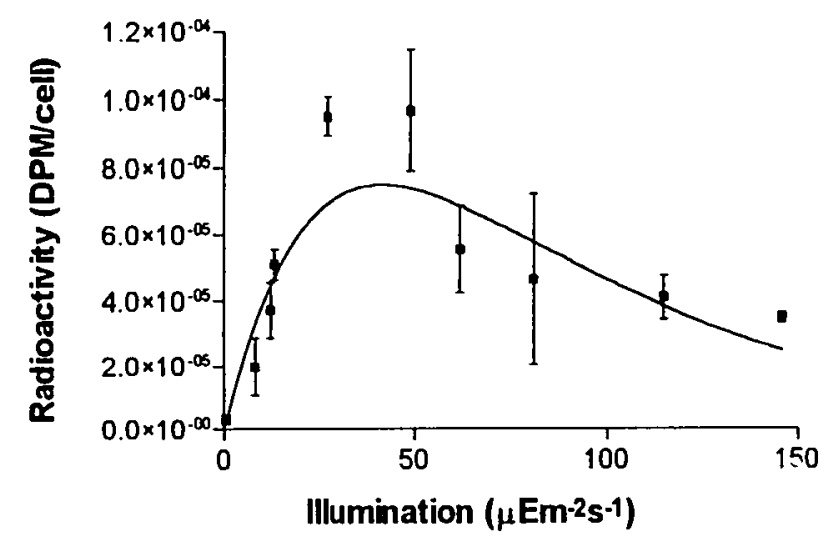

P vs. I, LohvHiFe d2 1/28/97

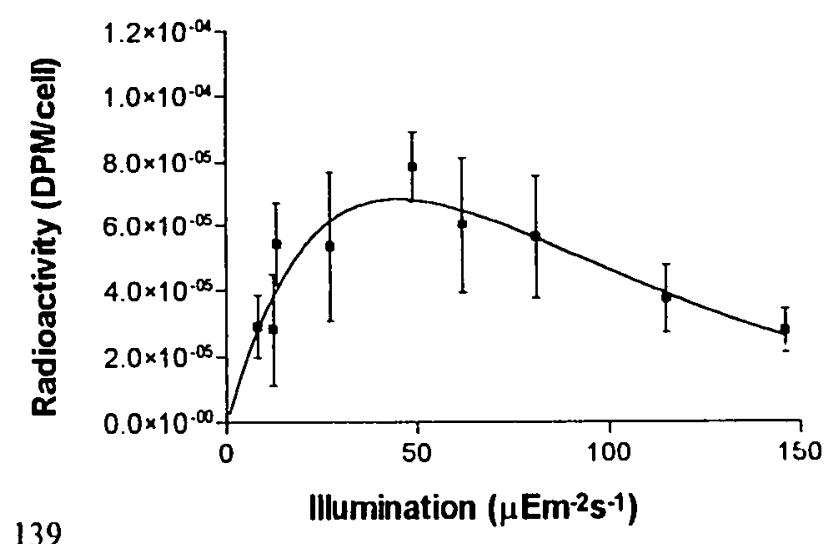

P vs. I, HihvLoFe d2 1/28/97

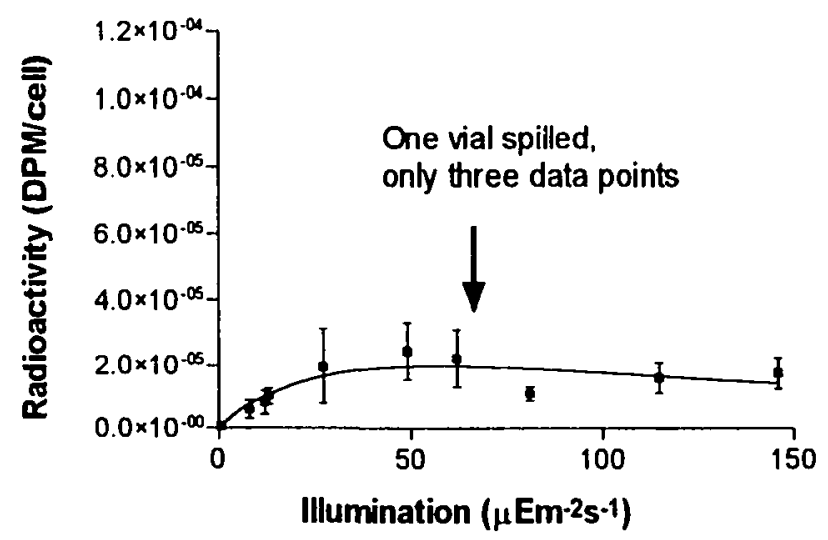

P vs. I, HihvHiFe d2 1/28/97

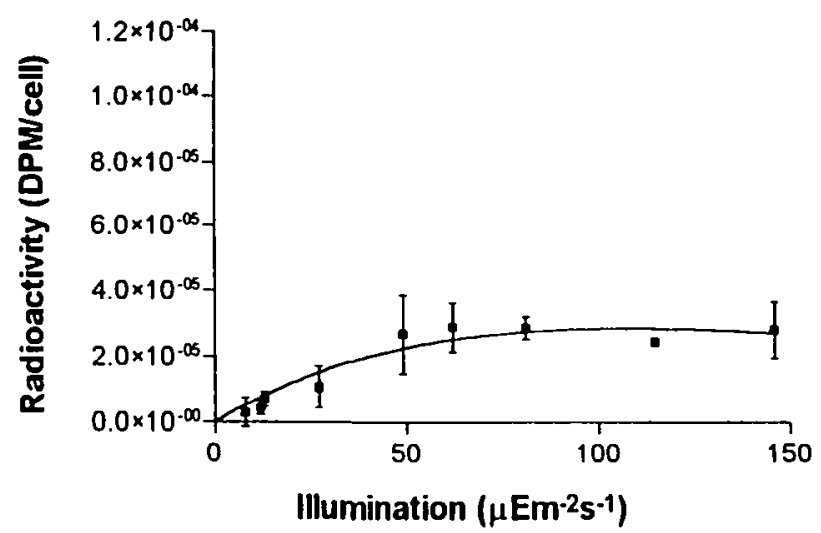

Averages of four scintillations plotted, two from each replicate culture. Error bars are standard deviation. 
P vs. I, LohvLoFe d4 1/30/97

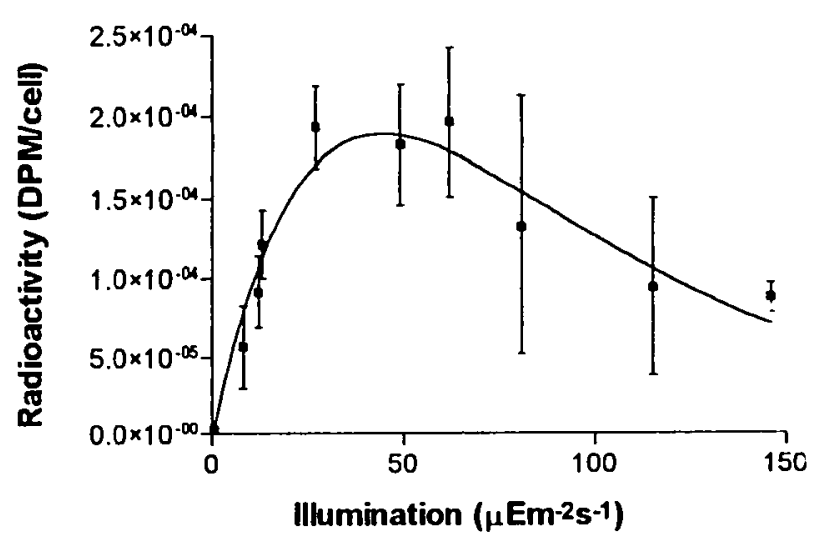

P vs. I, LohvHiFe d4 1/30/97

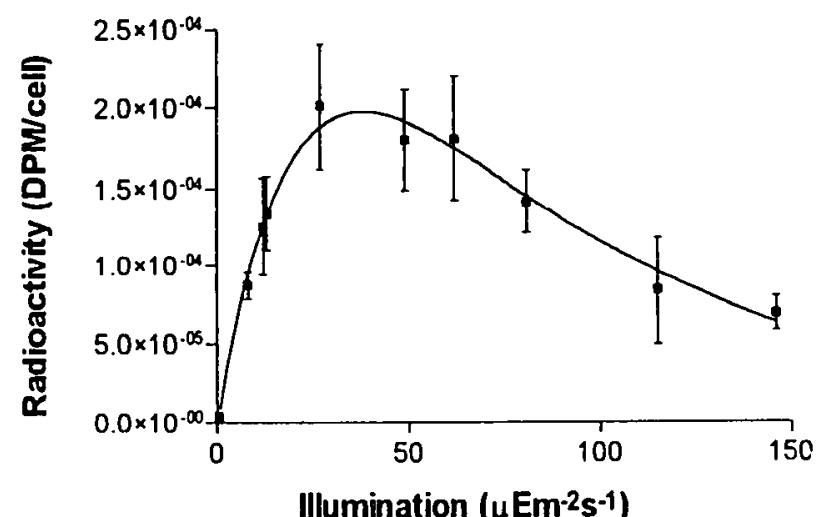

P vs. I, HihvLoFe d4 1/30/97

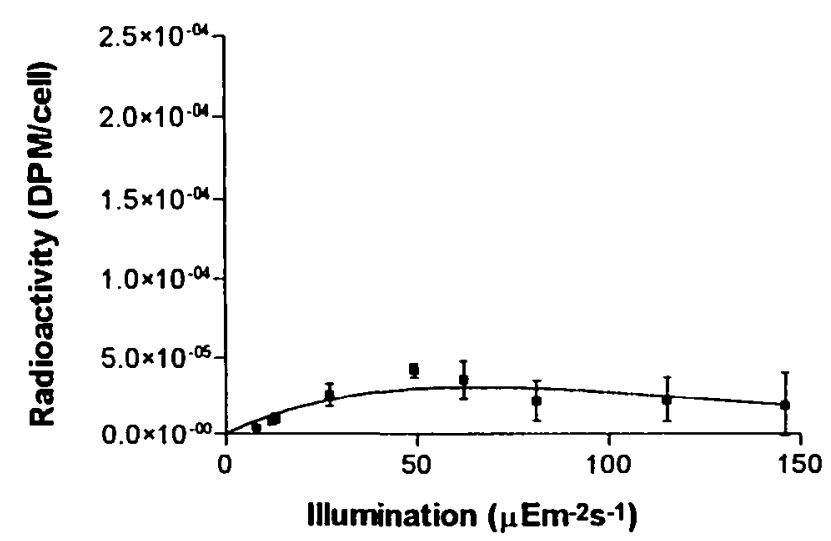

P vs. I, HihvHiFe d4 1/30/97

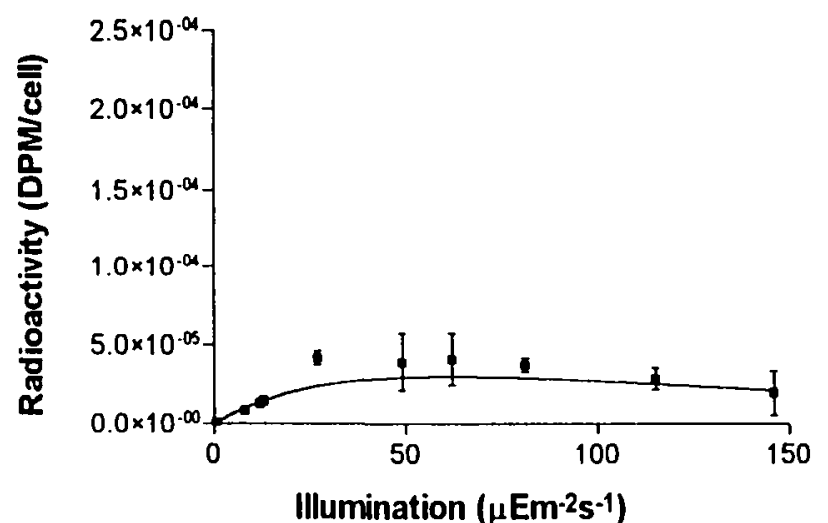

Averages of four scintillations plotted, two from each replicate culture. Error bars are standard deviation. 

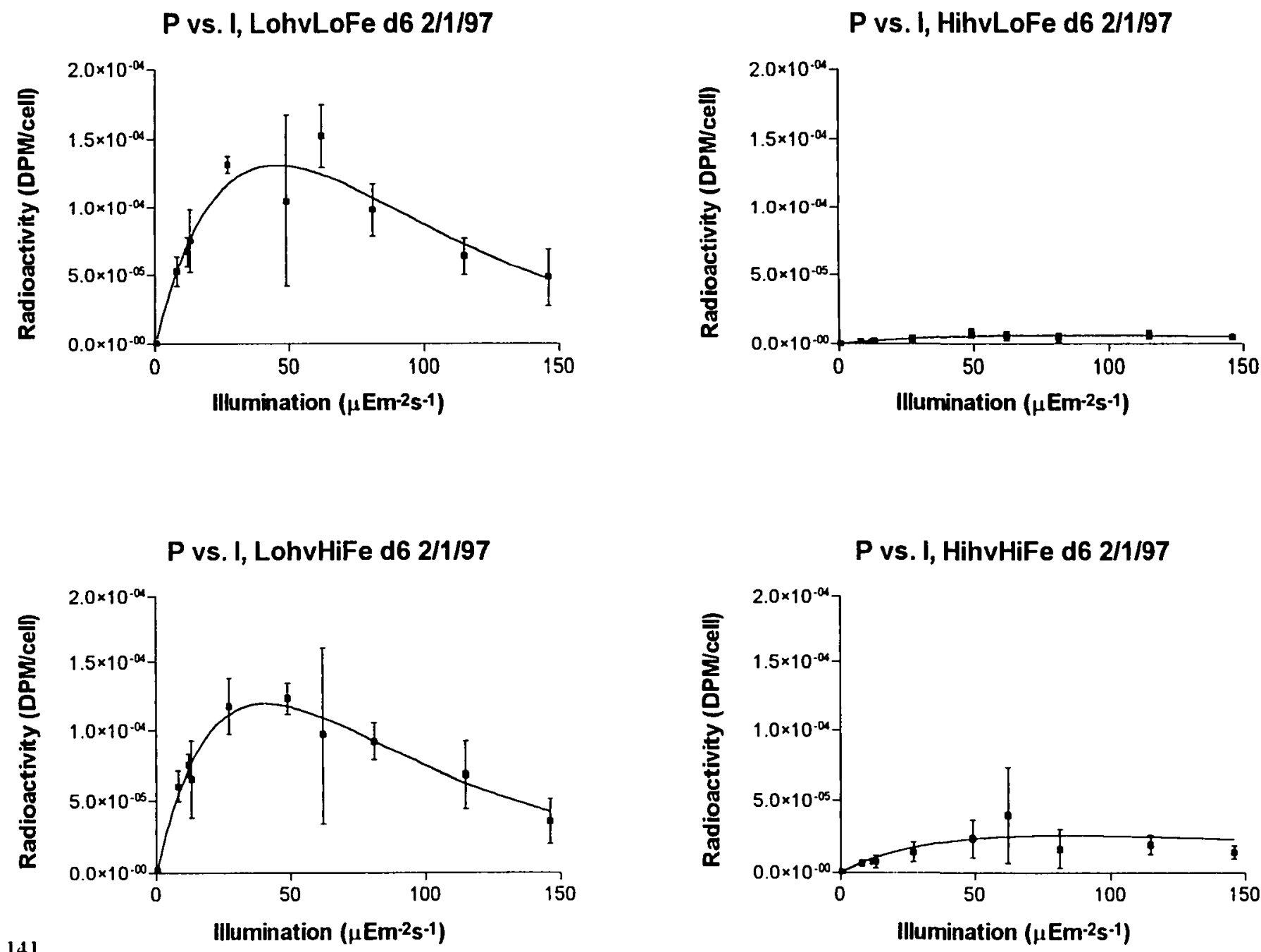

Averages of four scintillations plotted, two from each replicate culture. Error bars are standard deviation. 
P vs. I, LohvLoFe d8 2/3/97

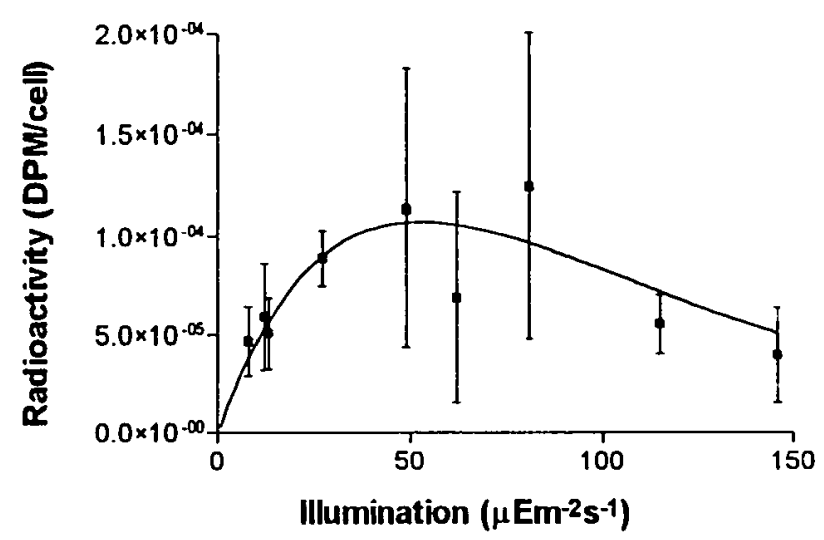

P vs. I, LohvHiFe d8 2/3/97

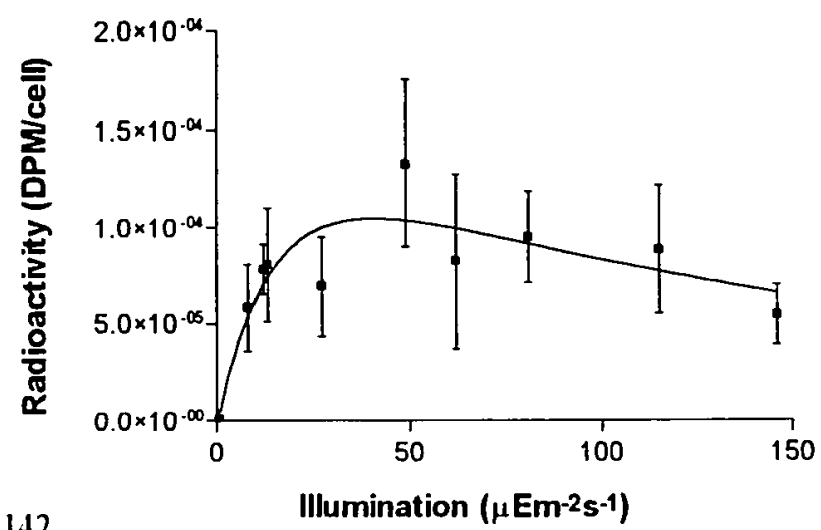

P vs. I, HihvLoFe d8 2/3/97

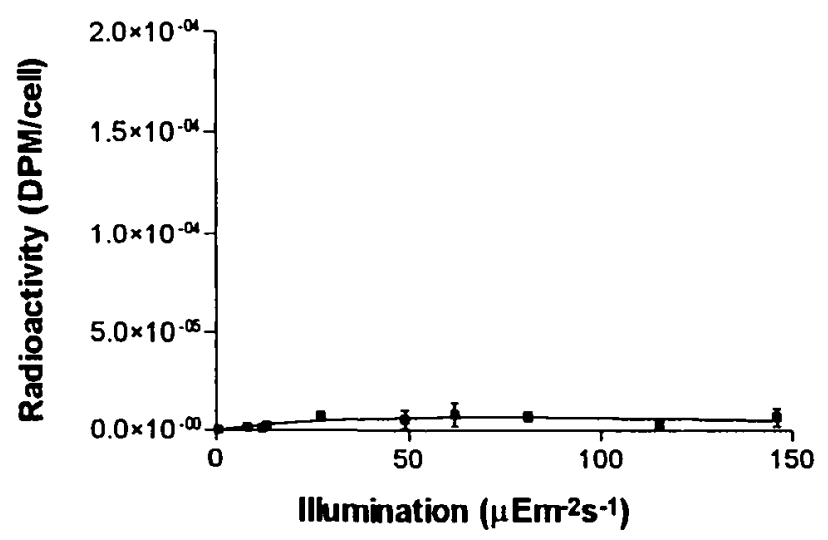

P vs. I, HihvHiFe d8 2/3/97

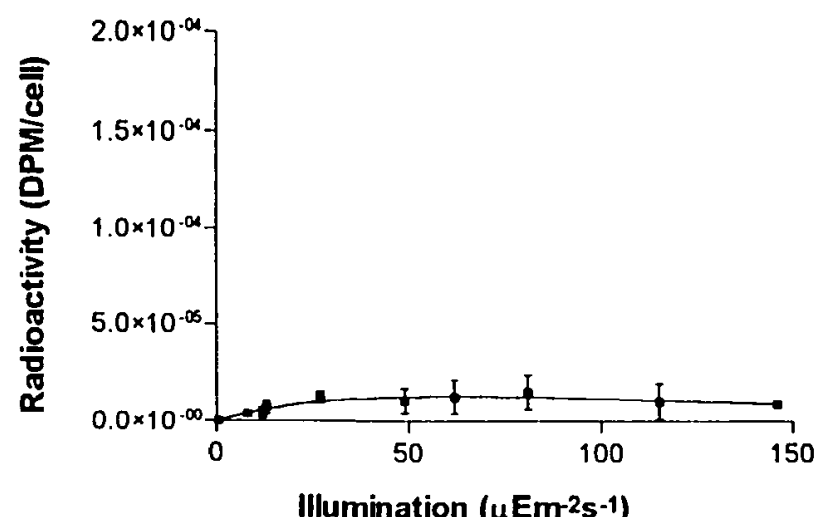

Averages of four scintillations plotted, two 'rom each replicate culture. Error bars are standard deviation. 

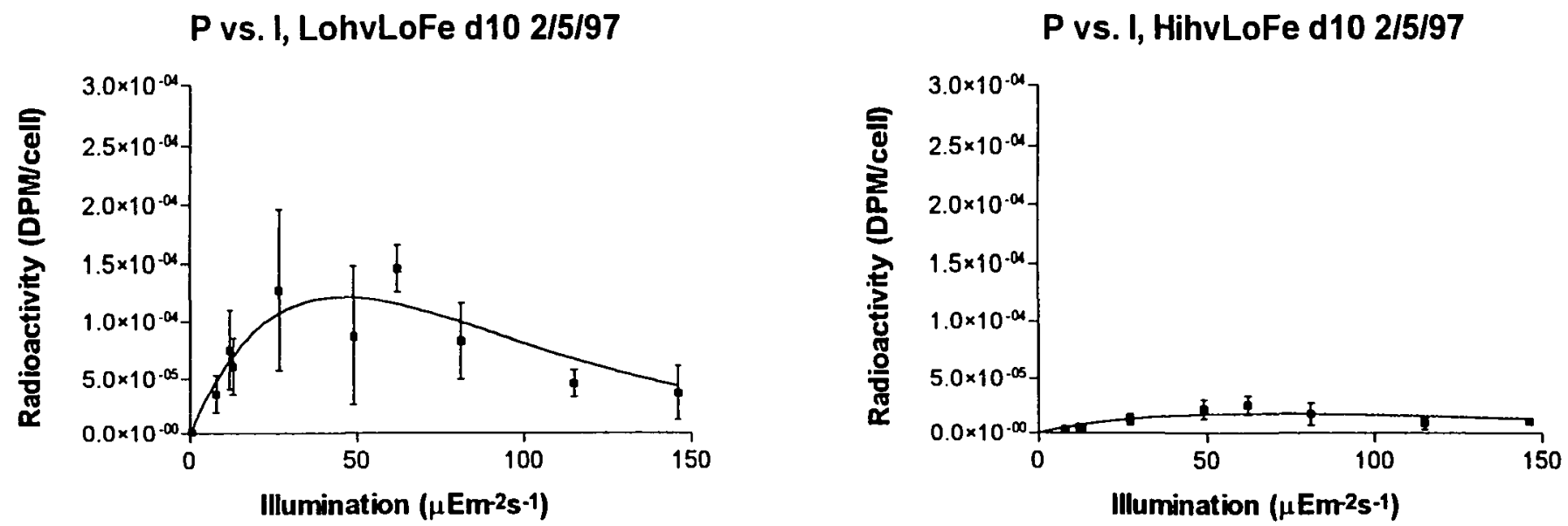

P vs. I, LohvHiFe d10 2/5/97

P vs. I, HihvHiFe d10 2/5/97
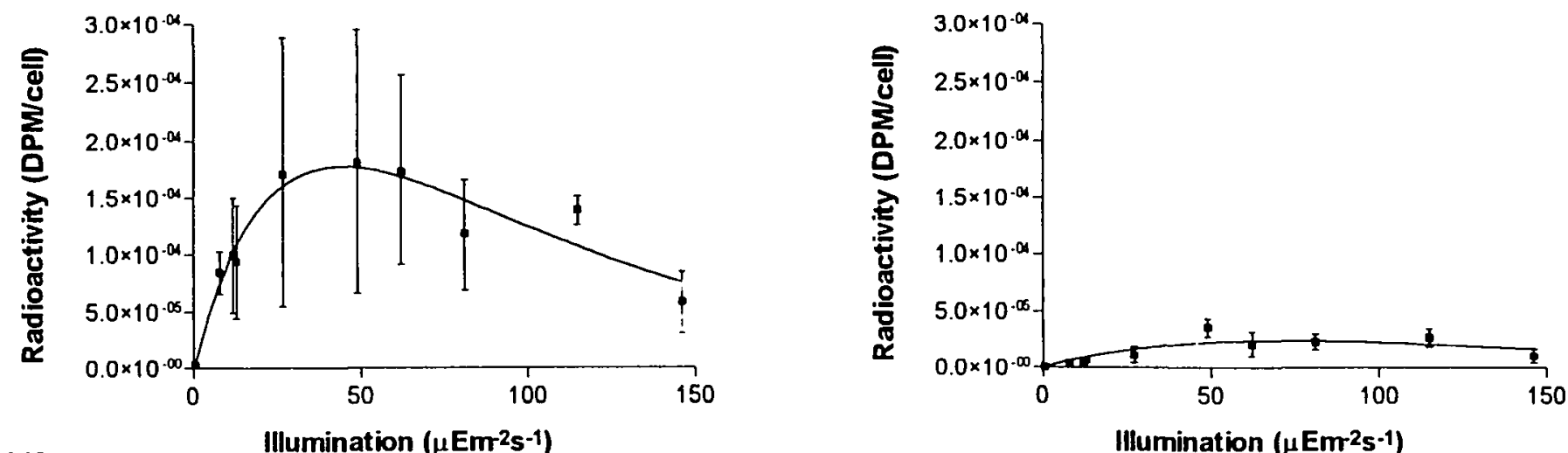

Averages of four scintillations plotted, two from each replicate culture. Error bars are standard deviation. 

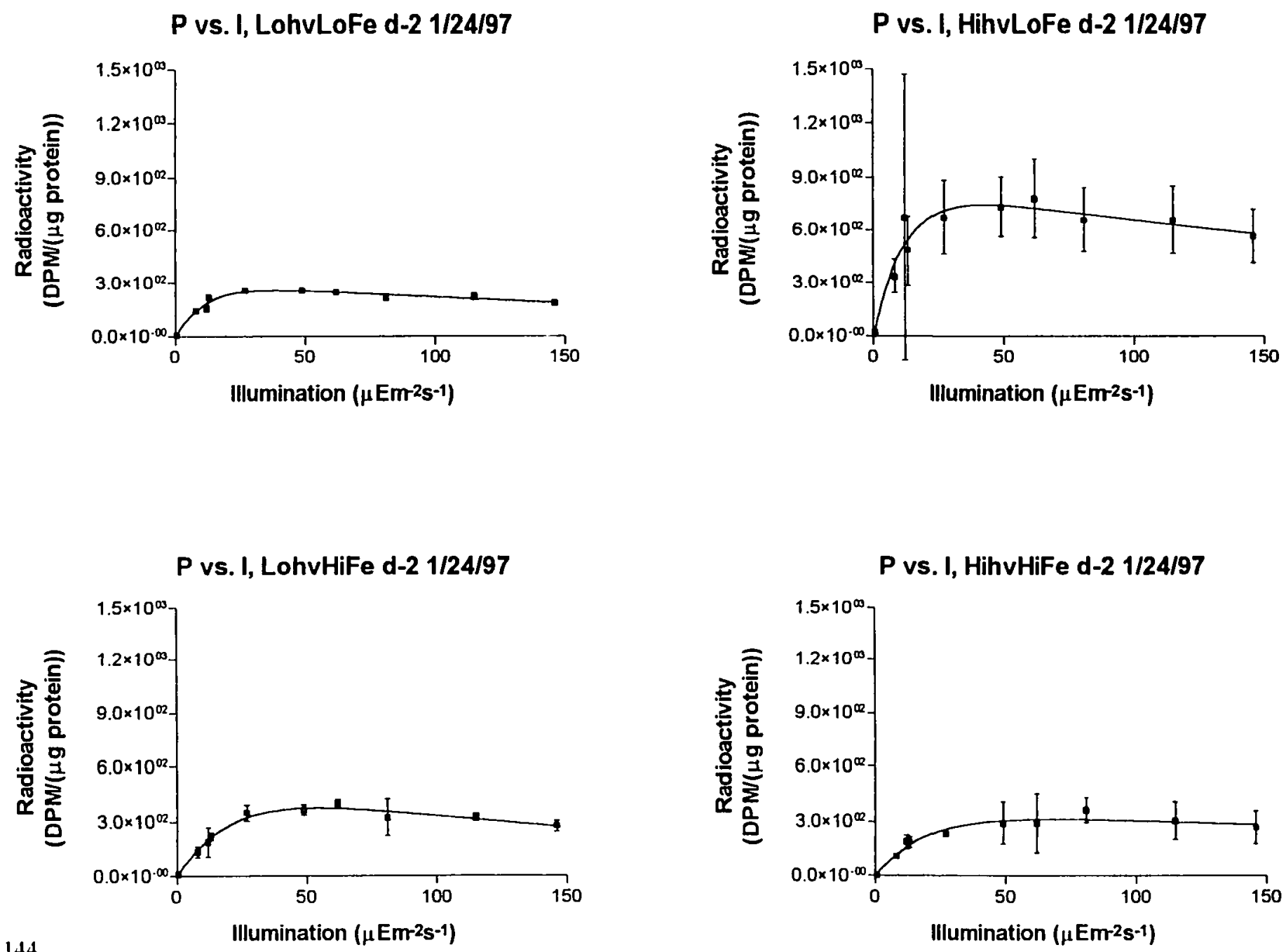

Averages of four scintillations plotted, two from each replicate culture. Error bars are standard deviation. 

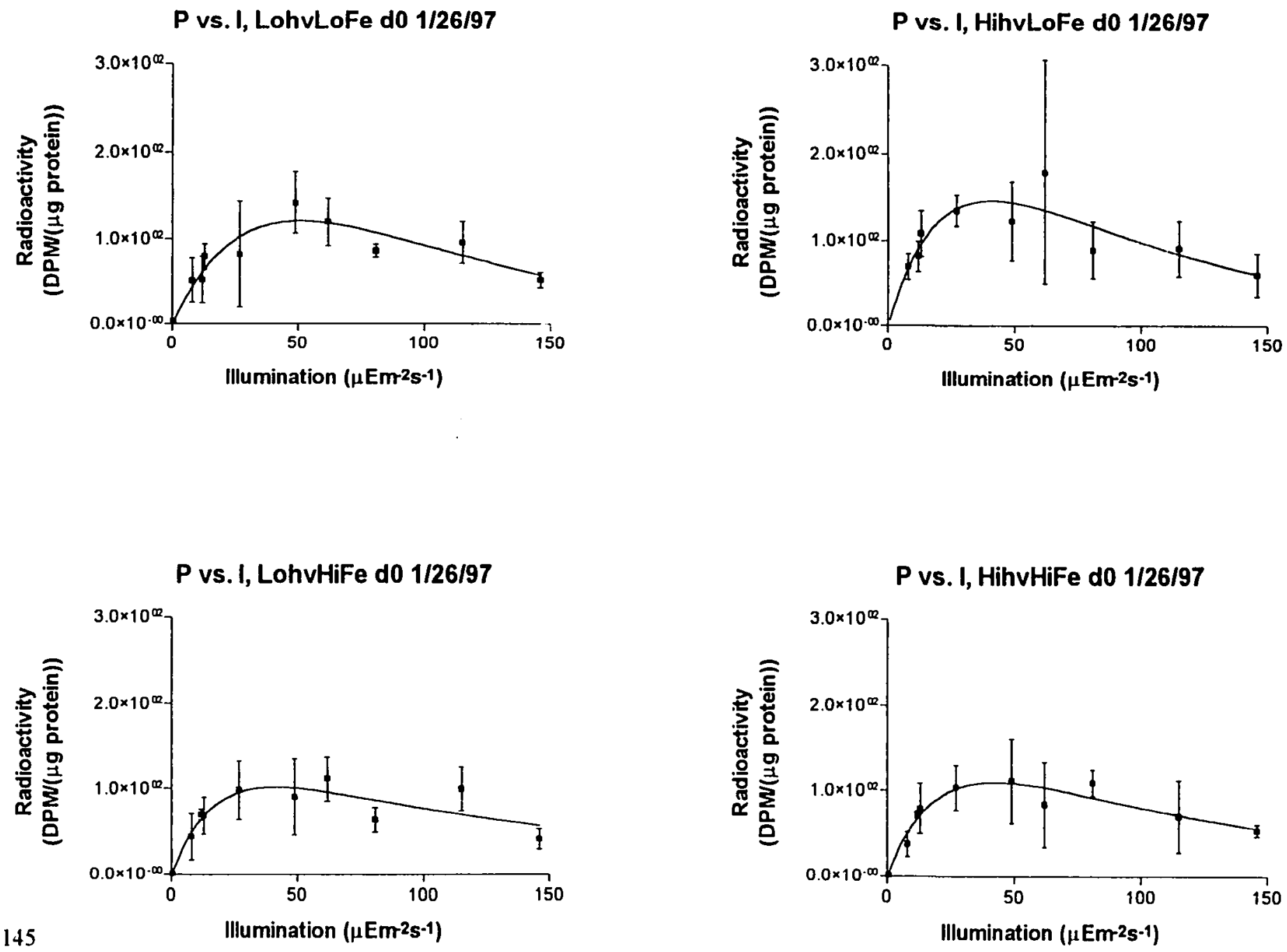

Averages of four scintillations plotted, two from each replicate culture. Error bars are standard deviation. 

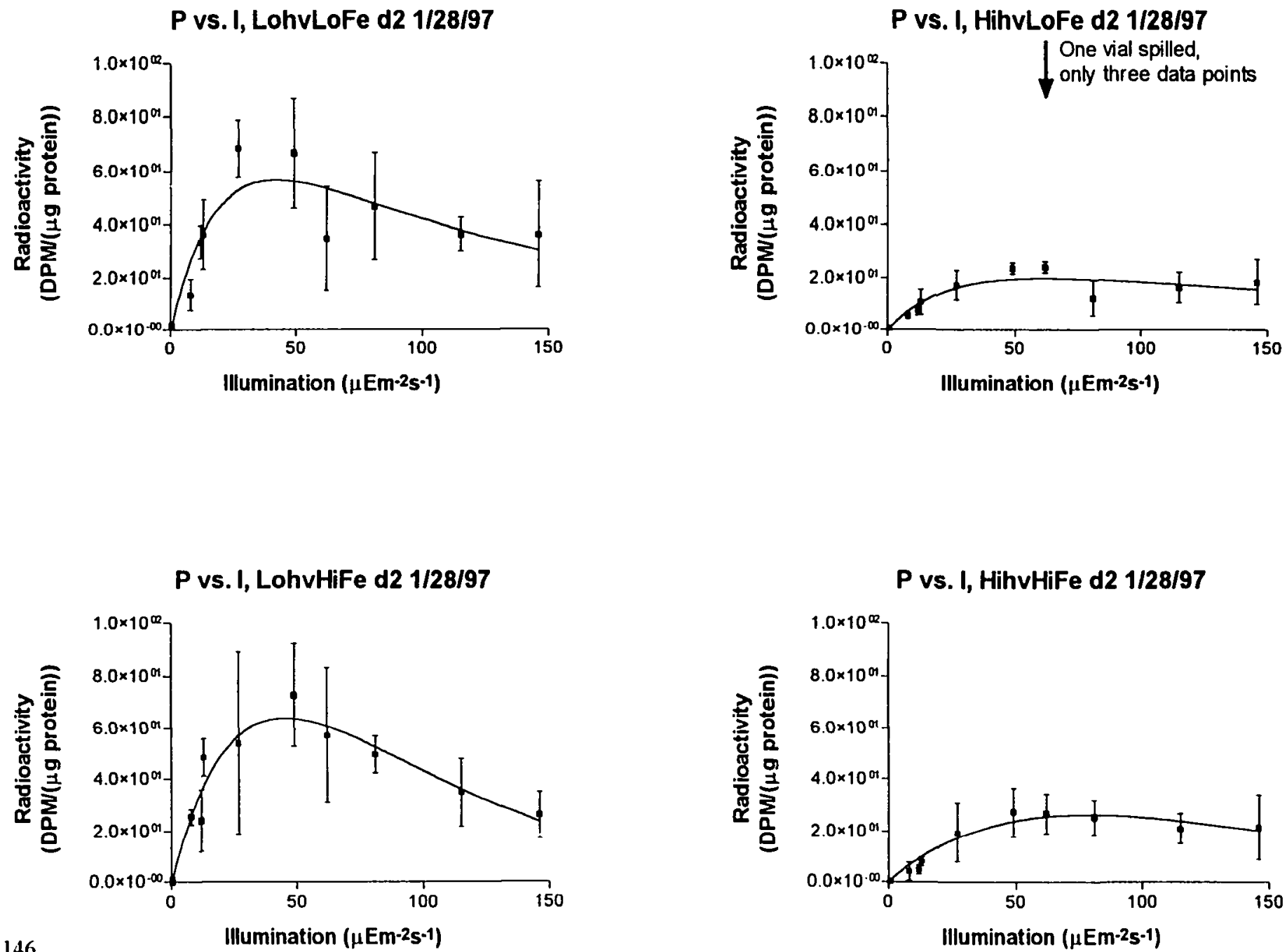

Averages of four scintillations plotted, two from each replicate cullure. Error bars are standard deviation. 

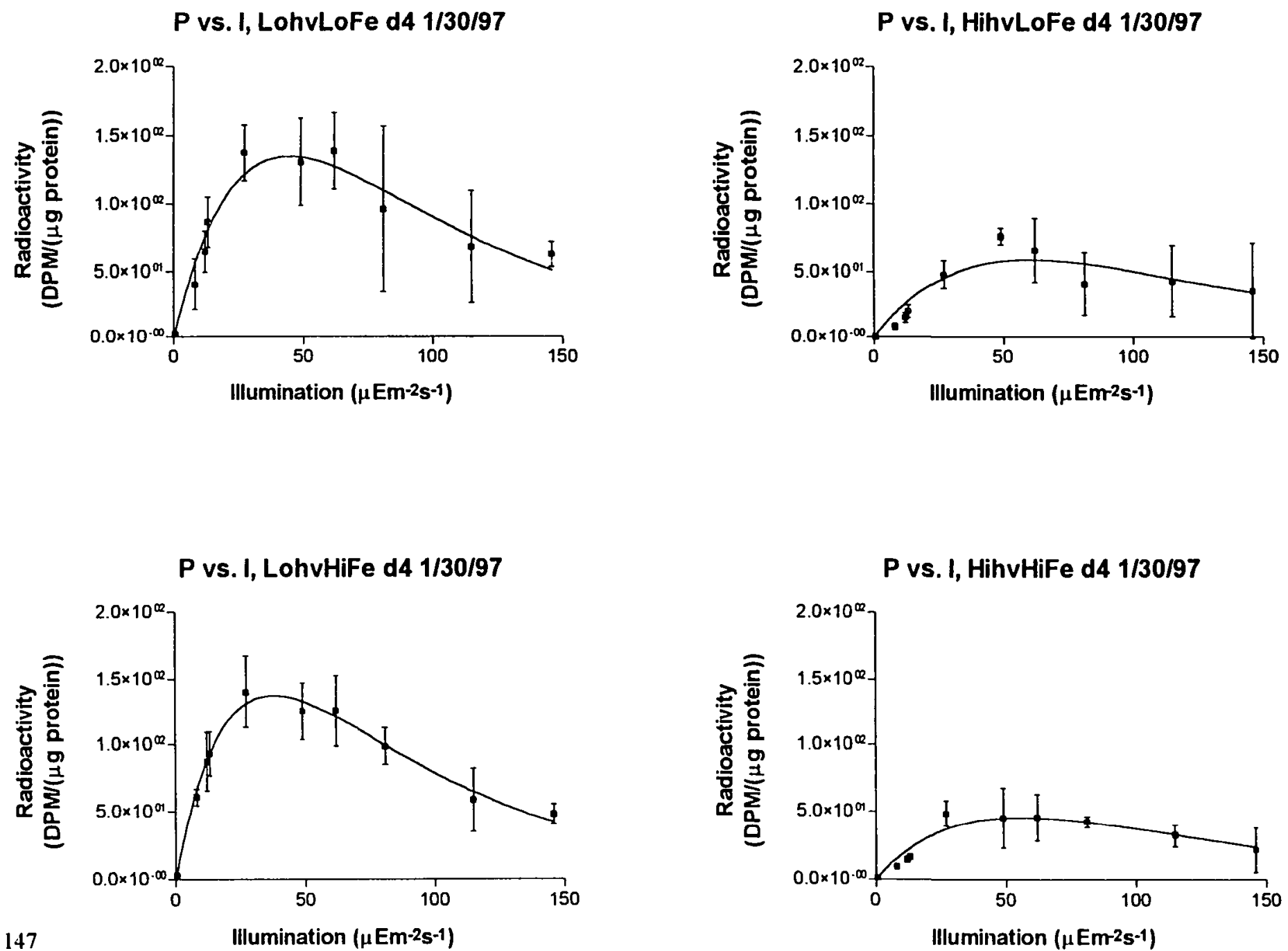

Averages of four scintillations plotted, two from each replicate culture. Error bars are standard deviation. 
P vs. I, LohvLoFe de 2/1/97

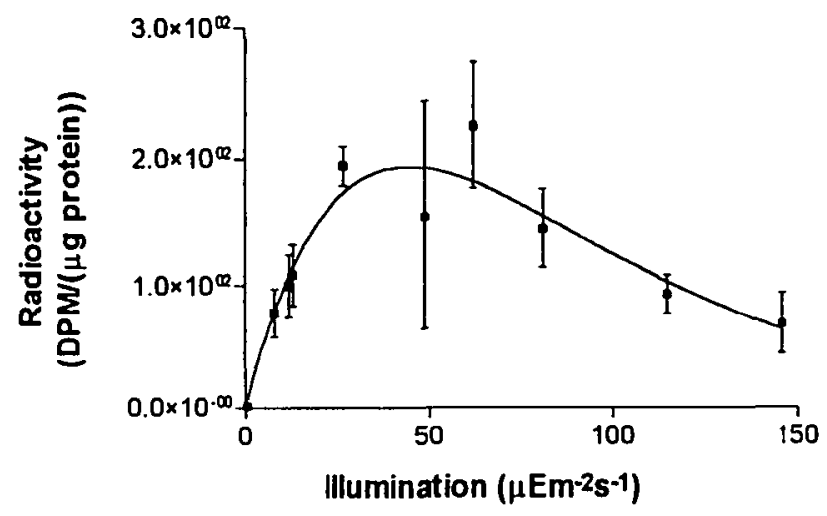

P vs. I, LohvHiFe dG 2/1/97

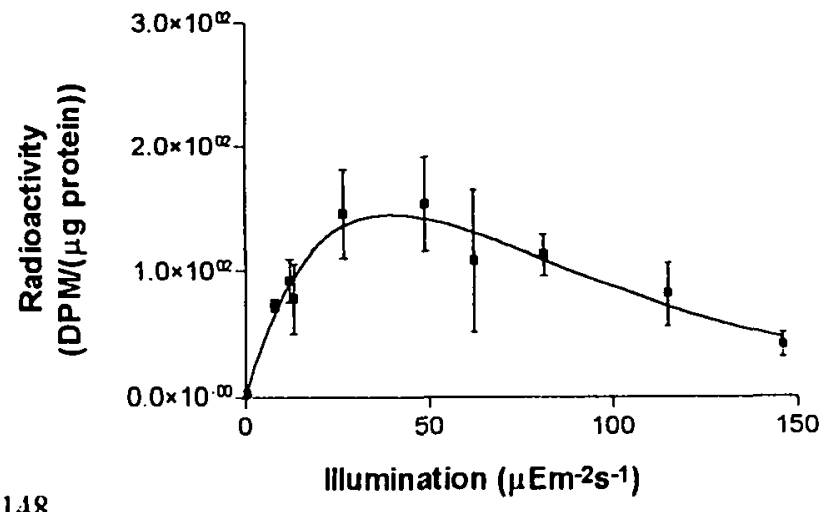

P vs. I, HinvLoFe dG 2/1/97

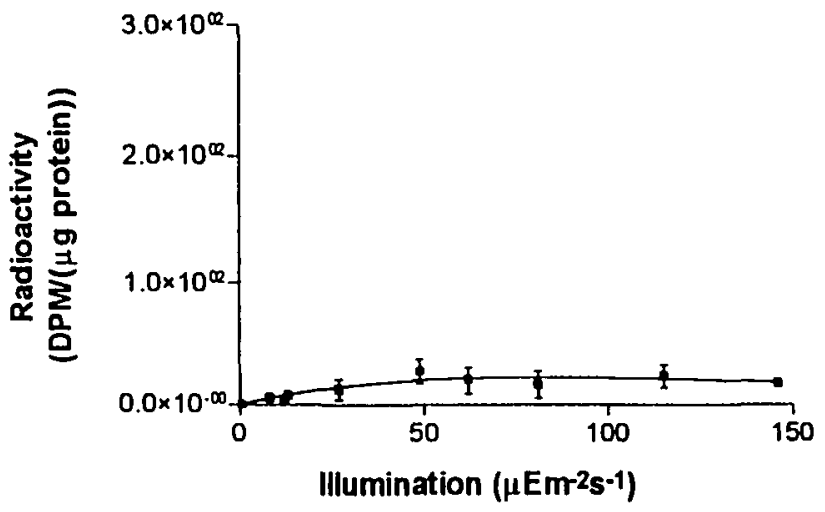

P vs. I, HihvHiFe do 2/1/97

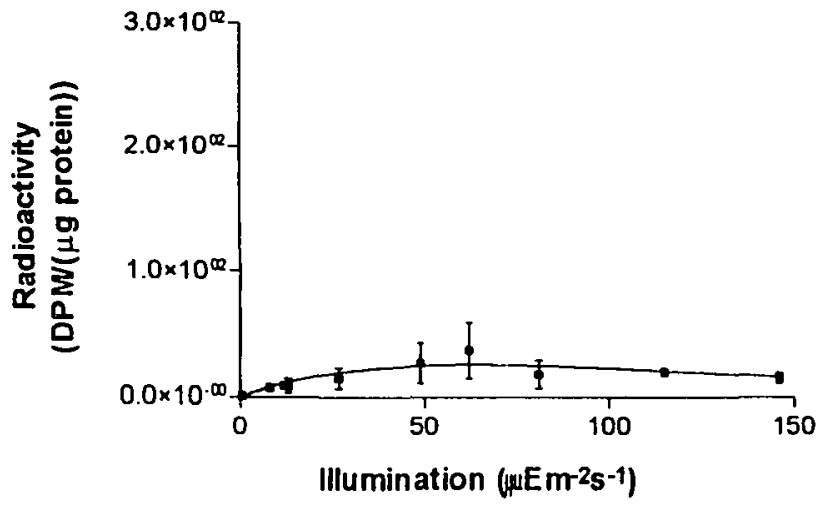

Averages of four scintillations plotted, two from each replicate culture. Error bars are standard deviation. 

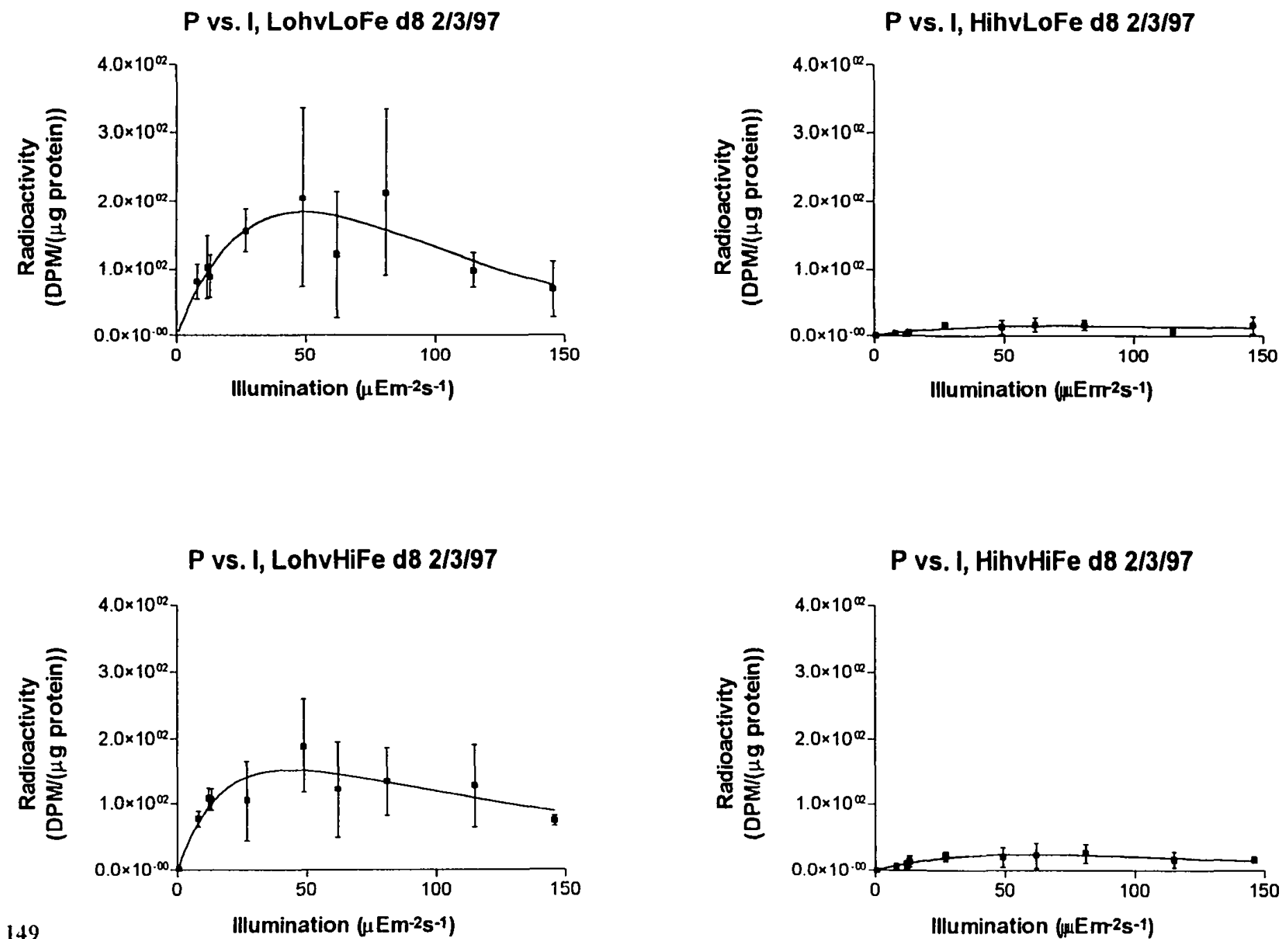

Averages of four scintillations plotted, two from each replicate culture. Error bars are standard deviation. 


\section{Appendix B}

Decreased light P vs. I curves, fit by Platt's equation as described in materials and methods. P vs. I curves for the increased light experiment have been normalized per cell, per $\mu \mathrm{g}$ chlorophyll $a$ and per $\mu \mathrm{g}$ protein and will follow in that order.

- radioactivity per cell (DPM/cell)

- radioactivity per chlorophyll (DPM/ $\mu \mathrm{g} \operatorname{chl} a)$

- radioactivity/protein (DPM/ $\mu \mathrm{g}$ protein)

Error bars show standard deviations of four data points: two scintillations each from two replicate cultures. 
P vs. I, LohvLoFe d-2 4/24/97

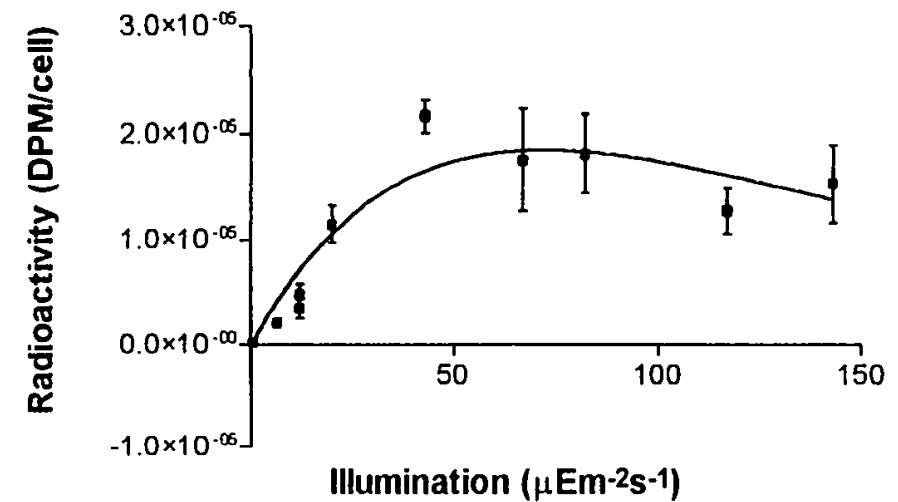

P vs. I, LohvHiFe d-2 4/24/97

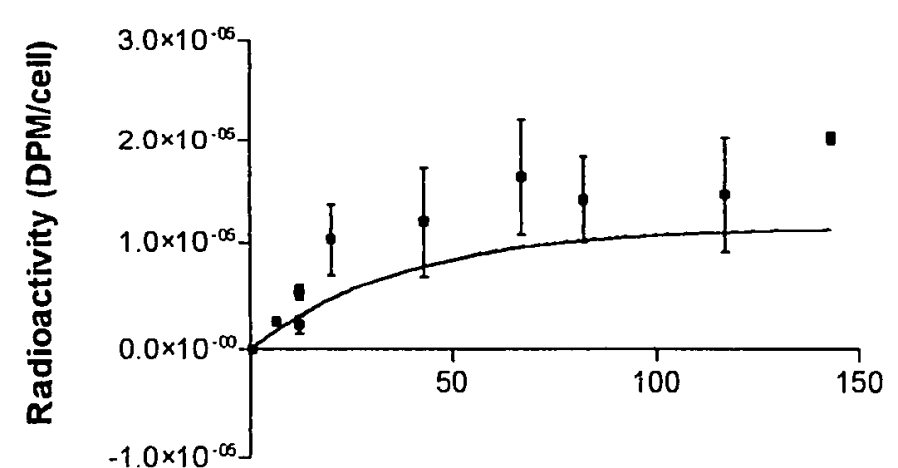

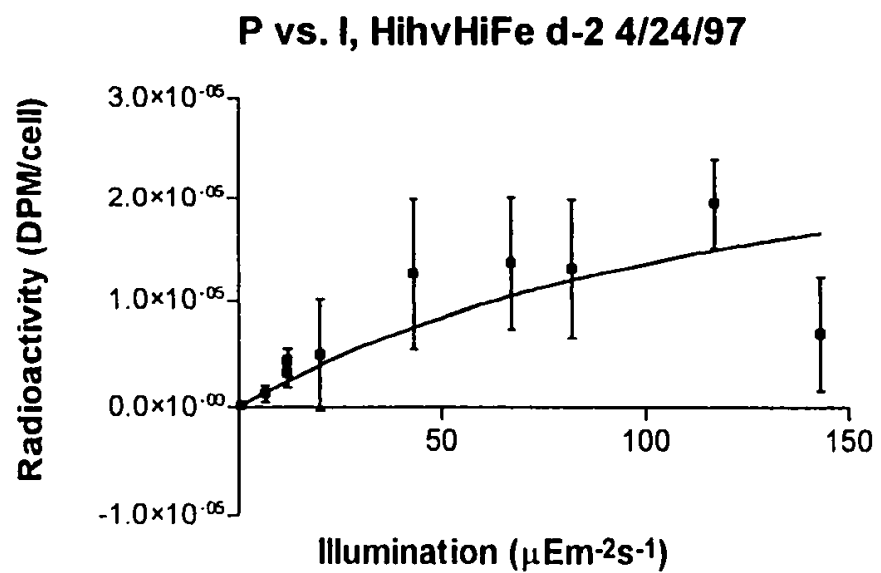


P vs. I, LohvLoFe d0 4/26/97

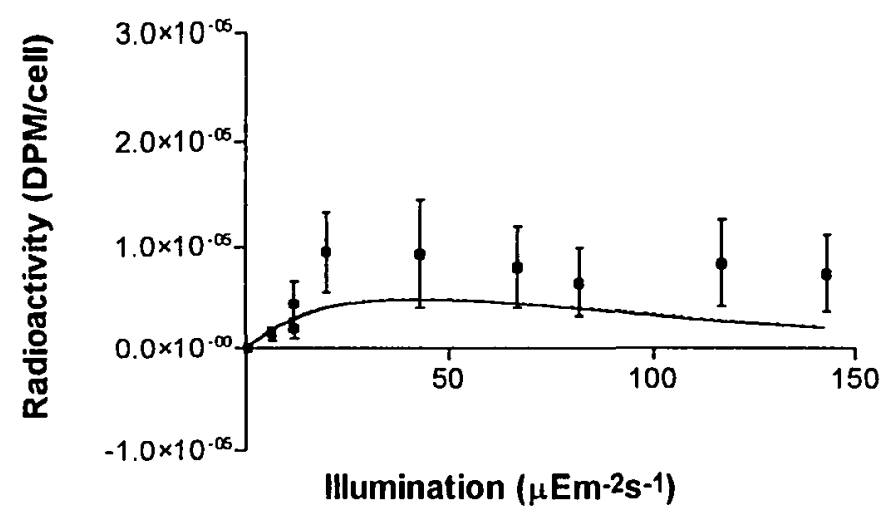

P vs. I, LohvHiFe do 4/26/97

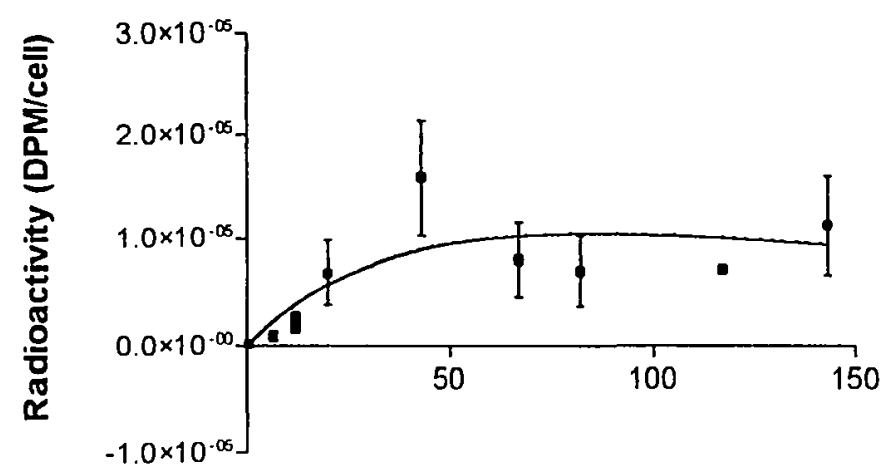

153 $-1.0 \times 10^{-06}$

Illumination $(\mu \mathrm{Em}-2 \mathrm{~s}-1)$
P vs. I, HihvLoFe do 4/26/97

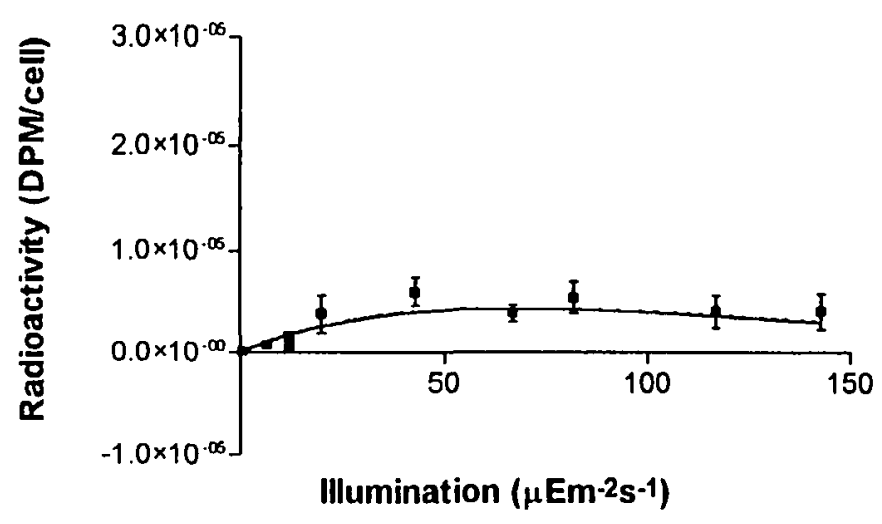

P vs. I, HihvHiFe do 4/26/97

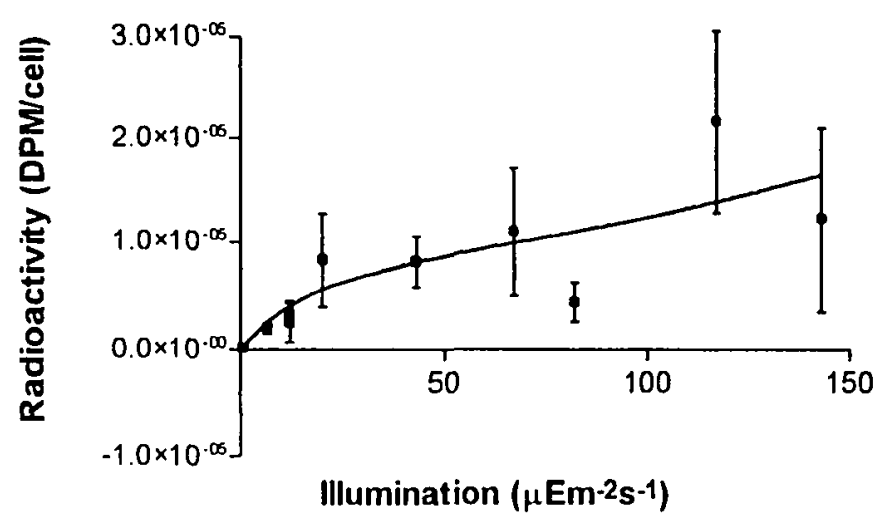


P vs. I, LohvLoFe d2 4/28/97

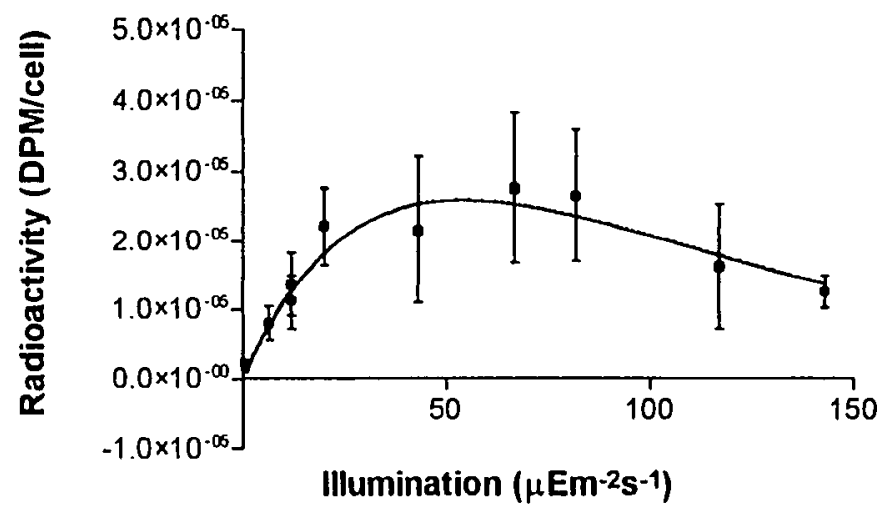

P vs. I, LohvHiFe d2 4/28/97

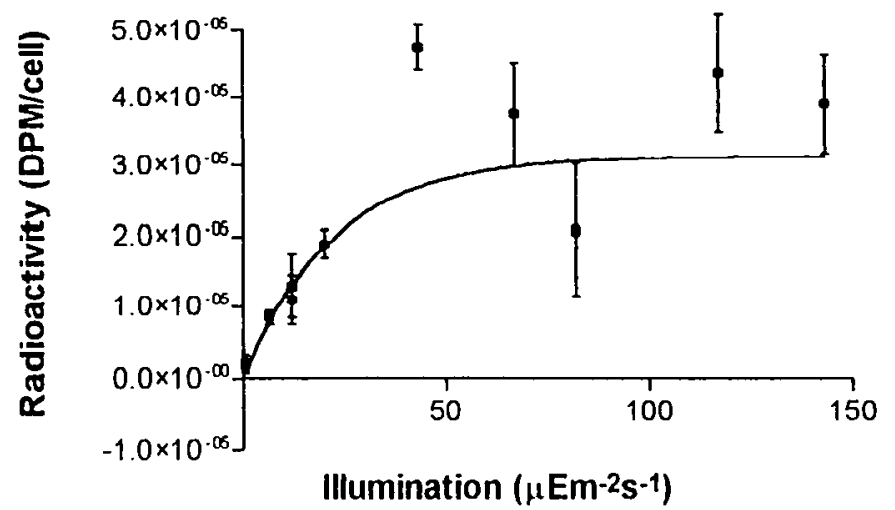

P vs. I, HihvLoFe d2 4/28/97

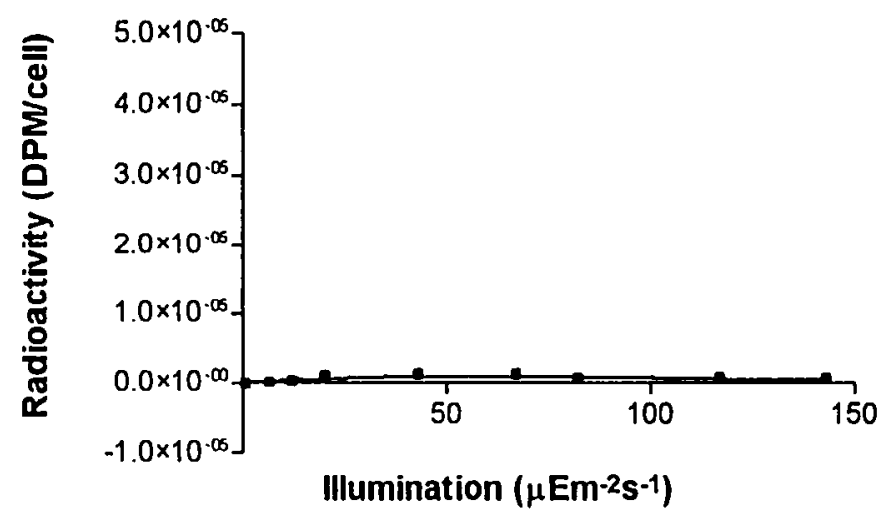

P vs. I, HihvHiFe d2 4/28/97

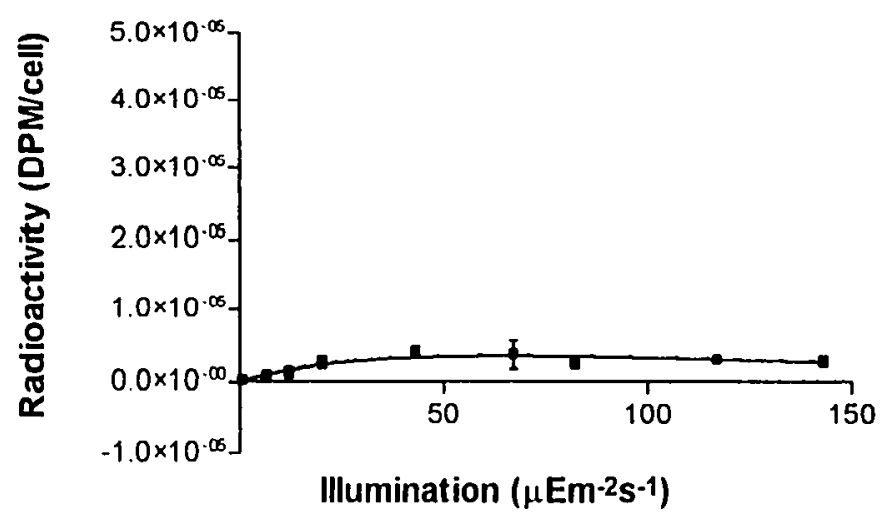




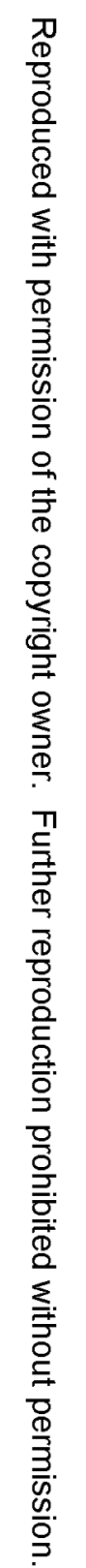
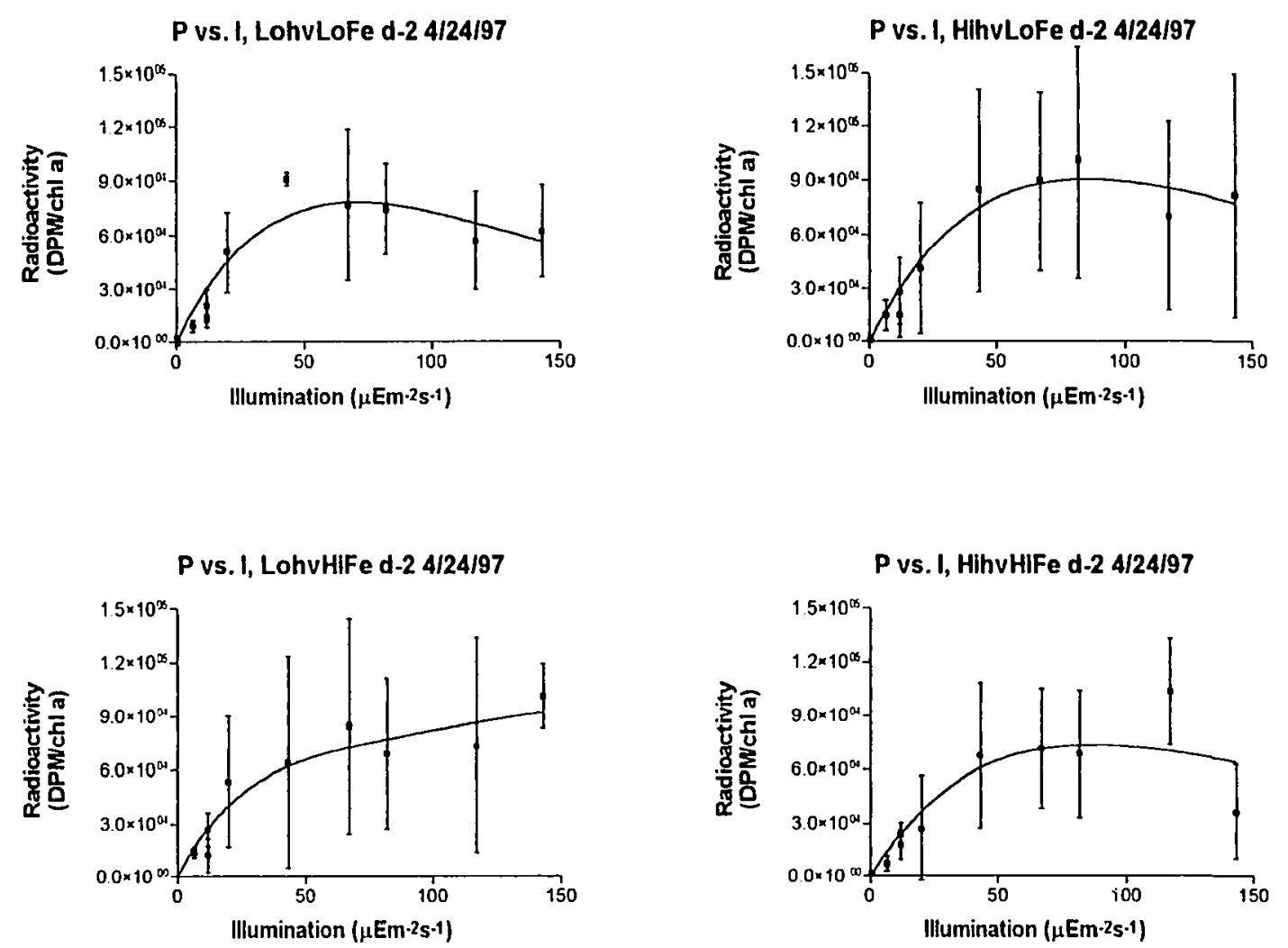


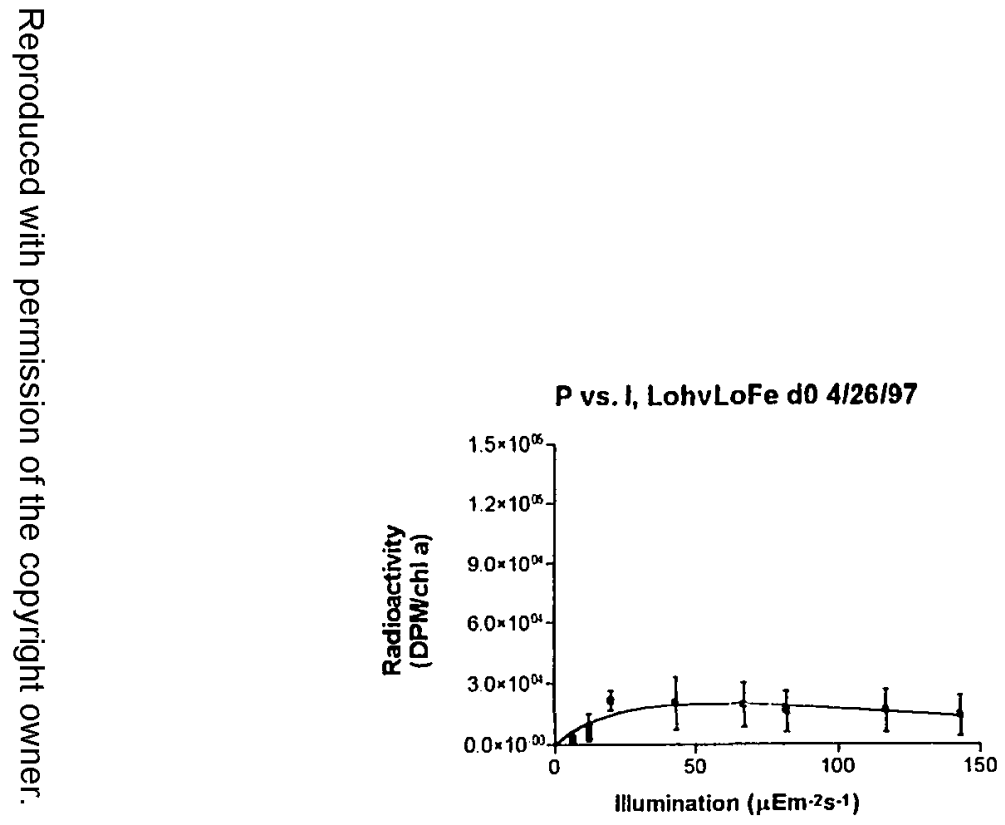

P vs. I, HihvLoFe d0 4/26/97

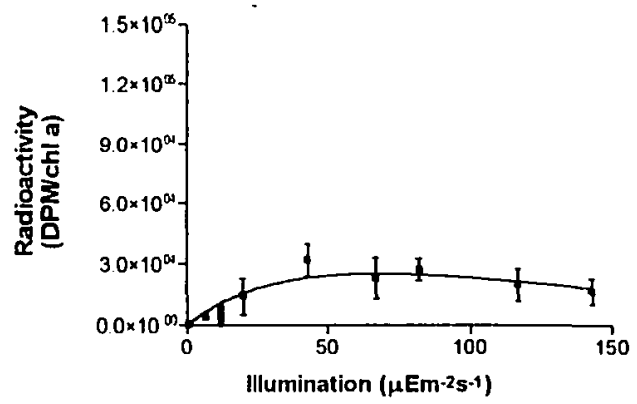

P vs. I, LohvHIFe d0 4/26/97

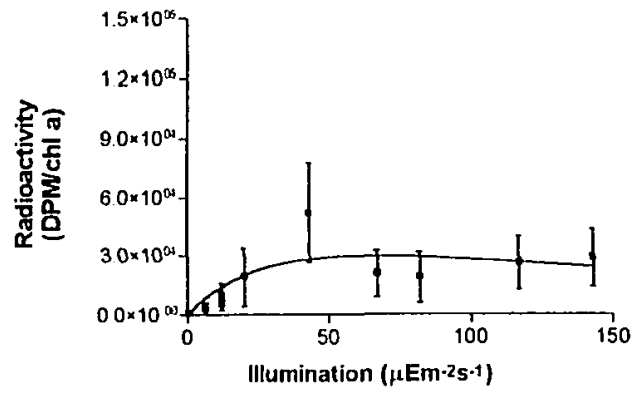

P vs. I, HihvHIFe do 4/26/97

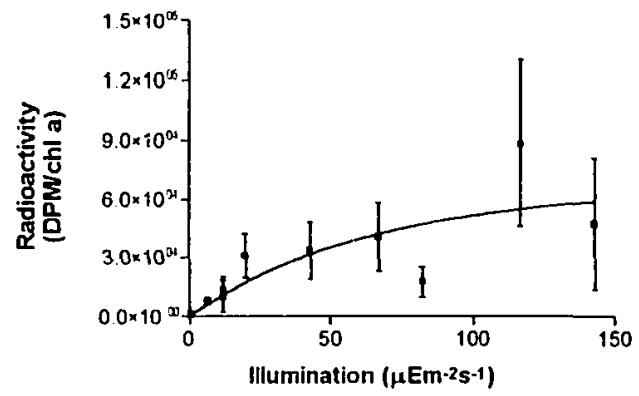

157 


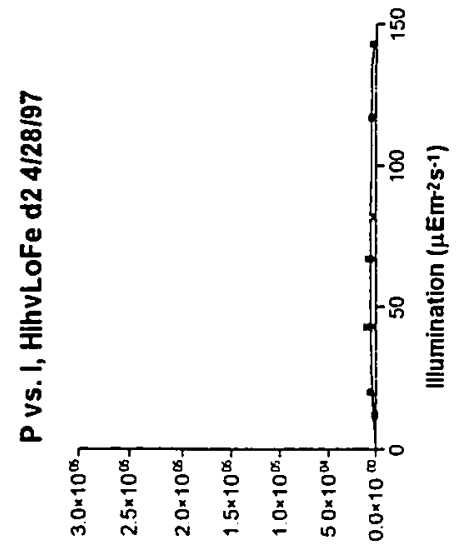

(e 145Mda)

A!npDeolpey

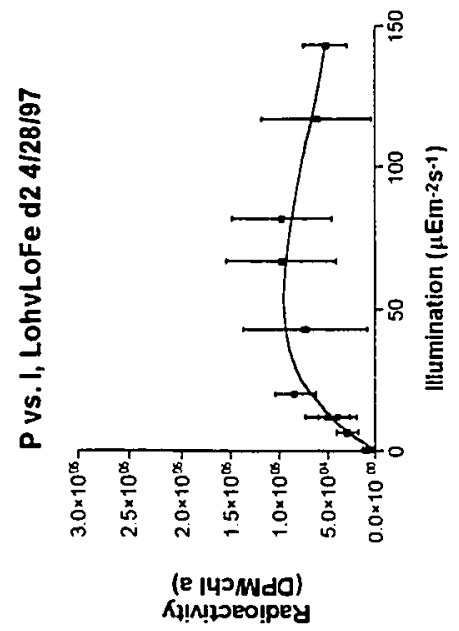

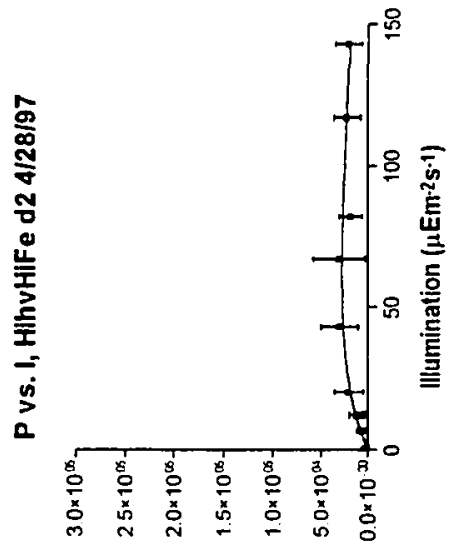

(e 140/Nda)

Kұ!n!?วEo!pey

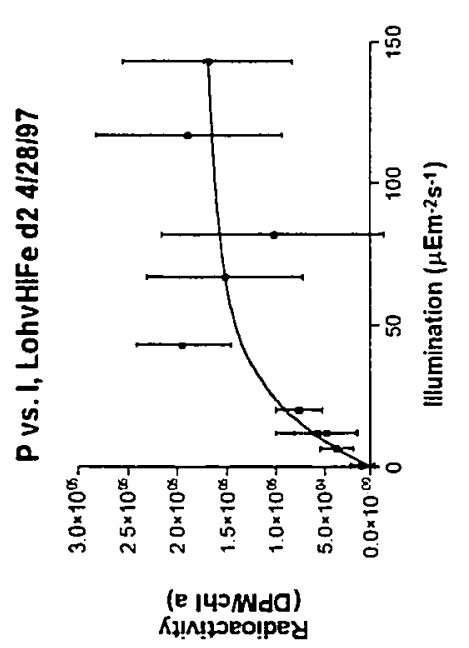




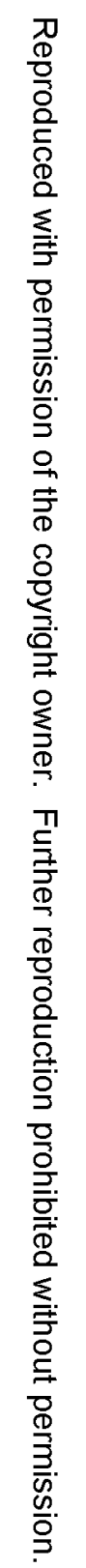
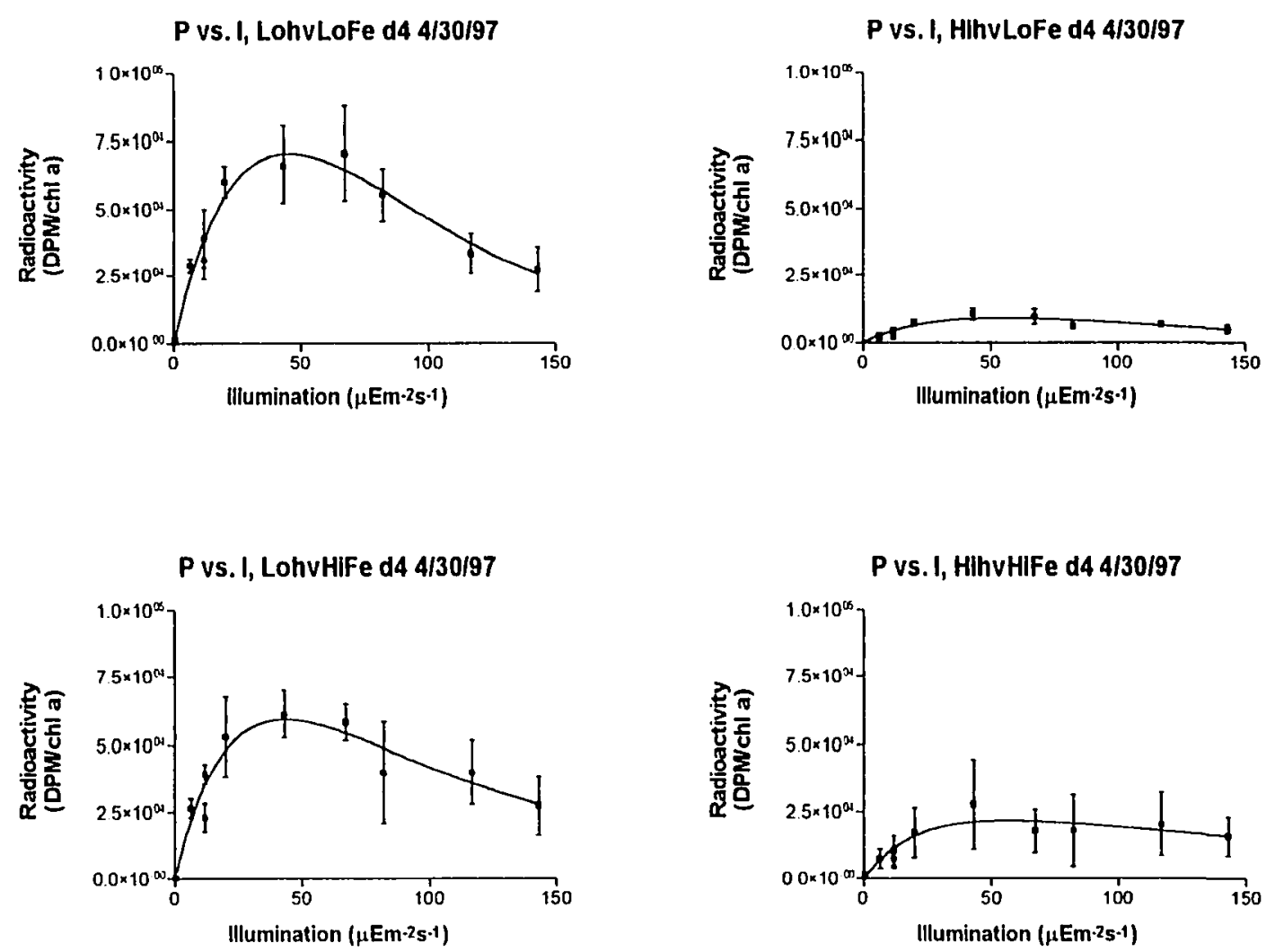

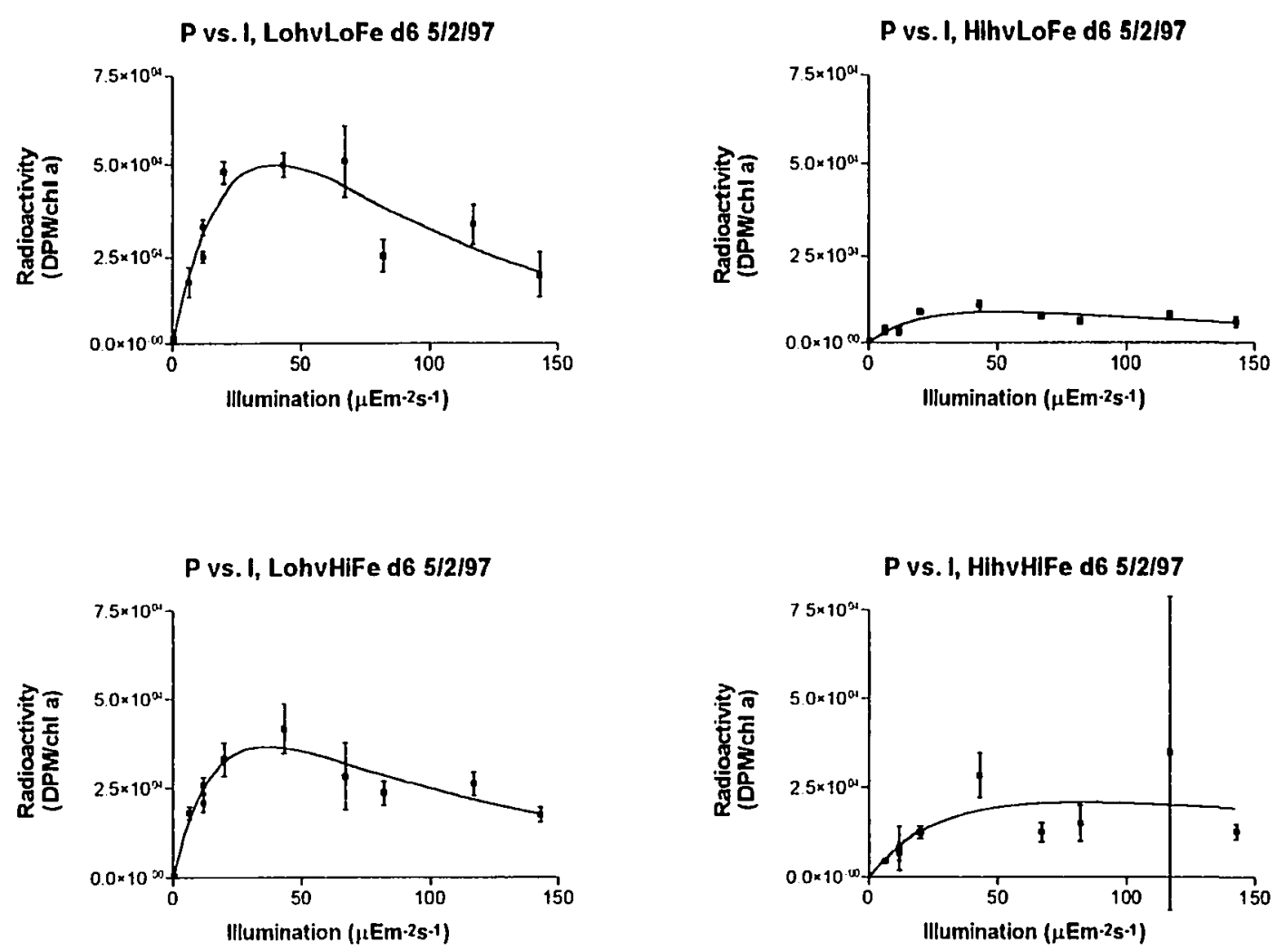


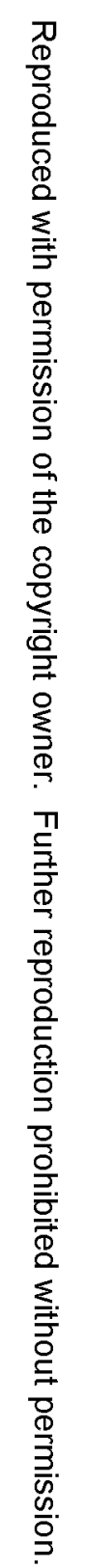
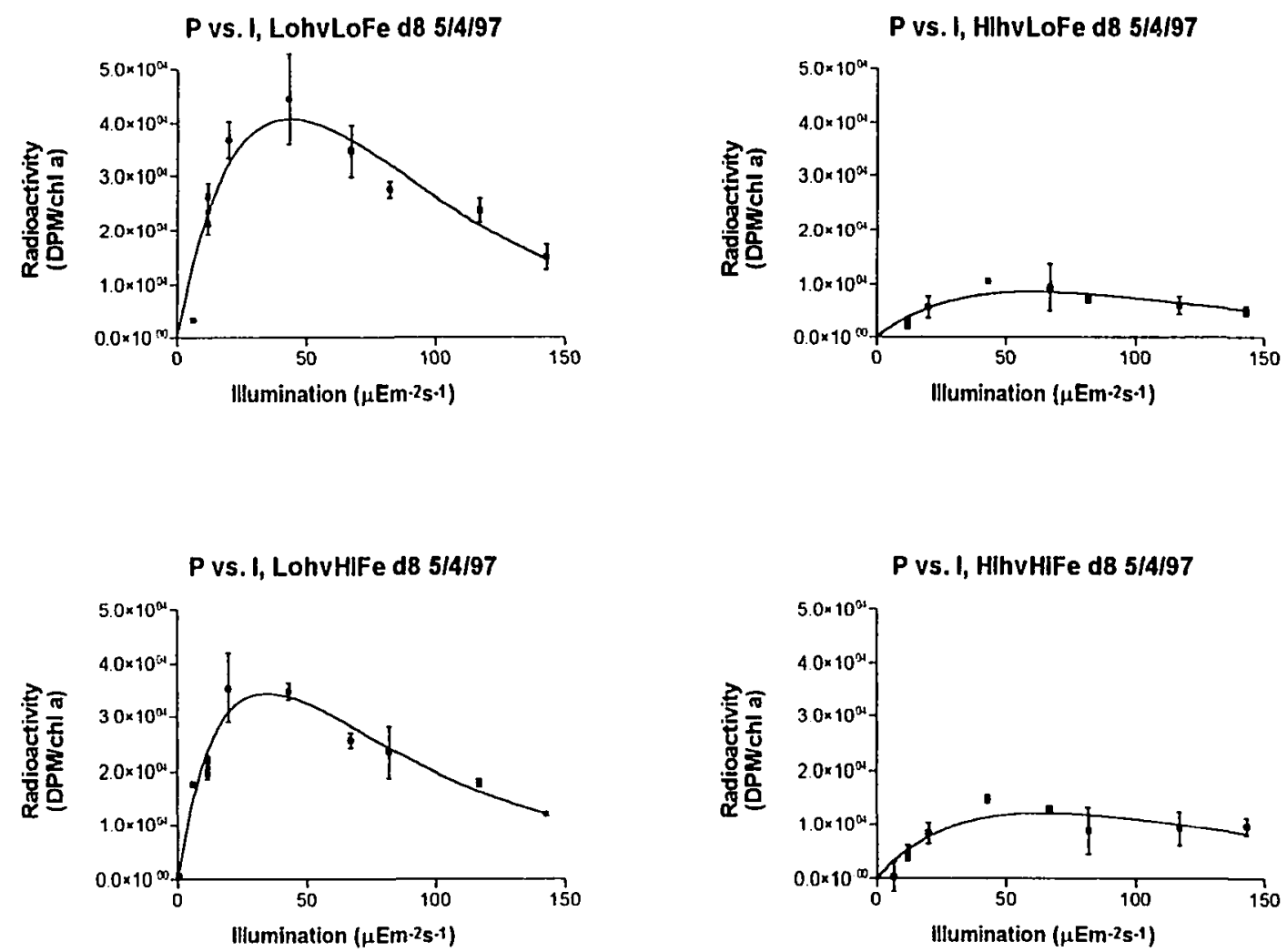

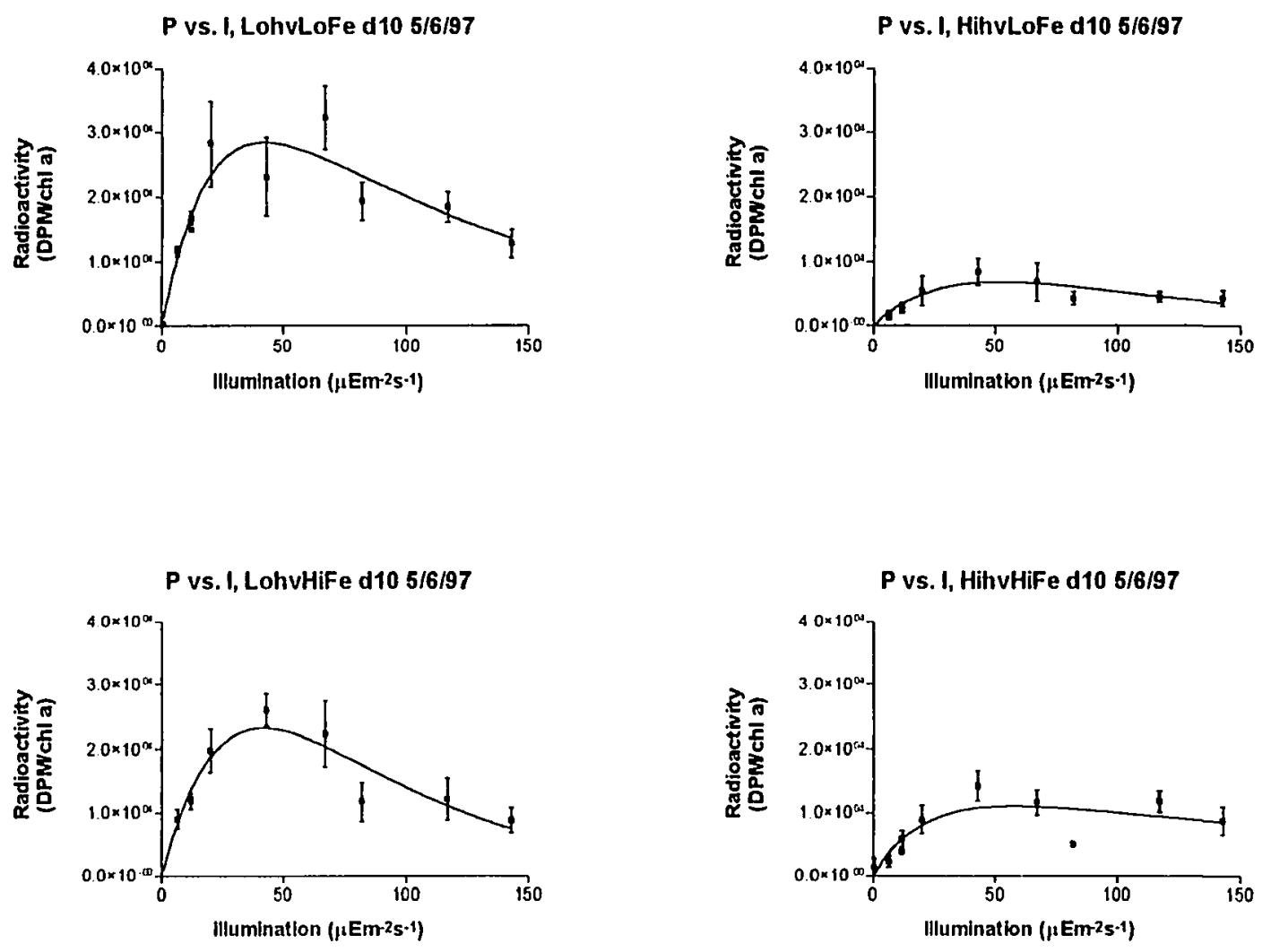


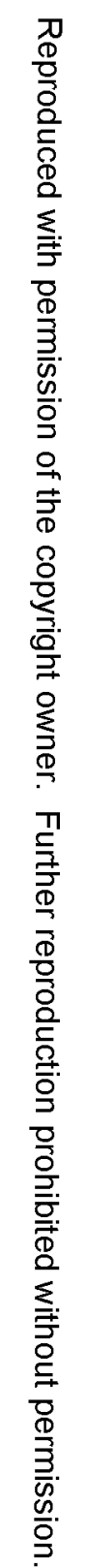
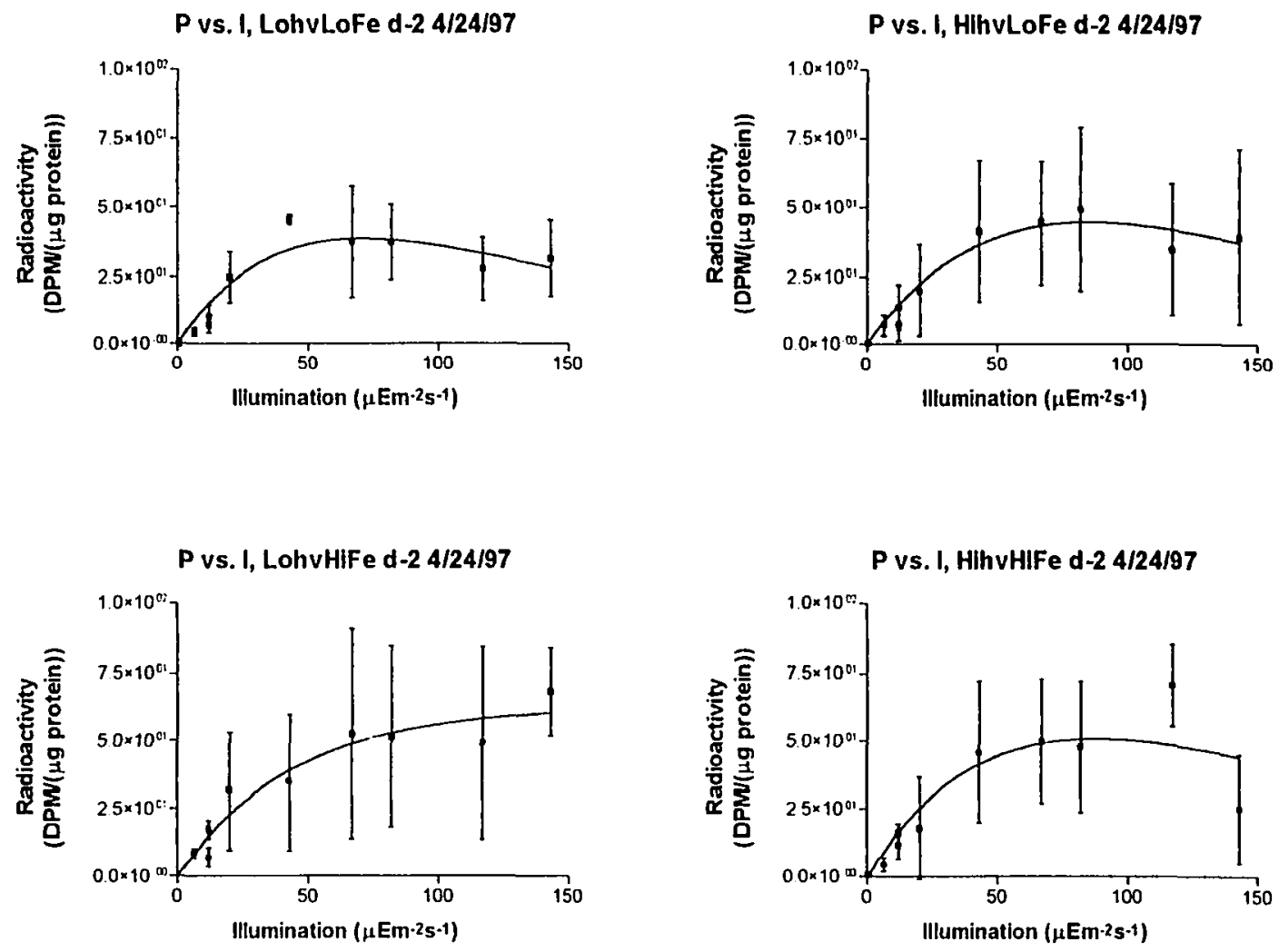


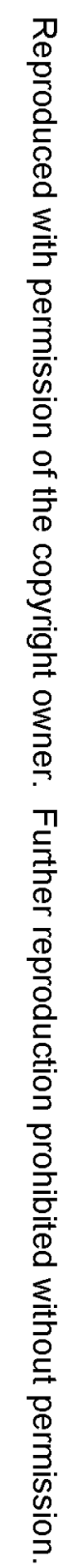

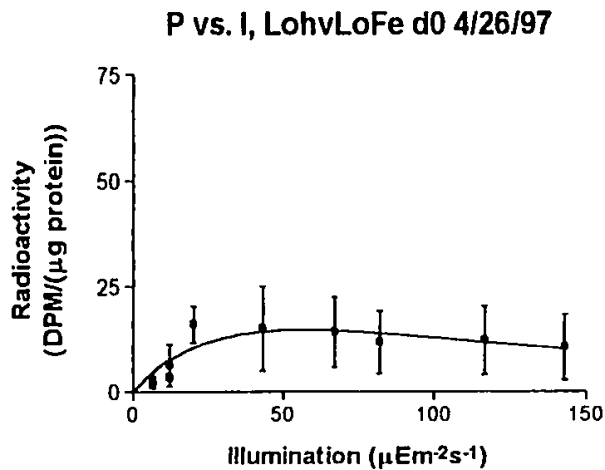

P vs. I, HihvLoFe d0 4/26/97
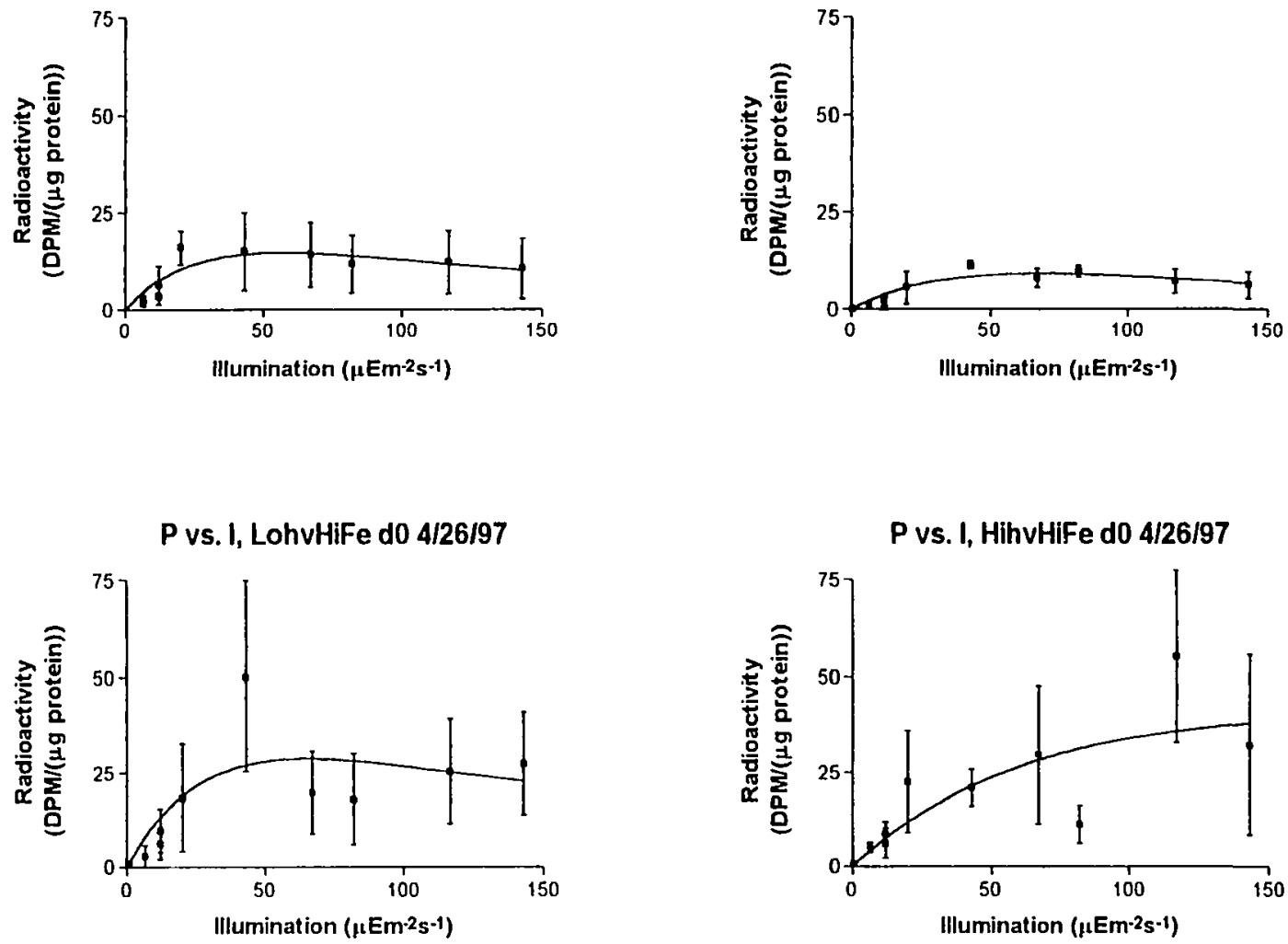
P vs. I, LohvLoFe d2 4/28/97

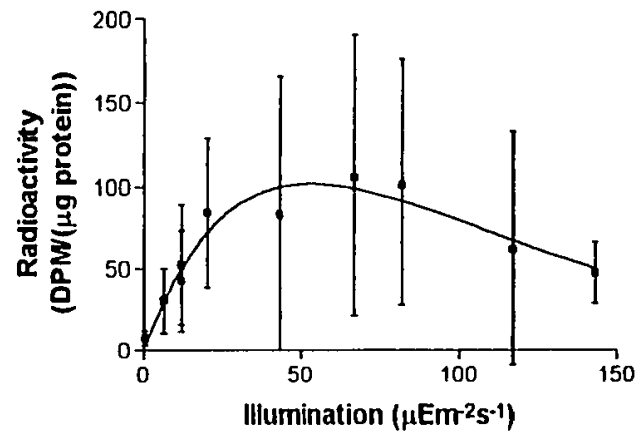

P vs. I, LohvHiFe d2 4/28/97

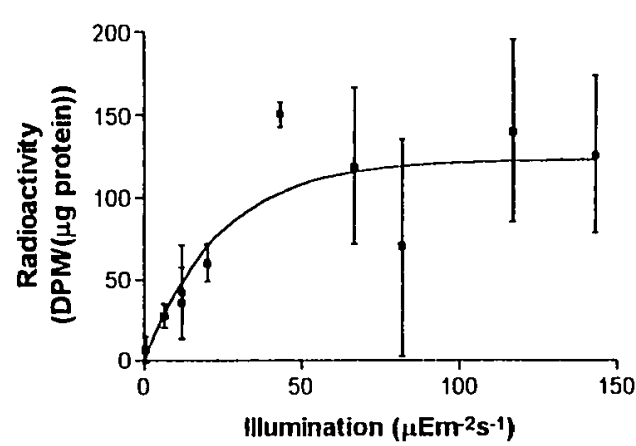

P vs. I, HihvLoFe d2 4/28/97

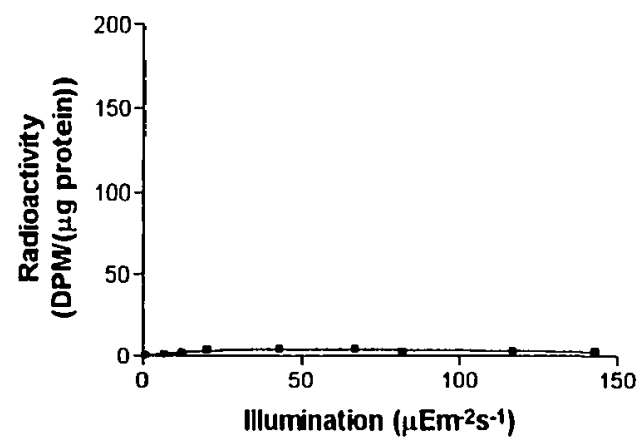

P vs. I, HihvHiFe d2 4/28/97

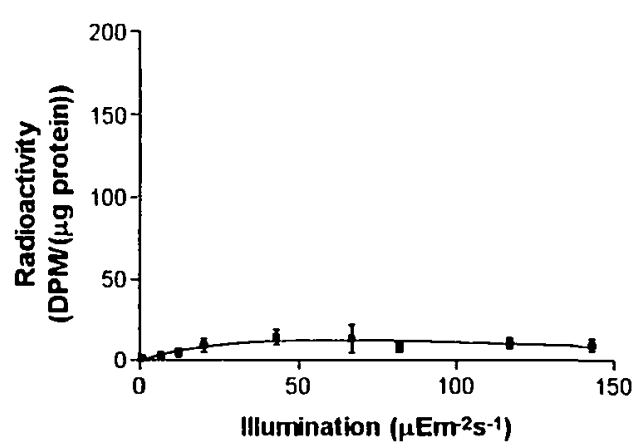



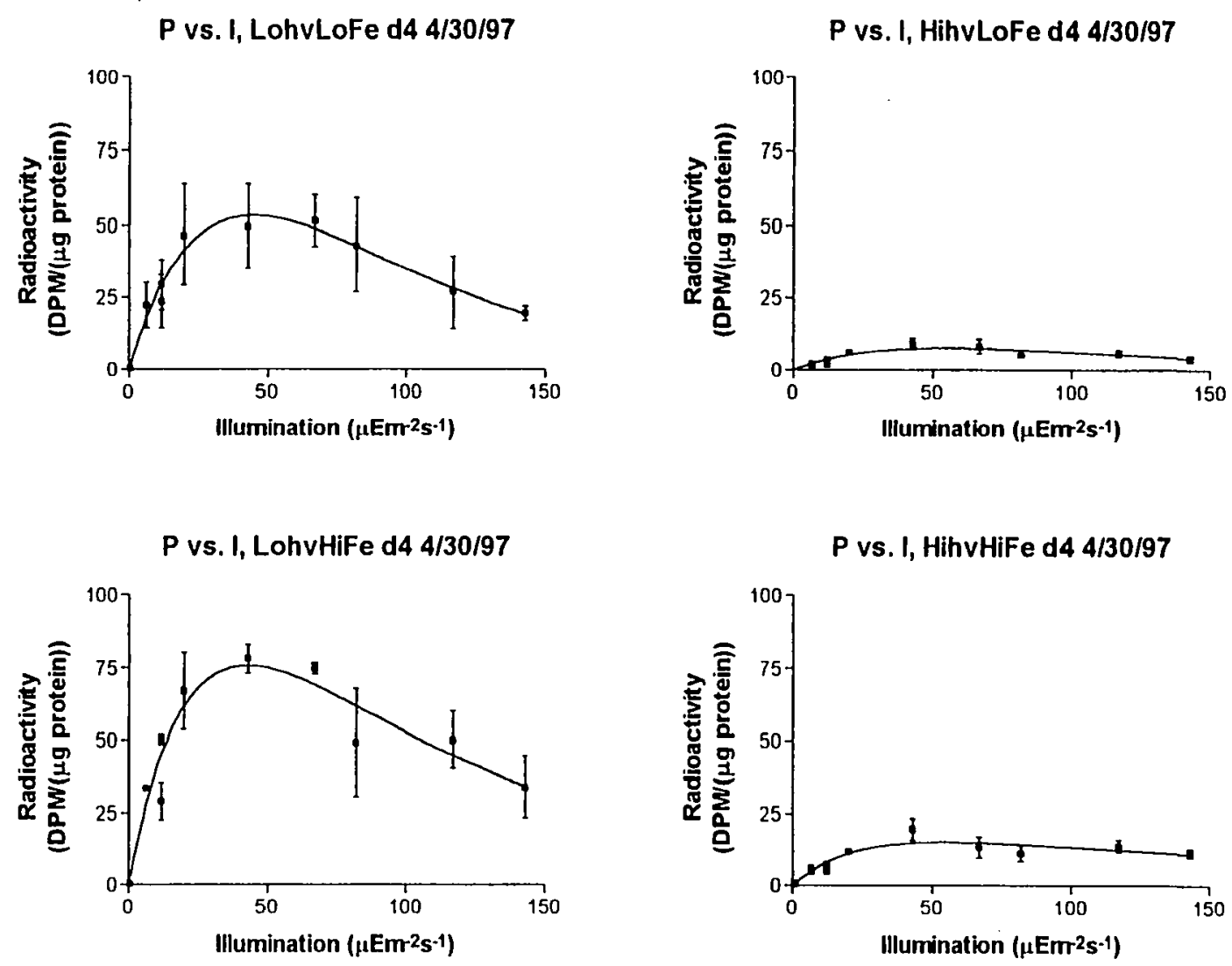


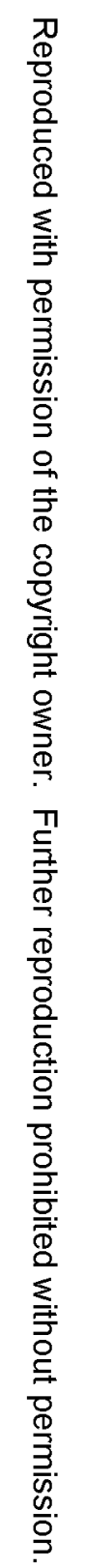
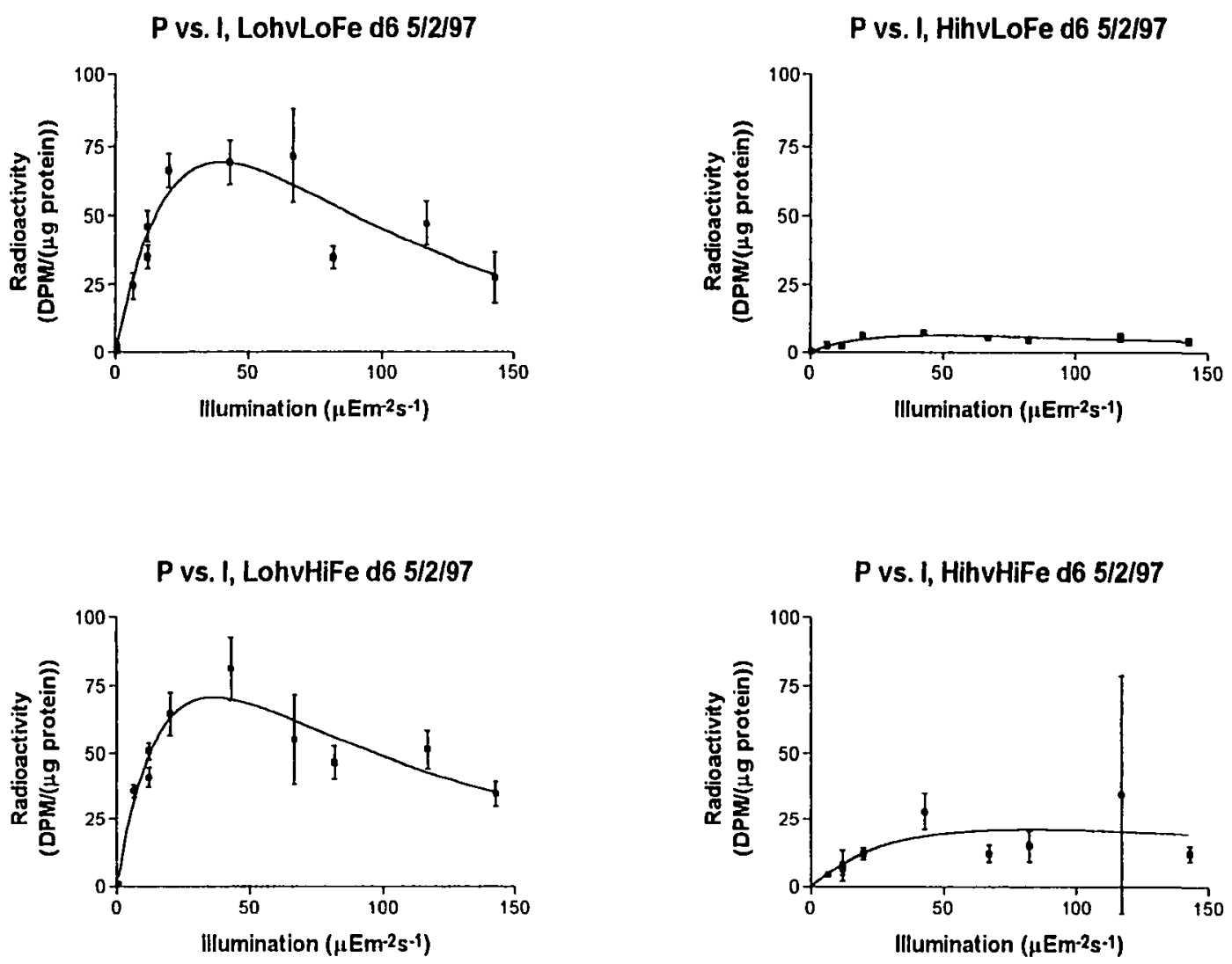

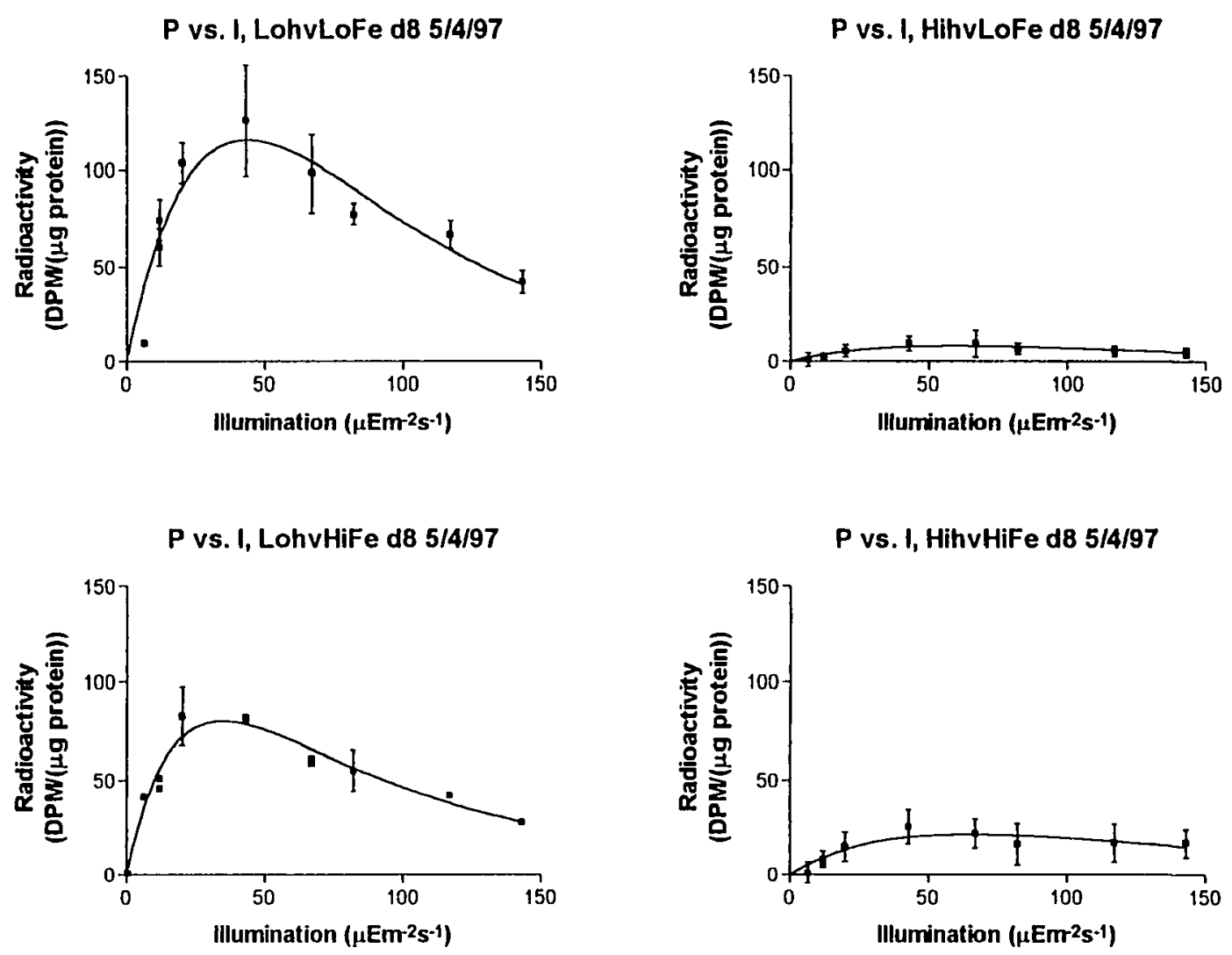


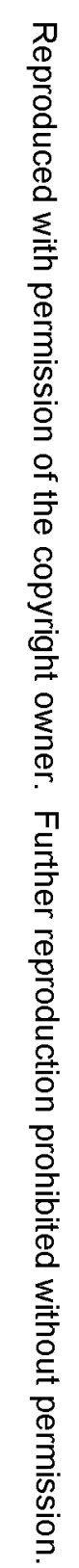

P vs. I, LohvLoFe d10 5/6/97

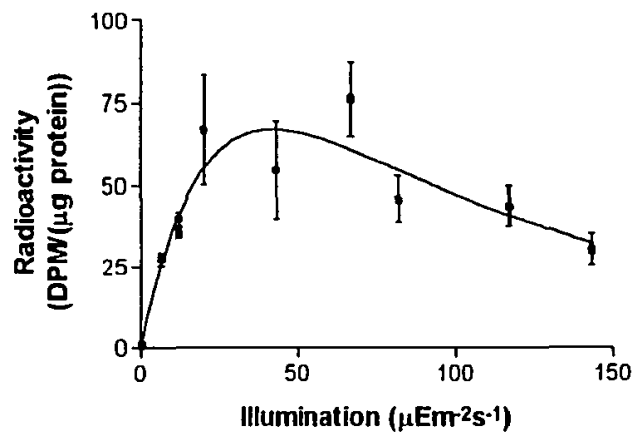

P vs. I, LohvHiFe d10 5/6/97

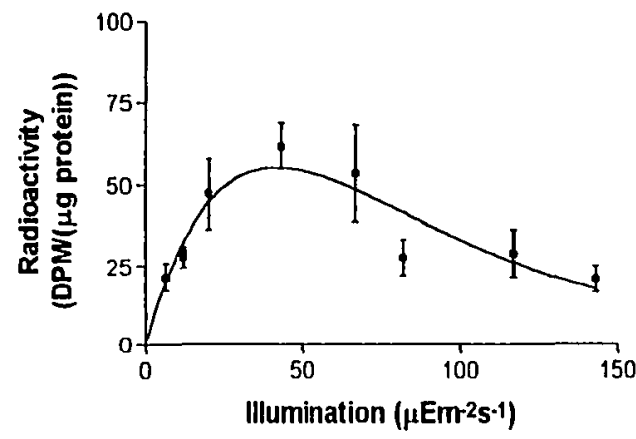

P vs. I, HihvLoFe d10 5/6/97

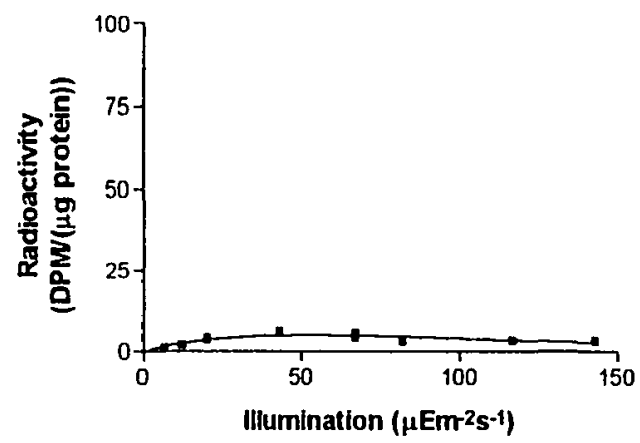

P vs. I, HihvHiFe d10 5/6/97

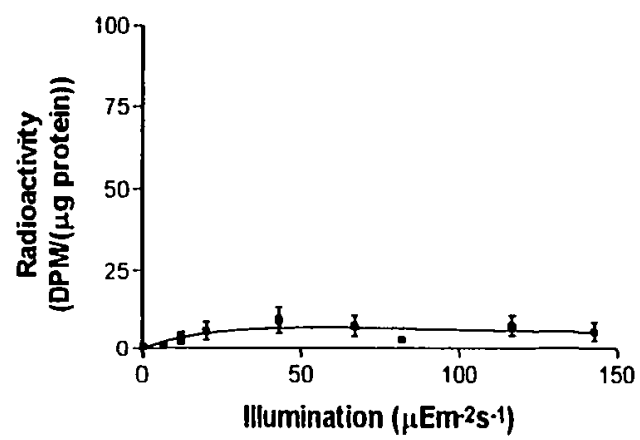


Constant hv, Low Fe sample lost

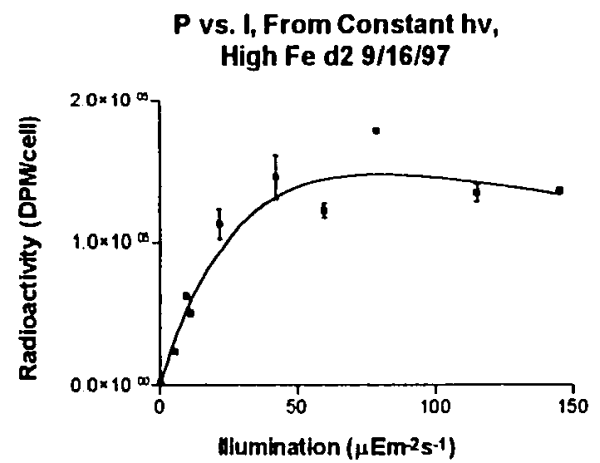

Fluctuating hv, Low Fe sample lost

P vs. I, From Fluctuating hv, High Fe d2 9/16/97

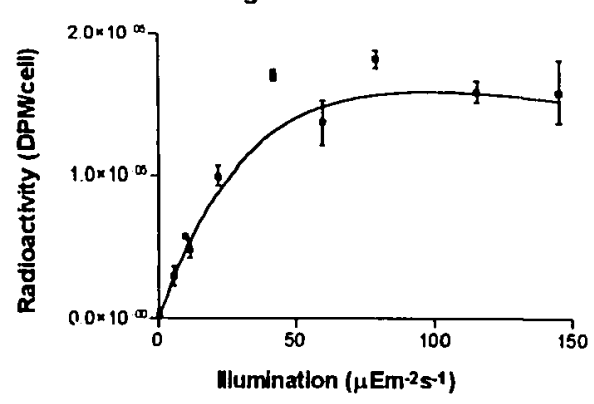

Points are averages of paired replicates; error bars span pairs of data points 


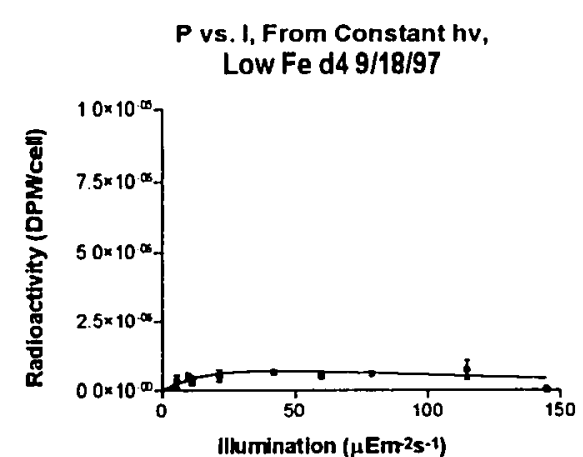

P vs. I, From Constant hv,

High Fe d4 9/18/97

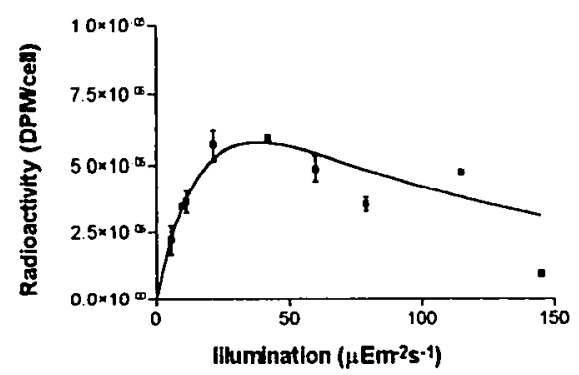

P vs. I, From Fluctuating hv,

Low Fe d4 9/48/97

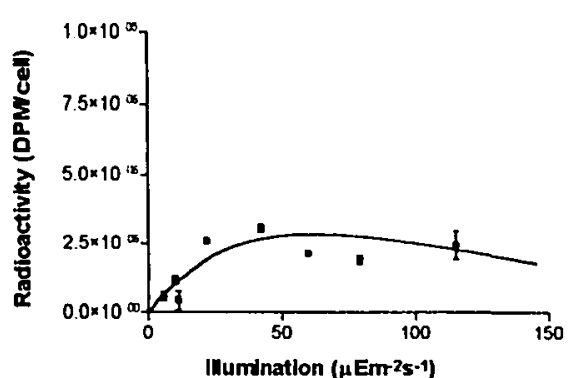

P vs. I, From Fluctuating hv, High Fe d4 9/18/97

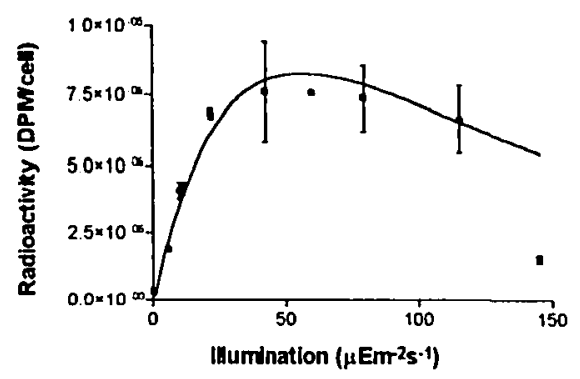

Points are averages of paired replicates; error bars span pairs of data points. 


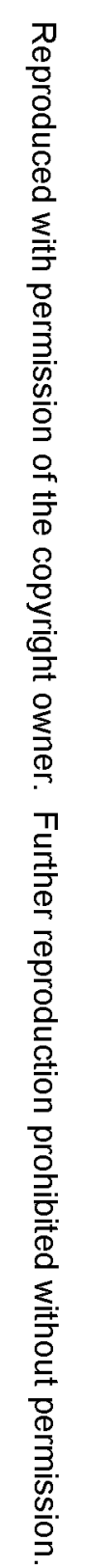
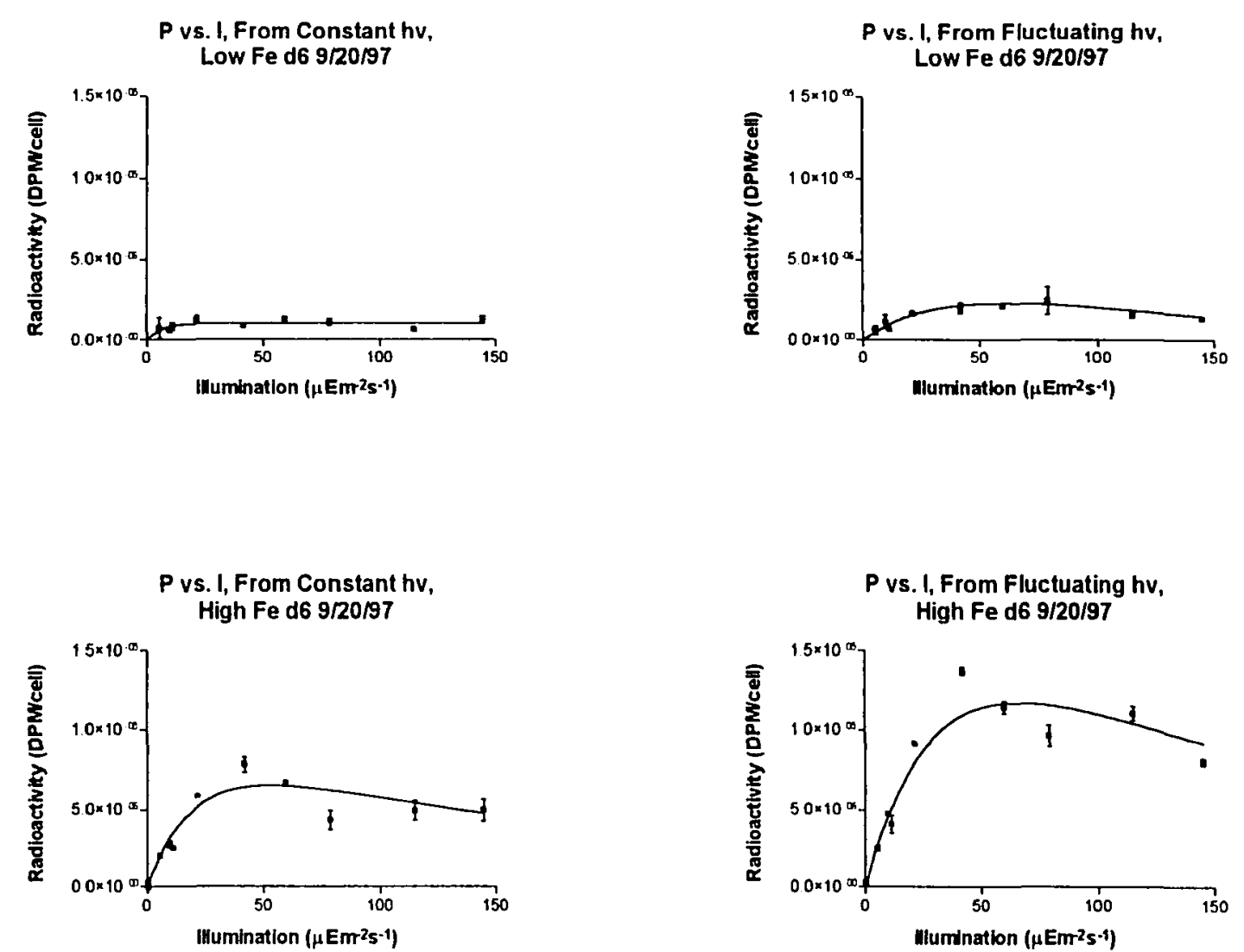

Points are averages of paired replicates; error bars span pairs of data points. 

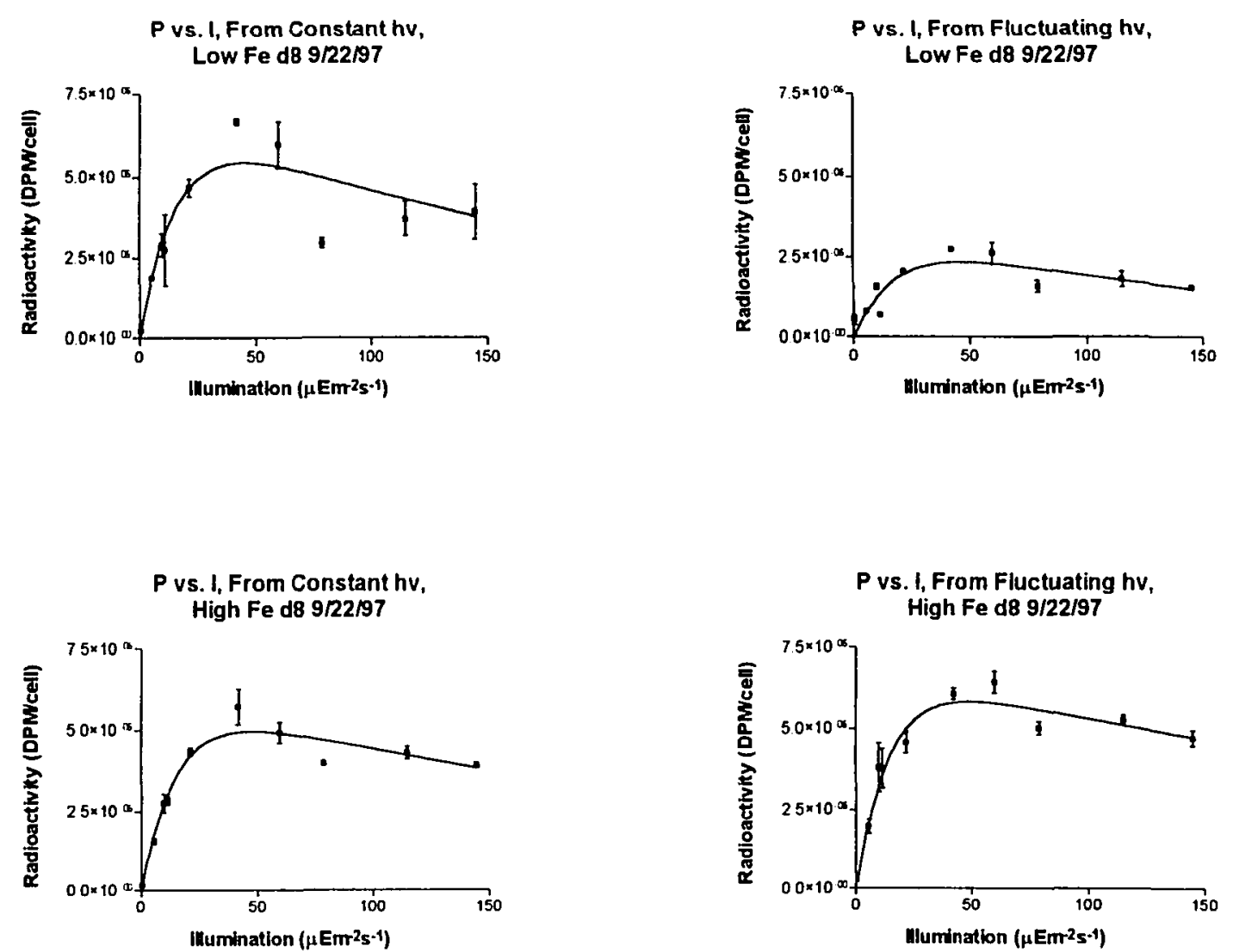

Points are averages of paired replicates; error bars span pairs of data points. 


$$
\begin{aligned}
& \mathrm{O}=\mathrm{O}= \\
& =\mathrm{O}=
\end{aligned}
$$




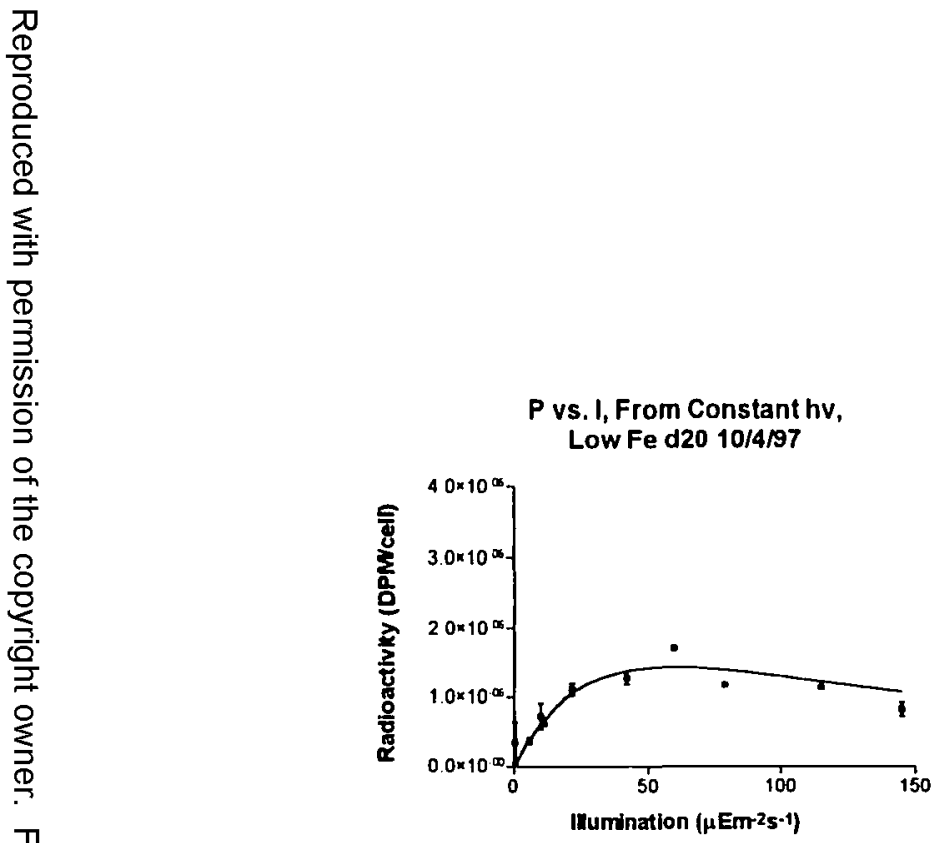

P vs. I, From Fluctuating hr, Low Fe d20 10/4/97

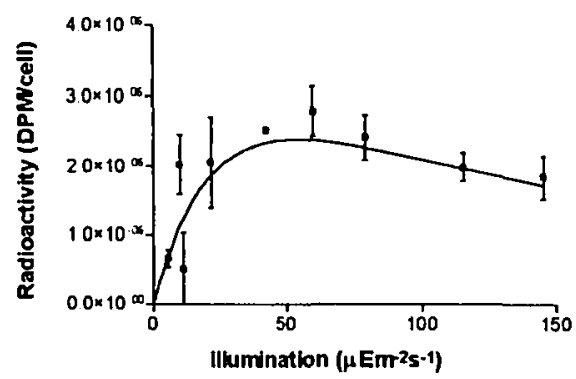

P vs. I, From Constant hr, High Fe d20 10/4/97

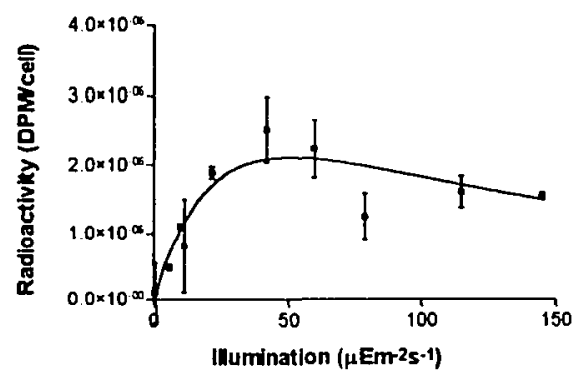

P vs. I, From Fluctuating hr, High Fe d20 10/4/97

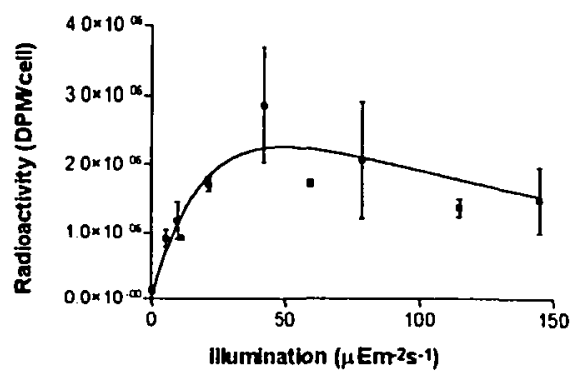

Points are averages of paired replicates; error bars span pairs of data points.

175 

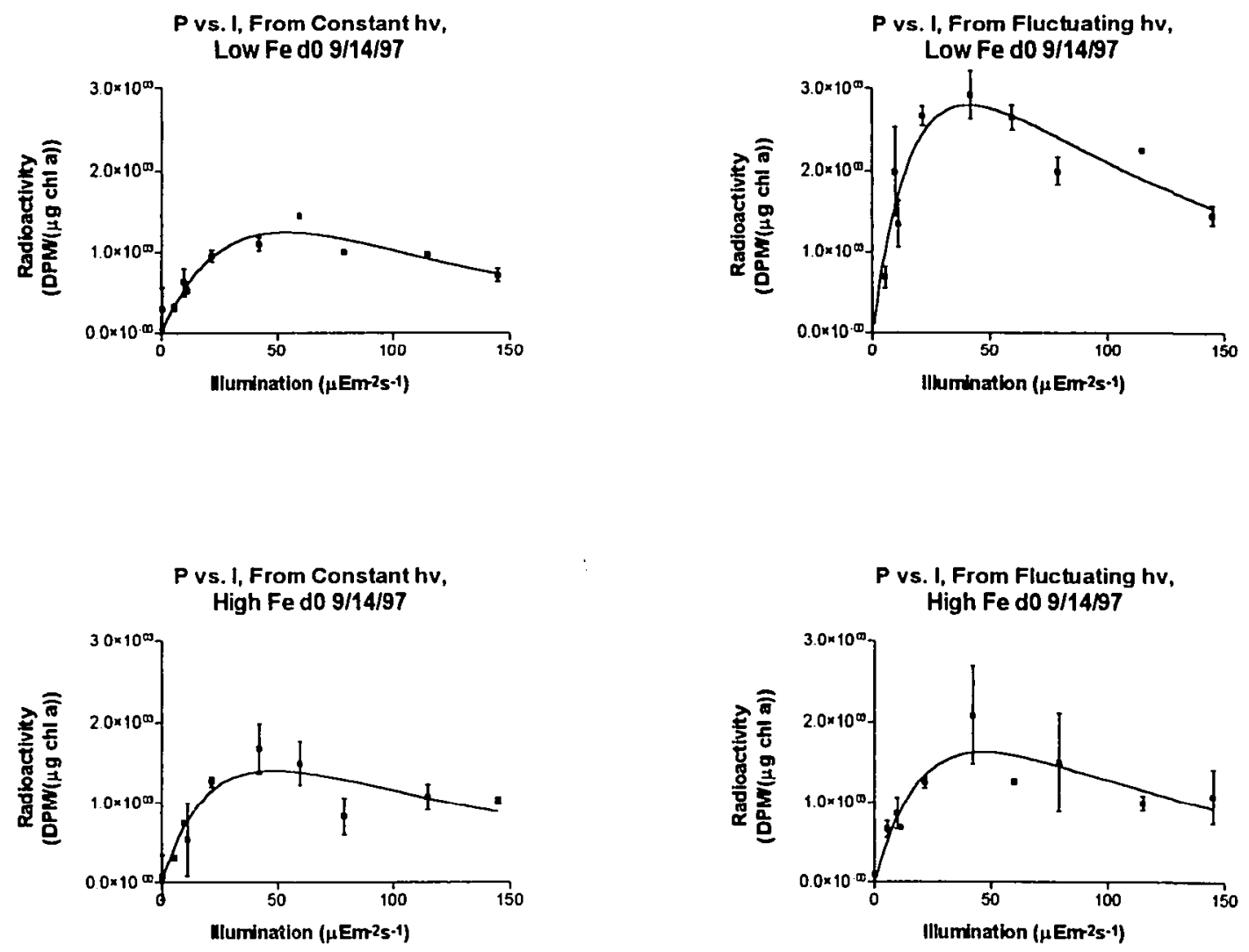

Points are averages of paired replicates; error bars span pairs of data points. 
Constant hv Low Fe sample lost

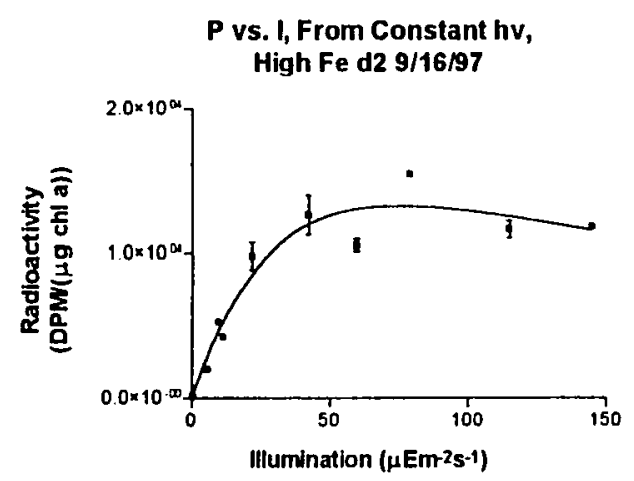

Fluctuating hv Low Fe sample bst

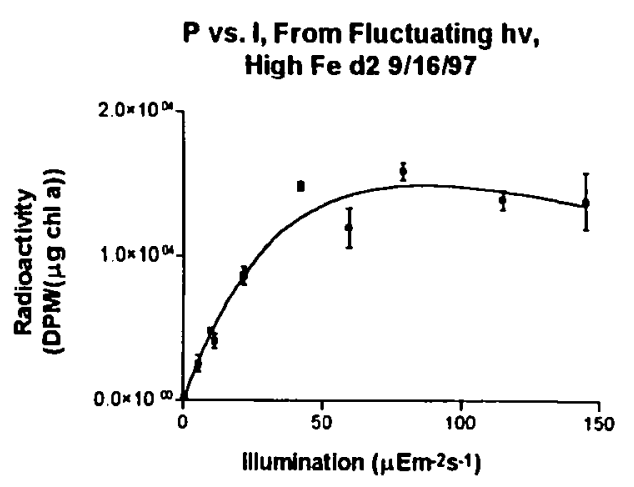



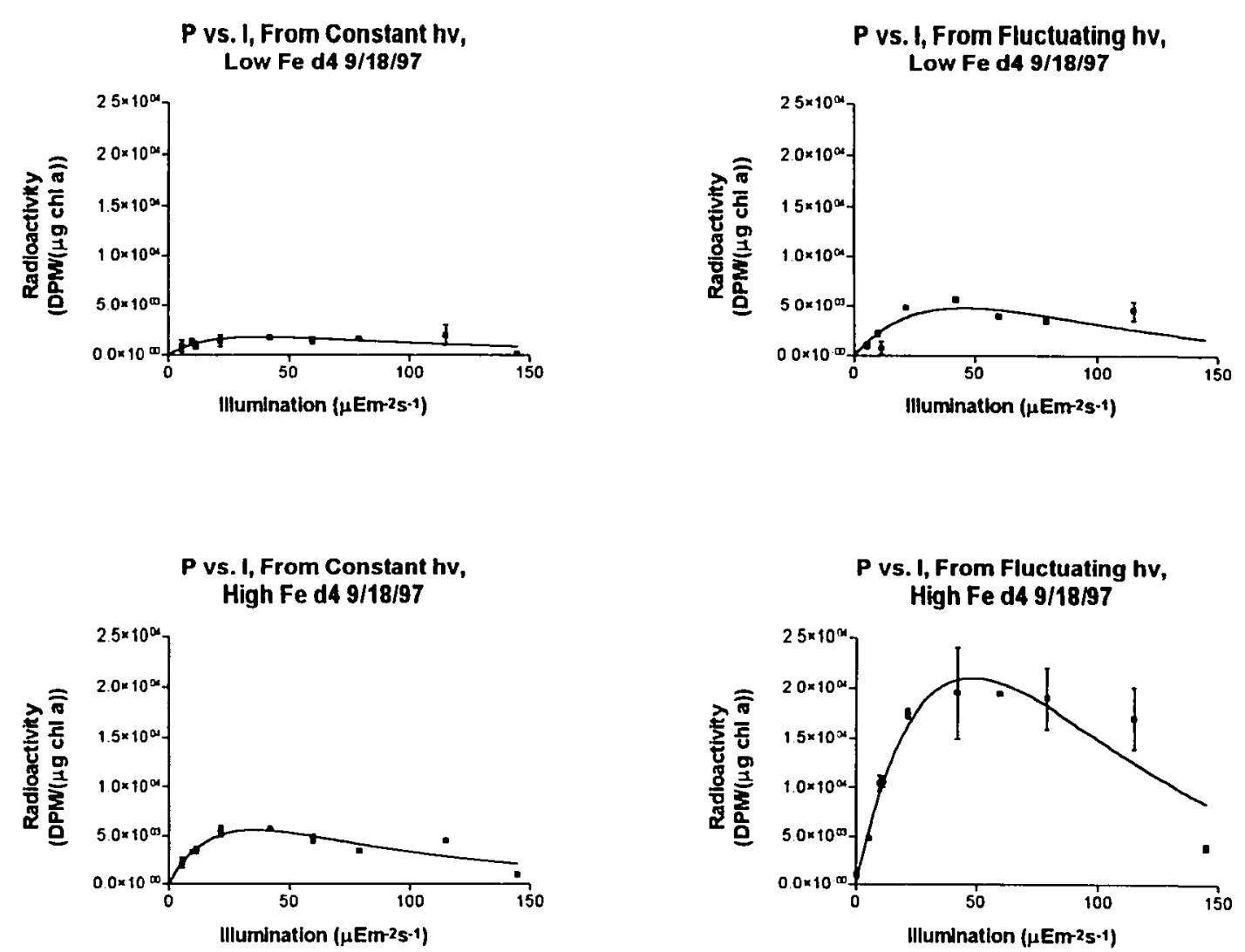

Points are averages of paired replicates; error bars span pairs of data points. 

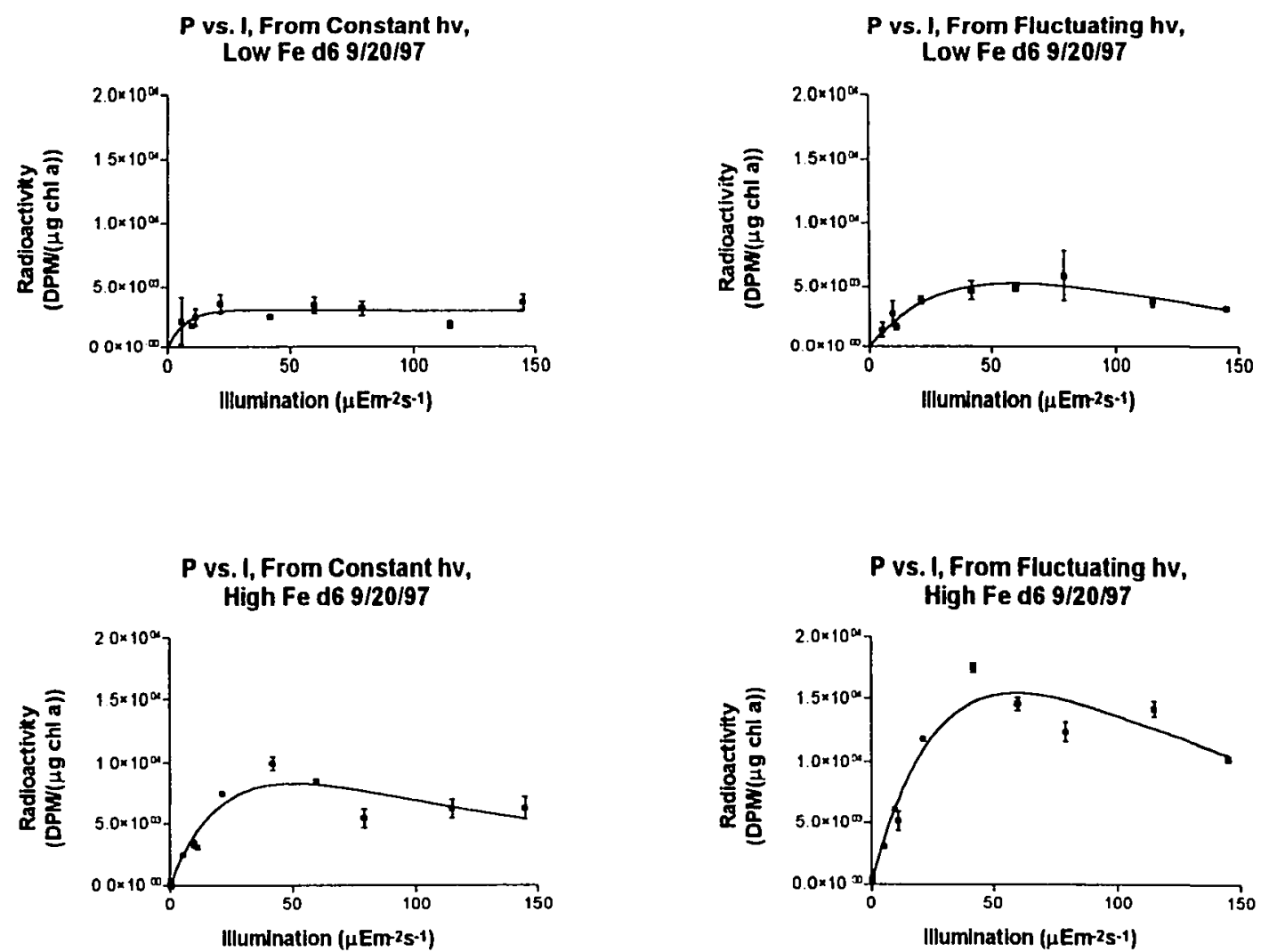

Points are averages of paired replicates; error bars span pairs of data points. 


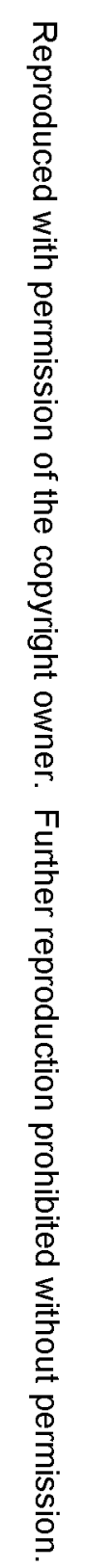
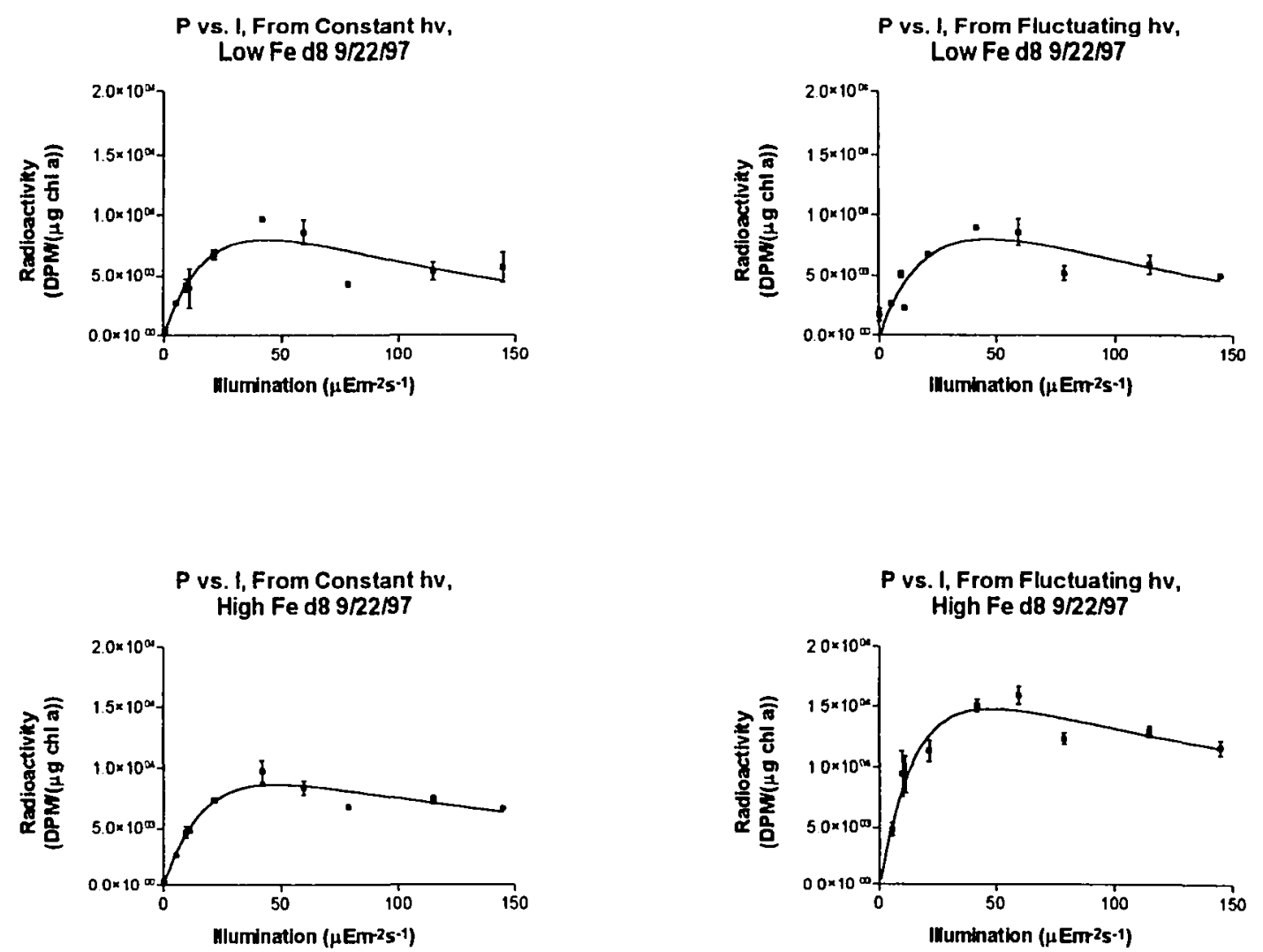

Points are averages of paired replicates; error bars span pairs of data points 

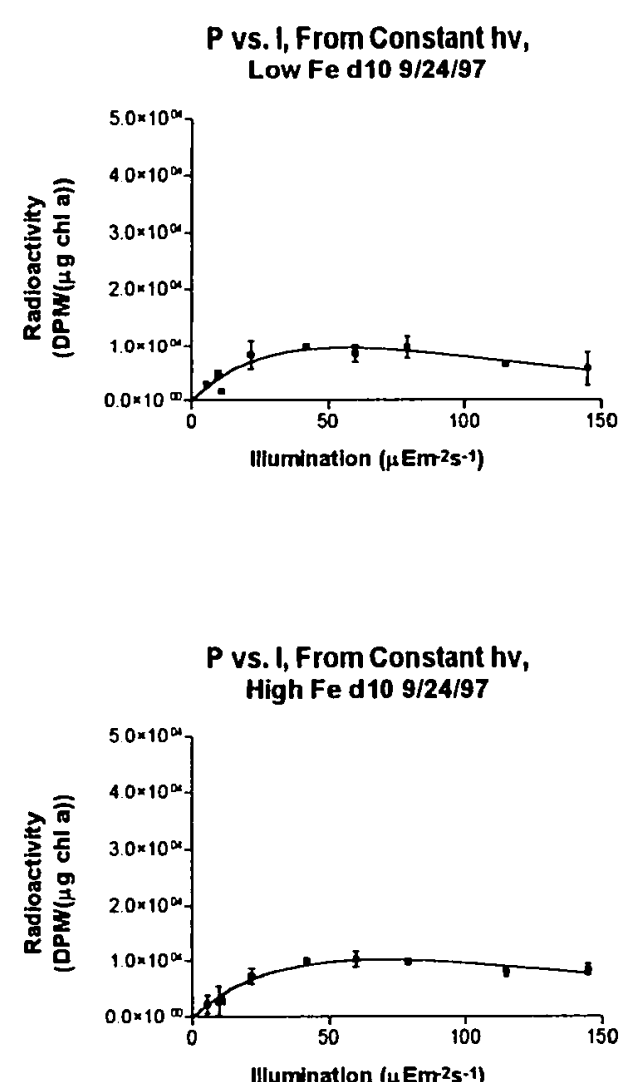

Points are averages of paired replicates; error bars span pairs of data points.
P vs. I, From Fluctuating hv, Low Fe d10 9/24/97
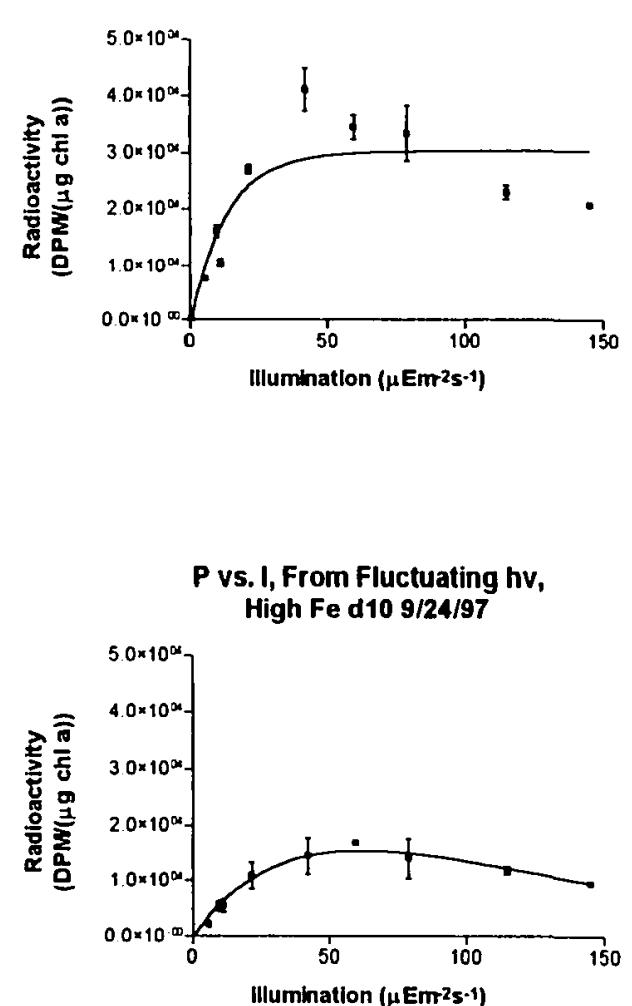

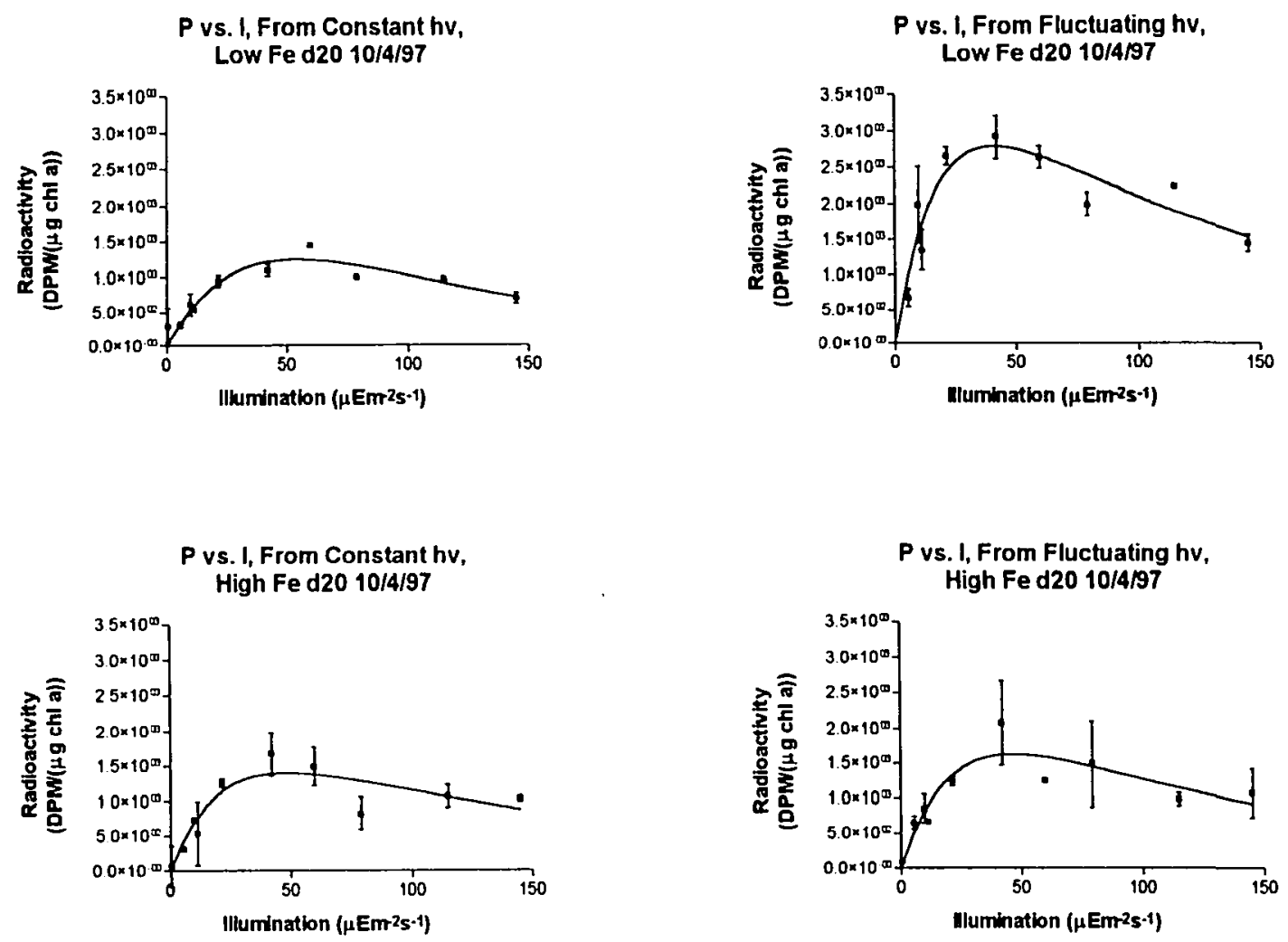

Points are averages of paired replicates; error bars span pairs of data points. 

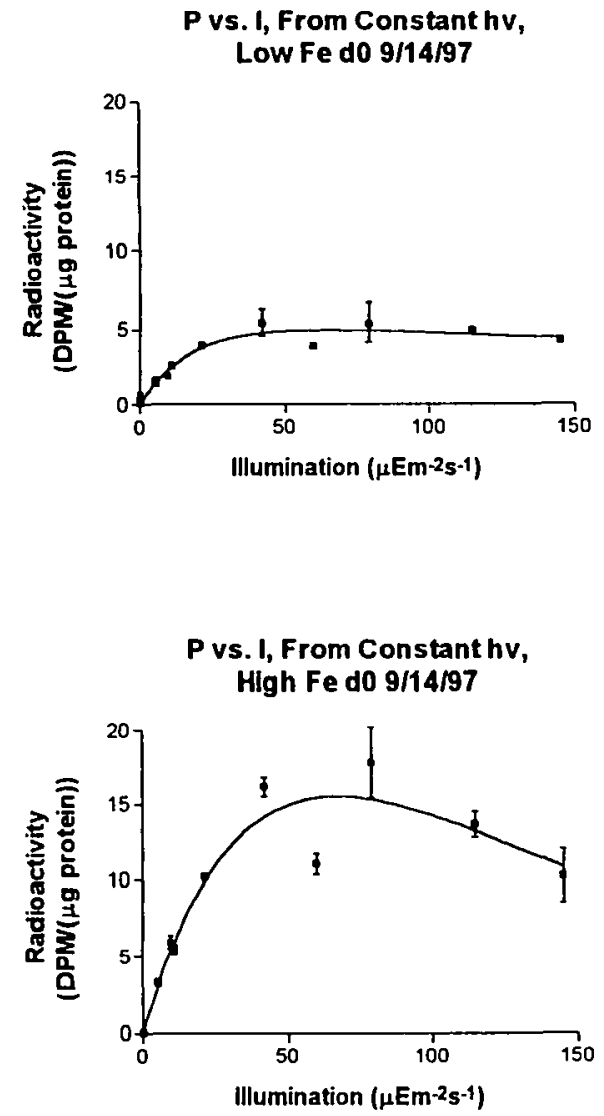

P vs. I, From Fluctuating hy, Low Fe do 9/14/97

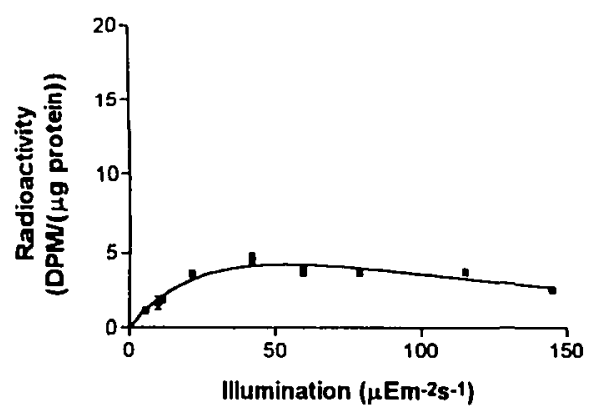

P vs. I, From Fluctuating hv, High Fe do 9/14/97

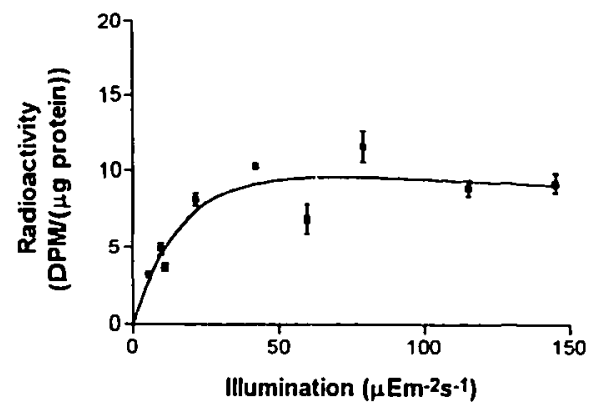

Points are averages of paired replicates; error bars span pairs of data points. 
Constant hv Low Fe sample lost

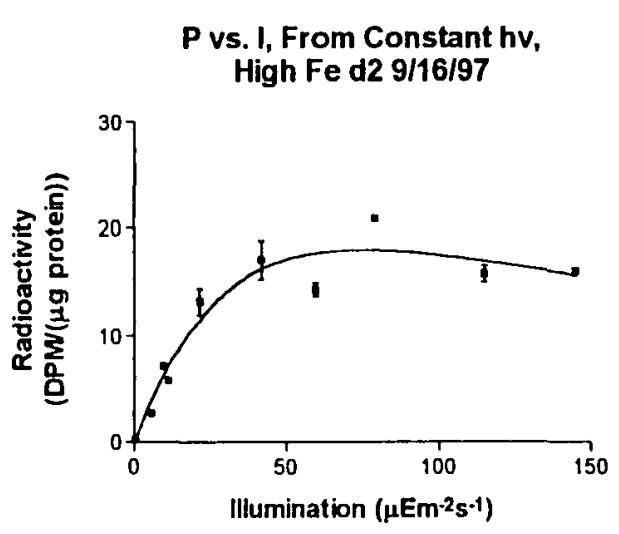

Fluctuating hv Low Fe sample lost

P vs. I, From Fluctuating hv,

High Fe d2 9/16/97

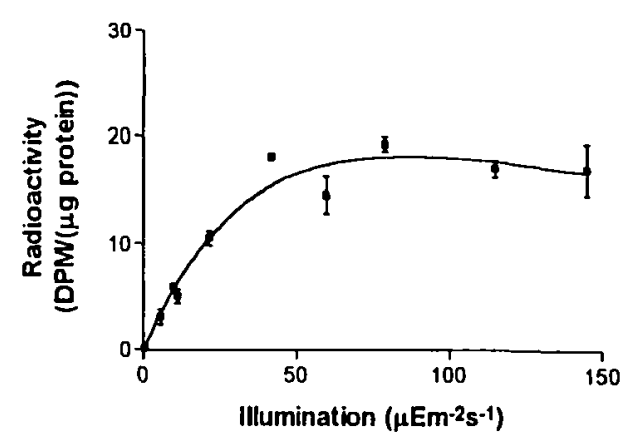




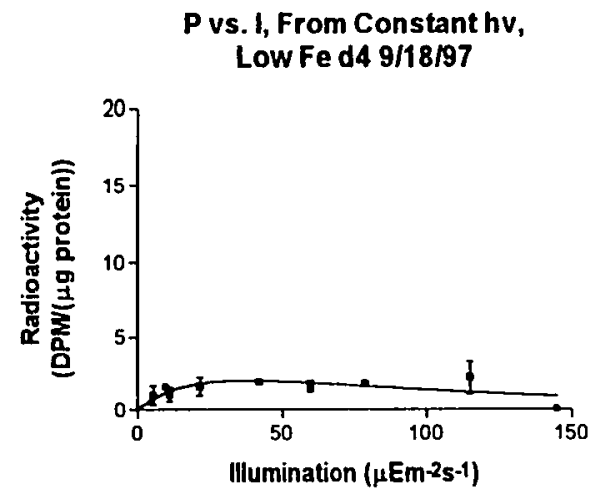

P vs. I, From Constant hv,

High Fe d4 9/18/97

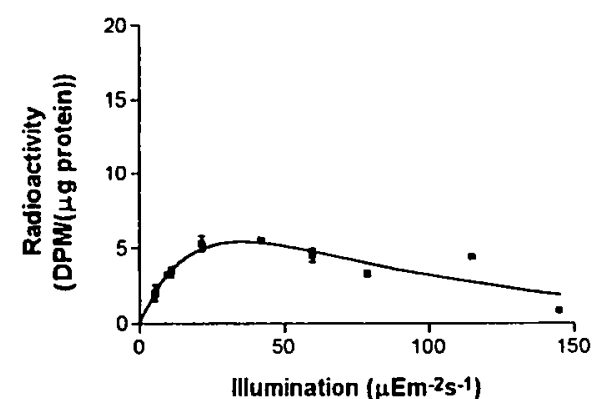

P vs. I, From fluctuating hv, Low Fe d4 9/18/97

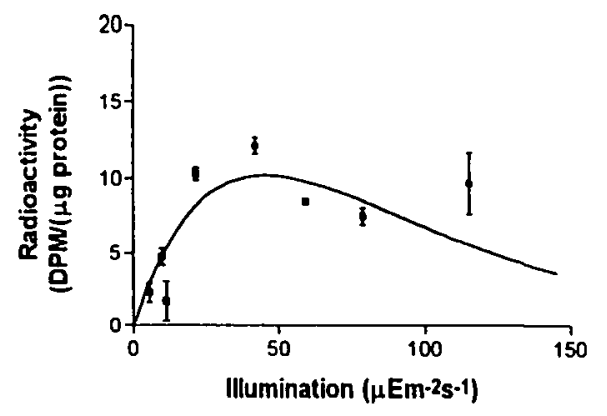

P vs. I, From Fluctuating hv, High Fe d4 9/18/97

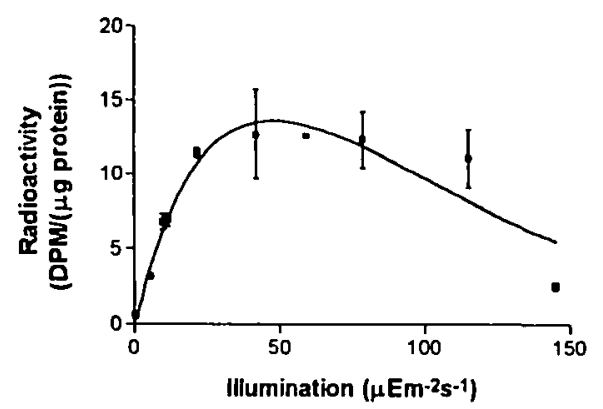

Points are averages of paired replicates; error bars span pairs of data points. 


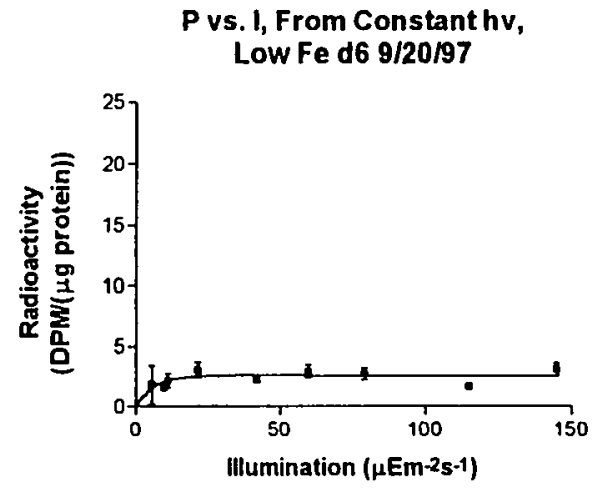

P vs. I, From Constant hv, High Fe d6 9/20/97

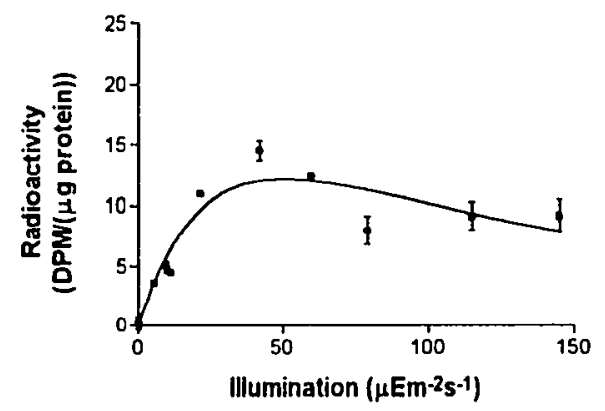

P vs. I, From Fluctuating hv, Low Fe d6 9/20/97

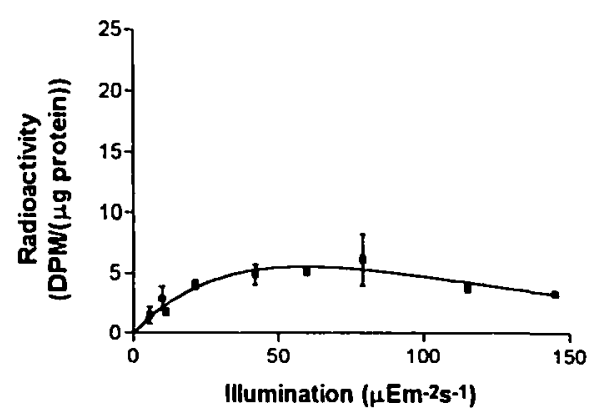

P vs. I, From Fluctuating hv, High Fe d6 9/20/97

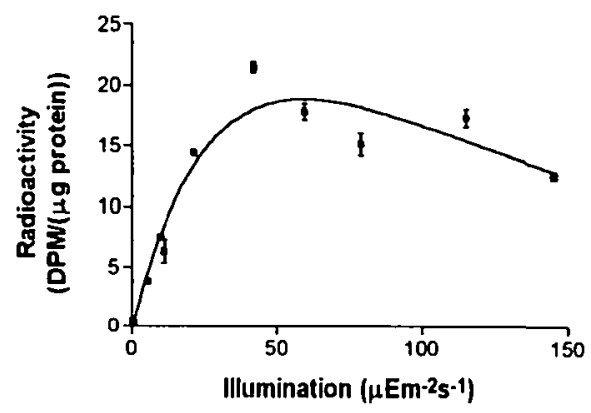

Points are averages of paired replicates; error bars span pairs of data points. 


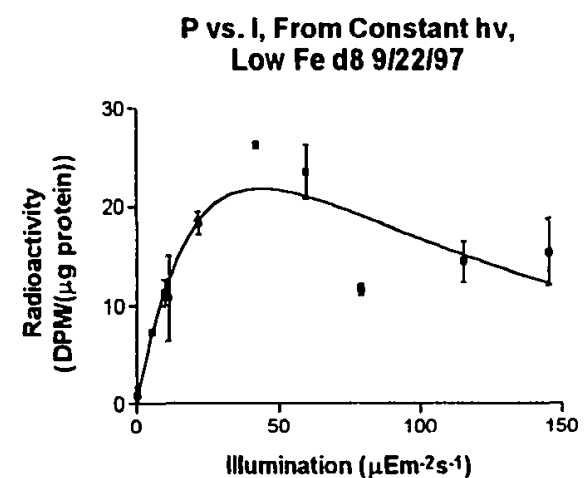

P vs. I, From Constant hv,

High Fe d8 9/22/97

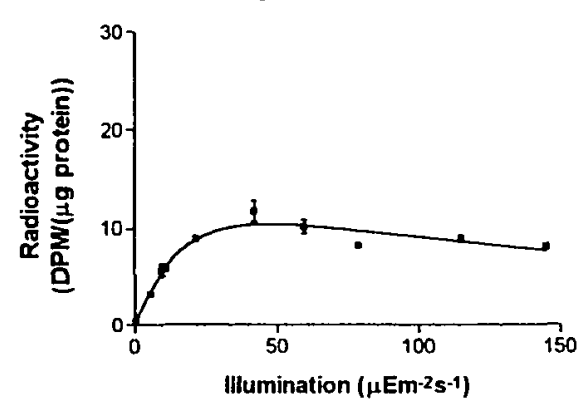

P vs. I, From Fluctuating hv, Low Fe d8 9/22/97

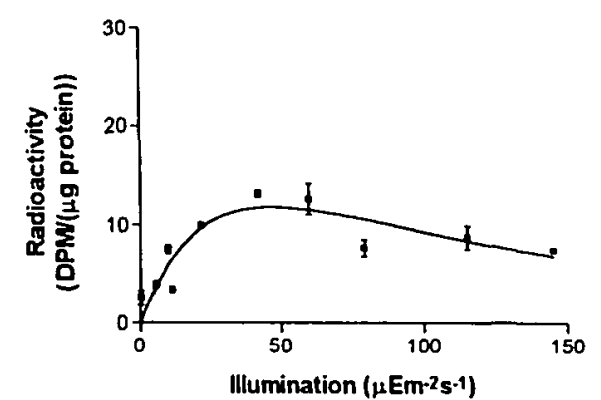

P vs. I, From Fluctuating hv,

High Fe d8 9/22/97

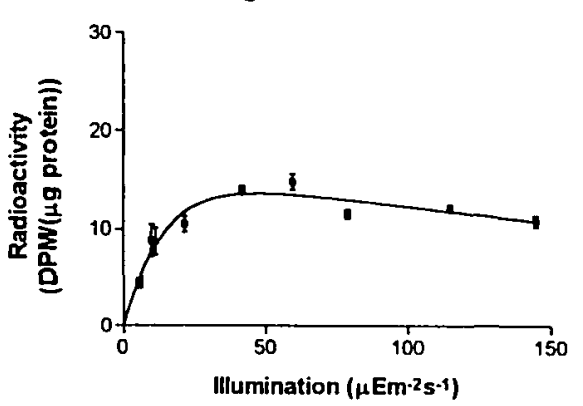

Points are averages of paired replicates; error bars span pairs of data points. 


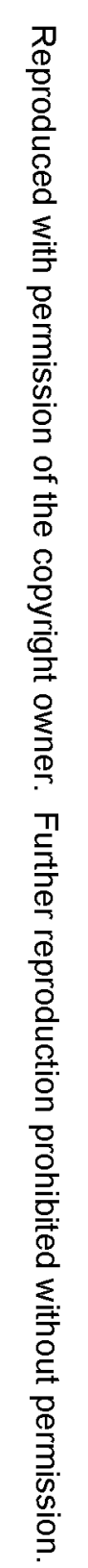

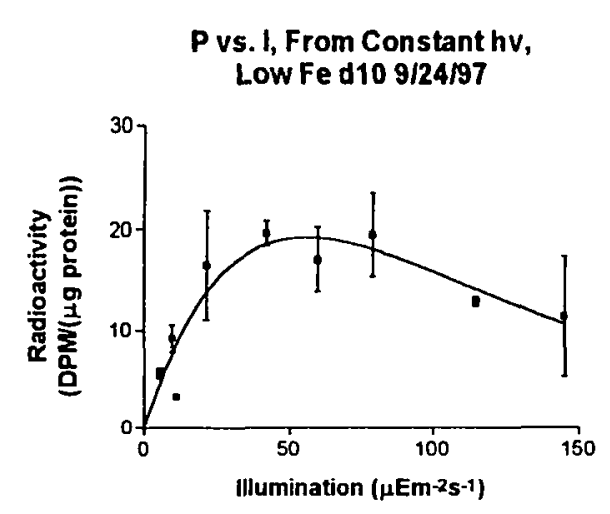

P vs. I, From Constant hv, High Fe d10 9/24/97

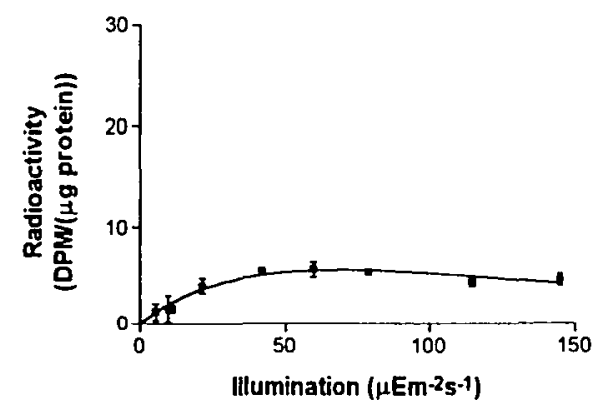

P vs. I, From Fluctuating hv, Low Fe d10 9/24/97

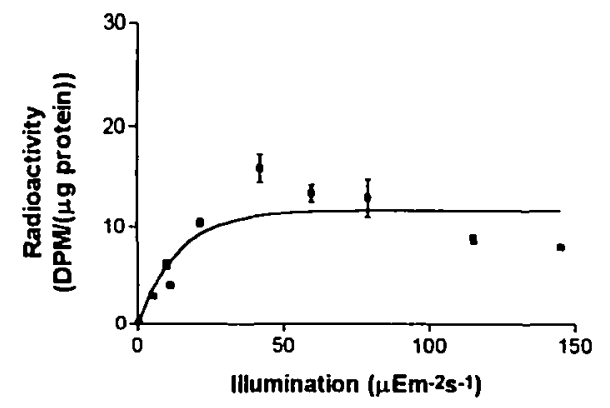

P vs. I, From Fluctuating hv, High Fe d10 9/24/97

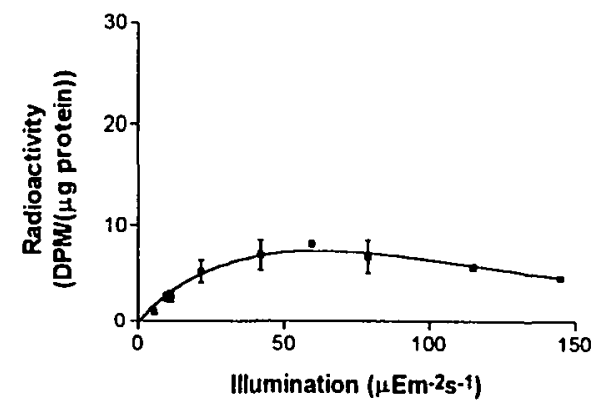

Points are averages of paired replicates; error bars span pairs of data points. 

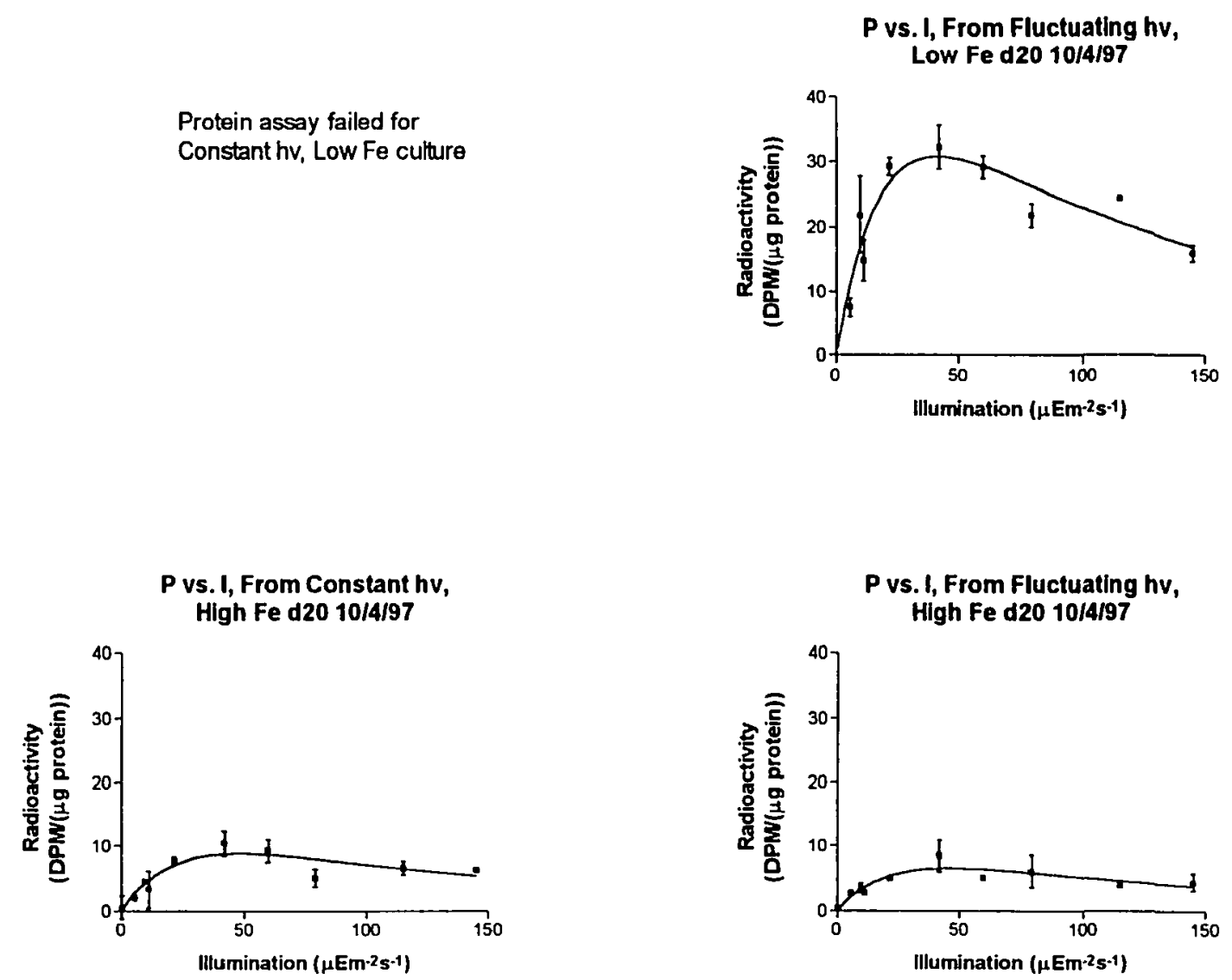

Points are averages of paired replicates; error bars span pairs of data points. 


\section{Appendix D}

\section{Touch Tone Controlled 117V AC Switching System}

To control the light intensity provided to cultures, a switching system was designed and built to control 12 channels of $117 \mathrm{~V} \mathrm{AC}$. It was used to control eight dual-tube fluorescent fixtures and two cooling fans, with additional channels available. A Macintosh Plus running QuickBASIC generated touch-tones and sent them to the Macintosh's audio output. The switching system turned twelve $117 \mathrm{~V}$ $\mathrm{AC}$ circuits on or off based on the tones received from the Macintosh.

Within the switching system, the touch tone is decoded into a 4-bit binary number by a Motorola MC145436 IC. One of sixteen channels is activated corresponding to the four bit number by decoding the four bit bus from the MC145436 using two $78 \mathrm{C} 138$ ICs. Twelve of these channels are used to activate flip-flop circuits in $74 \mathrm{C} 74$ ICs, three channels are used to reset groups of those flipflops, and one channel is not used. The three reset channels deactivate flip-flops in one group of seven, one group of three and one group of two.

The output from each of the twelve flip-flops are connected to the base of one of twelve transistors. Each of the transistors controls the $24 \mathrm{~V}$ potential used to switch a 117V AC circuit. Eleven of the transistors control the AC loads through Potter Brumfield KHS 17D13 relays. One transistor is used to control its AC load through an NTE RIM-OAC5 optoisolated solid-state relay. 


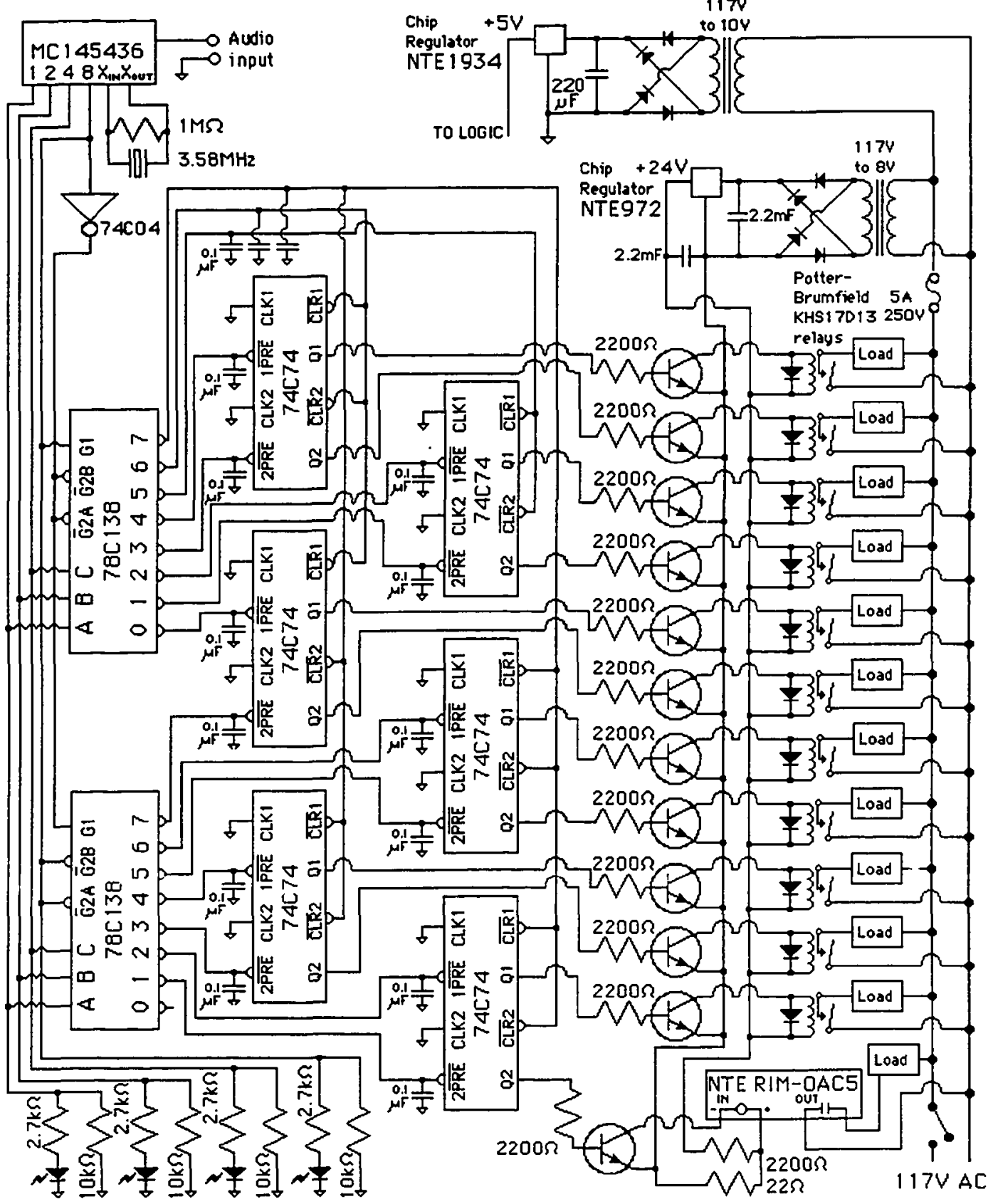


